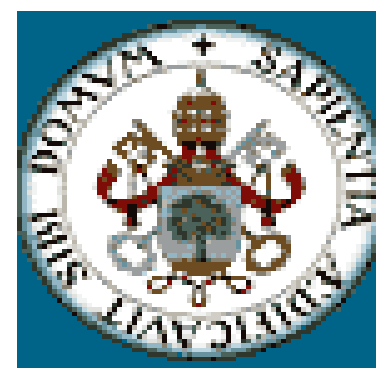

UNIVERSIDAD DE VALLADOLID

FACULTAD DE FILOSOFÍA Y LETRAS

DEPARTAMENTO DE LENGUA ESPAÑOLA

TESIS DOCTORAL:

\title{
ESTUDIO SOCIOLINGÜÍSTICO SOBRE EL USO DEL SUPERLATIVO EN LA REGIÓN DE VALPARAÍSO, CHILE
}

\author{
Presentada por María Isabel Peñailillo Fuentes, para optar al grado de \\ doctora por la Universidad de Valladolid
}

Dirigida por:

Doctor César Hernández Alonso 
A mi esposo Eric, por haber compartido con amor y paciencia, mi vida y mi trabajo.

A mi queridísima familia, por todo su apoyo y amor. 


\section{AGRADECIMIENTOS}

En primer lugar, quiero expresar mis agradecimientos a don César Hernández Alonso, por haber aceptado ser director de este trabajo y haberme animado a realizarlo con paciencia y esmero.

Agradezco a Eric su colaboración en la cuidadosa revisión y transcripción de las entrevistas.

Finalmente, mis especiales agradecimientos a las 34 personas que fueron entrevistadas, por el valioso tiempo de sus vidas que, con mucho agrado, dedicaron a estas conversaciones. 


\section{CONTENIDO}

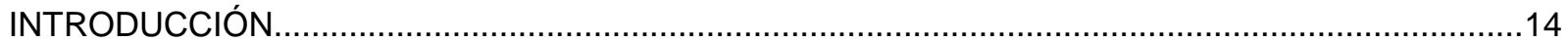

1. OBJETIVOS DE LA INVESTIGACIÓN Y PLANTEAMIENTO DE HIPÓTESIS .................................18

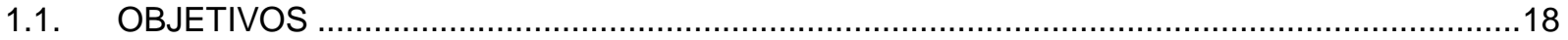

1.2. PLANTEAMIENTO DE HIPÓTESIS............................................................................. 19

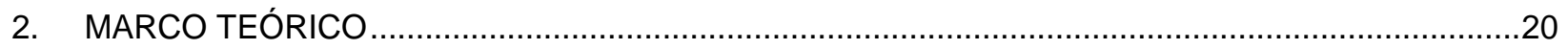

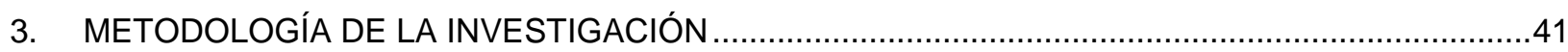

4. CARACTERIZACIÓN DE LA POBLACIÓN EN ESTUDIO ...........................................................48

5. ANÁLISIS CUANTITATIVO DE USO DEL SUPERLATIVO. ........................................................51

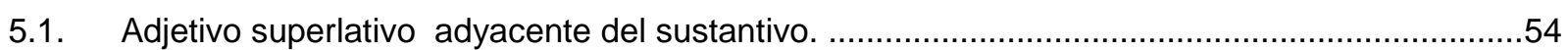

5.2. Adjetivo superlativo como atributo de los verbos ser y estar..................................................54

5.3. Adjetivo superlativo como complemento predicativo o atributo de verbos no copulativos ........55

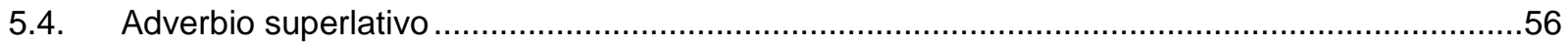

5.5. Léxico con valor superlativo o elativos léxicos ...................................................................57

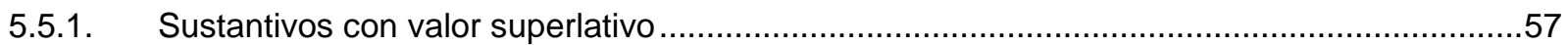

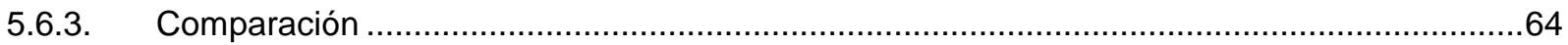

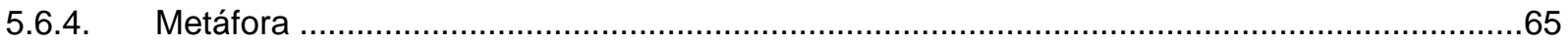

6. ANÁLISIS CUANTITATIVO DE USO DEL SUPERLATIVO, SEGÚN LAS VARIABLES SOCIOLINGÜÍSTICAS DE SEXO, EDAD Y NIVEL DE EDUCACIÓN. ..................................................66

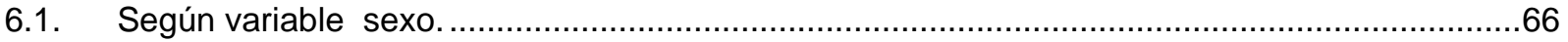

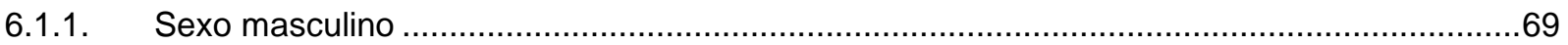

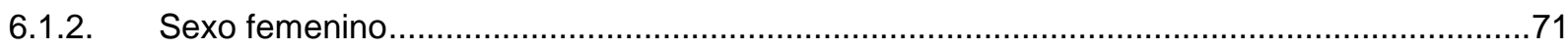

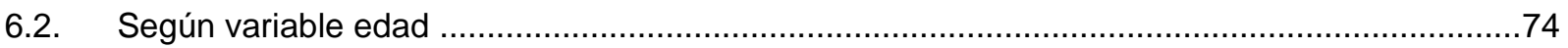

7. USO DE ADJETIVOS Y ADVERBIOS SUPERLATIVOS SEGÚN VARIABLES SOCIOLINGÜÍSTICAS DE SEXO, EDAD Y NIVEL EDUCACIONAL....................................................89

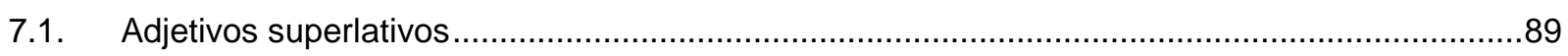

8. USO DE ADJETIVOS Y ADVERBIOS SUPERLATIVOS SINTÉTICOS Y ANALÍTICOS..................94

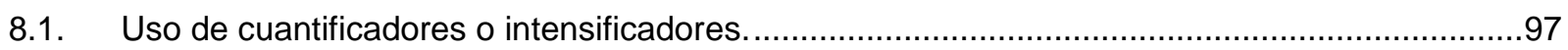

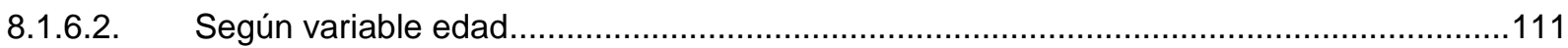

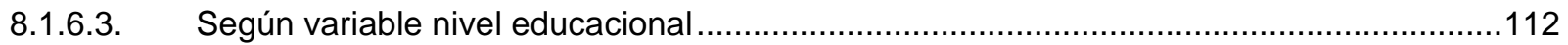

8.2. Uso de adjetivos y adverbios superlativos sintéticos y analíticos, según sexo, edad y nivel

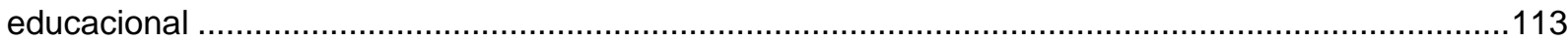

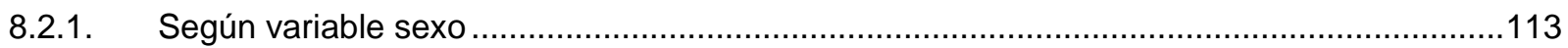

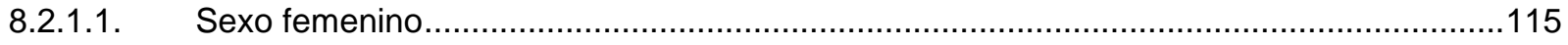

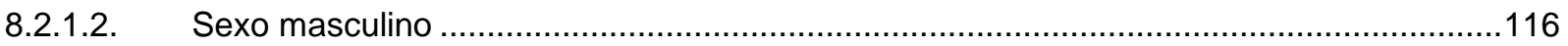




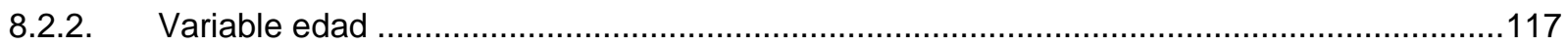

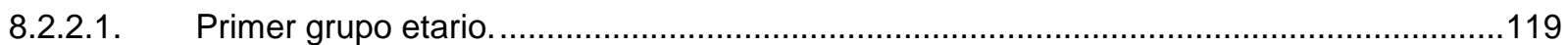

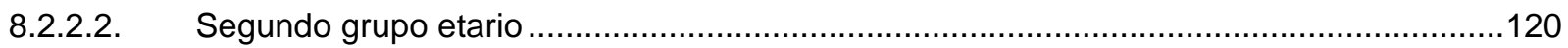

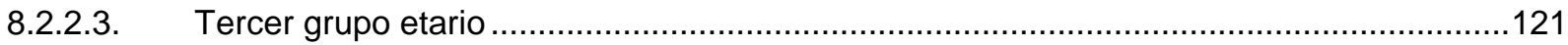

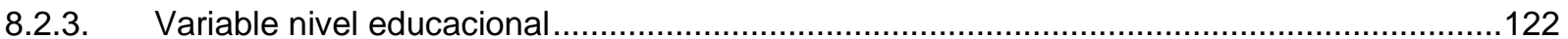

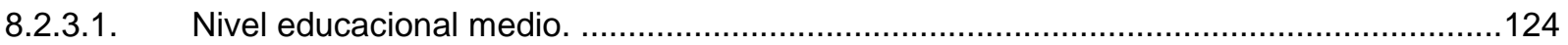

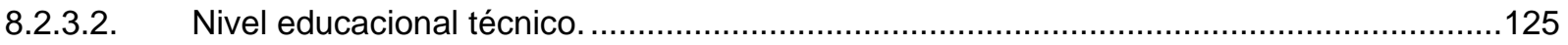

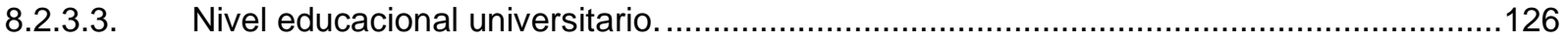

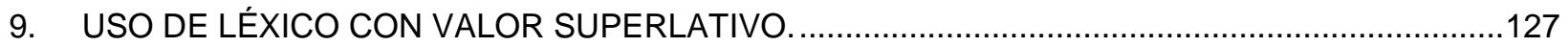

9.1. Léxico con mayor número de ocurrencia .........................................................................131

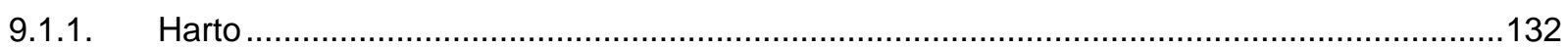

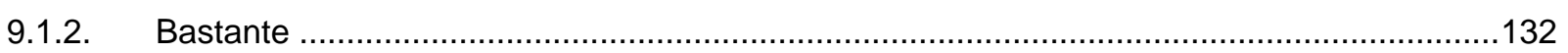

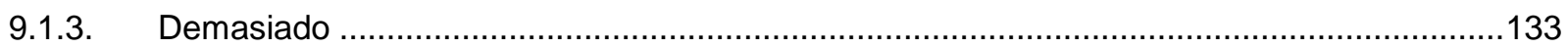

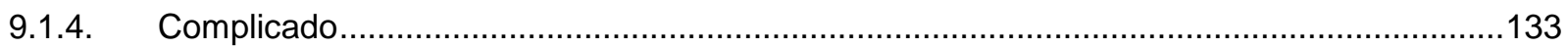

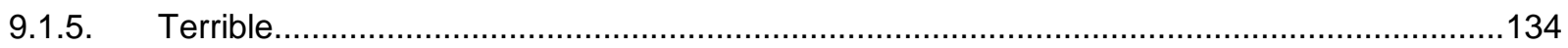

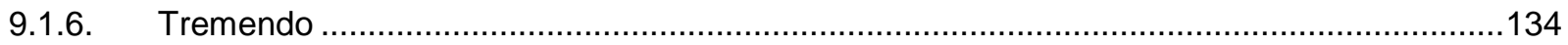

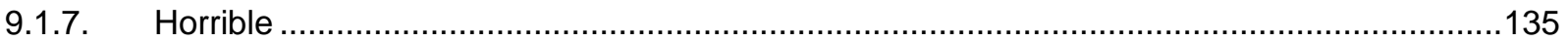

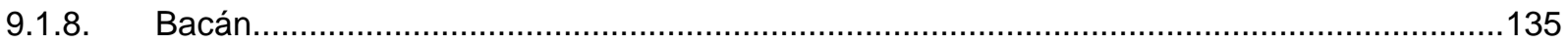

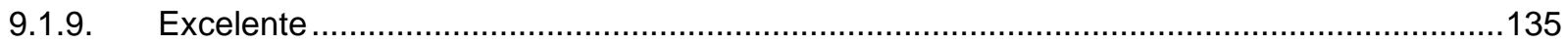

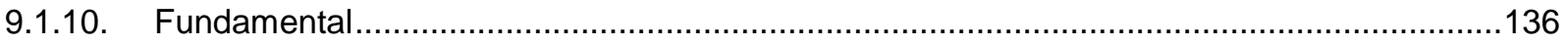

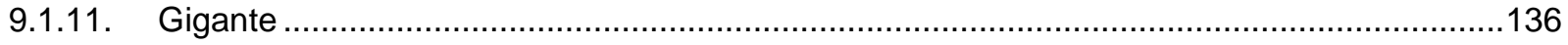

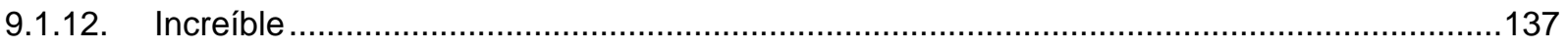

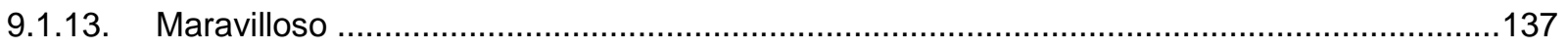

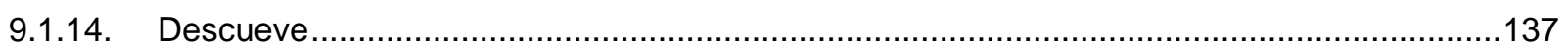

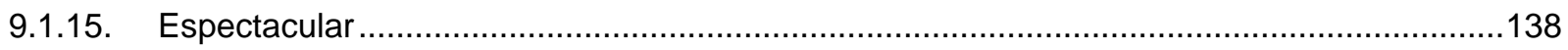

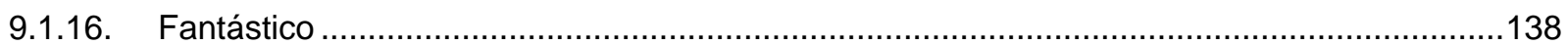

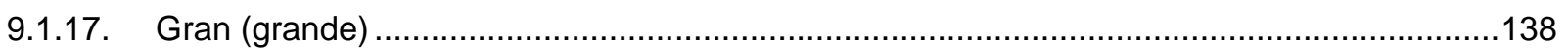

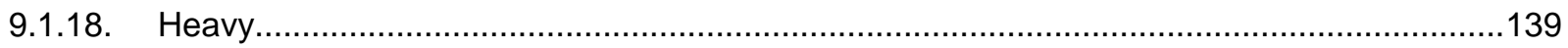

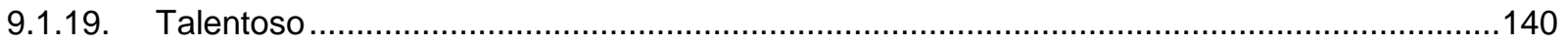

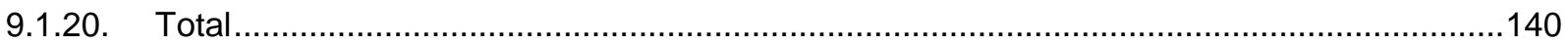

9.2. Léxico con valor superlativo según variables sociolingüísticas de sexo, edad y nivel

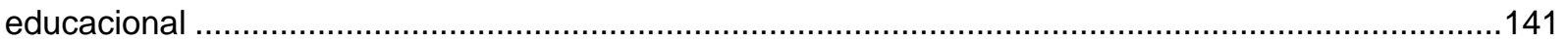

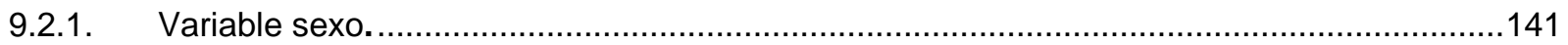

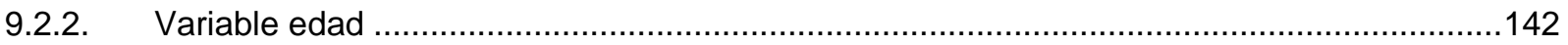

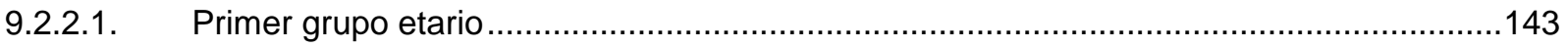

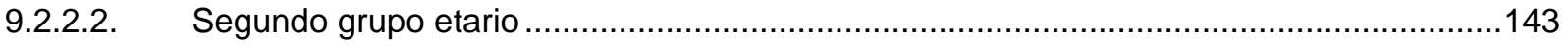




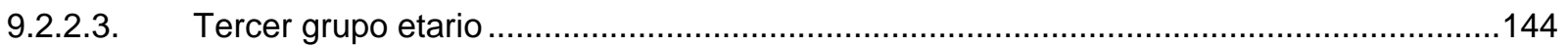

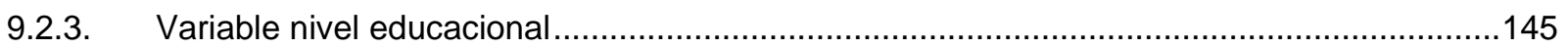

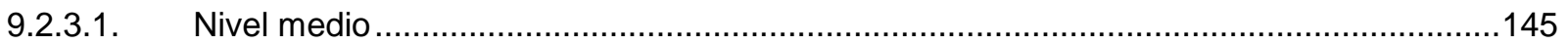

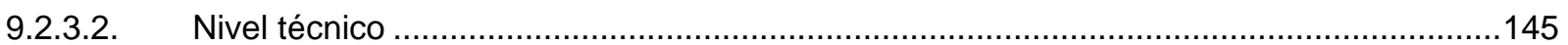

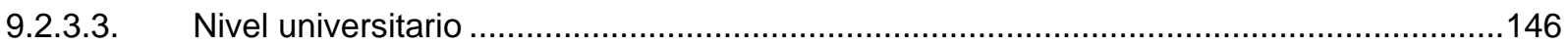

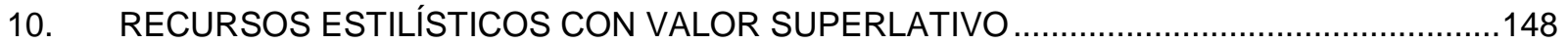

10.1. Listado de recursos estilísticos con valor superlativo. .....................................................149

10.2. Ocurrencia de los recursos estilísticos en las entrevistas...............................................153

10.3. Análisis cuantitativo de los recursos estilísticos según sexo, edad y nivel educacional. .....154

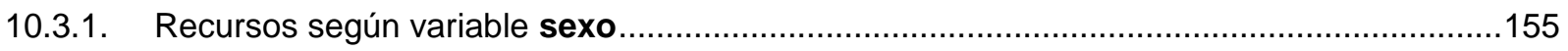

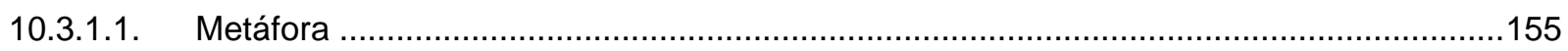

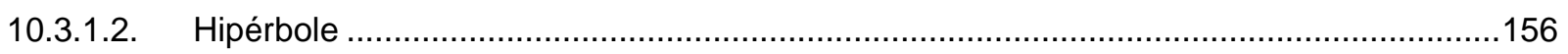

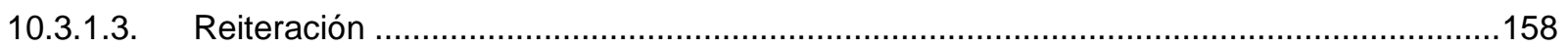

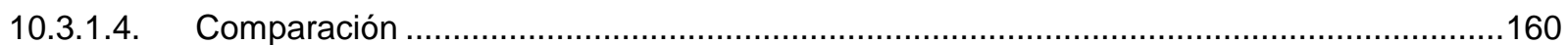

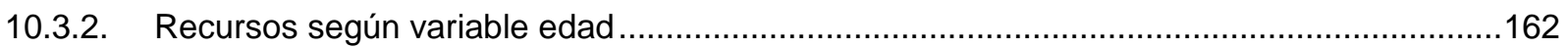

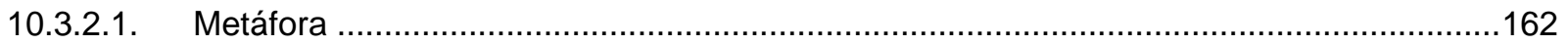

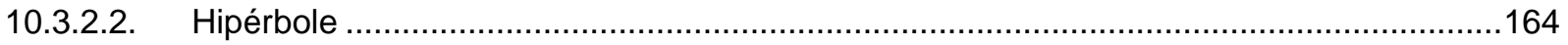

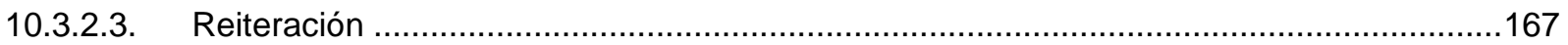

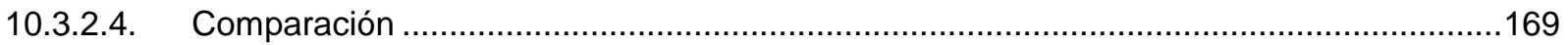

10.3.3. Recursos según variable nivel educacional ................................................................172

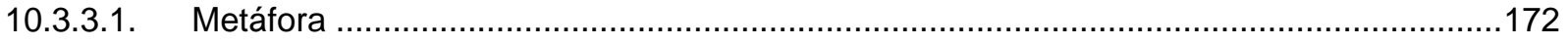

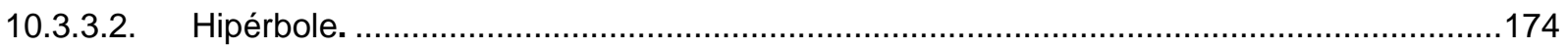

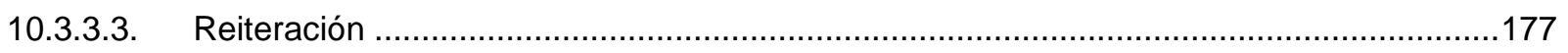

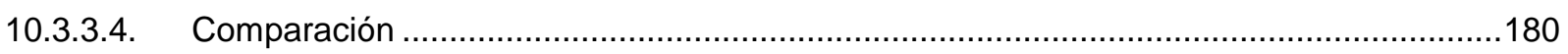

11. ASPECTOS PRAGMÁTICOS: EL ÉNFASIS Y LA POSICIÓN DEL SUPERLATIVO. .............183

11.1. ÉNFASIS EN LA EXPRESIÓN DEL SUPERLATIVO ...................................................... 183

11.1.1. El énfasis en los superlativos formados con el sufijo -ísimo .............................................188

11.1.2. El énfasis en los superlativos formados con prefijo enfatizador: ......................................190

11.1.3. El énfasis en los superlativos formados con cuantificadores adverbiales .........................191

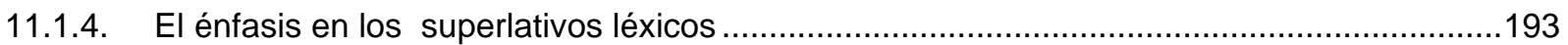

11.1.5. El énfasis en los recursos estilísticos .....................................................................198

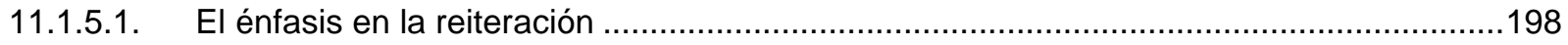

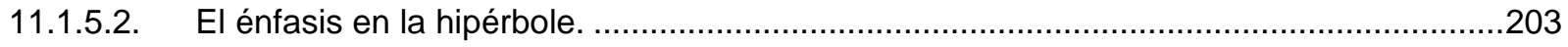

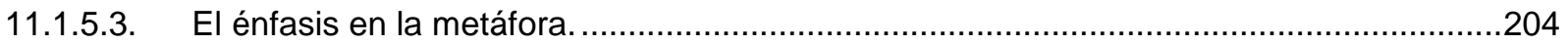

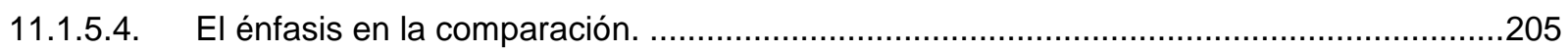

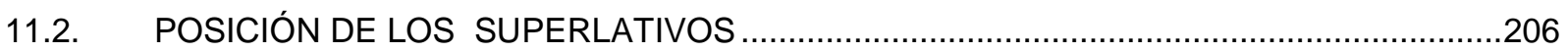


11.2.1. Posición del adjetivo superlativo adyacente .209

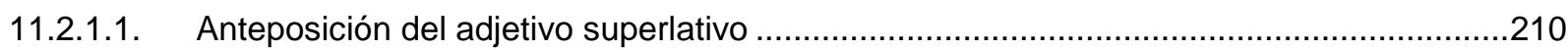

11.2.1.2. Posposición del adjetivo superlativo adyacente ..........................................................214

11.2.2. Posición del adjetivo superlativo en función atributiva .....................................................219

11.2.3. Posición de adjetivos superlativos en función de complemento predicativo ........................227

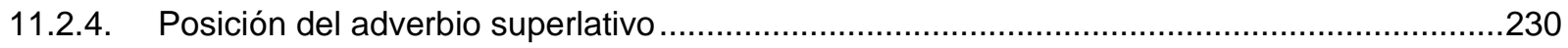

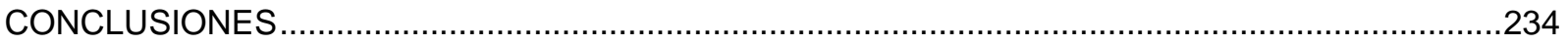

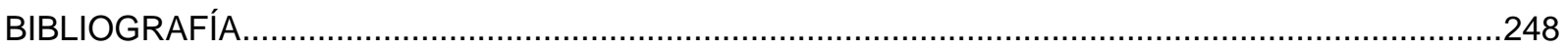

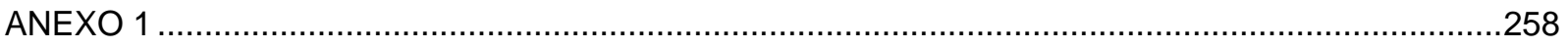

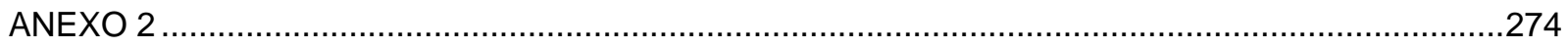

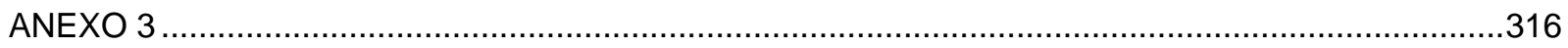




\section{ÍNDICE DE FIGURAS}

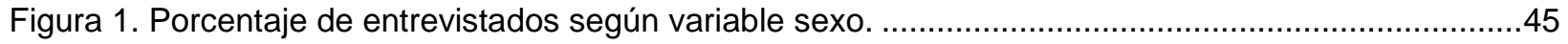

Figura 2. Porcentaje de entrevistados según variable edad...........................................................46

Figura 3. Porcentaje de entrevistados según variable nivel educacional. .............................................47

Figura 4. Distribución de entrevistados según sexo y rango etario. .......................................................49

Figura 5. Porcentaje de distribución de entrevistados según nivel educacional. .....................................50

Figura 6. Porcentaje de uso en las entrevistas, según forma de expresión del superlativo..................53

Figura 7. Promedio de valor superlativo utilizado por las personas entrevistadas, según forma de

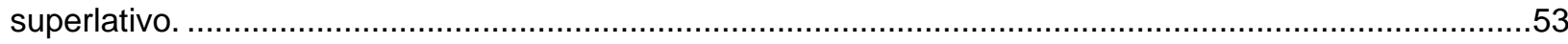

Figura 8. Promedio de formas con valor superlativo utilizadas por las personas entrevistadas, según

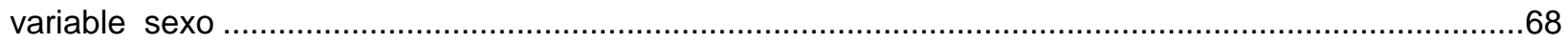

Figura 9. Porcentaje de uso de las formas superlativas de los entrevistados de sexo masculino...........70

Figura 10. Porcentaje de uso de las formas superlativas de los entrevistados de sexo femenino. ..........73

Figura 11. Promedio de uso de las formas superlativas utilizadas por las personas entrevistadas,

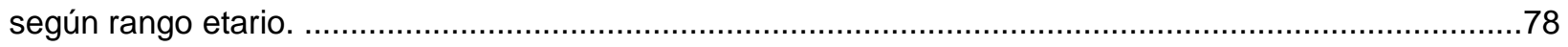

Figura 12. Porcentaje de uso del superlativo, según rango etario de 21 a 31 años..............................79

Figura 13. Porcentaje de uso del superlativo, según rango etario de 32 a 49 años...............................79

Figura 14. Porcentaje de uso del superlativo, según rango etario de 50 a 69 años..............................80

Figura 15. Distribución de entrevistados según nivel educacional. ......................................................81

Figura 16. Promedio de formas superlativas utilizadas por las personas entrevistadas, según nivel

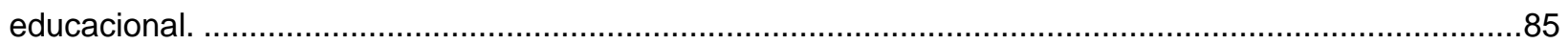

Figura 17. Porcentaje de uso del superlativo, según nivel medio.......................................................86

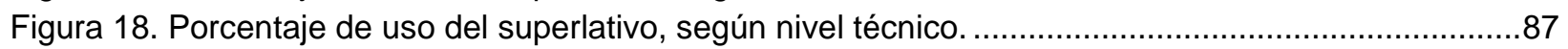

Figura 19. Porcentaje de uso del superlativo, según nivel universitario. ..............................................88

Figura 20. Porcentaje de uso de adjetivo superlativo, según variable sexo..........................................89

Figura 21. Porcentaje de uso de adjetivos superlativos, según rango etario. .......................................90

Figura 22. Porcentaje de uso de adjetivos superlativo, según nivel educacional....................................91

Figura 23. Porcentaje de uso de adverbio superlativo, según variable sexo. ........................................91

Figura 24. Porcentaje de uso de adverbio superlativo, según variable edad. .........................................92

Figura 25. Porcentaje de uso de adverbios superlativos, según nivel educacional. ...............................93

Figura 26. Porcentaje de uso de adjetivos y adverbios superlativos sintéticos y analíticos.....................94

Figura 27. Promedio de adjetivos y adverbios superlativos, analíticos y sintéticos, utilizados por las

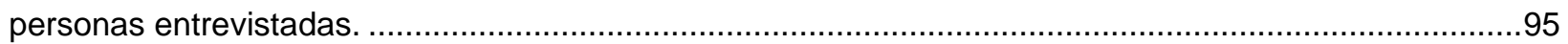

Figura 28. Número de cuantificadores usados en las entrevistas realizadas y su ocurrencia. ...............100

Figura 29. Porcentaje de uso de cuantificador muy en las entrevistas, según sexo. ..........................101

Figura 30. Porcentaje de uso de cuantificador muy, según rango etario...........................................102

Figura 31. Porcentaje de uso de cuantificador muy en las entrevistas, según nivel educacional. ...........102

Figura 32. Porcentaje de uso de cuantificador más en las entrevistas, según sexo.............................103

Figura 33. Porcentaje de uso de cuantificador más en las entrevistas, según rango etario. ..................104

Figura 34. Porcentaje de uso de cuantificador más en las entrevistas, según nivel educacional............104

Figura 35. Porcentaje de uso de cuantificador súper en las entrevistas, según sexo..........................105

Figura 36. Porcentaje de uso de cuantificador súper en las entrevistas, según rango etario. .................106

Figura 37. Porcentaje de uso de cuantificador súper en las entrevistas, según nivel educacional........106

Figura 38. . Porcentaje de uso de cuantificador bien en las entrevistas, según sexo. .........................107

Figura 39. Porcentaje de uso de cuantificador bien en las entrevistas, según rango etario. .................108

Figura 40. Porcentaje de uso de cuantificador bien en las entrevistas, según nivel educacional. ...........108

Figura 41. Porcentaje de uso de cuantificador bastante, según sexo. ...............................................109 
Figura 42. Porcentaje de uso de cuantificador bastante, según rango etario. 110

Figura 43. Porcentaje de uso de cuantificador bastante, según nivel educacional.

Figura 45. Porcentaje de uso de cuantificador tan en las entrevistas, según rango etario.

Figura 46. Porcentaje de uso de cuantificador tan en las entrevistas, según nivel educacional.

Figura 47. Promedio de uso del adjetivo y adverbio superlativo analítico y sintético, según variable sexo.

Figura 48. Porcentaje de uso de adjetivos y adverbios superlativos sintéticos y analíticos, según sexo femenino.

Figura 49. Porcentaje de uso de adjetivos y adverbios superlativos sintéticos y analíticos, según sexo masculino.

Figura 51. Porcentaje de uso de adjetivos y adverbios superlativos sintéticos y analíticos, según rango

etario de 21 a 31 años.

Figura 52. Porcentaje de uso de adjetivos y adverbios superlativos sintéticos y analíticos, según rango

etario de 32 a 49 años.

Figura 53. Porcentaje de uso de adjetivos y adverbios superlativos sintéticos y analíticos, según rango etario de 50 a 69 años.

Figura 54. Promedio de uso de adjetivos y adverbios superlativos sintéticos y analíticos utilizados por las personas entrevistadas, según nivel educacional.

Figura 55. Porcentaje de uso de adjetivos y adverbios superlativos sintéticos y analíticos en

entrevistados de nivel educacional medio.

Figura 56. Porcentaje de uso de adjetivos y adverbios superlativos sintéticos y analíticos en

entrevistados de nivel educacional técnico.

Figura 57. Porcentaje de uso de adjetivos y adverbios superlativos sintéticos y analíticos, según nivel educacional universitario.

Figura 58. Porcentaje de palabras utilizadas por los entrevistados en léxico con valor superlativo. .......128

Figura 59. Palabras de léxico con valor superlativo más utilizadas por los entrevistados. ....................131

Figura 60. Porcentaje de palabras de léxico con valor superlativo utilizadas por los entrevistados, según

sexo.

Figura 61. Número de palabras de léxico con valor superlativo, según categoría gramatical y variable

sexo.

Figura 62. Porcentaje de léxico con valor superlativo utilizado por entrevistados con rango etario 21 a 31

años.

Figura 63. Porcentaje de Léxico con valor superlativo utilizado por entrevistados con rango etario 32 a 49

años.

Figura 64. Porcentaje de léxico con valor superlativo utilizado por entrevistados con rango etario 50 a 69 años......

Figura 65. Porcentaje de léxico con valor superlativo utilizado por entrevistados con nivel educacional medio.

Figura 66. Porcentaje de léxico con valor superlativo utilizado por entrevistados con nivel educacional técnico.

Figura 67. Porcentaje de léxico con valor superlativo utilizado por entrevistados con nivel educacional universitario.

Figura 68. Porcentaje de ocurrencias de recursos en las entrevistas realizadas..............................153

Figura 69. Número de personas entrevistadas, según ocurrencia de metáfora y variable sexo..............156

Figura 70. Porcentaje de ocurrencia de metáfora, según variable sexo...............................................156

Figura 71. Número de personas entrevistadas, según ocurrencia de hipérbole y variable sexo. ...........157

Figura 72. Porcentaje de ocurrencia de hipérbole, según variable sexo..........................................158

Figura 73. Número de personas entrevistadas, según ocurrencia de reiteración y variable sexo. ..........159

Figura 74. Porcentaje de ocurrencia de reiteración, según variable sexo. ...........................................160 
Figura 75. Número de personas entrevistadas, según ocurrencia de comparación y variable sexo. .....161

Figura 76. Porcentaje de ocurrencia de comparación, según variable sexo. ...........................................162

Figura 77. Porcentaje de ocurrencia de metáfora en rango etario entre 21 a 31 años. .........................163

Figura 78. Porcentaje ocurrencia de metáfora en rango etario entre 32 a 49 años. ............................163

Figura 79. Porcentaje de ocurrencia de metáfora en rango etario entre 50 a 69 años. .......................164

Figura 80. Porcentaje de ocurrencia de hipérbole en rango etario entre 21 a 31 años.........................165

Figura 81. Porcentaje de ocurrencia de hipérbole en rango etario entre 32 a 49 años........................166

Figura 82. Porcentaje de ocurrencia de hipérbole en rango etario entre 50 a 69 años........................166

Figura 83. Porcentaje de ocurrencia de reiteración en rango etario entre 21 a 31 años........................168

Figura 84. Porcentaje de ocurrencia de reiteración en rango etario entre 32 a 49 años.......................168

Figura 85. Porcentaje de ocurrencia de reiteración en rango etario entre 50 a 69 años........................169

Figura 86. Porcentaje de ocurrencia de comparación en rango etario entre 21 a 31 años....................171

Figura 87. Porcentaje de ocurrencia de comparación en rango etario entre 32 a 49 años...................171

Figura 88. Porcentaje de ocurrencia de comparación en rango etario entre 50 a 69 años....................172

Figura 89. Porcentaje de ocurrencia de metáfora en nivel educacional medio. ....................................173

Figura 91. Porcentaje de ocurrencia de metáfora en nivel educacional universitario. ..........................174

Figura 92. Porcentaje de ocurrencia de hipérbole en nivel educacional medio. ...................................176

Figura 93. Porcentaje de ocurrencia de hipérbole en nivel educacional técnico...................................176

Figura 94. Porcentaje de ocurrencia de hipérbole en nivel educacional universitario.............................177

Figura 95. Porcentaje de ocurrencia de reiteración en nivel educacional medio. .................................178

Figura 96. Porcentaje de ocurrencia de reiteración en nivel educacional técnico................................179

Figura 97. Porcentaje de recurrencia de reiteración en nivel educacional universitario.........................180

Figura 98. Porcentaje de ocurrencia de comparación en nivel educacional medio...............................181

Figura 99. Porcentaje de ocurrencia de comparación en nivel educacional técnico. ............................181

Figura 100. Porcentaje de ocurrencia de comparación en nivel educacional universitario. .....................182 


\section{ÍNDICE DE TABLAS}

Tabla 1. Distribución de frecuencias del número de personas entrevistadas, según rango etario y sexo. 48 Tabla 2. Distribución de frecuencias del número de personas entrevistadas, según rango etario y nivel educacional

Tabla 3. Medidas descriptivas de formas de superlativo según sexo................................................67

Tabla 4. Medidas descriptivas de formas superlativas según rango etario. ..........................................76

Tabla 6. Medidas descriptivas de forma de superlativos, según nivel educacional ................................84

Tabla 7. Medidas descriptivas de adjetivos y adverbios superlativos sintéticos y analíticos, según variable sexo.

Tabla 8. Medidas descriptivas de adjetivos y adverbios superlativos sintéticos y analíticos, según rango etario.

Tabla 9. Medidas descriptivas de adjetivos y adverbios superlativos sintéticos y analíticos, según nivel educacional. 124

Tabla 10. Número de palabras de léxico con valor superlativo, según categoría gramatical y tipo de locución. 128

Tabla 11. Número de personas entrevistadas, según ocurrencia de metáfora y variable sexo. 155

Tabla 12. Número de personas entrevistadas, según ocurrencia de Hipérbole y variable sexo. 157

Tabla 13. Número de personas entrevistadas según ocurrencia de reiteración y variable sexo. 159 Tabla 14. Número de personas entrevistadas según ocurrencia de comparación y variable sexo. ........161

Tabla 15. Número de personas entrevistadas, según ocurrencia de metáfora y rango etario. 162

Tabla 16. Número de personas entrevistadas según ocurrencia de hipérbole y rango etario. 164

Tabla 17. Número de personas entrevistadas, según ocurrencia de reiteración y rango etario. 167

Tabla 18. Número de personas entrevistadas, según ocurrencia de comparación y rango etario. ........170 Tabla 19. Número de personas entrevistadas, según ocurrencia de metáfora y nivel educacional. .......172 Tabla 20. Número de personas entrevistadas, según ocurrencia de hipérbole y nivel educacional.......175 Tabla 21. Número de personas entrevistadas, según ocurrencia de reiteración y nivel educacional....177 Tabla 22. Número de personas entrevistadas, según ocurrencia de comparación y nivel educacional. 180 


\section{ÍNDICE DE ABREVIATURAS Y SIGLAS}

am.

ant.

apóc.

aum.

adj.

adv.

adv.cant.

adv.m.

ant.lat.

coloq.

Ch.

$\mathrm{Cu}$.

cult.

despect./desp.

Ec.

espon.

f.

fam.

fig.

hiperb.

juv.

lat

loc.

loc.adj.

loc.adv.

loc.pron.

loc.tr.

m.

Méx. americanismo

antiguo

apócope

aumentativo

adjetivo

adverbio

adverbio de cantidad

adverbio de modo

antiguo latín

coloquial

Chile

Cuba

culto

despectivo

Ecuador

espontáneo

femenino

familiar

figurado

hipérbole

juvenil

latín

locución

locución adjetiva

locución adverbial

locución pronominal

locución transitiva

masculino

México 
p.a.

Pe.

pond.

pop.

Ur.

v.g.

vulg.

$\mathrm{DECH}$

DRAE

DUECH

GRAE

RAE participio activo

Perú

ponderativo

popular

Uruguay

verbi gratia (verbigracia)

vulgar

Nuevo Diccionario Ejemplificado de Chilenismos

Diccionario de la Real Academia Española

Diccionario de Uso del Español de Chile.

Gramática de la Real Academia Española

Real Academia Española 


\section{INTRODUCCIÓN}

Los hablantes de una lengua pueden usar elementos lingüísticos distintos para expresar cosas distintas, o bien, tienen la posibilidad de usar elementos lingüísticos diferentes para expresar las mismas cosas. El uso de ciertas unidades lingüísticas en lugar de otras puede expresar significados diferentes, o valores semánticos diferentes (Moreno, 1998). Lo que los sociolingüistas denominan variación sociolingüística es el uso de un elemento en lugar de otro, sin que por esto haya algún tipo de alteración semántica, ya que si se usa uno u otro, se está diciendo lo mismo. Esto es lo que ocurre en el uso de formas superlativas para expresar enfáticamente lo que se quiere decir. Así, si se usa la forma sintética o analítica, la valoración semántica del adjetivo o del adverbio, en general, no es alterada, solo se produce una mayor intensificación de la característica expresada.

Los hablantes pueden también usar diversas estructuras para enfatizar lo que quieren decir, no solamente aquellas formas gramaticales propias de la lengua en uso. Así para intensificar la acción verbal o la característica de un sustantivo no sólo se vale de la gradación gramatical que posee la lengua española (con sufijos, prefijos, cuantificadores), sino que usa también elementos léxicos o recursos estilísticos para lograr su objetivo.

El uso lingüístico sólo puede tener lugar en contextos sociales y situacionales concretos, lo que supone que este uso al ser observado, siempre debe hacerse en situaciones y contextos reales. Por ello, para estudiar un determinado fenómeno de la 
lengua es necesario buscar su uso en dichos contextos para que la información recogida sea la que realmente refleja este uso.

En la variación lingüística, hay factores sociales que muestran una mayor capacidad de incidencia, como el sexo de los hablantes, la edad, el nivel de instrucción, el nivel sociocultural, la profesión, la etnia, entre otros (Moreno, 1998).

El objetivo principal de esta investigación es estudiar el uso del superlativo en hablantes de la Región de Valparaíso. Se pretende determinar la frecuencia de este uso, identificar los tipos de cuantificadores usados para la construcción superlativa analítica, la utilización de otras estructuras léxicas y gramaticales para este fin; demostrar la incidencia que pueden tener en este uso las distintas variables sociolingüísticas, como el sexo, la edad, y nivel educacional, así como algunos valores de tipo pragmático presentes en el discurso de estos hablantes.

Para lograr los propósitos del presente trabajo, se realizaron entrevistas a hablantes de la Región de Valparaíso. Luego de la construcción del corpus de las entrevistas, se hizo, en primer término, un análisis cuantitativo de los usos del superlativo, por cada uno de los hablantes entrevistados, considerando las formas de realización del superlativo, esto es, como adjetivo adyacente (antepuesto o pospuesto al sustantivo), como atributo predicativo(con verbos copulativos ser y estar), como predicativo (atributo con verbos no copulativos), como adverbio, como léxico con valor superlativo y como recursos estilísticos que manifiestan superlación.

En el trabajo, se analizan y ejemplifican con textos de las entrevistas, las 6 formas ya enunciadas de realización del superlativo. En el léxico superlativo, se consideran los elementos gramaticales registrados en las entrevistas, esto es, sustantivos, adjetivos, adverbios, locuciones adjetivas y locuciones adverbiales, y, en 
los recursos estilísticos, se ejemplifican las metáforas, hipérboles, reiteraciones y comparaciones que los hablantes usaron en su elocución.

Los adjetivos y adverbios superlativos, tanto sintéticos como analíticos, son tratados de manera especial, según el uso de éstos por cada entrevistado. Se ha considerado de particular interés analizar el uso de los diferentes cuantificadores utilizados para la construcción del superlativo absoluto analítico, por lo que se realizó un registro de éstos, con el fin de constatar cuáles son los más recurrentes en el discurso de los entrevistados.

Luego se hace el análisis de resultados de uso de todas las formas superlativas, de acuerdo con las tres variables sociolingüísticas consideradas en este estudio: sexo, edad y nivel educacional. Este análisis cuantitativo está basado en datos estadísticos, representados en tablas y gráficos explicativos de los resultados obtenidos.

Dada la importancia de los elementos pragmáticos en la elocución de los hablantes, se analiza la incidencia del énfasis del superlativo en la expresión de los entrevistados y también la posición del adjetivo o adverbio superlativo, en relación con el elemento gramatical al que modifica.

Al final, se agregan conclusiones generales en relación con el tema en estudio y también aquellas particulares que dicen relación con las variables sociolingüísticas consideradas y los dos aspectos pragmáticos tratados: posición del superlativo y el énfasis que éste tiene en la elocución de los 34 entrevistados.

En la parte correspondiente a los anexos, se agrega información complementaria sobre la investigación realizada.

El primer anexo contiene todas las palabras usadas por los entrevistados con valor superlativo. Se registra su valor semántico, extraído de diccionarios (DRAE, 
Diccionario de Americanismos, Diccionario de Chilenismos, entre otros). Junto a esta información semántica, se agrega un ejemplo de uso de estas palabras por parte de los entrevistados.

El segundo anexo corresponde al registro de todas las formas superlativas usadas por cada uno de los 34 entrevistados.

El corpus de la investigación, correspondiente a las 34 entrevistas realizadas, es anexado a la investigación, en un CD. 


\section{OBJETIVOS DE LA INVESTIGACIÓN Y PLANTEAMIENTO DE HIPÓTESIS}

\subsection{OBJETIVOS}

En este trabajo investigativo de carácter sociolingüístico, sobre el uso del superlativo en hablantes de la Región de Valparaíso, me he propuesto los siguientes objetivos:

1. Verificar el uso del superlativo de grado extremo, expresado tanto en forma sintética como analítica, en la elocución de hablantes de la Región de Valparaíso, en conversaciones informales sobre diversos temas (vida familiar, viajes, desastres naturales, realidad política nacional, estudios, cine, deportes, trabajo, educación, etc.).

2. Identificar los cuantificadores utilizados por los entrevistados para estructurar la frase superlativa analítica, tanto adjetiva como adverbial.

3. Constatar qué formas usan los hablantes para expresar lo superlativo (formas gramaticales, léxicas o estilísticas).

4. Comprobar la incidencia de las variables sociolingüísticas de sexo, edad y nivel educacional en el uso del superlativo de estos hablantes

5. Comprobar la incidencia de factores pragmáticos, como el énfasis de la expresión y la posición del superlativo, adjetivo o adverbio, en relación con el elemento gramatical al que se refiere. 


\subsection{PLANTEAMIENTO DE HIPÓTESIS.}

Sobre el uso que los hablantes entrevistados de la Región de Valparaíso hacen del superlativo, planteo las siguientes hipótesis:

\section{Hipótesis 1}

Las variables sociolingüísticas de sexo, edad y nivel educacional tienen incidencia en el uso de formas superlativas en la elocución de hablantes de la Región de Valparaíso.

\section{Hipótesis 2}

El superlativo de grado extremo sintético es menos usado por los hablantes en situaciones de comunicación oral coloquial.

\section{Hipótesis 3}

Tienen importancia, en la elocución de los entrevistados, el énfasis con que ellos expresan el superlativo y la posición de éste respecto del elemento gramatical al que modifica. 


\section{MARCO TEÓRICO}

El término superlativo es definido como un adjetivo que significa "muy grande y excelente en su línea" (DRAE, 2010). Es referido también a aquella forma del adjetivo con que se denota el sumo grado de cualidad que con él se expresa. Es el adjetivo superlativo un recurso para enfatizar lo que decimos.

El español posee una gran cantidad de formas para ponderar, enfatizar 0 intensificar de manera positiva o negativa una realidad. Lo superlativo tiene que ver con el grado máximo o mínimo de la cualidad o la cantidad que se expresa. Esta caracterización hiperbólica de la realidad se manifiesta a través de adjetivos (una mirada sutilísima), formas adjetivales (una mirada muy sutil), adverbios (vive lejísimo), o frases adverbiales (vive muy lejos).

Según Gili y Gaya (1961/1964: 99), desde un punto de vista sintáctico, tanto los adjetivos como los verbos son elementos necesariamente dependientes de un sustantivo, pues se piensan y expresan adheridos a él. Un adjetivo necesita referirse a un sustantivo, al cual añade notas que lo determinan o precisan.

El adjetivo, como elemento gramatical, tiene la función de referir al sustantivo una caracterización o especificación, ya por simple unión atributiva, ya como complemento predicativo con verbo copulativo (Esbozo de una Nueva Gramática de la Lengua Española, 1977).

Morfológicamente, el adjetivo, al igual que el nombre sustantivo, recibe morfemas constitutivos de la variación de género y de número. Sin embargo, presenta un 
morfema que le es propio: el morfema de grado. Este es un modificador que sirve para indicar el nivel de la cualidad que presenta la sustancia calificada.

El grado presenta la cualidad del sustantivo en relación con otros sustantivos (comparativo y superlativo relativo), o bien, sin relacionar con otros sustantivos (positivo y superlativo absoluto o elativo).

El uso de adjetivos que un determinado hablante haga en la composición de su texto o de su discurso es, habitualmente, una marca importante del grado de subjetividad de dicho texto o discurso, puesto que asignar cualidades a la realidad implica una perspectiva personal en relación con dicha realidad. El uso de la adjetivación en un texto es un primer dato de interés que nos permite determinar el grado de objetividad o subjetividad del constructor del texto. Si se busca representar una realidad con objetividad, se utilizarán sólo los adjetivos imprescindibles para la representación de dicha realidad, como ocurre en los textos científicos. En el texto literario, por razones de tipo estilístico, se aprecia una mayor abundancia de adjetivos, sin embargo, su empleo debe hacerse con especial cuidado, ya que de ello depende la fuerza expresiva que el autor ha de darle a su creación. En cambio, en el habla coloquial, en la que interesa fundamentalmente la interacción comunicativa y expresiva de los hablantes, la adjetivación es recurrente y con una variada presencia de elementos intensificadores del grado del adjetivo.

Según los autores Alsina y Blecua (1975), la lengua provee al hablante de varios y determinados recursos para expresar la gradación, a saber:

a) Recursos Prosódicos: con la utilización de acento afectivo o silábico del segmento afectado y semejantes fórmulas de relieve. Por ejemplo, ¡Magnífico! ; Es mag-ní-fi-co. 
b) Recursos Morfemáticos internos con utilización de marcas y derivativos que habilitan un determinado lexema en grados distintos: Bueno, bonísimo, archibueno.

c) Recursos sintácticos, cuando se acude a la asociación sintagmática (perifrástica) con segmentos terciarios: muy bueno, más bueno.

Dentro del proceso de atribución puntual, el sistema de la lengua reconoce una forma que expresa el valor lexical del adjetivo y una forma que expresa la intensificación de dicho contenido. Se corresponden así positivo y superlativo (superlativo absoluto).

En la atribución relativa, se distinguen, más que grados, dos valoraciones: una valoración comparativa, en la que la intensidad se da como distinta, y una excepcional con respecto a un conjunto de ejemplares que tienen la misma cualidad.

La gradación de los adjetivos con comparativos y superlativos es un fenómeno gramatical que se encuentra exclusivamente en los idiomas indoeuropeos (Lenz, 1935).

El superlativo español proviene de la lengua latina, en la que, a través de una desinencia, se expresaba la intensificación de la cualidad del adjetivo.

En latín, las formas regulares para la formación del grado superlativo correspondían a las desinencias: -issimus (masculina); -issima (femenina); issimum (neutra), las cuales se unían al tema del adjetivo en el grado positivo, por ejemplo: sapiens-entis (positivo) sabio; sapientissimus;- a;-um (superlativo) muy sabio o sapientísimo. Sin embargo, había un buen número de adjetivos que para la formación del grado superlativo, o bien, usaban de otros morfemas (formación irregular del grado), o bien, usaban de adverbios intensificadores de la cualidad, pues el tema del adjetivo positivo 
terminado en una vocal impedía el uso de morfemas, o bien, usaban de una forma léxica distinta del positivo, v.g.:

a) Adjetivos con morfema-ilis, como facilis, formaban el superlativo con el sufijo -limus;-a;-um. Así se decía facillimus;-a;-um, muy fácil o facilísimo.

b) Adjetivos con morfema -er, como pauper, formaban el superlativo con el sufijo -rimus;-a;-um. Un ejemplo de esta formación irregular es pauperrimus;-a;-um, muy pobre o paupérrimo.

c) Adjetivos cuya desinencia temática en el grado positivo impedía la formación del superlativo con el morfema regular. En este caso, la intensificación del grado se expresaba con adverbios como maxime 0 valde, por ejemplo, dubius;--a;-um (positivo), dudoso; maxime dubius (superlativo), muy dudoso.

d) Adjetivos que no usaban morfemas ni adverbios para la intensificación de la cualidad, sino que lo hacían con formas absolutamente irregulares respecto de la forma del positivo. Algunos ejemplos son:

1. Bonus;-a;-um (positivo) bueno ; Optimus;-a;-um (superlativo), óptimo, muy bueno.

2. Malus;-a;-um (positivo), malo ; Pessimus;-a;-um (superlativo), pésimo, muy malo.

3. Magnus;-a;-um (positivo), grande ; Maximus;-a;-um (superlativo, máximo, muy grande.

4. Parvus;-a;-um (positivo), pequeño ; Minimus;-a;-um (superlativo), mínimo, muy pequeno. 
5. Superus;-a;-um (positivo muy poco usado em latín); Supremus o Summus (superlativo), muy alto, supremo.

6. Inferus;-a;-um (positivo muy poço usado em latín) ; Infimus;-a;-um (superlativo), muy bajo, ínfimo.

El superlativo absoluto o elativo castellano conserva, en parte, el carácter de formación culta y literaria que tuvo en la época de su introducción en España. El carácter de palabra culta, y, en cierto modo, rara y excepcional, se agudiza para la conciencia idiomática española cuando el adjetivo incorporado en el superlativo aparece en su forma castellana más próxima a su forma latina.

En el uso de las formas superlativas, se mantienen las formaciones cultas tradicionales, derivadas del latín, junto con las formas propias del español; las primeras tienen un carácter más literario y las segundas, uno más coloquial y popular. Coexisten formas como las siguientes:

- Aspérrimo (culta) y asperísimo (popular)

- Crudelísimo (culta) y cruelísimo (popular)

- Integérrimo (culta) e integrísimo (popular)

- Nigérrimo (culta) y negrísimo (popular)

- Paupérrimo (culta) y pobrísimo (popular)

- Pulquérrimo (culta) y pulcrísimo (popular)

- Simplicísimo (culta) y simplísimo (popular) 
En algunos adjetivos, sólo existe la forma culta de la formación del superlativo, las que no son de uso habitual. En el habla popular, se prefiere el uso de superlativo analítico (perífrasis de adverbio muy más adjetivo en grado positivo). Algunos ejemplos son los siguientes:

- Antiquísimo ( de antiguo)

- Celebérrimo ( de célebre)

- Fidelísimo ( de fiel)

- Iniquísimo ( de inicuo)

- Libérrimo ( de libre)

- Misérrimo (de mísero)

- Salubérrimo ( de salubre)

Si bien la gradación superlativa es una característica morfológica del adjetivo, otros elementos gramaticales también adoptan el morfema flexivo -ísimo, como los adverbios ("es tardísimo"), participios pasados ("agotadísimo"). La Real Academia, en su Esbozo (1977: 195), señala: “También se usan nombres sustantivos, apelativos y propios en forma superlativa, especialmente con intención cómica y burlesca, o como parodia del estilo declamatorio y altisonante. Buen ejemplo de esto último es el episodio de la Dueña Dolorida, en el cap. XXXVIII de la segunda parte del Quijote, donde en pocas líneas se acumulan seis sustantivos en forma superlativa: cultísima, don Quijote de la Manchísima, escuderísimo, don Quijotísimo, dueñísima, servidorísimos, amén de la forma verbal quisieridísimis, que extrema el disparate". Así también, en el español coloquial actual, se usan voces como "yernísimo" (del sustantivo 
yerno), "cuñadísima" (del sustantivo cuñada), "generalísimo" (del sustantivo general), con un claro valor peyorativo, de burla, o de sarcasmo.

En latín, el superlativo tanto absoluto como relativo usaba la desinencia indicadora del grado. La diferencia entre estos era que el relativo se expresaba con el complemento, expresado en caso genitivo, en caso ablativo precedido de las preposiciones "e, ex" (forma usada preferentemente por los autores clásicos), o bien, en caso acusativo precedido de la preposición "inter". Por ejemplo:

a) Socrates sapientissimus omnium graecorum erat (Sócrates era el más sabio de todos los griegos).

b) Socrates sapientissimus ex omnibus graecis erat. (Sócrates era el más sabio de todos los griegos).

c) Socrates sapientissimus inter omnes graecos erat. (Sócrates era el más sabio entre todos los griegos)

En español, en cambio, el superlativo relativo no se expresa con el morfema superlativo, sino por una estructura construida con artículo definido + sustantivo + cuantificador (más o menos) + adjetivo en grado positivo + complemento del superlativo, por ejemplo, la persona más querida del barrio.

\begin{tabular}{|l|l|l|l|l|}
\hline Artículo & Sustantivo & Cuantificador & $\begin{array}{l}\text { Adjetivo } \\
\text { Posit.ivo }\end{array}$ & $\begin{array}{l}\text { Complemento } \\
\text { superlativo. }\end{array}$ \\
\hline La & persona & más & querida & del barrio \\
\hline
\end{tabular}


Según la RAE, el superlativo relativo se expresa mediante el grado comparativo del adjetivo precedido del artículo: Juan era el mejor alumno de su clase. Por esta razón, la Academia señala que, tanto por su significado como por su forma, podría denominarse más bien comparativo de excelencia o "comparativo relevante", antes que superlativo.

\begin{tabular}{|l|l|l|}
\hline Artículo & Comparativo & Complemento del Superlativo \\
\hline El & menor & de los hermanos \\
\hline La & más alta & de todas las casas \\
\hline
\end{tabular}

En un análisis sobre los grados del adjetivo, César Hernández (1984/1996: 553) explica que la formación de estos grados se expresa de tres modos, a saber:

1. Modificación por elemento adyacente $\{$ muy, sumamente + adjetivo

2. Modificación por morfema

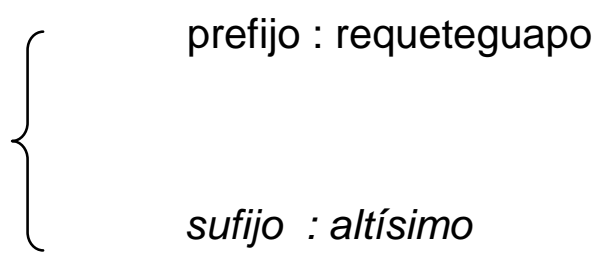

3. Modificación con cambio léxico

$$
\left\{\begin{array}{l}
\text { bueno - óptimo } \\
\text { alto - supremo }
\end{array}\right.
$$


Este mismo autor manifiesta que no considera que el comparativo y el superlativo sean una gradación del positivo del adjetivo. "Así pues, vemos que los llamados "comparativos y superlativos" no son sino modificaciones de un adjetivo (o adverbio) por medio de un adyacente cuantificador o por unos morfemas, generalmente, que aportan unos determinados rasgos al contenido; pero en ningún caso percibimos una gradación del supuesto positivo (forma básica normal), el comparativo y superlativo".

Rafael Seco (1977), por su parte, al hablar de los sufijos y prefijos que usa el español para la derivación y composición de palabras, señala que dentro de los sufijos apreciativos, que denotan unas veces tamaño (en los nombres), por ejemplo, piedrecita, o intensidad (en los adjetivos y adverbios, e.g.: poquito), hay que incluir el sufijo - ísimo, propio de los adjetivos, que expresa intensidad, e.g.: facilísimo.

Los autores Bosque y Demonte (2000), al analizar el superlativo relativo, manifiestan que estas formas superlativas usan sintagmas que funcionan como restrictores. Por otra parte, señalan que el superlativo absoluto carece de un restrictor.

Según su categoría, los restrictores pueden clasificarse en:
a) Sintagma preposicional: Él es el más alto de todos.
b) Oraciones relativas: Él es el más alto que conozco
c) Sintagmas adjetivos: Juan es el pintor más importante vivo

Según la Gramática de la RAE (2010), el sufijo -ísimo aporta el significado de grado extremo a un gran número de adjetivos calificativos, como bellísimo, contentísima, gravísima, sencillísima, entre otros. También señala que admiten este sufijo los adjetivos mismo, primero y último, y unos pocos cuantificadores como 
mucho, poco, cuanto o tanto, y algunos adverbios como temprano, tarde, pronto, cerca, lejos, despacio.

Rechazan el sufijo - ísimo muchos adjetivos que con el sufijo -mente forman un adverbio. Hay, sin embargo, algunas pocas excepciones en este caso, como brevísimamente, malísimamente, rarísimamente.

También rechazan el sufijo superlativo los adjetivos que terminan en -ío, como sombrío, tardío (aunque lo admite frío: frísimo); y los terminados en -uo, aunque existen algunos que sí aceptan el sufijo, como arduísimo de arduo.

Por razones semánticas, rechazan el sufijo -ísimo/ísima, los adjetivos de relación puesto que no denotan propiedades graduables, a menos que se interpreten como calificativos, pues los adjetivos calificativos son los que denotan una propiedad o cualidad susceptible de ser graduada. En otras palabras, los calificativos admiten la gradación.

El sufijo -ísimo se usa en el lenguaje culto y formal en adjetivos que manifiestan respeto hacia una autoridad (política, eclesiástica o jurídica). Por ejemplo: Excelentísimo señor Presidente de la República, Señores de la Ilustrísima Corte, Eminentísimo Cardenal, Reverendísimo Monseñor. Estas voces ponderativas tienen en el texto escrito una abreviatura que las identifica como superlativas: Excmo. (excelentísimo), IImo.(llustrísimo), Emmo. (eminentísimo).

Se usa, además, este sufijo en varios términos religiosos como una forma respetuosa para dirigirse a la divinidad. Santísima Cruz, el Altísimo, Virgen Purísima, Santísima Trinidad, etc.

El sufijo -érrimol -érrima, considerado por la gramática también un prefijo superlativo, no es usado en español para la formación del grado de cualquier adjetivo. 
Sólo aparece en ciertos adjetivos derivados de la forma culta latina y cuyo uso es poco frecuente en el habla coloquial. Los de uso más habitual son los siguientes: paupérrimo, celebérrimo, misérrimo.

Para la intensificación de lo dicho, en español, se utiliza también el mecanismo de la prefijación. La GRAE (2010: 184-185) dice que estos prefijos "miden y evalúan el grado con que se manifiesta la propiedad o ponderan la intensidad con la que tiene lugar una acción o un evento". Entre estos prefijos están archi- , cuasi -, hiper - , infra - , re -, super -, semi -, sobre -, vice - . Algunos de éstos expresan intensificación o grado máximo.

El prefijo re-sirve para expresar distintos valores en las palabras a las que se une (sustantivos, adjetivos, verbos, adverbios). Puede expresar reintegración o repetición (recaer), aumento (recargar), resistencia (rechazo), movimiento hacia atrás (refluir), negación (reprobar), intensidad o encarecimiento (rebonita). Alterna con requete $-y$ rete- en varias áreas lingüísticas. Expresa, según la GRAE (2010), intensificación cuando se junta a algunos adjetivos y participios adjetivales (reseco, rebueno, redicho), y aclara que en el español juvenil del área rioplatense, y con menor intensidad, de la chilena, este prefijo ha adquirido una extensión léxica inusual en otras áreas. Se forman en efecto, con él adjetivos como regrande, redivertido o reloco, adverbios como relejos y verbos como regustar.

El prefijo ultra - expresa grado máximo en combinación con adjetivos calificativos y relacionales (ultraligero, ultracivilizado). Estas formaciones son muy frecuentes con bases adjetivales relativas a quien profesa creencias (ultracatólico), o a quien es partidario de adscripciones políticas o de pensamiento (ultraconservador, ultraliberal) y 
otras actitudes que el hablante considere extremas. Este prefijo puede denotar también exceso (GRAE, 2010).

Se usa el prefijo archi - para expresar la intensificación del grado con que se manifiesta una propiedad. Se antepone a adjetivos calificativos o a participios en uso adjetival (archiconocido, archidivertido, archifamoso). Es frecuente su uso en el habla coloquial.

El prefijo hiper - denota exceso, sea en la intensidad con que sucede algo (hiperactividad) o en la cantidad o el grado que se atribuye a una propiedad (hipervitaminosis). En el habla coloquial, se antepone a adjetivos calificativos (hipergoloso).

El prefijo super- en el español coloquial actual, como dice el Diccionario Panhispánico de Dudas, se usa con mucha frecuencia para añadir valor superlativo a los adjetivos o adverbios a los que se une (superútil, superreservado, superbién). Aunque tanto el DRAE como el Diccionario Panhispánico de Dudas consideran incorrecto el uso de super- como elemento autónomo, esto es, como adverbio súper, en el habla informal es habitual su empleo como cuantificador. Así lo registra el Diccionario de Uso del Español de Chile (DUECH):

Súper. 1. Adv. Muy. espon. "Me iba súper bien en el colegio". 2. Adv. Muy bien. espon. "Me fue súper hoy día".

En la última gramática (2010), la RAE clasifica los adjetivos en graduables y no graduables. Los primeros sufren la gradación, considerada una forma de cuantificación. Admiten adverbios de grado (muy, poco, bastante, harto, etc.) y pueden formar parte de construcciones comparativas o de superlativo. Asimismo, sostiene que la gradación 
puede obtenerse también con recursos morfológicos, como la afijación afectiva (pequeñito, calentito, buenazo, pobretón, etc.), sintácticos, como la reduplicación léxica, a menudo reforzada por la entonación enfática. Al hacer un estudio de los sufijos característicos de los adjetivos calificativos, la RAE refiere lo relativo a los sufijos de grado extremo (- ísimo; - érrimo), que sirven para formar adjetivos superlativos elativos o llamados también adjetivos de grado extremo.

Al analizar los adjetivos de grado extremo, la Gramática de la RAE (2010) dice que se suelen denominar elativos y que en la gramática tradicional se han llamado también superlativos absolutos. Esta misma gramática distingue dos tipos de adjetivos de grado extremo:

1. Los elativos morfológicos, formados por prefijos como re-, requete-, super-, hiper-, mega-, ultra-, y por sufijos como -ísimo o - érrimo.

2. Los elativos léxicos, adjetivos de grado extremo que no manifiestan esta propiedad en su estructura morfológica, sino que denotan tal significado en función de su propia naturaleza léxica. Entre éstos, la Real Academia consigna los siguientes: abominable, atroz, brutal, colosal, delicioso, enorme, espantoso, espléndido, excelente, excelso, eximio, exquisito, extraordinario, fabuloso, fundamental, gélido, helado, horroroso, increíble, ínfimo, inmaculado, inmenso, insignificante, magnífico, maravilloso, máximo, mínimo, minúsculo, monstruoso, perverso, precioso, sensacional, supremo, terrible, tórrido, tremendo.

Tal como se ha señalado anteriormente, la lengua provee al hablante de variados recursos para la intensificación de lo dicho. Jam Renkema (2001) incluye, junto con los intensificadores semánticos (elativos léxicos), los intensificadores estilísticos, que 
son figuras del habla. Entre éstas, se consideran las repeticiones, las exageraciones, las metáforas y las comparaciones.

La repetición es definida en el DRAE, como una figura retórica que consiste en repetir a propósito palabras o conceptos. Los hablantes usan de la repetición o reiteración con una clara intención enfática. Por ejemplo, en la expresión "Esta fruta está mala mala", la reiteración del adjetivo equivale a la frase superlativa " muy mala".

La hipérbole es un recurso retórico que les permite a los hablantes aumentar 0 disminuir excesivamente aquello de que hablan. "¡Hacía un frío de los mil demonios! (un frío ‘muy intenso').

La metáfora, por su intención retórica de manifestar la realidad de manera figurada, es empleada en el habla coloquial, con el fin de expresar esta realidad con un mayor énfasis. "Su vida había sido un constante torbellino" (una vida "muy agitada").

La comparación, llamada también "símil", es definida como una figura retórica que consiste en comparar expresamente una cosa con otra, para dar idea viva y eficaz de una de ellas. La intención de la comparación es, entonces, intensificar lo dicho. "Su voz era como un terciopelo" (una voz "muy suave").

El adjetivo y el adverbio asumen para expresar la superlación, ciertos morfemas (sufijos o prefijos), o bien, utilizan elementos cuantificadores para estructurar una frase superlativa. En la gramática tradicional, los primeros son llamados superlativos sintéticos, y los segundos, superlativos analíticos.

En el estudio de las diferencias entre las construcciones superlativas sintéticas y analíticas, algunos autores consideran que son semánticamente equivalentes, pero diferentes desde el punto de vista morfológico. Esta diferencia es lo que Pottier (1970) llama cuantificación interna y externa. En cambio, otros, como Vidal Lamíquiz (1991) y 
la Academia (2010), consideran que existe una diferencia importante entre el superlativo absoluto desinencial y el perifrástico. Para ellos, el primero expresa una significación esencialmente cualitativa, mientras que el segundo, un valor cuantitativo. Sin embargo, en la mayoría de los casos de uso, esta diferencia cuantitativa o cualitativa, no es claramente percibida por los hablantes. Sí es importante señalar que existe una mayor carga expresiva en la forma sintética, hay un mayor énfasis de la expresión, dado el carácter esdrújulo que adquiere la palabra con el sufijo superlativo. Autores como Bello (1988), Matte Bon (1995), Palomo (2001) y la RAE (2010), consideran que la forma inflexiva le da un matiz enfático a la expresión.

Pero, por otro lado, este valor cualitativo o cuantitativo no puede aplicarse a todo adjetivo, ya que hay restricciones para aquellos que no pueden admitir la gradación con el sufijo -ísimo. Autores como Porto Dapena (1985), Bosque (1999), Palomo (2001), concuerdan en que la construcción con -ísimo y la construcción perifrástica con "muy", no pueden alternar libremente, dado que hay adjetivos que no permiten la gradación con el sufijo. Así en Bosque (1999), se ejemplifica con la incompatibilidad de la gradación superlativa sintética si existe en el adjetivo otro sufijo (aumentativo, diminutivo). Por ejemplo: "pequeñitísimo" (forma inaceptable). Y, como se ha expresado en párrafos anteriores, hay también adjetivos que, por su terminación, no admiten los sufijos de gradación.

Los adjetivos de grado extremo analíticos requieren de adverbios cuantificadores para la construcción de la frase. Estos son llamados por la GRAE (2010: 579-580), adverbios cuantificativos y los agrupa en varias subclases. Las que se relacionan con la estructura superlativa son las siguientes: 
PRIMERA SUBCLASE. Está formada por los adverbios indefinidos, que se corresponden con los adjetivos y pronombres indefinidos: algo, bastante, cuán(to), demasiado, harto, más, menos, mucho(muy), poco, suficiente, $\tan ($ to)

SEGUNDA SUBCLASE. Formada por los adverbios no indefinidos, que pueden expresar gradación o intensificación: bien, regular, sobremanera.

TERCERA SUBCLASE. Está formada por un amplio grupo de adverbios terminados en -mente, que pasan a expresar grado o cantidad: considerablemente, escasamente, extraordinariamente, extremadamente, increíblemente, notablemente, suficientemente, sumamente, etc.

Entre los adverbios cuantificadores que pueden usarse para la expresión superlativa analítica, hay algunos que tienen mayor ocurrencia en el habla coloquial (muy, bastante, bien, demasiado, harto, etc.). De estos cuantificadores, el más usado es muy. El Diccionario de la RAE (2001: 1560) lo define así:

Muy (Apóc. del ant. Multo, y éste del lat. Multum). Adv. Úsase antepuesto a nombres adjetivados, adjetivos, participios, adverbios y modos adverbiales, para denotar en ellos grado superlativo de significación. Muy hombre, Muy docto, Muy desengañado, Muy tarde, Muy de prisa.

De otros cuantificadores adverbiales, como bien, demasiado, tan, bastante, se registra en el DRAE su valor superlativo, equivalente a muy.

El cuantificador bien (del latín bene) es uno de los que se usa bastante para expresar la superlación. El diccionario académico registra la siguiente definición: // 7. 
"adv. Antepuesto a un adjetivo o adverbio, muy. Úsase en sentido ponderativo. Bien tarde. Bien rico. Bien malo".

El cuantificador demasiado es definido como un adverbio de cantidad con el valor semántico de "excesivamente". (Este ejercicio es demasiado difícil).

El adverbio de cantidad tan (apócope de tanto) tiene también un uso recurrente en el habla coloquial para la construcción del superlativo analítico. El DRAE dice que se usa para "modificar encareciéndola en proporción relativa, la significación del adjetivo, el adverbio o el participio”. (¡Ella era tan bonita!).

Uno de los cuantificadores que más se usa en el español coloquial de Chile para formar la frase superlativa es bastante. El Diccionario de la RAE lo define como un adverbio que significa "no poco" (Es bastante rico; es bastante bella).

Desde una perspectiva sintáctica, el adjetivo cumple función de atributo del sujeto oracional con verbos copulativos (ser, estar, parecer, semejar) y, con verbos no copulativos, cumple la función de complemento predicativo, que puede atribuirse al sujeto, al objeto directo o a otro elemento oracional (GRAE 2010).

El adjetivo se relaciona siempre con un sustantivo, con el cual está en concordancia y podrá tener una posición antenominal o posnominal. Nebrija (1492/1980: 165), lo define en su gramática como una palabra que se relaciona necesariamente con un sustantivo: "Adjectivo se llama, por que siempre se arrima al substantivo, como si le quisiésemos llamar arrimado; substantivo se llama, por que está por sí mesmo, y no se arrima a otro ninguno; como diciendo ombre bueno, ombre es substantivo, por que puede estar por sí mesmo; bueno, adjectivo, porque no puede estar por sí sin que se arrime al substantivo". 
En relación con la posición del adjetivo en el grupo nominal, se puede decir que existen muchos factores que influyen en ella. En español, a diferencia de otras lenguas, el adjetivo calificativo puede usarse antepuesto o pospuesto al sustantivo. En la mayoría de los casos, la anteposición o posposición no tiene incidencia en el valor semántico de la expresión, pero sí tiene una valoración enfática. Francisco Matte Bon (2002:185), afirma que cuando el adjetivo va junto al sustantivo puede ir inmediatamente antes o inmediatamente después, con matices expresivos ligeramente distintos. Si va después, el adjetivo constituye generalmente una información nueva respecto al sustantivo. Esto hace que tenga un relieve mayor (carácter enfático). En cambio, si va antes del sustantivo, el adjetivo ya no es nuevo con respecto al sustantivo y juntos forman un bloque. Se presupone la relación adjetivo-sustantivo.

Los adjetivos que admiten adverbios de grado (los calificativos y algunos intencionales), pueden ir acompañados de estos intensificadores en todas sus posiciones sintácticas. Los adjetivos en posición antenominal o posnominal pueden admitir intensificadores (un muy bonito retrato y un retrato extremadamente bonito), pero sólo los adjetivos superlativos pospuestos pueden admitir complementos (una mirada muy parecida a la mía).

En cuanto a los adverbios, se puede afirmar que muchos de éstos admiten los procedimientos derivativos propios del sustantivo y del adjetivo y adoptan significantes análogos a los que aparecen en los diminutivos (despacito, poquito, arribita, ahorita, lueguito); en los aumentativos (muchazo, pocazo, hartazo); y en los superlativos (tardísimo, cerquísima, muchísimo, poquísimo, tempranísimo). 
De igual modo, los adverbios expresan el grado superlativo mediante la anteposición de elementos cuantificadores, verbigracia: muy lejos, demasiado pronto, extremadamente rápido, bastante cerca, etc.

Los recursos que provee una lengua para sus hablantes son muchos y variados, como puede observarse en el uso del superlativo. Desde una perspectiva sociolingüística, existen algunas variables sociales que pueden incidir en el uso que los hablantes hacen de los recursos que su lengua les ofrece, como es el sexo, la edad, el nivel de educación o instrucción, la profesión u oficio, entre otros.

Sobre la incidencia de la variable sexo, algunos estudiosos piensan que debe considerarse junto con otras variables sociales, como nivel sociocultural, por ejemplo, ya que es difícil separar el habla de hombres o mujeres del grupo social al que pertenecen como hablantes. Algunos lingüistas, como Francisco Moreno (1998/ 2009: 40), han señalado, en estudios realizados sobre la incidencia de esta variable, que hay una serie de hechos que demuestran la diferenciación entre hombres y mujeres, respecto de los usos lingüísticos. Por ejemplo, que las mujeres muestran una actitud más positiva que los hombres a los usos que se ajustan a las normas, a la vez que los hombres suelen ceñir sus usos a los llamados "vernáculos" y a las variedades locales con más intensidad que las mujeres.

En cuanto a la variable edad, Francisco Moreno (1998/2009: 47) considera que ésta es uno de los factores sociales que con mayor fuerza y claridad puede determinar los usos lingüísticos de una comunidad de habla. Efectivamente, en todo hablante, la edad es un factor constante que no se ve alterada por cambios socioeconómicos o de actitud o de organización. El cambio de edad en los individuos es un hecho irremediable y continuo. Este cambio condiciona los hábitos y conductas 
sociales de los individuos, y, por supuesto, también los comunicativos y lingüísticos. Por esto, es posible distinguir en la vida lingüística de un individuo distintas etapas, aunque no exista acuerdo unánime sobre cuáles son y cómo han de caracterizarse.

El nivel educacional de los hablantes es un factor que incide en el mayor o menor dominio que las personas tengan de su lengua, y, por lo mismo, en el uso cotidiano de ésta, se evidenciará el nivel de apropiación lingüística que los integrantes de una comunidad de habla hayan logrado en las diferentes etapas de su educación. El nivel de educación alcanzado se manifiesta en la precisión y variedad del léxico empleado, en el uso de estructuras gramaticales más elaboradas, en la utilización de estructuras distintas para expresar ideas semejantes, como ocurre con el uso de distintas formas para manifestar lo superlativo

En estudios sociolingüísticos, como lo señala Moreno (1998/2009: 61), esta variable ha recibido distintas denominaciones: educación, nivel o grado de instrucción estudios o escolaridad. Con ella se hace referencia al tipo de formación académica o de titulación conseguidos por los hablantes, lo que está íntimamente relacionado con la cantidad de años que se ha estado estudiando. Este autor afirma que la sociolingüística, como otras disciplinas preocupadas por la lengua hablada, ha comprobado que el nivel educativo de los hablantes determina de forma directa y clara la variación lingüística. Se puede afirmar que es normal que las personas más instruidas hagan mayor uso de las variantes de una lengua que son consideradas más prestigiosas o que más se ajustan a la norma.

En síntesis, se puede afirmar que estas variables sociolingüísticas enunciadas (sexo, edad y nivel de educación) tienen especial incidencia en la expresión coloquial de los hablantes de una lengua determinada y permiten constatar algunos usos 
idiomáticos, como es la utilización de modos diversos para la expresión de lo superlativo. 


\section{METODOLOGÍA DE LA INVESTIGACIÓN}

Con el superlativo se expresa la ponderación en grado máximo o mínimo de la cantidad o de la cualidad. Como dice González Calvo (1985: 173), la lengua española posee abundantes medios para ponderar, enfatizar o intensificar: morfemas, palabras, sintagmas, oraciones, textos. Estos medios se relacionan con el contenido de "muy" (el adverbio cuantificador más usado para expresar lo superlativo).

Este concepto mucho más amplio de lo superlativo, referido no sólo a la gradación de los adjetivos calificativos o de los adverbios, sino también a otras formas de expresión ponderativa, es el que se aplica en este trabajo.

Para poder llevar a cabo esta investigación, se buscó la construcción de un corpus que permitiera tener la información necesaria sobre los diferentes medios que usan hablantes del sector urbano de la Región de Valparaíso para expresar lo superlativo (medios morfológicos, sintácticos, léxicos o estilísticos). Para lograr este objetivo, se hicieron entrevistas a personas de diferentes edades y de distintos niveles de formación educacional, con el fin de recoger la información requerida para el estudio.

Este corpus corresponde a entrevistas realizadas durante el período comprendido entre enero 2010 y febrero 2011, a 34 personas que viven en distintas comunas de la Región de Valparaíso (Viña del Mar, Valparaíso, Quilpué, Villa Alemana, Santo Domingo, Llolleo). La edad de los entrevistados fluctúa entre 21 y 69 años. El nivel de formación educacional de cada uno de ellos corresponde a medio, técnico o universitario. 
El tiempo de duración de cada una de las entrevistas media entre 30 y 45 minutos. El tiempo total de grabación de las entrevistas es de 1.242 minutos (20 horas y 7 minutos).

En el transcurso de la entrevista, se sostuvo una conversación con el entrevistado sobre diversos temas: vivencias personales, acontecimientos nacionales e internacionales, vida laboral, relaciones familiares, opiniones sobre deporte, política, cultura, viajes, etc. Para lograr el objetivo de la entrevista, se procuró crear un clima de agrado y cercanía que les permitiese a los entrevistados expresarse con toda libertad.

Cada una de las conversaciones se grabó y luego transcribió, cuidando de registrar todo lo dicho por el hablante. La transcripción de las entrevistas está contenida en 456 páginas de texto.

Una vez transcritas las entrevistas, se procedió a identificar todas las formas superlativas usadas por los hablantes: morfológicas, sintácticas, léxicas y estilísticas. Los adjetivos superlativos fueron registrados de acuerdo con su función, esto es, como adyacente, atributo o complemento predicativo.

El registro de estos usos se realizó según el siguiente formato:

1. Adjetivo superlativo adyacente del sustantivo.

2. Adjetivo superlativo como atributo de los verbos "ser" y "estar".

3. Adjetivo superlativo como complemento predicativo.

4. Adverbio superlativo.

5. Léxico con valor superlativo.

6. Recursos estilísticos con valor superlativo. 
Con los datos obtenidos, se realizó el estudio estadístico de las formas superlativas, considerando las variables sociolingüísticas de sexo, edad y nivel educacional.

Este análisis estadístico se basa principalmente en resumir los resultados de las entrevistas a través de medidas descriptivas, como el promedio, desviación estándar y coeficiente de variación.

En el análisis, se incorporaron tablas de distribución de frecuencias y gráficos, tanto de columnas como circulares, del número de personas entrevistadas, según variables en estudio.

En el siguiente cuadro, se registran los datos de los 34 entrevistados en cuanto a las variables consideradas para esta investigación: sexo, edad, nivel de educación. Se agrega también, como información, la profesión u oficio de los entrevistados, aunque no se considera como variable para este trabajo. 
Sexo, edad, nivel de educación y profesión de los entrevistados

\begin{tabular}{|c|c|c|c|c|}
\hline $\begin{array}{l}\text { № de } \\
\text { Entrevista }\end{array}$ & Sexo & Edad & Educación & Profesión u Oficio \\
\hline 1 & $\mathrm{~F}$ & 56 & Universitaria & Trabajos de hogar \\
\hline 2 & $\mathrm{M}$ & 21 & Universitaria & Estudiante de Medicina \\
\hline 3 & $\mathrm{M}$ & 28 & Técnica & Técnico en Electricidad \\
\hline 4 & $\mathrm{~F}$ & 49 & Universitaria & Cirujano Dentista \\
\hline 5 & $\mathrm{M}$ & 63 & Universitaria & Arquitecto \\
\hline 6 & $\mathrm{M}$ & 28 & Técnica & Egresado de Técnico en Turismo \\
\hline 7 & $\mathrm{M}$ & 28 & Técnica & Diseñador Industrial \\
\hline 8 & $\mathrm{~F}$ & 27 & Universitaria & Contador Público Auditor \\
\hline 9 & M & 33 & Universitaria & Profesor de Enseñanza Básica \\
\hline 10 & $\mathrm{~F}$ & 28 & Universitaria & Educadora de Párvulos \\
\hline 11 & $\mathrm{~F}$ & 35 & Universitaria & Educadora de Párvulos \\
\hline 12 & $\mathrm{~F}$ & 59 & Técnica & Técnico en Enfermería \\
\hline 13 & $\mathrm{~F}$ & 24 & Universitaria & Profesora de Historia \\
\hline 14 & $\mathrm{M}$ & 21 & Técnica & Técnico en Enfermería \\
\hline 15 & $\mathrm{~F}$ & 25 & Universitaria & Estudiante de Kinesiología \\
\hline 16 & $\mathrm{~F}$ & 24 & Universitaria & Profesora de Castellano \\
\hline 17 & $\mathrm{M}$ & 49 & Media & Empleado Municipal \\
\hline 18 & $\mathrm{~F}$ & 57 & Técnica & Técnico en Enfermería \\
\hline 19 & $\mathrm{~F}$ & 25 & Universitaria & Profesora Educación Básica \\
\hline 20 & $\mathrm{~F}$ & 24 & Universitaria & Estudiante Universitaria \\
\hline 21 & $\mathrm{~F}$ & 42 & Media & Secretaria Administrativa \\
\hline 22 & $\mathrm{M}$ & 46 & Media & Agente de Ventas \\
\hline 23 & $\mathrm{M}$ & 54 & Media & Paradocente \\
\hline 24 & $\mathrm{M}$ & 63 & Universitaria & Constructor Civil \\
\hline 25 & $\mathrm{M}$ & 69 & Universitaria & Profesor de Educación Física \\
\hline 26 & M & 57 & Media & Auxiliar de Educación \\
\hline 27 & $\mathrm{M}$ & 21 & Técnica & Estudiante Técnico en Informática \\
\hline 28 & $\mathrm{M}$ & 22 & Universitaria & Estudiante de Arquitectura \\
\hline 29 & $\mathrm{~F}$ & 59 & Media & Funcionaria Administrativa \\
\hline 30 & $\mathrm{~F}$ & 63 & Universitaria & Constructor Civil \\
\hline 31 & $\mathrm{~F}$ & 26 & Universitaria & Kinesióloga \\
\hline 32 & $\mathrm{M}$ & 38 & Media & Contador \\
\hline 33 & $\mathrm{M}$ & 39 & Técnica & Técnico en Acuicultura \\
\hline 34 & $\mathrm{~F}$ & 37 & Universitaria & Egresada de Derecho \\
\hline
\end{tabular}

En las páginas siguientes se presenta la distribución de los entrevistados, según las variables sociolingüísticas de sexo, edad y nivel de educación. 
De acuerdo con la variable sexo, los 34 entrevistados corresponden a 17 hombres y 17 mujeres. Tal como lo muestra la Figura 1, en porcentaje, corresponde $50 \%$ al sexo masculino y $50 \%$ al femenino.

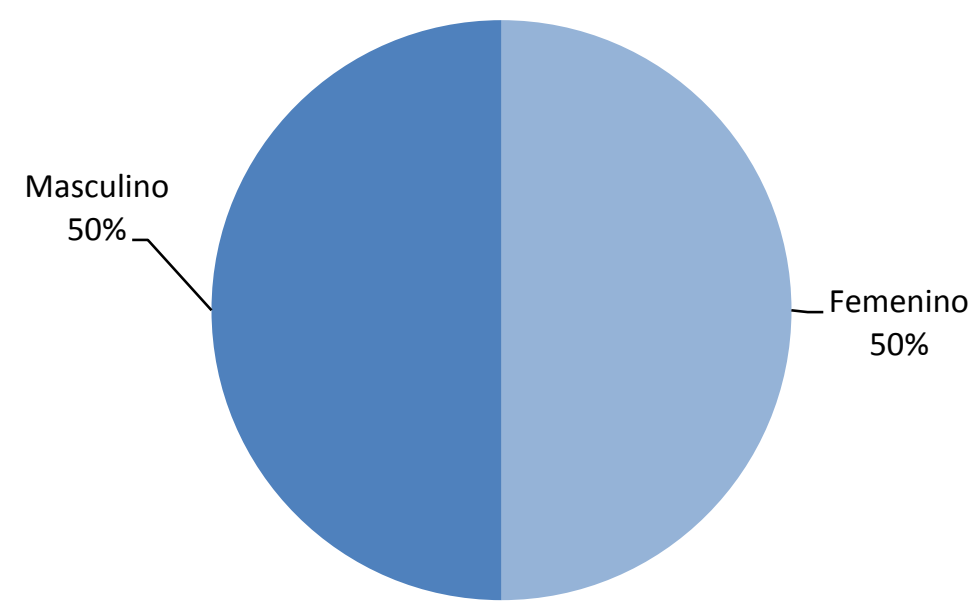

Figura 1. Porcentaje de entrevistados según variable sexo.

Para el estudio de la variable edad de los entrevistados, se formaron los siguientes grupos etarios, considerando que las edades de los hablantes fluctúan entre 21 y 69 años.

\begin{tabular}{|l|l|c|}
\hline Grupo Etario & Rango etario & Cantidad \\
\hline Primer grupo & 21 años a 31 años & 15 \\
\hline Segundo grupo & 32 años a 49 años & 9 \\
\hline Tercer grupo & 50 años a 69 años & 10 \\
\hline
\end{tabular}


En la Figura 2, se grafica el porcentaje de cada uno de los tres grupos etarios, de acuerdo con el número de entrevistados.

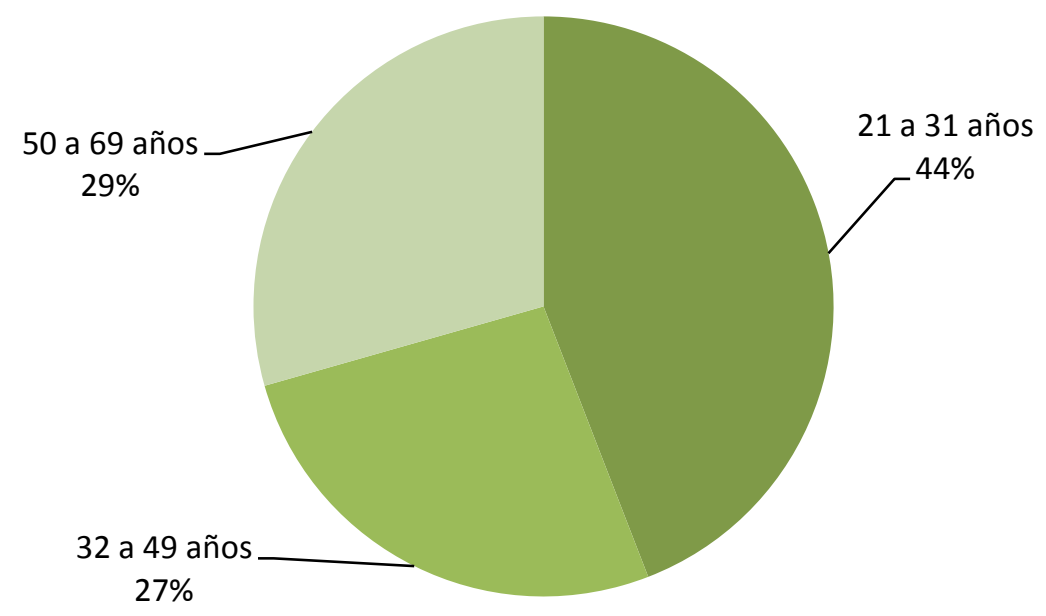

Figura 2. Porcentaje de entrevistados según variable edad.

Para realizar el análisis de acuerdo con la variable nivel educacional, en un primer momento, se separó a los entrevistados en dos grupos: uno correspondiente a personas con formación universitaria (19), y un segundo grupo de personas sin formación universitaria (15). Sin embargo, dado que, en el grupo de entrevistados con una formación no universitaria, había personas solamente con la educación media completa y otras con estudios técnicos de dos años o más, después de la educación media, se decidió considerar separadamente estos tipos de formación. Por lo tanto, para la realización del análisis de la variable, se agrupó a los entrevistados en los siguientes niveles:

1. Nivel medio, que corresponde a personas que han terminado la

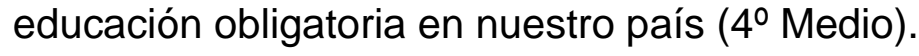


2. Nivel técnico, correspondiente a una formación de postmedia, realizada por los entrevistados en institutos profesionales.

3. Nivel universitario, correspondiente al nivel superior de educación.

El esquema siguiente contiene la cantidad de entrevistados por grupo educacional, y, en la Figura 3, se expresan los porcentajes correspondientes.

\begin{tabular}{|l|c|}
\hline Nivel Educacional & Cantidad \\
\hline Nivel medio & 7 \\
\hline Nivel técnico & 8 \\
\hline Nivel universitario & 19 \\
\hline
\end{tabular}

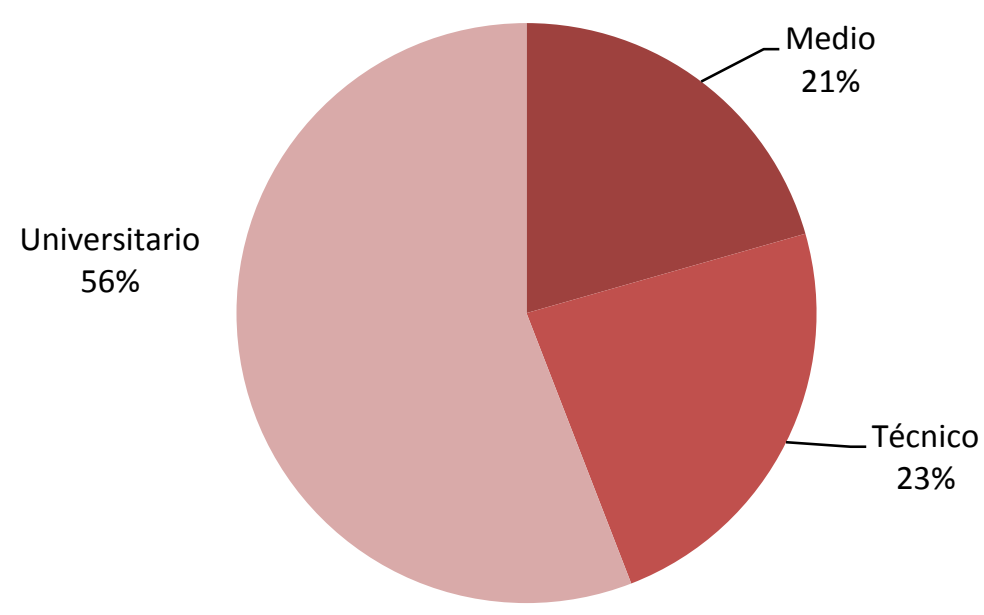

Figura 3. Porcentaje de entrevistados según variable nivel educacional. 


\section{CARACTERIZACIÓN DE LA POBLACIÓN EN ESTUDIO}

De acuerdo con 2 de las variables consideradas para este estudio, sexo y edad, la población objetivo de esta investigación se caracteriza, como se aprecia en la Tabla 1, por tener la misma cantidad de entrevistados de ambos sexos (50\% femenino y $50 \%$ masculino). Según el rango etario, el mayor porcentaje (44\%) corresponde al grupo de los entrevistados que tienen entre 21 a 31 años, como se muestra en la Figura 4.

La distribución de los entrevistados de acuerdo con la variable sexo en los tres grupos etarios es equitativa, ya que, en el primer grupo, hay 8 mujeres y 7 hombres; en el segundo, 4 mujeres y 5 hombres; y, en el tercero, 5 hombres y 5 mujeres.

Tabla 1. Distribución de frecuencias del número de personas entrevistadas, según rango etario y sexo.

\begin{tabular}{|l|c|c|r|r|}
\hline \multirow{2}{*}{ Rango Etario } & \multicolumn{2}{|c|}{ Género } & \multirow{2}{*}{ Total } & Porcentaje \\
\cline { 2 - 3 } & Femenino & Masculino & 15 & $44 \%$ \\
\hline 21 a 31 años & 8 & 7 & 9 & $26 \%$ \\
\hline 32 a 49 años & 4 & 5 & 10 & $29 \%$ \\
\hline 50 a 69 años & 5 & 5 & 34 & \\
\hline Total & 17 & 17 & $50 \%$ & \multicolumn{2}{|c}{} \\
\hline Porcentaje & $50 \%$ & \multicolumn{2}{|r}{}
\end{tabular}




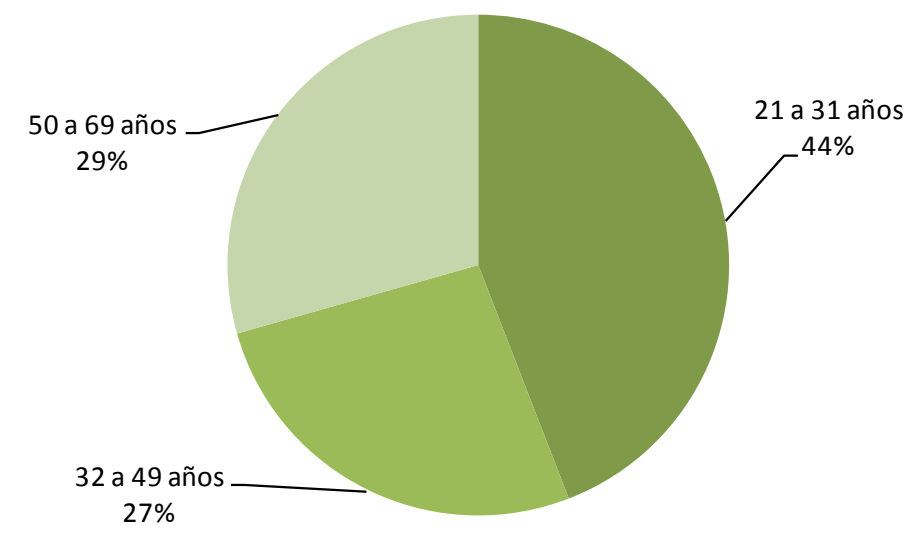

Figura 4. Distribución de entrevistados según sexo y rango etario.

En relación con el nivel educacional y el rango etario, la distribución de las personas entrevistadas es la siguiente: el primer grupo etario registra 5 entrevistados con nivel educacional técnico y 10 con nivel universitario; el segundo grupo registra 4 personas de nivel medio, 1 de nivel técnico, y 4 de nivel universitario; y el último grupo está conformado por 3 personas de nivel medio, 2 de nivel técnico y 5 de nivel universitario, como se observa en la Tabla 2.

En la Figura 5, se registra el porcentaje de distribución de los entrevistados según los niveles de educación. Los resultados indican que el mayor porcentaje corresponde al nivel universitario (56\%) y el menor, al nivel medio (21\%). 
Tabla 2. Distribución de frecuencias del número de personas entrevistadas, según rango etario y nivel educacional

\begin{tabular}{|c|c|c|c|c|c|}
\hline \multirow{2}{*}{ Rango Etario } & \multicolumn{3}{|c|}{ Nivel Educacional } & \multirow{2}{*}{ Total } & \multirow{2}{*}{ Porcentaje } \\
\hline & Medio & Técnico & Universitario & & \\
\hline 21 a 31 años & & 5 & 10 & 15 & $44 \%$ \\
\hline 32 a 49 años & 4 & 1 & 4 & 9 & $26 \%$ \\
\hline 50 a 69 años & 3 & 2 & 5 & 10 & $29 \%$ \\
\hline Total & 7 & 8 & 19 & 34 & \\
\hline Porcentaje & $21 \%$ & $24 \%$ & $56 \%$ & & \\
\hline
\end{tabular}

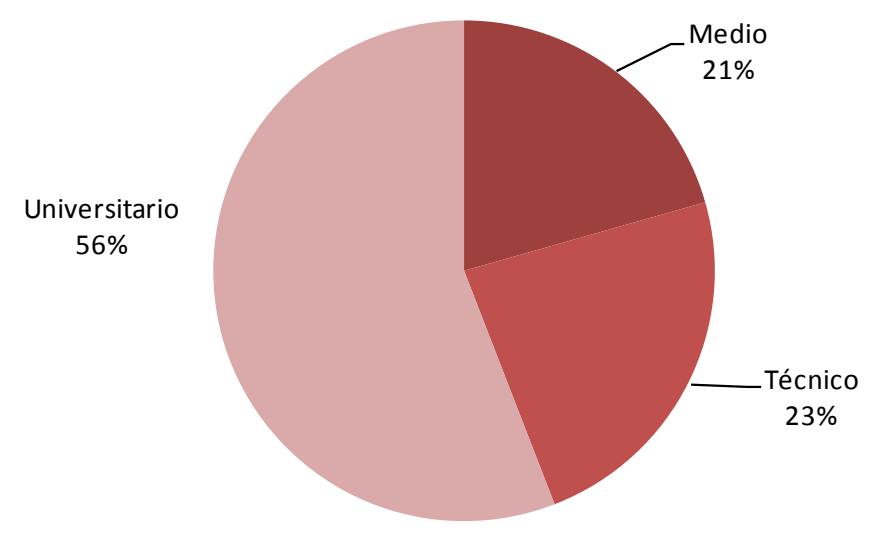

Figura 5. Porcentaje de distribución de entrevistados según nivel educacional. 


\section{ANÁLISIS CUANTITATIVO DE USO DEL SUPERLATIVO.}

En las conversaciones sostenidas con los 34 entrevistados, se pudo recoger un total de 1.164 casos de uso de formas superlativas. Estas corresponden a adjetivos (adyacentes, atributos, predicativos), a adverbios, a léxico con valor superlativo y a recursos estilísticos (metáforas, reiteraciones, hipérboles y comparaciones).

En el siguiente cuadro, se presenta la cantidad de formas superlativas usadas por cada uno de los 34 entrevistados, distribuidas según las 6 modalidades antes señaladas. 
Cuadro general de formas superlativas

\begin{tabular}{|c|c|c|c|c|c|c|c|}
\hline Entrevista & Adyacente & $\begin{array}{l}\text { Atributo(ser } \\
\text { y estar }\end{array}$ & Predicativo & Adverbio & $\begin{array}{l}\text { Léxico con } \\
\text { valor } \\
\text { superlativo }\end{array}$ & Recursos & Total \\
\hline 1 & 6 & 13 & 4 & 4 & 7 & 4 & 38 \\
\hline 2 & 6 & 7 & 1 & 1 & 0 & 0 & 15 \\
\hline 3 & 0 & 13 & 0 & 0 & 1 & 3 & 17 \\
\hline 4 & 5 & 6 & 0 & 0 & 3 & 0 & 14 \\
\hline 5 & 5 & 5 & 1 & 2 & 13 & 6 & 32 \\
\hline 6 & 6 & 10 & 0 & 2 & 10 & 7 & 35 \\
\hline 7 & 2 & 8 & 0 & 0 & 3 & 6 & 19 \\
\hline 8 & 4 & 12 & 1 & 6 & 9 & 2 & 34 \\
\hline 9 & 11 & 7 & 1 & 5 & 3 & 4 & 31 \\
\hline 10 & 3 & 8 & 0 & 3 & 10 & 1 & 25 \\
\hline 11 & 10 & 8 & 1 & 3 & 2 & 6 & 30 \\
\hline 12 & 3 & 10 & 0 & 3 & 7 & 2 & 25 \\
\hline 13 & 10 & 13 & 0 & 1 & 1 & 2 & 27 \\
\hline 14 & 15 & 17 & 0 & 2 & 5 & 0 & 39 \\
\hline 15 & 3 & 2 & 0 & 4 & 6 & 4 & 19 \\
\hline 16 & 12 & 21 & 0 & 3 & 6 & 1 & 43 \\
\hline 17 & 12 & 10 & 0 & 2 & 7 & 2 & 33 \\
\hline 18 & 4 & 13 & 2 & 6 & 7 & 4 & 36 \\
\hline 19 & 5 & 13 & 2 & 3 & 1 & 0 & 24 \\
\hline 20 & 1 & 15 & 1 & 3 & 5 & 4 & 29 \\
\hline 21 & 12 & 14 & 1 & 3 & 13 & 6 & 49 \\
\hline 22 & 6 & 11 & 1 & 1 & 9 & 3 & 31 \\
\hline 23 & 13 & 10 & 1 & 3 & 7 & 3 & 37 \\
\hline 24 & 6 & 9 & 0 & 4 & 7 & 3 & 29 \\
\hline 25 & 12 & 6 & 0 & 4 & 3 & 0 & 25 \\
\hline 26 & 2 & 5 & 1 & 1 & 6 & 0 & 15 \\
\hline 27 & 13 & 13 & 1 & 2 & 5 & 2 & 36 \\
\hline 28 & 6 & 13 & 0 & 1 & 9 & 1 & 30 \\
\hline 29 & 21 & 13 & 2 & 4 & 11 & 11 & 62 \\
\hline 30 & 10 & 12 & 3 & 2 & 10 & 8 & 45 \\
\hline 31 & 13 & 16 & 1 & 1 & 23 & 3 & 57 \\
\hline 32 & 15 & 15 & 2 & 3 & 5 & 6 & 46 \\
\hline 33 & 4 & 29 & 1 & 4 & 10 & 0 & 48 \\
\hline 34 & 12 & 41 & 2 & 8 & 24 & 2 & 89 \\
\hline Total & 268 & 417 & 30 & 94 & 248 & 106 & 1164 \\
\hline
\end{tabular}

Al hacer un análisis de los resultados, se puede decir que, tal como se observa en la Figura 6, las formas de superlativo más utilizadas por las personas entrevistadas 
fueron las de atributo (ser y estar) y de adyacente del sustantivo, con $36 \%$ y $23 \%$, respectivamente, y la menos utilizada es la correspondiente a complemento predicativo (atributo con otros verbos (3\%).

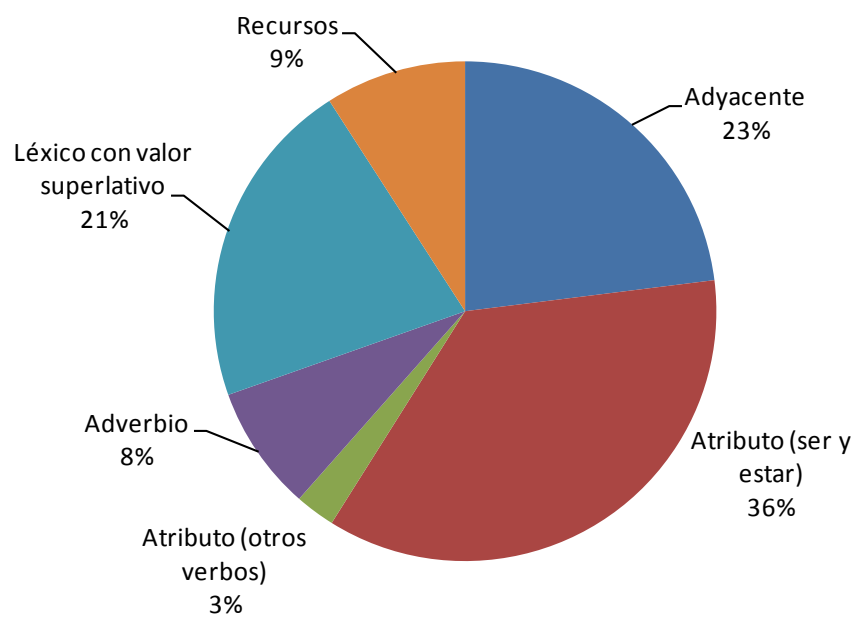

Figura 6. Porcentaje de uso en las entrevistas, según forma de expresión del superlativo.

En la Figura 7, se presenta el promedio de valor superlativo, correspondiente a cada una de las formas de expresión del superlativo usadas por los entrevistados.

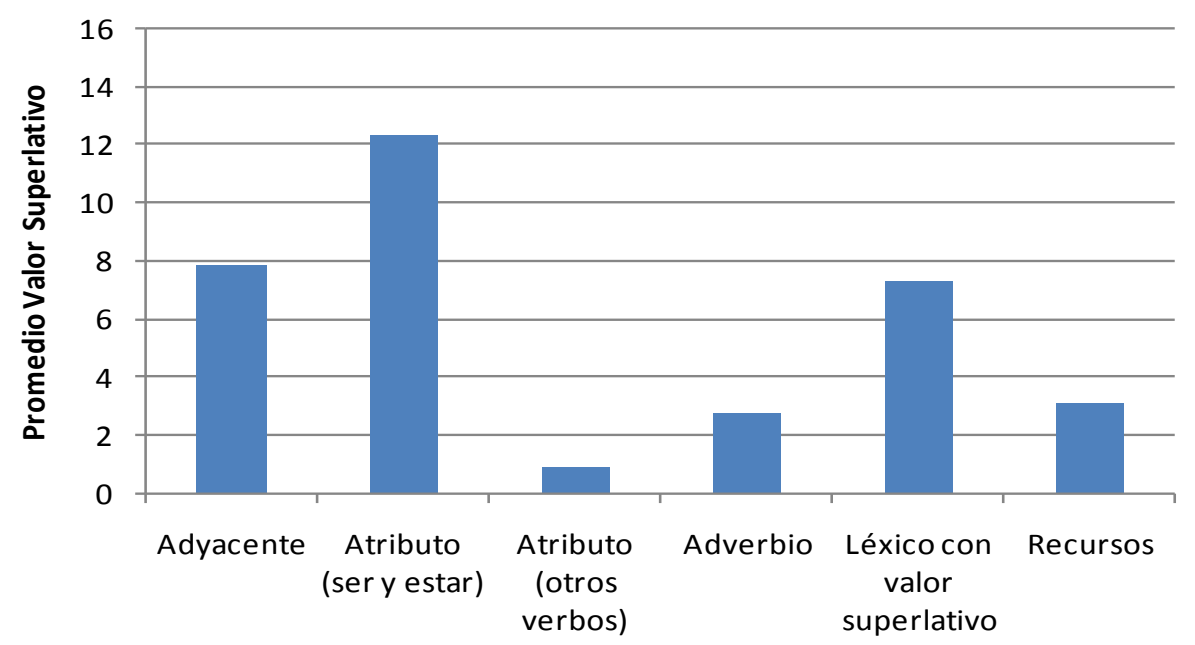

Figura 7. Promedio de valor superlativo utilizado por las personas entrevistadas, según forma de superlativo. 
Como ya se ha manifestado, los entrevistados usaron distintos medios para enfatizar lo dicho. A continuación, se analizan y ejemplifican las formas superlativas usadas por los entrevistados con el propósito de ponderar su expresión.

5.1. Adjetivo superlativo adyacente del sustantivo.

En este caso, se consideran las formas adjetivas superlativas de grado extremo, tanto sintéticas como analíticas que, antepuestas o pospuestas, cumplen la función gramatical de modificar a un sustantivo. La forma pospuesta al sustantivo es la de mayor ocurrencia en el discurso de los entrevistados. Como ejemplos de superlativos absolutos sintéticos y analíticos se pueden citar los siguientes:

"Es un país carísimo" (Entrevista № 6).

"Opiniones muy científicas" (Entrevista № 4).

La anteposición del superlativo, tanto sintético como analítico, es menos usada por los hablantes entrevistados. Algunos ejemplos son los siguientes:

“Un pésimo director" (Entrevista № 14).

"Muy buenos promedios" (Entrevista №11).

En la estadística general, el adjetivo superlativo adyacente registra 268 casos, lo que equivale al $23 \%$ de la totalidad de usos.

5.2. Adjetivo superlativo como atributo de los verbos ser y estar.

La estructura oracional con los verbos copulativos o atributivos "ser" y "estar" es, lógicamente, la más usada, ya que los hablantes requieren intensificar las características de los sujetos gramaticales de sus oraciones. Al realizar el análisis 
estadístico de las entrevistas, se contabilizaron 417 casos de uso, equivalentes al $35.82 \%$ del total de formas superlativas De éstos, la mayoría corresponde a superlativos de grado extremo analíticos y, preferentemente, con el cuantificador "muy" como elemento intensificador de la cualidad.

Ejemplos con el verbo "ser":

"Las pastillas eran muy fuertes" (Entrevista № 1).

“La televisión es muy culpable" (Entrevista № 17).

Ejemplos con el verbo "estar":

"Estaban todos muy unidos" (Entrevista №23).

"Está muy chiquitito" (Entrevista № 29).

La atribución con el verbo "ser" es la de mayor ocurrencia, ya que, de los 417 casos de atributos predicativos, 348 corresponden a este uso (83.45\%), mientras que, con el verbo "estar", sólo se registran 69 casos (16.54\%).

5.3. Adjetivo superlativo como complemento predicativo o atributo de verbos no copulativos

Se encuentra también el uso de la atribución con verbos predicativos. A esta función, la GRAE (2010) la denomina complemento predicativo. El atributo actúa, en estos casos, bien como predicativo subjetivo (característica del sujeto), o bien, como predicativo objetivo (característica del objeto directo). Algunos ejemplos de esta función son los siguientes: 
De complemento predicativo del sujeto: "Nos vimos muy afectados" (Entrevista №1).

De predicativo del objeto directo: "Dejó al país muy mal parado" (Entrevista №22).

En la estadística general, los usos del superlativo en función de complemento predicativo, tanto del sujeto como del objeto directo, sólo alcanzan a 2.57\% del total (30 casos).

\subsection{Adverbio superlativo}

El adverbio superlativo tiene, en la elocución de los entrevistados, un uso relativamente pequeño. Se registraron solamente 94 casos (8.07\%). De éstos, 10 corresponden a adverbios superlativos sintéticos y 84 , a adverbios superlativos analíticos.

Ejemplos de adverbios superlativos sintéticos:

“Es lejísimo" (Entrevista № 25).

“Se preocupan muchísimo" (Entrevista № 25).

Ejemplos de adverbios superlativos analíticos:

“Las recibió muy bien" (Entrevista № 1).

“Entiendo bastante bien (Entrevista № 6).

“Hacía más rápido las cosas" (Entrevista № 8). 


\subsection{Léxico con valor superlativo o elativos léxicos}

En el habla cotidiana oral, es muy frecuente el uso de vocablos cuyos significados tienen incluido el valor de intensificación de lo que con ellos se expresa. Entre estos términos hay sustantivos, adjetivos, adverbios y también frases adjetivas o adverbiales. Todos estos se incluyen en este trabajo como "léxico con valor superlativo". Se registran 248 casos de este uso (correspondiente al $21.30 \%$ del total de superlativos).

Tanto el Diccionario de la Real Academia Española como diccionarios de chilenismos y de americanismos, consignan el valor superlativo de estos vocablos.

Algunos ejemplos de superlativos léxicos usados por los entrevistados, con el correspondiente valor semántico registrado en los diccionarios, son los siguientes:

\subsubsection{Sustantivos con valor superlativo}

Cuesco (un):loc.pron.m.sing.pond.coloq. Un rábano (absolutamente nada). (Nuevo Diccionario Ejemplificado de Chilenismos, DECH, pág. 754). Ej.: “Siempre, o sea, a mí me importaba un cuesco que la fiesta empezara a las tres, cuatro de la mañana”. (Entrevista № 17).

Descueve (el): m. sing. fig. pond. coloq. El colmo, el sumo, el grado más alto al que se puede llegar una cosa, como para producir notable impresión. (Nuevo Diccionario Ejemplificado de Chilenismos, DECH, pág. 877). Ej. “..., pero este gallo era en realidad el descueve". (Entrevista №5).

Escoba. // la escoba. f.sing. fig. Desbarajuste, desastre, ruina o destrucción general. (Nuevo Diccionario Ejemplificado de Chilenismos, DECH, pág. 1055).Ej.: "Pero era sin pensar que las personas que habían antes en la empresa... estaba la escoba, el desorden, las deudas, entonces."(Entrevista $\left.\mathrm{N}^{\circ} 8\right)$. 
5.5.2. Adjetivos con valor superlativo

Bacán, na: I. 2. adj. Cu. Ec. Pe. Ch. juv. Referido a persona o cosa muy buena, estupenda. (Diccionario de Americanismos, pág. 189) Ej.: "Somos muy cariñosos, mantenemos una comunicación bacán" (Entrevista №31).

Espectacular: adj. fig. coloq. Maravilloso, magnífico, sorprendente. (Nuevo Diccionario Ejemplificado de Chilenismos, DECH, pág 1064). Ej.: "Pero, finalmente tú puedes decir, ya pero como museos son espectaculares, ¿cachai?, son espectaculares, no sé, yo nunca he ido, ¿cachai?”. (Entrevista $\left.N^{\circ} 28\right)$.

Estratosférico: adj. fig. pond. coloq. Astronómico, dicho especialmente de un precio o una cantidad, excesivamente elevado. (Nuevo Diccionario Ejemplificado de Chilenismos, DECH, pág. 1085). Ej.: "ahí va a poder entrar a estudiar, efectivamente, solo el que pueda pagar esos aranceles estratosféricos,..." (Entrevista № 5 ).

\subsubsection{Frases adjetivas con valor superlativo}

De película: loc. adj. pond. coloq. Espectacular, impresionante. (Nuevo Diccionario Ejemplificado de Chilenismos, DECH, Tomo II, pág. 2113). Ej.: “...los médicos, ejemplo típico, son de excelencia, o sea de película" (Entrevista № 5). De excelencia: loc. adj. Muy bueno, espectacular (Nuevo Diccionario Ejemplificado de Chilenismos, DECH, pág.1012). Ej.: “, los médicos son de excelencia, o sea de película,...” (Entrevista № 5). 
5.5.4. Adverbios con valor superlativo

Harto: adv. cant. pond. coloq. Mucho o muy; con abundancia, en gran cantidad. (Nuevo Diccionario Ejemplificado de Chilenismos, DECH, pág. 1334).Ej.: "Me ayudaron harto unos amigos míos y... uno de ellos también me dijo: yo prefiero que sufrai ahora... y que no seai un amargado toda la vida". (Entrevista № 9).

Demasiado: adv. En demasía (DRAE, pág. 431). Ej.: "Es demasiado, aquí en Chile, los capitales están mal distribuidos mucho, muy mal distribuidos". (Entrevista № 12).

5.5.5. Locuciones adverbiales con valor superlativo

Raja .VIII. b // la raja, loc.adj./ adv. Ch. Muy bueno, excelente. vulg; pop. hiperb. (Diccionario de Americanismos, pág.1813). Ej.: “Estar ahí relajados, con un clima distinto, eeh, guatita al sol todo el día, comiendo bacán, sí la raja, perooo, faltó el carrete no más, en las discoteques, pero era muy chica todavía así que no podía salir sola". (Entrevista № 31).

5.6. Recursos estilísticos con valor superlativo o enfático

Los entrevistados usan también, para enfatizar su expresión oral, algunos recursos estilísticos que les permiten reforzar lo dicho. Entre los recursos más usados están las reiteraciones, las exageraciones o hipérboles, las comparaciones y las metáforas. 
En el siguiente cuadro, se registra la cantidad de reiteraciones, hipérboles, metáforas y comparaciones usadas por los hablantes y su correspondiente porcentaje.

\begin{tabular}{|l|c|c|}
\hline Recursos & Cantidad & Porcentaje \\
\hline Reiteración & 68 & $64.15 \%$ \\
\hline Hipérbole & 19 & $17.92 \%$ \\
\hline Metáfora & 13 & $12.26 \%$ \\
\hline Comparación & 6 & $5.66 \%$ \\
\hline Total & 106 & $99.99 \%$ \\
\hline
\end{tabular}

\subsubsection{Reiteración}

Este es uno de los recursos más empleado por los entrevistados. Se reiteran palabras, frases y hasta oraciones. En los siguientes ejemplos, puede observarse la reiteración o repetición de cuantificadores adverbiales, de adjetivos, de sustantivos, etc.

Repetición del cuantificador adverbial

En las frases adjetivas o adverbiales, se repite en dos o más ocasiones el cuantificador utilizado para enfatizar la expresión (muy, súper, bastante, etc.).

a. "Estaba muy, muy feliz" (Entrevista №10).

b. "Súper, súper fuerte" (Entrevista N 13).

c. "Personas bastante, bastante amplias" (Entrevista $\left.N^{\circ} 3\right)$.

\section{$\underline{\text { Repetición de un adjetivo }}$}

Se reitera el adjetivo con la finalidad de expresar la intensificación de la cualidad. Este interesante recurso es característico del habla oral y, en él, el énfasis con que se emite el adjetivo que se reitera, sin que medie pausa con el anterior, es lo más 
significativo. Lo encontramos en el discurso de varios de los entrevistados. Algunos ejemplos son los siguientes:

a. "Sí, la Santa María, pero es que ahí van los... la gente cabezona cabezona, intelectual intelectual"' (Entrevista № 1).

b. "Cuando yo era chico chico" (Entrevista No 6).

c. "Y eso, y ahí tenía una profesora que era francesa francesa, que impartía el francés quebecuas e impartía el francés francés” (Entrevista № 6).

\section{$\underline{\text { Repetición de sustantivos }}$}

En algunos casos, se reitera al sustantivo simplemente para dar más énfasis a lo dicho por el hablante. En el ejemplo citado a continuación, el entrevistado manifiesta, con la repetición del sustantivo "francés", su intención de definir con claridad de qué francés está hablando.

"Y eso, y ahí tenía una profesora que era francesa francesa, que impartía el francés quebecuas e impartía el francés francés” (Entrevista № 6).

$\underline{\text { Repetición exagerada de adjetivos }}$

En los siguientes ejemplos, se repiten los adjetivos varias veces para intensificar la característica del sustantivo.

a. "Me da un miedo terrible, terrible, terrible, terrible" (Entrevista № 18).

b. “Unos poemas horribles, horribles” (Entrevista № 1). 
$\underline{\text { Repetición de adverbios }}$

En este caso, se reitera dos o tres veces el adverbio para intensificar la acción verbal. Algunos ejemplos son los siguientes:

a. "Me sacrificaba mucho, mucho, mucho" (Entrevista $\left.N^{\circ} 8\right)$.

b. "Yo le agradezco mucho, mucho" (Entrevista № 18).

c. "Yo sufrí mucho, mucho, mucho" (Entrevista N²0).

\section{$\underline{\text { Repetición de frases y oraciones }}$}

En ocasiones, los hablantes repiten estructuras oracionales completas, para ser más enfáticos. Ejemplos:
a. “Costó harto, costó harto" (Entrevista No 9).
b. "Yo corría, y corría y corría” (Entrevista № 11).
c. "Es una cosa increíble, es una cosa increíble" (Entrevista $\left.N^{\circ} 21\right)$.

\subsubsection{Exageración o hipérbole}

Este recurso se usa tanto para aumentar la realidad como para minimizarla. Para ello se recurre, en algunos casos, a la sufijación con valor aumentativo o diminutivo. Por ejemplo, para aludir a la capacidad intelectual de una persona, el hablante de la entrevista № 1 usa el aumentativo de la palabra cabeza.

"Sí, la Santa María, pero es que ahí van los... la gente cabezona cabezona, intelectual intelectual”' (Entrevista № 1 ).

En otra de las entrevistas, se crea el aumentativo "gorilona" (derivado del sustantivo gorila), que no se encuentra registrado en el diccionario académico, para hacer referencia a la estatura exagerada de mujeres de origen escandinavo. 
"Entonces él decía, ya mira, el hombre mide 1 metro 70, no sé, en el caso de mis compañeras escandinavas son 2 metros 47 - gorilonas gorilonas - y él hacía techos muy bajos, perdón, cielos muy bajos, pero son casas inhabitables" (Entrevista № 28).

La exageración de la realidad es un recurso muy utilizado por los hablantes para expresar "aquello que traspasa los límites de lo justo, verdadero o razonable", como lo define el diccionario académico. En suma, consiste en aumentar o disminuir excesivamente la realidad.

De este recurso, que registra 19 casos de uso (17.92\%), se pueden citar los siguientes ejemplos:

a. “...mi mamá le daba gracias a Dios de que yo llegaba en la casa en la noche, yo llegaba como a las ocho, nueve y yo quedaba zeta, muerta, muerta ya..., con un cansancio terrible..."(Entrevista $\left.N^{\circ} 11\right)$.

b. "Y ahí casi me morí, poh, le conté a mi mamá, mi mamá se puso a llorar y todo..." (Entrevista N 15).

c. “...o sea, mis papás me obligaban a comer carne, porque o me daban arroz con carne o puré con carne o lo que sea, entonces si yo comía tres cucharadas de puré y quedaba muerta de hambre y no me hacían comida especial..." (Entrevista № 20).

d. "Es muy difícil, por lo que ha dicho el Presidente de la República, por la gente que está trabajando, pero lo bueno es queee no los dan por perdidos y y y se tiene que seguir trabajando hasta las últimas consecuencias, o sea, hasta el final, ya sea para bien o para mal...” (Entrevista №23). 
e. "No sé, los nuevos procesos, los..., esos sistemas que vienen ahora para instalar que le cambian la vida a uno, que le enseñan que, en un dos por tres, uno está en contacto con los bancos, puede comprar todo". (Entrevista № 29).

\subsubsection{Comparación}

La comparación que los hablantes usan tiene como elemento estructurador el adverbio comparativo "como", y, en la mayoría de los casos, aparece como un giro idiomático, característico del habla coloquial, en el que el rasgo comparativo aparece disminuido, en un límite con la exageración. Es el caso de la expresión "como el hoyo" considerada una locución adverbial modal de registro vulgar y con un valor semántico superlativo, equivalente a "de manera pésima".

En las entrevistas realizadas, se registran 6 usos de este recurso, lo que corresponde a un $5.66 \%$.

Algunos ejemplos de comparación son los siguientes:

a. "...en la mitad de octavo básico me dicen: sabes que te vai a mitad de..., te vai en junio y no te dai ni cuenta y el 31 de junio estaba en Canadá, te vai el 29 y el 31 ya estai allá, o sea fue una cosa de, por decirlo así como de segundos" (Entrevista №6).

b. "O sea vemos grupos que salen, no sé, van a tocar a un pub, van a tocar, hacen una tocata, tipos re buenos, entonces, pero resulta que los tipos los atienden como el hoyo, les va mal" (Entrevista $\left.N^{\circ} 27\right)$. 
c. “...era como súper estrecho el camino, era como un cuchillo y era un precipicio súper grande". (Entrevista $\left.N^{\circ} 15\right)$.

\subsubsection{Metáfora}

La metáfora, como recurso estilístico, es recurrente en el habla oral coloquial. Se usa con el fin de representar la realidad en forma figurada, porque se considera más enfática esta expresión que la correspondiente a la realidad representada. Dentro de los 107 recursos registrados en la expresión de los entrevistados, hay 13 metáforas, que corresponden al $12 \%$ del total de recursos empleados.

Ejemplos de este recurso utilizado por los entrevistados son los siguientes:

a. 'El año 2000 nació el niño, y ese mismo año, a su vez, el año anterior, el 99' murió mi abuela, que era un bastión pa'mí, en cuanto a apoyo". (Entrevista № 9).

b. “...entonces me llevaron a los médicos, porque la niña no se podía quedar quieta, era un canguro saltando, una pulga todo el día" (Entrevista № 11).

c. “¿Cómo se les ocurre traer a Chile, esos tremendos monstruos oruga, cuando tenemos un país con calles hace sesenta, ochenta, cien años atrás, que son estrechas?" (Entrevista № 24). 


\section{ANÁLISIS CUANTITATIVO DE USO DEL SUPERLATIVO, SEGÚN LAS VARIABLES SOCIOLINGÜÍSTICAS DE SEXO, EDAD Y NIVEL DE EDUCACIÓN.}

Uno de los objetivos de esta investigación es realizar un análisis cuantitativo de las formas superlativas usadas por los 34 entrevistados, considerando las variables sociolingüísticas de sexo, edad y nivel educacional, con el fin de establecer qué formas son las más recurrentes en estos hablantes.

En primer lugar, se presentan los resultados del análisis cuantitativo según la variable sexo; en segundo término, de acuerdo con la variable edad; y, por último, según el nivel educacional.

\subsection{Según variable sexo.}

De acuerdo con esta variable, las personas entrevistadas corresponden a 17 personas de sexo masculino y 17 de sexo femenino.

En la Tabla 3, se representan las medidas descriptivas de las formas superlativas usadas por los entrevistados (promedio, desviación estándar, coeficiente de variación) y, en la Figura 8, se representa la totalidad de formas superlativas usadas por los entrevistados, de acuerdo con esta variable. 
Tabla 3. Medidas descriptivas de formas de superlativo según sexo

\begin{tabular}{|c|c|c|c|c|}
\hline Superlativos & Medida Descriptiva & Femenino & Masculino & Total \\
\hline \multirow{3}{*}{ 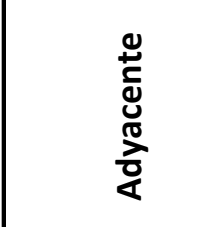 } & Promedio & 7.88 & 7.88 & 7.88 \\
\hline & Desviación Estándar & 5.19 & 4.81 & 4.93 \\
\hline & Coeficiente de Variación & 0.66 & 0.61 & 0.63 \\
\hline \multirow{3}{*}{ 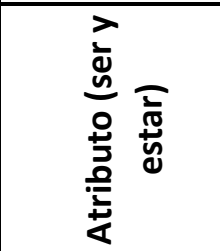 } & Promedio & 13.53 & 11.06 & 12.29 \\
\hline & Desviación Estándar & 8.25 & 5.77 & 7.12 \\
\hline & Coeficiente de Variación & 0.61 & 0.52 & 0.58 \\
\hline \multirow{3}{*}{ 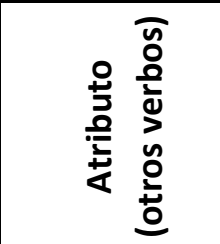 } & Promedio & 1.18 & 0.59 & 0.88 \\
\hline & Desviación Estándar & 1.19 & 0.62 & 0.98 \\
\hline & Coeficiente de Variación & 1.01 & 1.05 & 1.11 \\
\hline \multirow{3}{*}{$\begin{array}{l}\frac{0}{0} \\
\frac{2}{0} \\
\frac{2}{0}\end{array}$} & Promedio & 3.35 & 2.18 & 2.76 \\
\hline & Desviación Estándar & 1.97 & 1.47 & 1.81 \\
\hline & Coeficiente de Variación & 0.59 & 0.67 & 0.65 \\
\hline \multirow{3}{*}{ 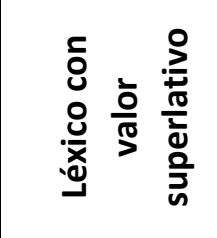 } & Promedio & 8.53 & 6.06 & 7.29 \\
\hline & Desviación Estándar & 6.61 & 3.47 & 5.35 \\
\hline & Coeficiente de Variación & 0.77 & 0.57 & 0.73 \\
\hline \multirow{3}{*}{ 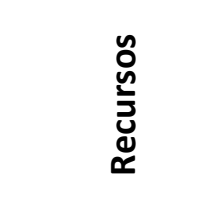 } & Promedio & 3.53 & 2.71 & 3.12 \\
\hline & Desviación Estándar & 2.92 & 2.42 & 2.67 \\
\hline & Coeficiente de Variación & 0.83 & 0.89 & 0.86 \\
\hline
\end{tabular}




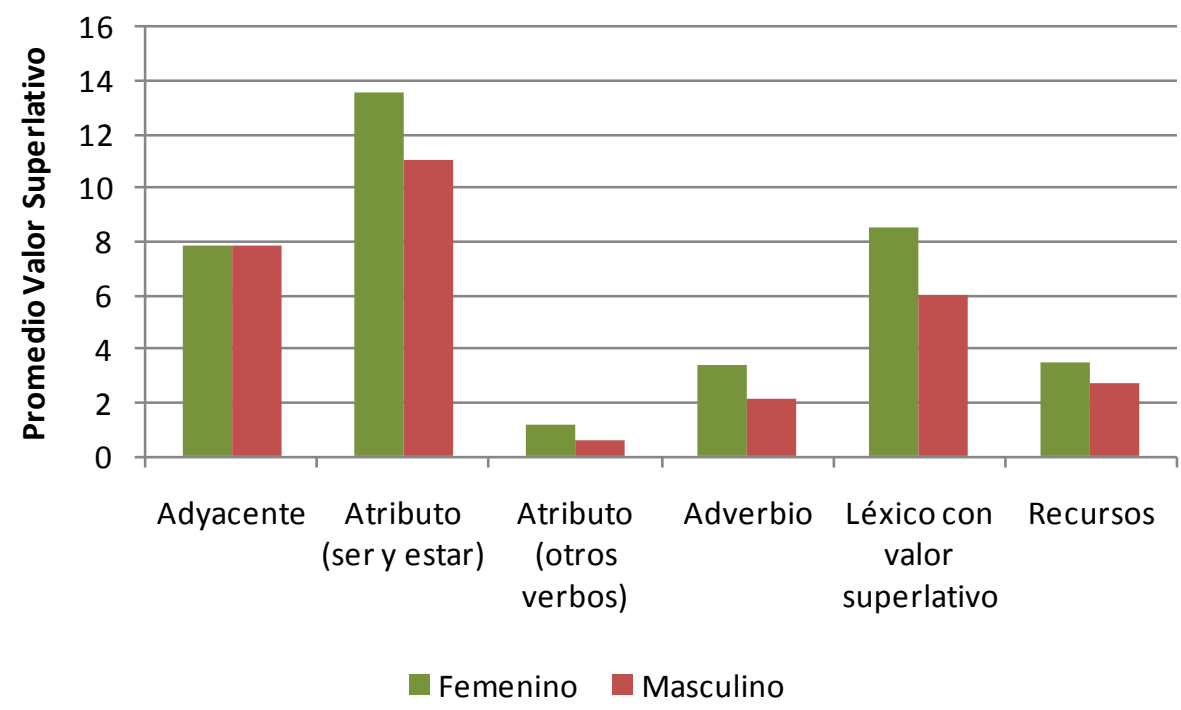

Figura 8. Promedio de formas con valor superlativo utilizadas por las personas entrevistadas, según variable sexo.

De acuerdo con los resultados representados en la Figura 8, el promedio de uso de formas superlativas, según la variable sexo, es el siguiente:

1. El adjetivo superlativo adyacente del sustantivo tiene el mismo promedio en el sexo masculino que en el femenino (7.88).

2. El adjetivo superlativo como atributo de los verbos copulativos "ser" y "estar" tiene, en el sexo femenino un promedio de 13.53, mientras que en el sexo masculino, 11.06. En este caso, se observa un mayor uso de esta forma de superlativo por parte del sexo femenino.

3. El adjetivo superlativo como predicativo tiene, en el sexo femenino, un promedio de 1.18 , y en el masculino, 0.59 .

4. El adverbio superlativo registra un promedio de 3.35 en el sexo femenino y 2.18, en el masculino. 
5. En el léxico con valor superlativo, el sexo femenino registra un promedio de 8.53, mientras que el masculino, 2.18 .

6. Los recursos con valor superlativo tienen un promedio de uso de 3.53 en el sexo femenino y 2.71 , en el masculino.

Se puede decir, entonces, que, de las 6 formas de uso del superlativo, el sexo femenino presenta un mayor uso en 5 de éstas, exceptuándose el caso de la primera forma (adyacente), ya que ambos sexos registran el mismo promedio.

Se analizan a continuación, los resultados estadísticos de las formas superlativas por cada uno de los sexos

\subsubsection{Sexo masculino}

En el siguiente cuadro se registra la cantidad de superlativos usados por cada uno de los entrevistados pertenecientes al género masculino, de acuerdo con las distintas formas de expresión de lo superlativo (adyacente, atributo con los verbos ser y estar, atributo con otros verbos, adverbio, léxico con valor superlativo y recursos estilísticos con valor superlativo).

La totalidad de superlativos correspondiente a este género es de 518 casos (44.50\%). El entrevistado que registra el mayor número de formas superlativas es el № 33, con un total de 48 usos. La menor cantidad de superlativos (15 casos) corresponde a dos entrevistados: № 2 y № 26. 


\begin{tabular}{|l|l|l|l|l|l|l|l|}
\hline Entrevista & Adyacente & $\begin{array}{l}\text { Atributo(ser } \\
\text { y estar }\end{array}$ & $\begin{array}{l}\text { Predicativo } \\
\text { Atributo(otros } \\
\text { verbos) }\end{array}$ & Adverbio & $\begin{array}{l}\text { Léxico } \\
\text { superlativo }\end{array}$ & Recursos & Total \\
\hline 2 & 6 & 7 & 1 & 1 & 0 & 0 & $\mathbf{1 5}$ \\
\hline 3 & 0 & 13 & 0 & 0 & 1 & 3 & $\mathbf{1 7}$ \\
\hline 5 & 5 & 5 & 1 & 2 & 13 & 6 & $\mathbf{3 2}$ \\
\hline 6 & 6 & 10 & 0 & 2 & 10 & 7 & $\mathbf{3 5}$ \\
\hline 7 & 2 & 8 & 0 & 0 & 3 & 6 & $\mathbf{1 9}$ \\
\hline 9 & 11 & 7 & 1 & 5 & 3 & 4 & $\mathbf{3 1}$ \\
\hline 14 & 15 & 17 & 0 & 2 & 5 & 0 & $\mathbf{3 9}$ \\
\hline 17 & 12 & 10 & 0 & 2 & 7 & 2 & $\mathbf{3 3}$ \\
\hline 22 & 6 & 11 & 1 & 1 & 9 & 3 & $\mathbf{3 1}$ \\
\hline 23 & 13 & 10 & 1 & 3 & 7 & 3 & $\mathbf{3 7}$ \\
\hline 24 & 6 & 9 & 0 & 4 & 7 & 3 & $\mathbf{2 9}$ \\
\hline 25 & 12 & 6 & 0 & 4 & 3 & 0 & $\mathbf{2 5}$ \\
\hline 26 & 2 & 5 & 1 & 1 & 6 & 0 & $\mathbf{1 5}$ \\
\hline 27 & 13 & 13 & 1 & 2 & 5 & 2 & $\mathbf{3 6}$ \\
\hline 28 & 6 & 13 & 0 & 1 & 9 & 1 & $\mathbf{3 0}$ \\
\hline 32 & 15 & 15 & 2 & 3 & 5 & 6 & $\mathbf{4 6}$ \\
\hline 33 & 4 & 29 & 1 & 4 & 10 & 0 & $\mathbf{4 8}$ \\
\hline Total & $\mathbf{1 3 4}$ & $\mathbf{1 8 7}$ & $\mathbf{1 0}$ & $\mathbf{3 7}$ & $\mathbf{1 0 3}$ & $\mathbf{4 6}$ & $\mathbf{5 1 8}$ \\
\hline & & & & & & & \\
\hline
\end{tabular}

En la figura siguiente, se expresan en términos porcentuales los resultados de uso del superlativo en el sexo masculino, de acuerdo con las 6 formas registradas.

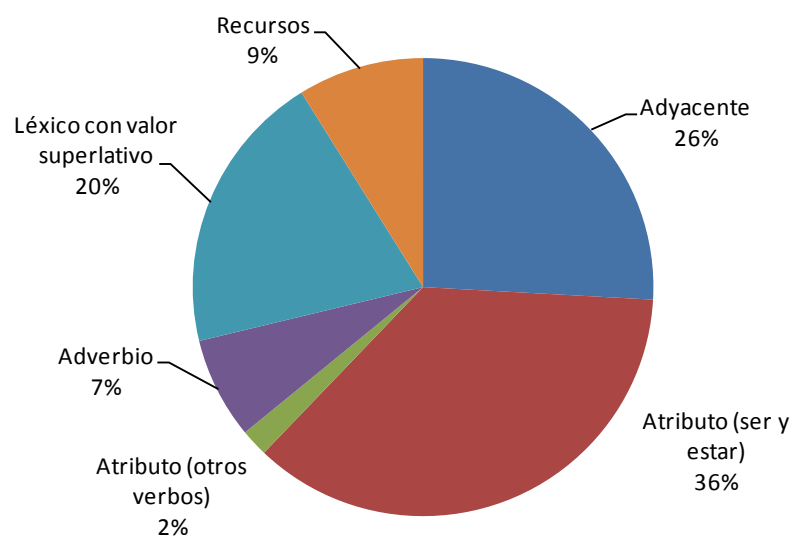

Figura 9. Porcentaje de uso de las formas superlativas de los entrevistados de sexo masculino. 
Al analizar estos resultados, se puede observar que los entrevistados de sexo masculino registran un mayor uso del superlativo como atributo con los verbos "ser" y "estar", correspondiente al $36 \%$ del total. Asimismo, se constata que el menor uso que estos hablantes hacen del superlativo es en función de predicativo o atributo con otros verbos (2\%).

\subsubsection{Sexo femenino}

Las 17 personas entrevistadas pertenecientes a este género usaron 646 formas superlativas, que equivalen al $55.50 \%$.

Al comparar los resultados, se puede apreciar una diferencia de un $11 \%$ en el uso del superlativo en los hablantes de género femenino por sobre los de género masculino. El género femenino registra 128 casos más de uso. 
En el cuadro siguiente, se registra la cantidad de superlativos correspondiente al género femenino. De acuerdo con los resultados registrados, el mayor uso corresponde a la entrevistada № 34, con 89 usos, y el menor uso, a la № 4, con 14 usos.

\begin{tabular}{|l|l|l|l|l|l|l|l|}
\hline Entrevista & Adyacente & $\begin{array}{l}\text { Atributo(ser } \\
\text { y estar }\end{array}$ & $\begin{array}{l}\text { Predicativo } \\
\text { Atributo(otros } \\
\text { verbos) }\end{array}$ & Adverbio & $\begin{array}{l}\text { Léxico } \\
\text { superlativo }\end{array}$ & Recursos & Total \\
\hline 1 & 6 & 13 & 4 & 4 & 7 & 4 & $\mathbf{3 8}$ \\
\hline 4 & 5 & 6 & 0 & 0 & 3 & 0 & $\mathbf{1 4}$ \\
\hline 8 & 4 & 12 & 1 & 6 & 9 & 2 & $\mathbf{3 4}$ \\
\hline 10 & 3 & 8 & 0 & 3 & 10 & 1 & $\mathbf{2 5}$ \\
\hline 11 & 10 & 8 & 1 & 3 & 2 & 6 & $\mathbf{3 0}$ \\
\hline 12 & 3 & 10 & 0 & 3 & 7 & 2 & $\mathbf{2 5}$ \\
\hline 13 & 10 & 13 & 0 & 1 & 1 & 2 & $\mathbf{2 7}$ \\
\hline 15 & 3 & 2 & 0 & 4 & 6 & 4 & $\mathbf{1 9}$ \\
\hline 16 & 12 & 21 & 0 & 3 & 6 & 1 & $\mathbf{4 3}$ \\
\hline 18 & 4 & 13 & 2 & 6 & 7 & 4 & $\mathbf{3 6}$ \\
\hline 19 & 5 & 13 & 2 & 3 & 1 & 0 & $\mathbf{2 4}$ \\
\hline 20 & 1 & 15 & 1 & 3 & 5 & 4 & $\mathbf{2 9}$ \\
\hline 21 & 12 & 14 & 1 & 3 & 13 & 6 & $\mathbf{4 9}$ \\
\hline 29 & 21 & 13 & 2 & 4 & 11 & 11 & $\mathbf{6 2}$ \\
\hline 30 & 10 & 12 & 3 & 2 & 10 & 8 & $\mathbf{4 5}$ \\
\hline 31 & 13 & 16 & 1 & 1 & 23 & 3 & $\mathbf{5 7}$ \\
\hline 34 & 12 & 41 & 2 & 8 & 24 & 2 & $\mathbf{8 9}$ \\
\hline Total & $\mathbf{1 3 4}$ & $\mathbf{2 3 0}$ & $\mathbf{2 0}$ & $\mathbf{5 7}$ & $\mathbf{1 4 5}$ & $\mathbf{6 0}$ & $\mathbf{6 4 6}$ \\
\hline & & & & & & & \\
\hline
\end{tabular}


En la figura siguiente, se expresan, en términos porcentuales, los resultados de uso del superlativo de acuerdo con las 6 formas registradas.

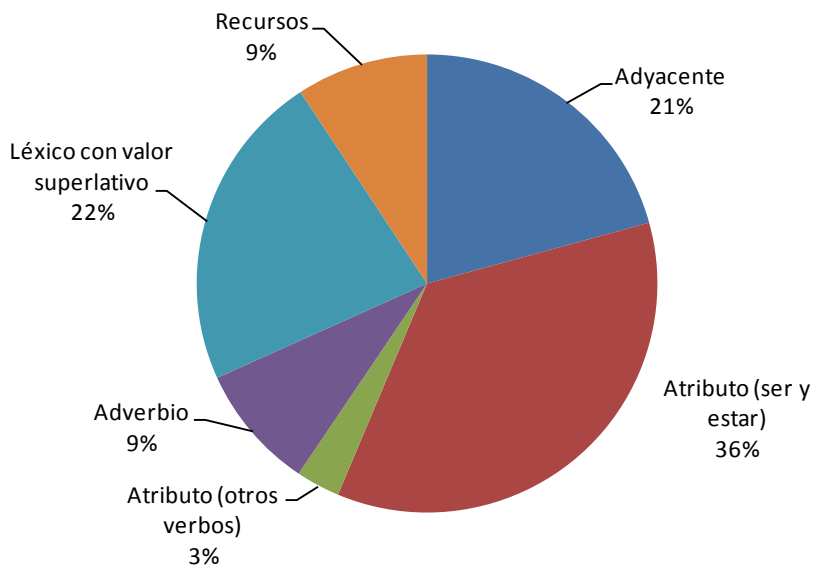

Figura 10. Porcentaje de uso de las formas superlativas de los entrevistados de sexo femenino.

Al analizar estos resultados, representados en la Figura 10, se puede observar que las personas entrevistadas correspondientes al género femenino tienen un mayor uso del superlativo como atributo con los verbos "ser" y "estar" (36\% del total), y que el menor porcentaje de uso es el de predicativo o atributo con otros verbos (3\%).

En cuanto a los entrevistados que registran mayor número de formas superlativas utilizadas en cada uno de los géneros, los resultados del análisis demuestran que hay una diferencia significativa a favor del sexo femenino, ya que la entrevistada № 34 , registra 89 usos, mientras que el entrevistado № 33 , de sexo masculino, usa un total de 48 superlativos. 


\subsection{Según variable edad}

Para el estudio de esta variable, se formaron los siguientes grupos etarios, dado que las edades de las personas entrevistadas fluctúan entre los 21 y los 69 años.

\begin{tabular}{|l|l|l|}
\hline Grupo etario & Edades & Cantidad \\
\hline Primer grupo & 21 años a 31 años & 15 \\
\hline Segundo grupo & 32 años a 49 años & 9 \\
\hline Tercer grupo & 50 años a 69 años & 10 \\
\hline
\end{tabular}

En los siguientes cuadros, se registran los usos de superlativo en las formas de adjetivo adyacente del sustantivo, atributo con los verbos ser y estar, predicativo o atributo con otros verbos, adverbio, léxico con valor superlativo y recursos estilísticos con este valor, por cada uno de los entrevistados en los grupos etarios conformados.

Primer grupo etario

\begin{tabular}{|l|l|l|l|l|l|l|l|}
\hline Entrevista & Adyacente & $\begin{array}{l}\text { Atributo(ser } \\
\text { y estar }\end{array}$ & $\begin{array}{l}\text { Predicativo } \\
\text { Atributo(otros } \\
\text { verbos) }\end{array}$ & Adverbio & $\begin{array}{l}\text { Léxico con } \\
\text { valor } \\
\text { superlativo }\end{array}$ & Recursos & Total \\
\hline 2 & 6 & 7 & 1 & 1 & 0 & 0 & $\mathbf{1 5}$ \\
\hline 3 & 0 & 13 & 0 & 0 & 1 & 3 & $\mathbf{1 7}$ \\
\hline 6 & 6 & 10 & 0 & 2 & 10 & 7 & $\mathbf{3 5}$ \\
\hline 7 & 2 & 8 & 0 & 0 & 3 & 6 & $\mathbf{1 9}$ \\
\hline 8 & 4 & 12 & 1 & 6 & 9 & 2 & $\mathbf{3 4}$ \\
\hline 10 & 3 & 8 & 0 & 3 & 10 & 1 & $\mathbf{2 5}$ \\
\hline 13 & 10 & 13 & 0 & 1 & 1 & 2 & $\mathbf{2 7}$ \\
\hline 14 & 15 & 17 & 0 & 2 & 5 & 0 & $\mathbf{3 9}$ \\
\hline 15 & 3 & 2 & 0 & 4 & 6 & 4 & $\mathbf{1 9}$ \\
\hline 16 & 12 & 21 & 0 & 3 & 6 & 1 & $\mathbf{4 3}$ \\
\hline 19 & 5 & 13 & 2 & 3 & 1 & 0 & $\mathbf{2 4}$ \\
\hline 20 & 1 & 15 & 1 & 3 & 5 & 4 & $\mathbf{2 9}$ \\
\hline 27 & 13 & 13 & 1 & 2 & 5 & 2 & $\mathbf{3 6}$ \\
\hline 28 & 6 & 13 & 0 & 1 & 9 & 1 & $\mathbf{3 0}$ \\
\hline 31 & 13 & 16 & 1 & 1 & 23 & 3 & $\mathbf{5 7}$ \\
\hline Total & $\mathbf{9 9}$ & $\mathbf{1 8 1}$ & $\mathbf{7}$ & $\mathbf{3 2}$ & $\mathbf{9 4}$ & $\mathbf{3 6}$ & $\mathbf{4 4 9}$ \\
\hline
\end{tabular}


Segundo grupo etario

\begin{tabular}{|l|l|l|l|l|l|l|l|}
\hline Entrevista & Adyacente & $\begin{array}{l}\text { Atributo(ser } \\
\text { y estar }\end{array}$ & $\begin{array}{l}\text { Predicativo } \\
\text { Atributo(otros } \\
\text { verbos) }\end{array}$ & Adverbio & $\begin{array}{l}\text { Léxico con } \\
\text { valor } \\
\text { superlativo }\end{array}$ & Recursos & Total \\
\hline 4 & 5 & 6 & 0 & 0 & 3 & 0 & $\mathbf{1 4}$ \\
\hline 9 & 11 & 7 & 1 & 5 & 3 & 4 & $\mathbf{3 1}$ \\
\hline 11 & 10 & 8 & 1 & 3 & 2 & 6 & $\mathbf{3 0}$ \\
\hline 17 & 12 & 10 & 0 & 2 & 7 & 2 & $\mathbf{3 3}$ \\
\hline 21 & 12 & 14 & 1 & 3 & 13 & 6 & $\mathbf{4 9}$ \\
\hline 22 & 6 & 11 & 1 & 1 & 9 & 3 & $\mathbf{3 1}$ \\
\hline 32 & 15 & 15 & 2 & 3 & 5 & 6 & $\mathbf{4 6}$ \\
\hline 33 & 4 & 29 & 1 & 4 & 10 & 0 & $\mathbf{4 8}$ \\
\hline 34 & 12 & 41 & 2 & 8 & 24 & 2 & $\mathbf{8 9}$ \\
\hline Total & $\mathbf{8 7}$ & $\mathbf{1 4 0}$ & $\mathbf{9}$ & $\mathbf{2 9}$ & $\mathbf{7 6}$ & $\mathbf{3 0}$ & $\mathbf{3 7 1}$ \\
\hline
\end{tabular}

Tercer grupo etario

\begin{tabular}{|l|l|l|l|l|l|l|l|}
\hline Entrevista & Adyacente & $\begin{array}{l}\text { Atributo(ser } \\
\text { y estar }\end{array}$ & $\begin{array}{l}\text { Predicativo } \\
\text { Atributo(otros } \\
\text { verbos) }\end{array}$ & Adverbio & $\begin{array}{l}\text { Léxico con } \\
\text { valor } \\
\text { superlativo }\end{array}$ & Recursos & Total \\
\hline 1 & 6 & 13 & 4 & 4 & 7 & 4 & $\mathbf{3 8}$ \\
\hline 5 & 5 & 5 & 1 & 2 & 13 & 6 & $\mathbf{3 2}$ \\
\hline 12 & 3 & 10 & 0 & 3 & 7 & 2 & $\mathbf{2 5}$ \\
\hline 18 & 4 & 13 & 2 & 6 & 7 & 4 & $\mathbf{3 6}$ \\
\hline 23 & 13 & 10 & 1 & 3 & 7 & 3 & $\mathbf{3 7}$ \\
\hline 24 & 6 & 9 & 0 & 4 & 7 & 3 & $\mathbf{2 9}$ \\
\hline 25 & 12 & 6 & 0 & 4 & 3 & 0 & $\mathbf{2 5}$ \\
\hline 26 & 2 & 5 & 1 & 1 & 6 & 0 & $\mathbf{1 5}$ \\
\hline 29 & 21 & 13 & 2 & 4 & 11 & 11 & $\mathbf{6 2}$ \\
\hline 30 & 10 & 12 & 3 & 2 & 10 & 8 & $\mathbf{4 5}$ \\
\hline Total & $\mathbf{8 2}$ & $\mathbf{9 6}$ & $\mathbf{1 4}$ & $\mathbf{3 3}$ & $\mathbf{7 8}$ & $\mathbf{4 1}$ & $\mathbf{3 4 4}$ \\
\hline
\end{tabular}

Según estos resultados, el grupo etario que registra mayor cantidad de uso de formas superlativas es el primero, con 449 usos, y el con menor cantidad, el tercero, que registra 344 usos.

En la Tabla 4, se presentan las medidas descriptivas de las formas de superlativos de acuerdo con el rango etario. 
Tabla 4. Medidas descriptivas de formas superlativas según rango etario.

\begin{tabular}{|c|c|c|c|c|c|}
\hline Superlativos & Medida Descriptiva & 21 a 31 años & 32 a 49 años & 50 a 69 años & Total \\
\hline \multirow{3}{*}{ 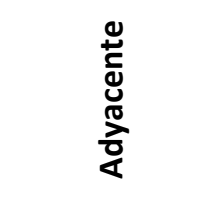 } & Promedio & 6.60 & 9.67 & 8.20 & 7.88 \\
\hline & Desviación Estándar & 4.82 & 3.77 & 5.85 & 4.93 \\
\hline & Coeficiente de Variación & 0.73 & 0.39 & 0.71 & 0.63 \\
\hline \multirow{3}{*}{ 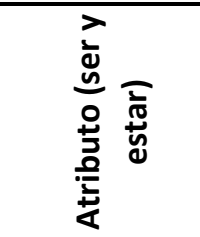 } & Promedio & 12.07 & 15.67 & 9.60 & 12.29 \\
\hline & Desviación Estándar & 4.61 & 11.75 & 3.27 & 7.12 \\
\hline & Coeficiente de Variación & 0.38 & 0.75 & 0.34 & 0.58 \\
\hline \multirow{3}{*}{ 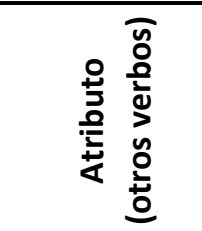 } & Promedio & 0.47 & 1.00 & 1.40 & 0.88 \\
\hline & Desviación Estándar & 0.64 & 0.71 & 1.35 & 0.98 \\
\hline & Coeficiente de Variación & 1.37 & 0.71 & 0.96 & 1.11 \\
\hline \multirow{3}{*}{$\begin{array}{l}\frac{0}{0} \\
\frac{2}{0} \\
\frac{2}{0} \\
\frac{0}{4}\end{array}$} & Promedio & 2.13 & 3.22 & 3.30 & 2.76 \\
\hline & Desviación Estándar & 1.60 & 2.33 & 1.42 & 1.81 \\
\hline & Coeficiente de Variación & 0.75 & 0.72 & 0.43 & 0.65 \\
\hline \multirow{3}{*}{ 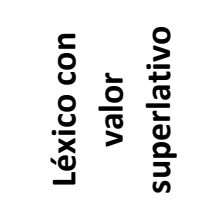 } & Promedio & 6.27 & 8.44 & 7.80 & 7.29 \\
\hline & Desviación Estándar & 5.74 & 6.89 & 2.82 & 5.35 \\
\hline & Coeficiente de Variación & 0.92 & 0.82 & 0.36 & 0.73 \\
\hline \multirow{3}{*}{ 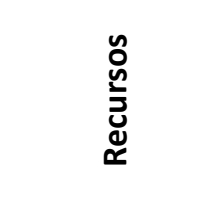 } & Promedio & 2.40 & 3.22 & 4.10 & 3.12 \\
\hline & Desviación Estándar & 2.13 & 2.44 & 3.45 & 2.67 \\
\hline & Coeficiente de Variación & 0.89 & 0.76 & 0.84 & 0.86 \\
\hline
\end{tabular}

De acuerdo con los resultados obtenidos, los promedios de uso, según los grupos etarios determinados, son los siguientes:

1. El adjetivo adyacente del sustantivo tiene, en el primer grupo etario, el menor promedio (6.6); en el segundo grupo, se registra el mayor promedio de uso $(9,67) ; y$, en el tercero, un promedio de uso de 8.20 . 
2. El atributo con los verbos "ser" y estar", que corresponde a la forma superlativa más usada, tiene un promedio de 12.07 en el primer grupo etario; en el segundo, se registra el mayor porcentaje, 15.67; y en el tercero, 9.60, que corresponde al menor promedio de uso.

3. El atributo con otros verbos tiene el mayor promedio en el grupo etario № 3 (1.40) y el menor, en el grupo etario № $1(0.47)$.

4. El adverbio superlativo tiene un mayor promedio de uso en el tercer grupo etario (3.30) y el menor promedio corresponde al grupo etario № 1 (2.13).

5. En cuanto al léxico con valor superlativo, el segundo grupo etario es el que tiene mayor promedio de uso (8.44); y el de menor promedio (6.27), corresponde al grupo № 1.

6. Los recursos estilísticos tienen un promedio mayor de uso, 3.22, en el segundo grupo etario, y el menor promedio corresponde al primer grupo (2.40).

Estos resultados se representan en la Figura 11, en la que se grafican los promedios de uso de todas las formas superlativas en relación con cada uno de los grupos etarios. 


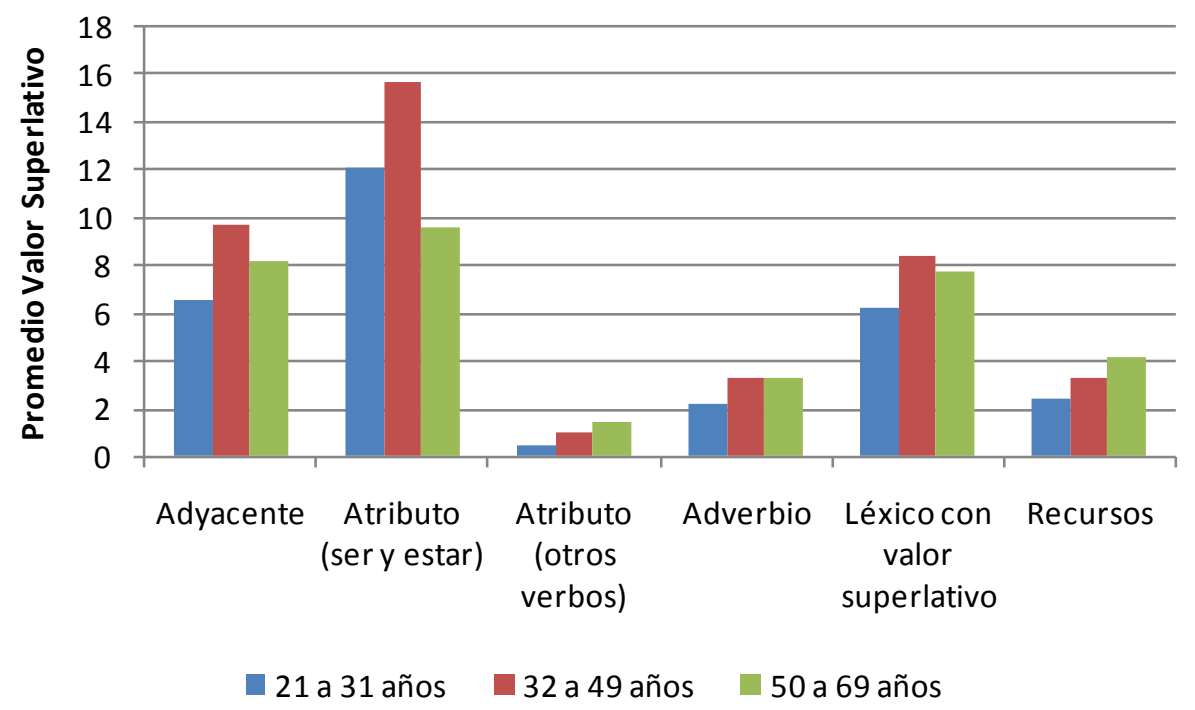

Figura 11. Promedio de uso de las formas superlativas utilizadas por las personas entrevistadas, según rango etario.

Se realiza a continuación, el análisis de las formas superlativas usadas por cada grupo etario.

\subsubsection{Primer grupo etario}

Los entrevistados que pertenecen a este rango ( 21 a 31 años) tienen el mayor porcentaje de uso del superlativo como atributo con los verbos "ser" y "estar" (40\%); en segundo lugar, está el uso del adjetivo superlativo como adyacente del sustantivo, con $22 \%$; en tercer lugar, el léxico con valor superlativo, con $21 \%$; los recursos con valor superlativo, un $8 \%$ y el adverbio superlativo, 7\%. El menor porcentaje de uso corresponde al superlativo en función predicativa o atributiva con otros verbos con sólo 2\%. Los porcentajes de uso se pueden observar en la Figura 12. 


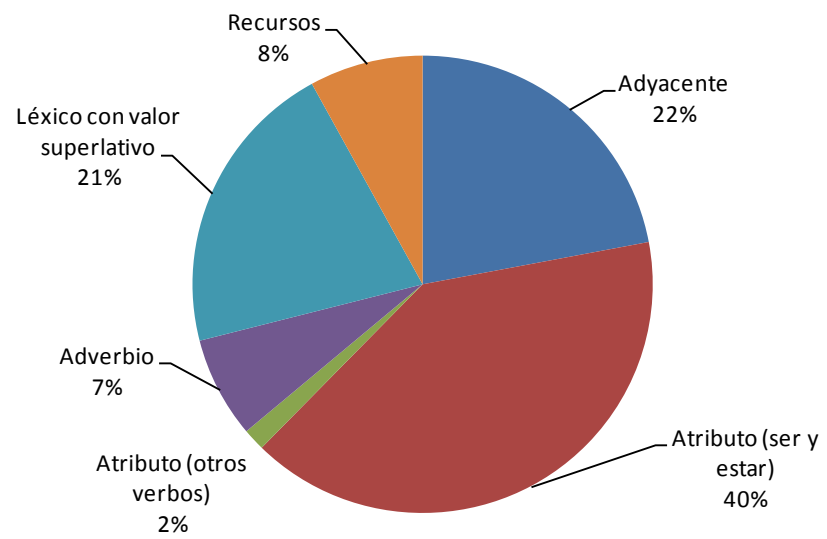

Figura 12. Porcentaje de uso del superlativo, según rango etario de 21 a 31 años.

\subsubsection{Segundo grupo etario}

Tal como se observa en la Figura 13, los entrevistados que pertenecen a este grupo tienen mayor porcentaje de uso del superlativo como atributo con los verbos "ser" y "estar", con $38 \%$; el superlativo adyacente del sustantivo, con $23 \%$; el léxico con valor superlativo tiene $21 \%$ de uso; tanto el adverbio superlativo como los recursos tienen el mismo porcentaje (8\%); y el menor porcentaje corresponde al predicativo o atributo con otros verbos, con $2 \%$.

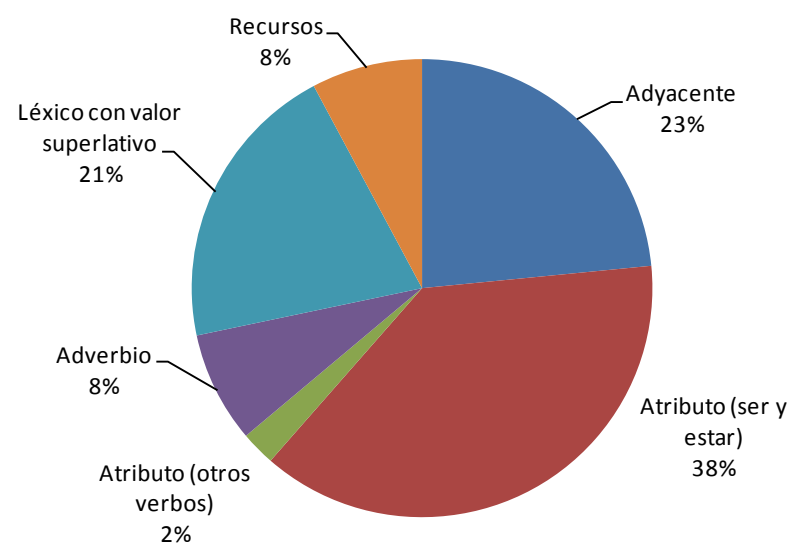

Figura 13. Porcentaje de uso del superlativo, según rango etario de 32 a 49 años. 


\subsubsection{Tercer grupo etario}

Los porcentajes de uso, representados en la Figura 14, muestran que el mayor uso de superlativos corresponde a la función atributiva con los verbos "ser" y "estar" (28\%); en segundo término, está el superlativo como adyacente del sustantivo, con $24 \%$; luego, el léxico con valor superlativo, con $23 \%$; los recursos con valor superlativo tienen un porcentaje de 12\%; el adverbio superlativo, $9 \%$; y el menor porcentaje corresponde al superlativo en función atributiva con otros verbos, con $4 \%$.

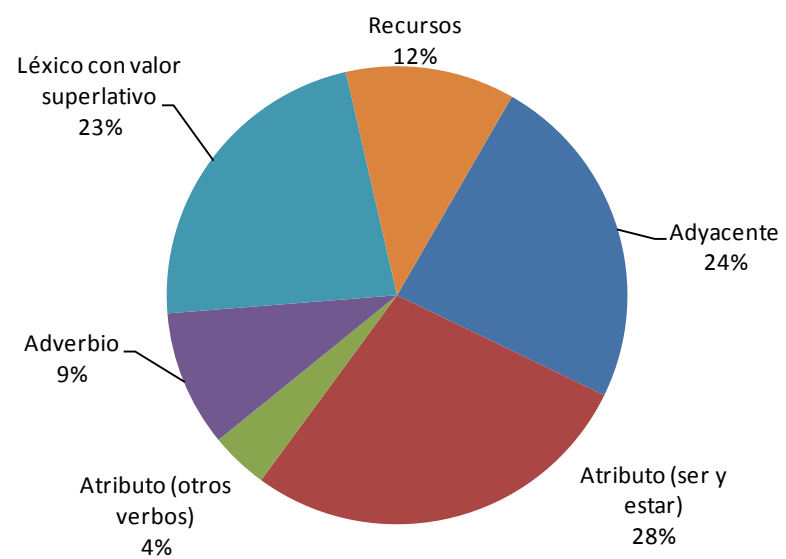

Figura 14. Porcentaje de uso del superlativo, según rango etario de 50 a 69 años. 
6.3. Según variable nivel educacional

Para el estudio de esta variable, se han considerado 3 niveles educacionales: el nivel medio, correspondiente a 7 entrevistados que han terminado la educación media obligatoria; el nivel técnico, a 8 entrevistados titulados en centros de formación técnica; y el nivel universitario, a 19 personas con estudios superiores en universidades chilenas y que, al momento de la entrevista, tenían la calidad de egresados o titulados.

En relación al nivel educacional, la distribución de las personas entrevistadas corresponde a un $21 \%$ con nivel medio, $24 \%$ con nivel técnico y $56 \%$ con nivel universitario, tal como puede observarse en la Tabla 5 y Figura 15.

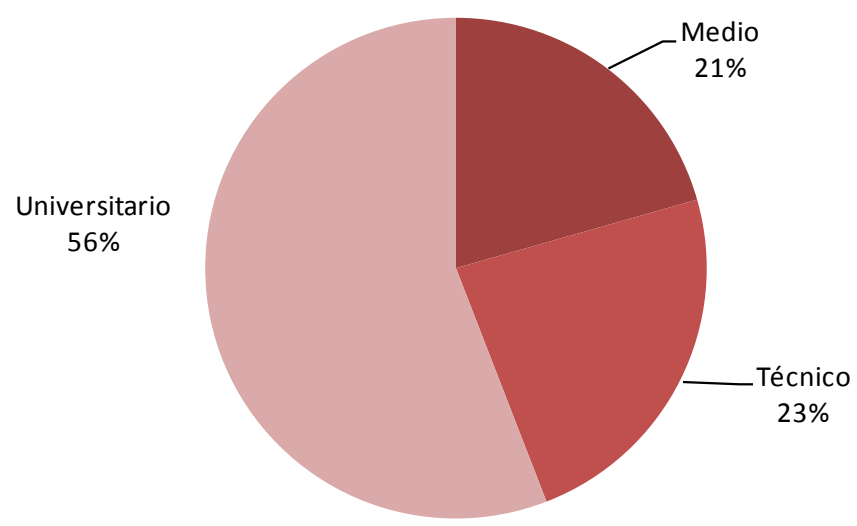

Figura 15. Distribución de entrevistados según nivel educacional. 
Tabla 5. Distribución de frecuencias del número de personas entrevistadas, según rango etario y nivel educacional.

\begin{tabular}{|c|c|c|c|c|c|}
\hline \multirow{2}{*}{ Rango Etario } & \multicolumn{3}{|c|}{ Nivel Educacional } & \multirow{2}{*}{ Total } & \multirow{2}{*}{ Porcentaje } \\
\hline & Medio & Técnico & Universitario & & \\
\hline 21 a 31 años & & 5 & 10 & 15 & $44 \%$ \\
\hline 32 a 49 años & 4 & 1 & 4 & 9 & $26 \%$ \\
\hline 50 a 69 años & 3 & 2 & 5 & 10 & $29 \%$ \\
\hline Total & 7 & 8 & 19 & 34 & \\
\hline Porcentaje & $21 \%$ & $24 \%$ & $56 \%$ & & \\
\hline
\end{tabular}

En las siguientes tablas, se presenta el total de formas superlativas usadas por cada uno de los entrevistados, según el nivel de educación

Nivel medio

\begin{tabular}{|l|l|l|l|l|l|l|l|}
\hline Entrevista & Adyacente & $\begin{array}{l}\text { Atributo(ser } \\
\text { y estar }\end{array}$ & $\begin{array}{l}\text { Predicativo } \\
\text { Atributo(otros } \\
\text { verbos) }\end{array}$ & Adverbio & $\begin{array}{l}\text { Léxico con } \\
\text { valor } \\
\text { superlativo }\end{array}$ & Recursos & Total \\
\hline 17 & 12 & 10 & 0 & 2 & 7 & 2 & $\mathbf{3 3}$ \\
\hline 21 & 12 & 14 & 1 & 3 & 13 & 6 & $\mathbf{4 9}$ \\
\hline 22 & 6 & 11 & 1 & 1 & 9 & 3 & $\mathbf{3 1}$ \\
\hline 23 & 13 & 10 & 1 & 3 & 7 & 3 & $\mathbf{3 7}$ \\
\hline 26 & 2 & 5 & 1 & 1 & 6 & 0 & $\mathbf{1 5}$ \\
\hline 29 & 21 & 13 & 2 & 4 & 11 & 11 & $\mathbf{6 2}$ \\
\hline 32 & 15 & 15 & 2 & 3 & 5 & 6 & $\mathbf{4 6}$ \\
\hline & $\mathbf{8 1}$ & $\mathbf{7 8}$ & $\mathbf{8}$ & $\mathbf{1 7}$ & $\mathbf{5 8}$ & $\mathbf{3 1}$ & $\mathbf{2 7 3}$ \\
\hline
\end{tabular}


Nivel técnico

\begin{tabular}{|l|l|l|l|l|l|l|l|}
\hline Entrevista & Adyacente & $\begin{array}{l}\text { Atributo(ser } \\
\text { y estar }\end{array}$ & $\begin{array}{l}\text { Predicativo } \\
\text { Atributo(otros } \\
\text { verbos) }\end{array}$ & Adverbio & $\begin{array}{l}\text { Léxico con } \\
\text { valor } \\
\text { superlativo }\end{array}$ & Recursos & Total \\
\hline 3 & 0 & 13 & 0 & 0 & 1 & 3 & $\mathbf{1 7}$ \\
\hline 6 & 6 & 10 & 0 & 2 & 10 & 7 & $\mathbf{3 5}$ \\
\hline 7 & 2 & 8 & 0 & 0 & 3 & 6 & $\mathbf{1 9}$ \\
\hline 12 & 3 & 10 & 0 & 3 & 7 & 2 & $\mathbf{2 5}$ \\
\hline 14 & 15 & 17 & 0 & 2 & 5 & 0 & $\mathbf{3 9}$ \\
\hline 18 & 4 & 13 & 2 & 6 & 7 & 4 & $\mathbf{3 6}$ \\
\hline 27 & 13 & 13 & 1 & 2 & 5 & 2 & $\mathbf{3 6}$ \\
\hline 33 & 4 & 29 & 1 & 4 & 10 & 0 & $\mathbf{4 8}$ \\
\hline & $\mathbf{4}$ & $\mathbf{1 1 3}$ & $\mathbf{4}$ & $\mathbf{1 9}$ & $\mathbf{4 8}$ & $\mathbf{2 4}$ & $\mathbf{2 5 5}$ \\
\hline
\end{tabular}

Nivel universitario

\begin{tabular}{|l|l|l|l|l|l|l|l|}
\hline Entrevista & Adyacente & $\begin{array}{l}\text { Atributo(ser } \\
\text { y estar }\end{array}$ & $\begin{array}{l}\text { Predicativo } \\
\text { Atributo(otros } \\
\text { verbos) }\end{array}$ & Adverbio & $\begin{array}{l}\text { Léxico con } \\
\text { valor } \\
\text { superlativo }\end{array}$ & Recursos & Total \\
\hline 1 & 6 & 13 & 4 & 4 & 7 & 4 & $\mathbf{3 8}$ \\
\hline 2 & 6 & 7 & 1 & 1 & 0 & 0 & $\mathbf{1 5}$ \\
\hline 4 & 5 & 6 & 0 & 0 & 3 & 0 & $\mathbf{1 4}$ \\
\hline 5 & 5 & 5 & 1 & 2 & 13 & 6 & $\mathbf{3 2}$ \\
\hline 8 & 4 & 12 & 1 & 6 & 9 & 2 & $\mathbf{3 4}$ \\
\hline 9 & 11 & 7 & 1 & 5 & 3 & 4 & $\mathbf{3 1}$ \\
\hline 10 & 3 & 8 & 0 & 3 & 10 & 1 & $\mathbf{2 5}$ \\
\hline 11 & 10 & 8 & 1 & 3 & 2 & 6 & $\mathbf{3 0}$ \\
\hline 13 & 10 & 13 & 0 & 1 & 1 & 2 & $\mathbf{2 7}$ \\
\hline 15 & 3 & 2 & 0 & 4 & 6 & 4 & $\mathbf{1 9}$ \\
\hline 16 & 12 & 21 & 0 & 3 & 6 & 1 & $\mathbf{4 3}$ \\
\hline 19 & 5 & 13 & 2 & 3 & 1 & 0 & $\mathbf{2 4}$ \\
\hline 20 & 1 & 15 & 1 & 3 & 5 & 4 & $\mathbf{2 9}$ \\
\hline 24 & 6 & 9 & 0 & 4 & 7 & 3 & $\mathbf{2 9}$ \\
\hline 25 & 12 & 6 & 0 & $\mathbf{4}$ & 3 & 0 & $\mathbf{2 5}$ \\
\hline 28 & 6 & 13 & 0 & 1 & 9 & 1 & $\mathbf{3 0}$ \\
\hline 30 & 10 & 12 & 3 & 2 & 10 & 8 & $\mathbf{4 5}$ \\
\hline 31 & 13 & 16 & 1 & 1 & 23 & 3 & $\mathbf{5 7}$ \\
\hline 34 & 12 & 41 & 2 & 8 & 24 & 2 & $\mathbf{8 9}$ \\
\hline & & & & & & & \\
Total & $\mathbf{1 4 0}$ & $\mathbf{2 2 7}$ & $\mathbf{1 8}$ & $\mathbf{5 8}$ & $\mathbf{1 4 2}$ & $\mathbf{5 1}$ & $\mathbf{6 3 6}$ \\
\hline
\end{tabular}


Tabla 6. Medidas descriptivas de forma de superlativos, según nivel educacional.

\begin{tabular}{|c|c|c|c|c|c|}
\hline Superlativos & Medida Descriptiva & Medio & Técnico & Universitario & Total \\
\hline \multirow{3}{*}{ 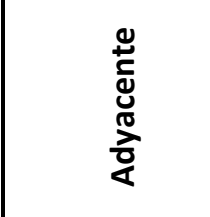 } & Promedio & 11.57 & 5.88 & 7.37 & 7.88 \\
\hline & Desviación Estándar & 6.13 & 5.33 & 3.68 & 4.93 \\
\hline & Coeficiente de Variación & 0.53 & 0.91 & 0.50 & 0.63 \\
\hline \multirow{3}{*}{ 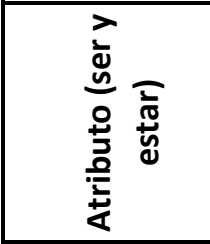 } & Promedio & 11.14 & 14.13 & 11.95 & 12.29 \\
\hline & Desviación Estándar & 3.34 & 6.60 & 8.38 & 7.12 \\
\hline & Coeficiente de Variación & 0.30 & 0.47 & 0.70 & 0.58 \\
\hline \multirow{3}{*}{ 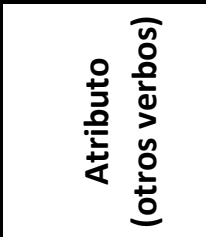 } & Promedio & 1.14 & 0.50 & 0.95 & 0.88 \\
\hline & Desviación Estándar & 0.69 & 0.76 & 1.13 & 0.98 \\
\hline & Coeficiente de Variación & 0.60 & 1.51 & 1.19 & 1.11 \\
\hline \multirow{3}{*}{$\begin{array}{l}\frac{0}{0} \\
\frac{2}{0} \\
\frac{2}{0} \\
\frac{0}{4}\end{array}$} & Promedio & 2.43 & 2.38 & 3.05 & 2.76 \\
\hline & Desviación Estándar & 1.13 & 2.00 & 1.96 & 1.81 \\
\hline & Coeficiente de Variación & 0.47 & 0.84 & 0.64 & 0.65 \\
\hline \multirow{3}{*}{ 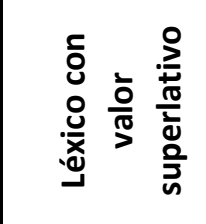 } & Promedio & 8.29 & 6.00 & 7.47 & 7.29 \\
\hline & Desviación Estándar & 2.87 & 3.16 & 6.68 & 5.35 \\
\hline & Coeficiente de Variación & 0.35 & 0.53 & 0.89 & 0.73 \\
\hline \multirow{3}{*}{ 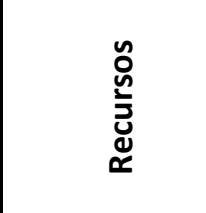 } & Promedio & 4.43 & 3.00 & 2.68 & 3.12 \\
\hline & Desviación Estándar & 3.60 & 2.56 & 2.31 & 2.67 \\
\hline & Coeficiente de Variación & 0.81 & 0.85 & 0.86 & 0.86 \\
\hline
\end{tabular}




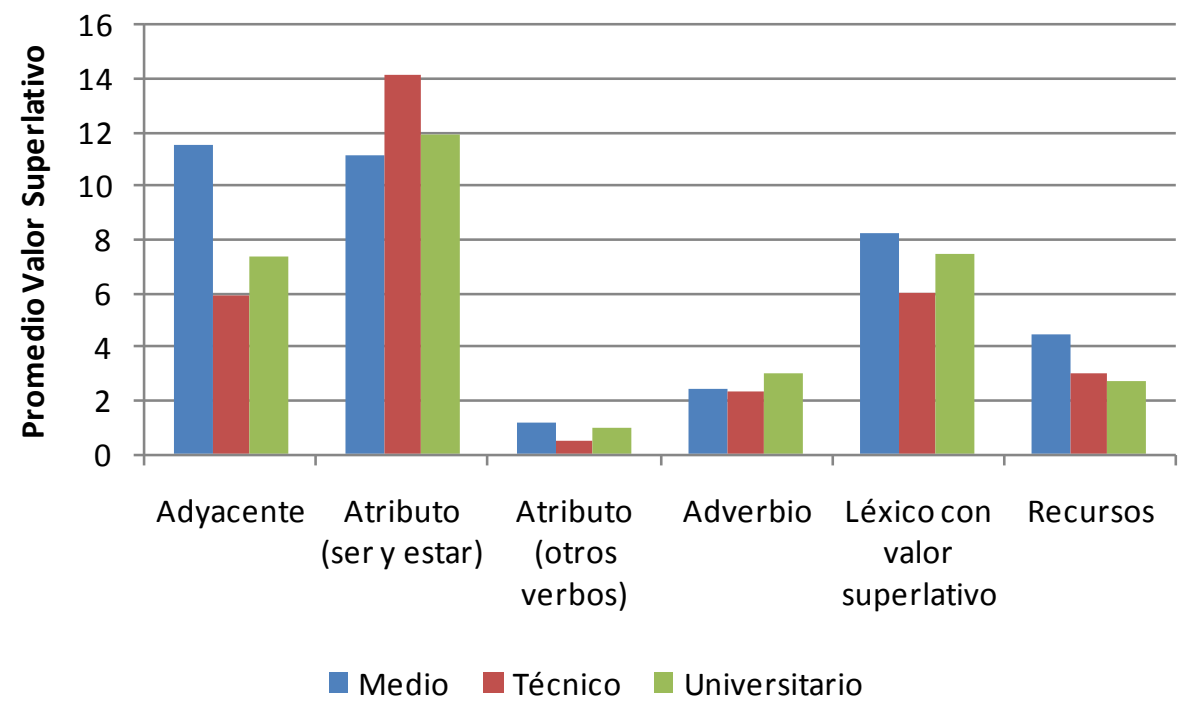

Figura 16. Promedio de formas superlativas utilizadas por las personas entrevistadas, según nivel educacional.

Al comparar los promedios de uso de las formas superlativas, representados en Tabla 6 y en la Figura 16, se puede observar lo siguiente:

1. En el caso del adjetivo adyacente, el mayor promedio de uso corresponde al nivel medio (11.57) y el menor promedio, al nivel técnico (5.88).

2. El adjetivo superlativo como atributo tiene mayor promedio de uso en el nivel técnico (14.13) y el menor promedio en el nivel medio (11.14).

3. El atributo con otros verbos (predicativo) tiene 1.14 de promedio en el nivel medio, mientras que, en el universitario y en el técnico, el promedio es de $0.95 \mathrm{y}$ 0.50 , respectivamente.

4. En cuanto al promedio de uso del adverbio superlativo, el mayor corresponde al nivel universitario, con 3.05, y el menor, al nivel medio con 2.43 . 
5. El léxico con valor superlativo tiene mayor promedio de uso en el nivel medio (8.29) y el menor promedio corresponde al nivel técnico (6.00).

6. Finalmente, en los recursos, el mayor promedio corresponde al nivel medio (4.43); en segundo lugar, se encuentra el nivel técnico con 3.00; y, en el tercer lugar, el nivel universitario con 2.68 de promedio.

Análisis de los resultados de uso de las formas superlativas en estudio, por cada uno de los niveles educacionales.

\subsubsection{Nivel medio}

En el nivel medio, los resultados indican que los superlativos de mayor uso son el superlativo adyacente, con $30 \%$ y el atributo con los verbos "ser" y "estar", con $29 \%, y$ el de menor uso, el predicativo o atributo con otros verbos (3\%), tal como se aprecia en la Figura 17.

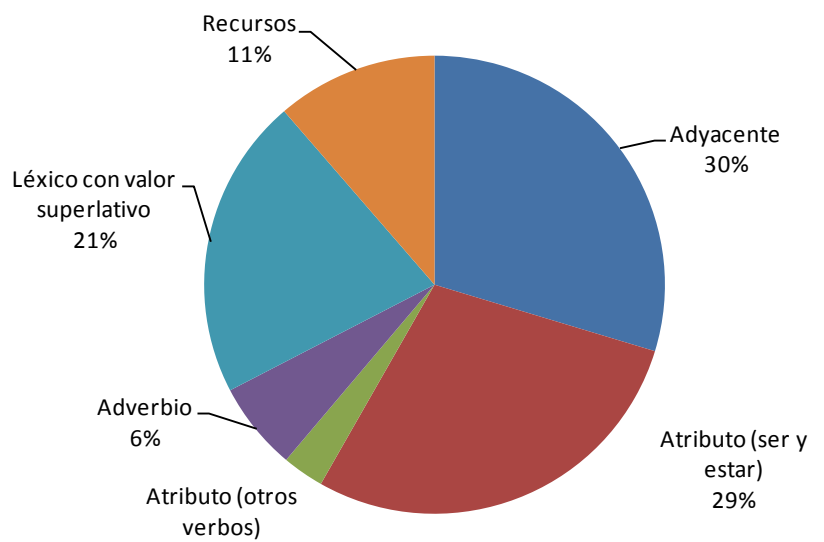

$3 \%$

Figura 17. Porcentaje de uso del superlativo, según nivel medio. 


\subsubsection{Nivel técnico}

En el caso del nivel técnico, como puede observarse en la Figura 18, hay claramente un mayor uso del superlativo como atributo con los verbos "ser" y "estar" (44\%). El léxico con valor superlativo ocupa, en este nivel educacional, el segundo lugar con un $19 \%$, y el de menor porcentaje es el atributo con otros verbos, con un $2 \%$.

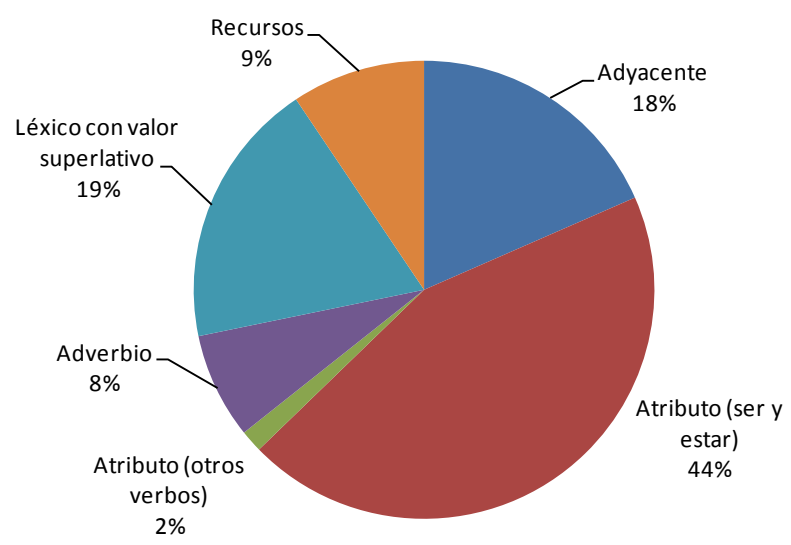

Figura 18. Porcentaje de uso del superlativo, según nivel técnico.

\subsubsection{Nivel universitario}

Al analizar los resultados del nivel universitario, representados en la Figura 19, se observa que el atributo con los verbos "ser" y "estar", es el de mayor ocurrencia (36\%). En este nivel, tanto el superlativo adyacente como el léxico con valor superlativo tienen $22 \%$ de uso. El superlativo de menor uso es el atributo con otros verbos, con un $3 \%$. 


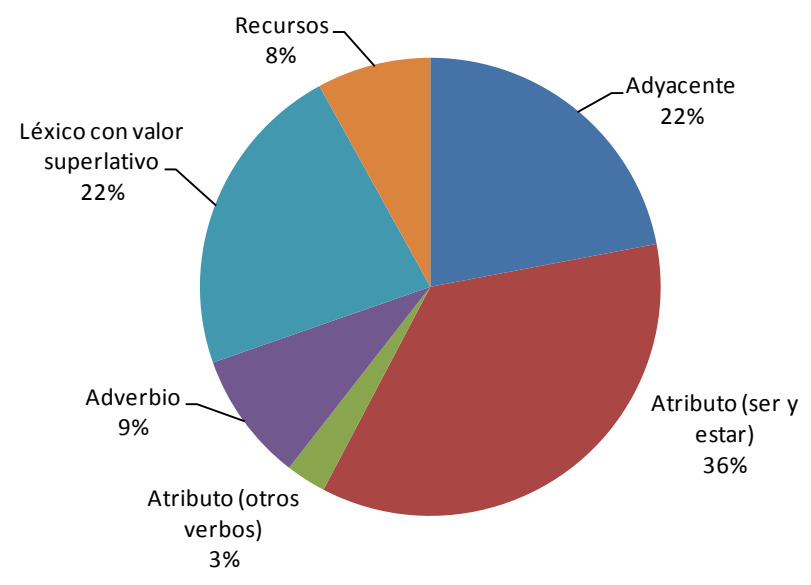

Figura 19. Porcentaje de uso del superlativo, según nivel universitario. 


\section{USO DE ADJETIVOS Y ADVERBIOS SUPERLATIVOS SEGÚN VARIABLES SOCIOLINGÜÍSTICAS DE SEXO, EDAD Y NIVEL EDUCACIONAL.}

El adjetivo superlativo es un caracterizador del sustantivo y puede ser un elemento adyacente de éste o funcionar como atributo en oraciones copulativas o como predicativo referido al sujeto o al objeto directo con verbos predicativos. El adverbio es una categoría gramatical que modifica principalmente a un verbo.

En las figuras siguientes, se muestran porcentualmente los resultados de uso del superlativo como adjetivo y como adverbio, según las variables consideradas para este trabajo (sexo, edad y nivel educacional).

\subsection{Adjetivos superlativos}

\subsubsection{Adjetivo superlativo según variable sexo}

En primer lugar, de acuerdo con la variable sexo, el adjetivo superlativo tiene mayor uso en los entrevistados de sexo femenino (54\%), tal como se observa en la Figura 20.

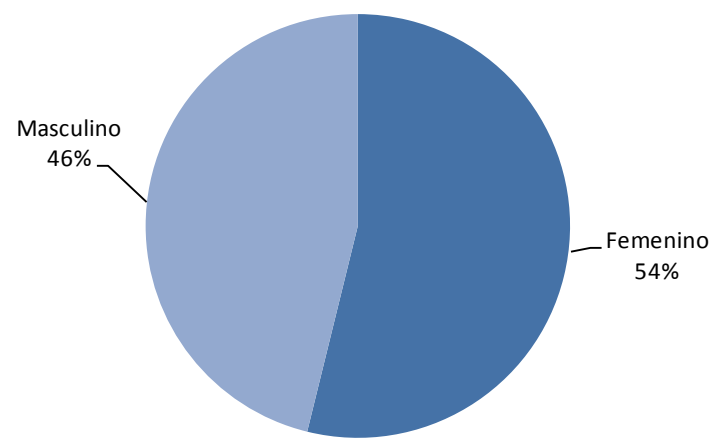

Figura 20. Porcentaje de uso de adjetivo superlativo, según variable sexo. 


\subsubsection{Adjetivo superlativo según variable edad}

De acuerdo con esta variable, los resultados demuestran que los entrevistados más jóvenes, que tienen entre 21 y 31 años de edad, son los que tienen un mayor uso de adjetivos superlativos (40\%), mientras que el rango etario que corresponde a los de mayor edad, registra el menor uso (27\%).

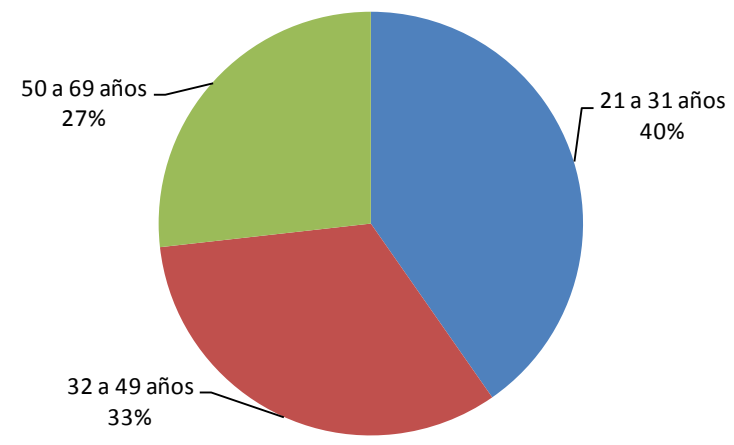

Figura 21. Porcentaje de uso de adjetivos superlativos, según rango etario.

\subsubsection{Adjetivo superlativo según variable nivel educacional}

Según esta variable, los que registran un mayor porcentaje de uso son los entrevistados de nivel universitario (54\%). Los niveles medio y técnico tienen el mismo porcentaje (23\%). Estos resultados pueden observarse en la Figura 22. 


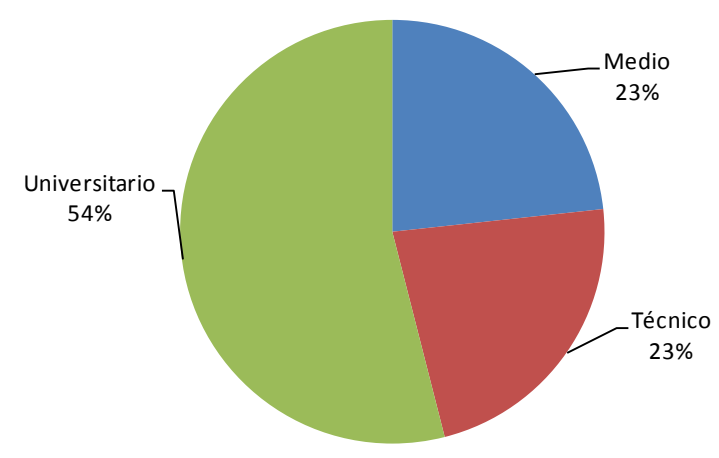

Figura 22. Porcentaje de uso de adjetivos superlativo, según nivel educacional.

\section{2. $\quad$ Adverbios superlativos}

7.2.1. Adverbio superlativo, según variable sexo

En el uso de las formas adverbiales superlativas, los entrevistados de sexo femenino tienen un porcentaje significativamente mayor que el de los pertenecientes al sexo masculino, tal como puede observarse en la figura siguiente, $61 \%$ para el femenino y $39 \%$ para el masculino.

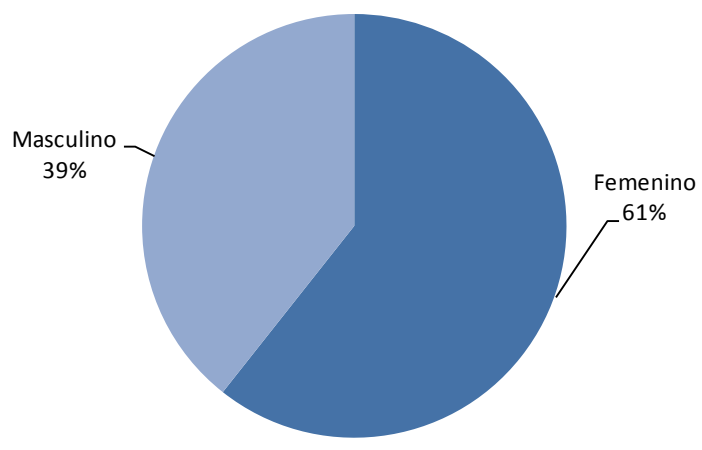

Figura 23. Porcentaje de uso de adverbio superlativo, según variable sexo. 
7.2.2. Adverbio superlativo, según variable edad

Al analizar los resultados de acuerdo con esta variable, puede observarse que el rango etario que corresponde a los entrevistados que tienen entre 50 y 69 años de edad, es el que presenta un mayor uso del adverbio superlativo (35\%). El grupo etario con menor uso (34\%), es el de los entrevistados con edades que fluctúan entre los 32 y 49 años.

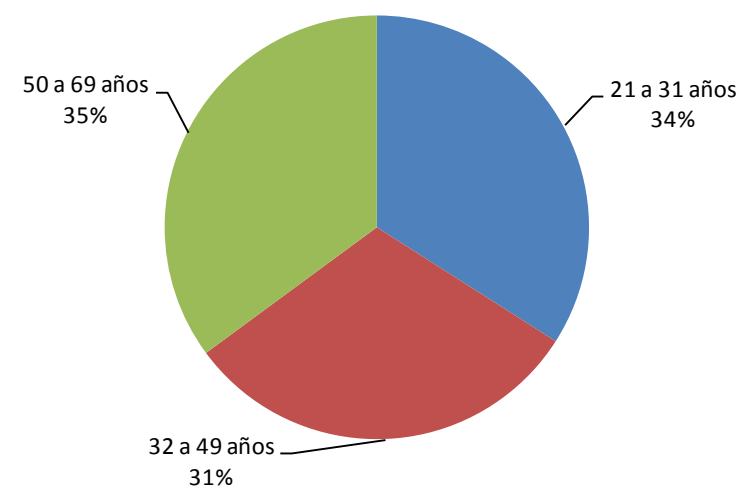

Figura 24. Porcentaje de uso de adverbio superlativo, según variable edad.

7.2.3. Adverbio superlativo según variable nivel educacional

En este caso, el grupo de entrevistados con nivel educacional universitario tiene el mayor porcentaje de uso de adverbios superlativos (62\%) y el menor uso corresponde al nivel medio, con $18 \%$. Estos resultados pueden observarse en la Figura 25. 


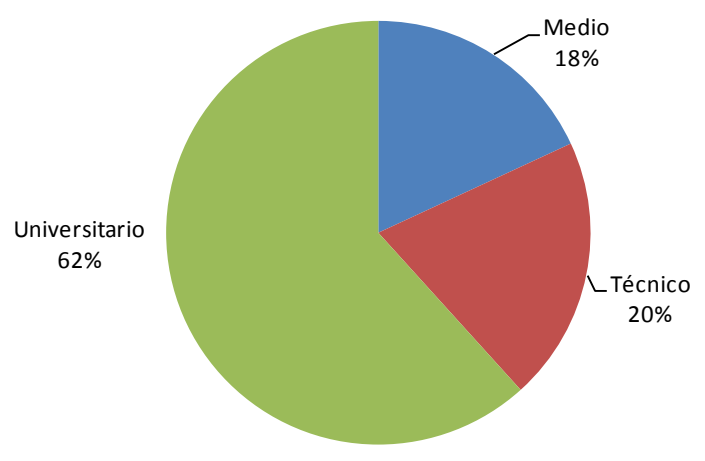

Figura 25. Porcentaje de uso de adverbios superlativos, según nivel educacional. 


\section{USO DE ADJETIVOS Y ADVERBIOS SUPERLATIVOS SINTÉTICOS Y ANALÍTICOS.}

Uno de los objetivos de este trabajo es verificar el uso del superlativo de grado extremo, expresado tanto en forma sintética como analítica, en la elocución de hablantes de la Región de Valparaíso, en conversaciones informales sobre diversos temas (vida familiar, viajes, desastres naturales, realidad política nacional, estudios, cine, deportes, trabajo, educación, etc.).

De acuerdo con los resultados obtenidos, en las 34 entrevistas realizadas, el adjetivo superlativo expresado en forma analítica, es decir, con la presencia de cuantificadores, tuvo un porcentaje de $80 \%$; en cambio, la forma sintética sólo alcanzó un $9 \%$.

En el caso del adverbio superlativo, la forma analítica tiene $10 \%$ del total de usos registrados y la sintética, apenas un $1 \%$.

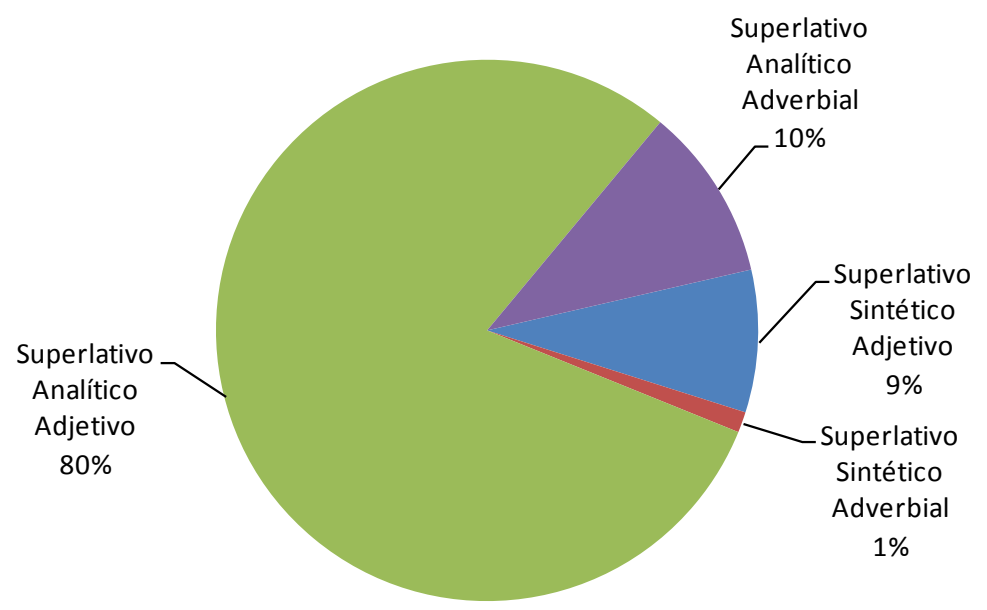

Figura 26. Porcentaje de uso de adjetivos y adverbios superlativos sintéticos y analíticos. 
Como se observa en la Figura 26, es claramente definida la tendencia de los entrevistados a usar más el adjetivo superlativo analítico que el sintético.

En la figura siguiente, se observa el promedio de adjetivos y adverbios superlativos utilizados por las personas entrevistadas, tanto expresados de manera sintética como analítica. Se puede apreciar con claridad que el mayor uso, por parte de los entrevistados, es el de las formas analíticas (adjetivas y adverbiales).

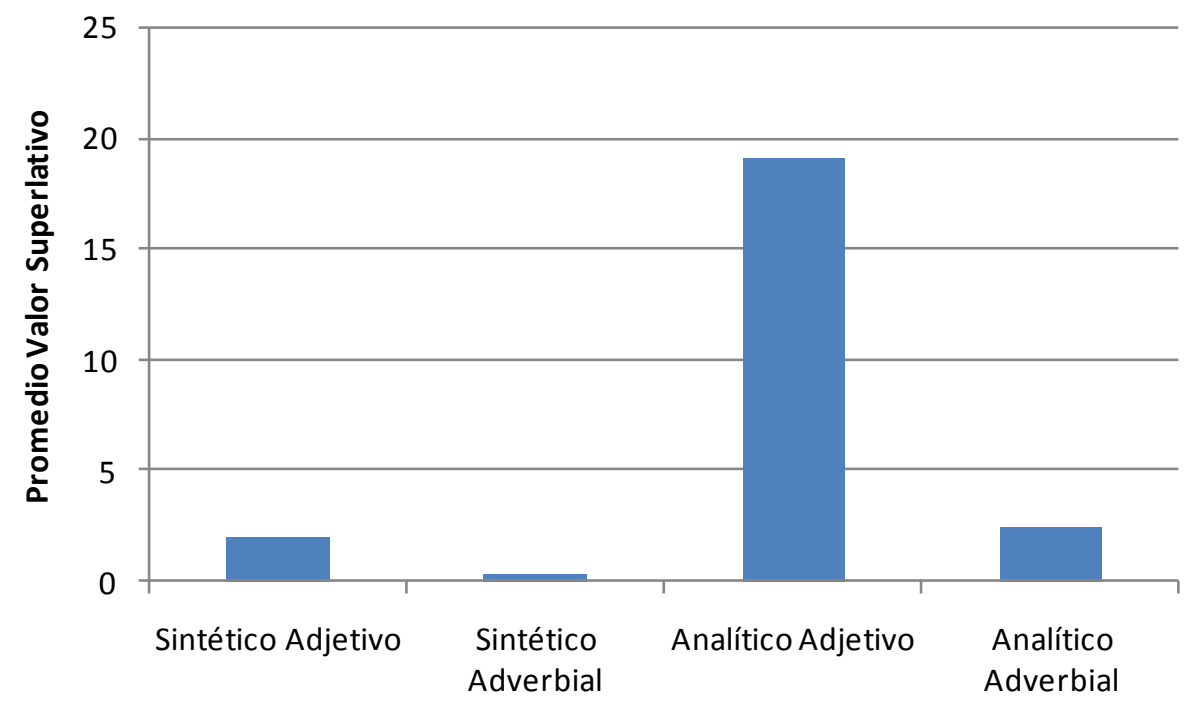

Figura 27. Promedio de adjetivos y adverbios superlativos, analíticos y sintéticos, utilizados por las personas entrevistadas. 
En la tabla que se presenta a continuación, se registra la cantidad de formas adjetivas y adverbiales (sintéticas y analíticas) que cada uno de los entrevistados usó en su elocución.

\begin{tabular}{|c|c|c|c|c|c|}
\hline $\begin{array}{l}\text { № } \\
\text { Entrevista }\end{array}$ & $\begin{array}{l}\text { superlativo } \\
\text { sintético } \\
\text { adjetivo }\end{array}$ & $\begin{array}{l}\text { superlativo } \\
\text { sintético } \\
\text { adverbial }\end{array}$ & $\begin{array}{l}\text { superlativo } \\
\text { analítico } \\
\text { adjetivo }\end{array}$ & $\begin{array}{l}\text { superlativo } \\
\text { analítico } \\
\text { adverbial }\end{array}$ & Total \\
\hline 1 & 0 & 2 & 23 & 2 & 27 \\
\hline 2 & 0 & 1 & 14 & 0 & 15 \\
\hline 3 & 3 & 0 & 10 & 0 & 13 \\
\hline 4 & 1 & 0 & 10 & 0 & 11 \\
\hline 5 & 5 & 1 & 6 & 1 & 13 \\
\hline 6 & 2 & 0 & 14 & 2 & 18 \\
\hline 7 & 0 & 0 & 10 & 0 & 10 \\
\hline 8 & 3 & 0 & 14 & 6 & 23 \\
\hline 9 & 0 & 0 & 19 & 5 & 24 \\
\hline 10 & 0 & 0 & 12 & 2 & 14 \\
\hline 11 & 4 & 0 & 15 & 3 & 22 \\
\hline 12 & 0 & 0 & 13 & 3 & 16 \\
\hline 13 & 2 & 0 & 21 & 1 & 24 \\
\hline 14 & 4 & 0 & 28 & 2 & 34 \\
\hline 15 & 0 & 0 & 5 & 4 & 9 \\
\hline 16 & 2 & 0 & 31 & 3 & 36 \\
\hline 17 & 0 & 0 & 22 & 2 & 24 \\
\hline 18 & 0 & 0 & 19 & 6 & 25 \\
\hline 19 & 2 & 0 & 18 & 3 & 23 \\
\hline 20 & 0 & 0 & 18 & 2 & 20 \\
\hline 21 & 7 & 2 & 20 & 1 & 30 \\
\hline 22 & 3 & 0 & 15 & 1 & 19 \\
\hline 23 & 4 & 0 & 20 & 3 & 27 \\
\hline 24 & 5 & 0 & 10 & 4 & 19 \\
\hline 25 & 8 & 3 & 10 & 1 & 22 \\
\hline 26 & 0 & 0 & 8 & 1 & 9 \\
\hline 27 & 3 & 0 & 24 & 2 & 29 \\
\hline 28 & 1 & 0 & 18 & 1 & 20 \\
\hline 29 & 3 & 0 & 33 & 4 & 40 \\
\hline 30 & 1 & 0 & 24 & 2 & 27 \\
\hline 31 & 2 & 0 & 28 & 1 & 31 \\
\hline 32 & 2 & 0 & 30 & 3 & 35 \\
\hline 33 & 0 & 0 & 34 & 4 & 38 \\
\hline 34 & 2 & 1 & 53 & 7 & 63 \\
\hline Total & 69 & 10 & 648 & 84 & 811 \\
\hline
\end{tabular}


El segundo de los objetivos planteados en esta tesis es identificar los cuantificadores utilizados por los entrevistados para estructurar la frase superlativa analítica, tanto adjetiva como adverbial, y determinar cuáles de estos son los de mayor uso en los hablantes entrevistados.

Para lograr el objetivo antes enunciado, se hace un análisis cuantitativo de los cuantificadores que los entrevistados usaron en su elocución.

8.1. Uso de cuantificadores o intensificadores.

Para la formación de los adjetivos y adverbios superlativos analíticos, los entrevistados utilizan un total de 21 elementos cuantificadores o intensificadores (adverbios y prefijos).

En la siguiente tabla, se registran los cuantificadores o intensificadores con la cantidad que cada uno de los hablantes usó en su elocución. 


\begin{tabular}{|c|c|c|c|c|c|c|c|c|c|c|c|c|c|c|c|c|c|c|c|c|}
\hline $\begin{array}{l}\text { No } \\
\text { de } \\
\text { E } \\
\text { N } \\
\text { T } \\
\text { R } \\
\text { V } \\
\text { I } \\
\text { S } \\
\text { T } \\
\text { A }\end{array}$ & $\begin{array}{l}e \\
x \\
t \\
r \\
e \\
m \\
a \\
d \\
a \\
m \\
e \\
n \\
t \\
e\end{array}$ & \begin{tabular}{l|l}
$a$ & $m$ \\
$b$ & $e$ \\
$s$ & $d$ \\
$o$ & $i$ \\
$l$ & $o$ \\
$u$ & \\
$t$ & \\
$a$ & \\
$m$ & \\
$e$ & \\
$n$ & \\
$t$ & \\
$e$ &
\end{tabular} & $\begin{array}{l}v \\
e \\
r \\
d \\
a \\
d \\
d \\
e \\
r \\
a \\
m \\
e \\
e \\
n \\
t \\
e\end{array}$ & $\begin{array}{l}\mathrm{m} \\
\mathrm{u} \\
\mathrm{y}\end{array}$ & $\begin{array}{l}\text { t } \\
o \\
t \\
a \\
\text { l } \\
m \\
e \\
n \\
t \\
e\end{array}$ & $\begin{array}{l}d \\
e \\
m \\
a \\
s \\
i \\
a \\
d \\
o\end{array}$ & $\begin{array}{l}\mathrm{b} \\
\mathrm{a} \\
\mathrm{s} \\
\mathrm{t} \\
\mathrm{a} \\
\mathrm{n} \\
\mathrm{t} \\
\mathrm{e}\end{array}$ & $\begin{array}{l}\mathrm{m} \\
\mathrm{u} \\
\mathrm{c} \\
\mathrm{h} \\
\mathrm{o}\end{array}$ & $\begin{array}{l}\mathrm{s} \\
\mathrm{u} \\
\mathrm{p} \\
\mathrm{e} \\
\mathrm{r}\end{array}$ & $\begin{array}{l}\mathrm{b} \\
\mathrm{i} \\
\mathrm{e} \\
\mathrm{n}\end{array}$ & $\begin{array}{l}\mathrm{t} \\
\mathrm{a} \\
\mathrm{n}\end{array}$ & $\begin{array}{l}\mathrm{m} \\
\text { á } \\
\mathrm{s}\end{array}$ & $\begin{array}{l}\mathrm{m} \\
\mathrm{u} \\
\mathrm{c} \\
\mathrm{h} \\
\mathrm{o}\end{array}$ & $\begin{array}{lll}h & c \\
a & o \\
r & n \\
t & p \\
o & l \\
& e \\
t \\
a \\
e \\
n \\
t \\
e\end{array}$ & $\begin{array}{l}\mathrm{s} \\
\mathrm{u} \\
\mathrm{m} \\
\mathrm{a} \\
\mathrm{m} \\
\mathrm{e} \\
\mathrm{n} \\
\mathrm{t} \\
\mathrm{e}\end{array}$ & & $\begin{array}{l}s \\
e \\
n \\
c \\
i \\
l \\
l \\
a \\
m \\
e \\
n \\
t \\
e\end{array}$ & $\begin{array}{l}p \\
r \\
a \\
c \\
t \\
i \\
c \\
a \\
m \\
e \\
n \\
t \\
e\end{array}$ & & $\begin{array}{l}\mathbf{T} \\
0 \\
T \\
\mathbf{A} \\
\mathbf{L}\end{array}$ \\
\hline 1 & - & --1 & - & 18 & - & 2 & - & - & - & - & 1 & - & 1 & -- & - & - & - & - & \begin{tabular}{l|l}
-2 \\
\end{tabular} & 22 \\
\hline 2 & - & $-1-$ & 1 & 1 & 2 & - & - & - & - & - & - & 10 & - & $-1-$ & - & - & - & - & \begin{tabular}{l|l}
- & 1 \\
\end{tabular} & 14 \\
\hline 3 & - & $-1-$ & - & 3 & - & - & 5 & - & 1 & - & - & 5 & - & - - & - & - & - & - & \begin{tabular}{l|l}
-1 & 1
\end{tabular} & 14 \\
\hline 4 & - & $-1-$ & - & 3 & - & - & - & - & - & - & - & 3 & - & - - - & - & - & - & - & - & 6 \\
\hline 5 & - & $-1-$ & - & 1 & - & - & 1 & - & - & 1 & 1 & 1 & - & $-1-$ & - & - & - & - & 2 & 7 \\
\hline 6 & - & $-1-$ & - & 2 & - & - & 2 & - & 1 & 7 & - & 1 & - & - & - & . & - & - & \begin{tabular}{l|l}
1 & 1 \\
\end{tabular} & 14 \\
\hline 7 & - & --1 & - & 5 & - & - & - & - & - & 3 & - & 1 & - & - & - & 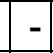 & - & - & \begin{tabular}{l|l}
- & \\
\end{tabular} & 9 \\
\hline 8 & - & -- & - & 5 & 5 & - & - & - & 5 & 1 & - & 3 & 1 & - & - & 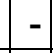 & - & - & $\begin{array}{l}-2 \\
\end{array}$ & 20 \\
\hline 9 & - & $-1-$ & - & 7 & - & - & 2 & 1 & - & 4 & 1 & 7 & - & $\begin{array}{ll}- & -\end{array}$ & - & - & 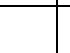 & - & \begin{tabular}{l|l}
-2 \\
\end{tabular} & 22 \\
\hline 10 & - & $-1-$ & - & 7 & - & - & - & - & - & 2 & - & - & & $1-$ & - & - & - & - & \begin{tabular}{l|l}
-1 & 1
\end{tabular} & 10 \\
\hline 11 & - & $-1-$ & - & 10 & - & 1 & 1 & - & - & - & - & 1 & - & $-1-$ & - & . & - & - & \begin{tabular}{l|l}
1 & 1 \\
\end{tabular} & 14 \\
\hline 12 & - & $-1-$ & - & 9 & - & - & - & - & - & - & - & 1 & 1 & - & - & - & - & - & \begin{tabular}{l|l}
-1 \\
\end{tabular} & 11 \\
\hline 13 & - & $-1-$ & - & 11 & - & - & 1 & 1 & 3 & 2 & 2 & 1 & - & $-1-$ & - & - & - & - & \begin{tabular}{l|l}
-2 \\
\end{tabular} & 21 \\
\hline 14 & - & $-1-$ & - & 15 & - & - & 1 & 2 & 1 & 3 & 1 & 3 & - & $-1-$ & - & 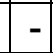 & - & - & \begin{tabular}{l|l}
-2 \\
\end{tabular} & 26 \\
\hline 15 & - & --1 & - & - & - & - & - & - & 6 & 2 & - & 1 & 1 & - & - & 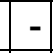 & - & - & 1 & 10 \\
\hline 16 & - & -1 & - & 6 & - & - & 1 & - & 8 & 2 & - & 6 & - & -- & - & - & - & - & $\begin{array}{l}-2 \\
\end{array}$ & 24 \\
\hline 17 & - & \begin{tabular}{l|l}
-1 \\
\end{tabular} & - & 9 & 1 & - & 3 & - & - & 2 & - & 7 & - & - & - & - & - & - & 2 & 22 \\
\hline 18 & - & \begin{tabular}{l|l} 
& -
\end{tabular} & - & 13 & 3 & - & - & - & 3 & 1 & 1 & 7 & - & - & - & 2 & - & - & 3 & 30 \\
\hline 19 & - & $-1-$ & - & 3 & - & - & - & - & 4 & - & & 10 & - & - & - & . & - & - & 1 & 17 \\
\hline 20 & - & $-1-$ & - & 4 & - & - & 1 & 1 & 10 & - & 1 & 3 & - & - & - & - & - & - & 2 & 20 \\
\hline 21 & - & -- & - & 16 & 1 & 1 & 3 & - & - & 3 & - & - & - & -1 & - & 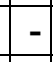 & - & - & 2 & 25 \\
\hline 22 & - & $-1-$ & - & 9 & 2 & - & 1 & - & - & - & 2 & 2 & - & $-1-$ & - & 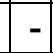 & - & - & 1 & 16 \\
\hline 23 & - & $-1-$ & - & 7 & 3 & - & 2 & - & - & 2 & & 2 & - & - & - & T. & - & 1 & 1 & 17 \\
\hline 24 & - & $-1-$ & - & 3 & 1 & - & - & - & - & - & 2 & 7 & - & - & - & - & - & - & 1 & 13 \\
\hline 25 & - & $-1-$ & - & 7 & - & - & - & - & - & - & 1 & 2 & - & $-1-$ & - & . & - & - & 1 & 10 \\
\hline 26 & - & $-1-$ & - & 4 & 1 & - & 1 & - & - & - & - & 3 & - & $-1-$ & - & 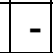 & - & - & - & 9 \\
\hline 27 & - & $--1-$ & - & 15 & - & 1 & 1 & 6 & 2 & - & - & 1 & - & - & - & & 1 & - & \begin{tabular}{l|l}
1 & 2 \\
\end{tabular} & 28 \\
\hline 28 & - & $-1-$ & - & 5 & - & - & - & - & 9 & - & 1 & - & - & - - - & - & L. & - & - & \begin{tabular}{l|l}
-1 \\
\end{tabular} & 15 \\
\hline 29 & - & $-1-$ & - & 37 & 2 & - & - & - & - & 1 & 3 & 4 & - & -- & - & & - & - & 4 & 47 \\
\hline 30 & - & $-1-$ & - & 14 & - & - & 1 & - & 3 & 4 & - & & - & $-1-$ & - & & - & - & 2 & 22 \\
\hline
\end{tabular}




\begin{tabular}{|c|c|c|c|c|c|c|c|c|c|c|c|c|c|c|c|c|c|c|c|}
\hline 31 & - & $-1-$ & - & 17 & - & - & 3 & 2 & 2 & 3 & & 2 & - & -- & - & $-1-$ & - & 1 & 30 \\
\hline 32 & - & $-1-$ & - & 26 & - & 1 & 1 & - & - & 3 & 2 & 2 & - & -- & - & $--1-$ & - & - & 35 \\
\hline 33 & 1 & $3-$ & - & 21 & - & - & - & - & 2 & - & 5 & 1 & - & $-1-$ & 1 & $-1-$ & - & 1 & 35 \\
\hline 34 & - & - - - & - & 16 & - & 1 & - & - & 18 & 8 & 7 & 1 & - & $1-$ & - & $-1-$ & - & - & 52 \\
\hline $\begin{array}{l}\text { Tota } \\
\text { I }\end{array}$ & 1 & \begin{tabular}{l|l}
3 & 1
\end{tabular} & 1 & 329 & 21 & 7 & 31 & 13 & 78 & 54 & 31 & 98 & 4 & 21 & 1 & $\begin{array}{ll}2 & 1\end{array}$ & 1 & 7 & $\begin{array}{l}68 \\
7\end{array}$ \\
\hline
\end{tabular}

El número total de cuantificadores usados por los entrevistados, como ya se ha dicho, es 21. Los 20 primeros representados en la tabla anterior corresponden a adverbios cuantificadores. Se incluye como cuantificador "súper" y no como prefijo, pues en el habla coloquial de Chile se usa con la equivalencia de "muy".

El único prefijo registrado en las entrevistas es "re" y con un uso muy poco significativo (sólo 7 ocurrencias).

La ocurrencia de los cuantificadores, tanto de los adverbios como de prefijos corresponde a 687 casos.

Los 6 cuantificadores que registran un mayor número de uso son los siguientes: muy (329), más (98), súper - (78), bien (54), bastante (31) y tan (31). 


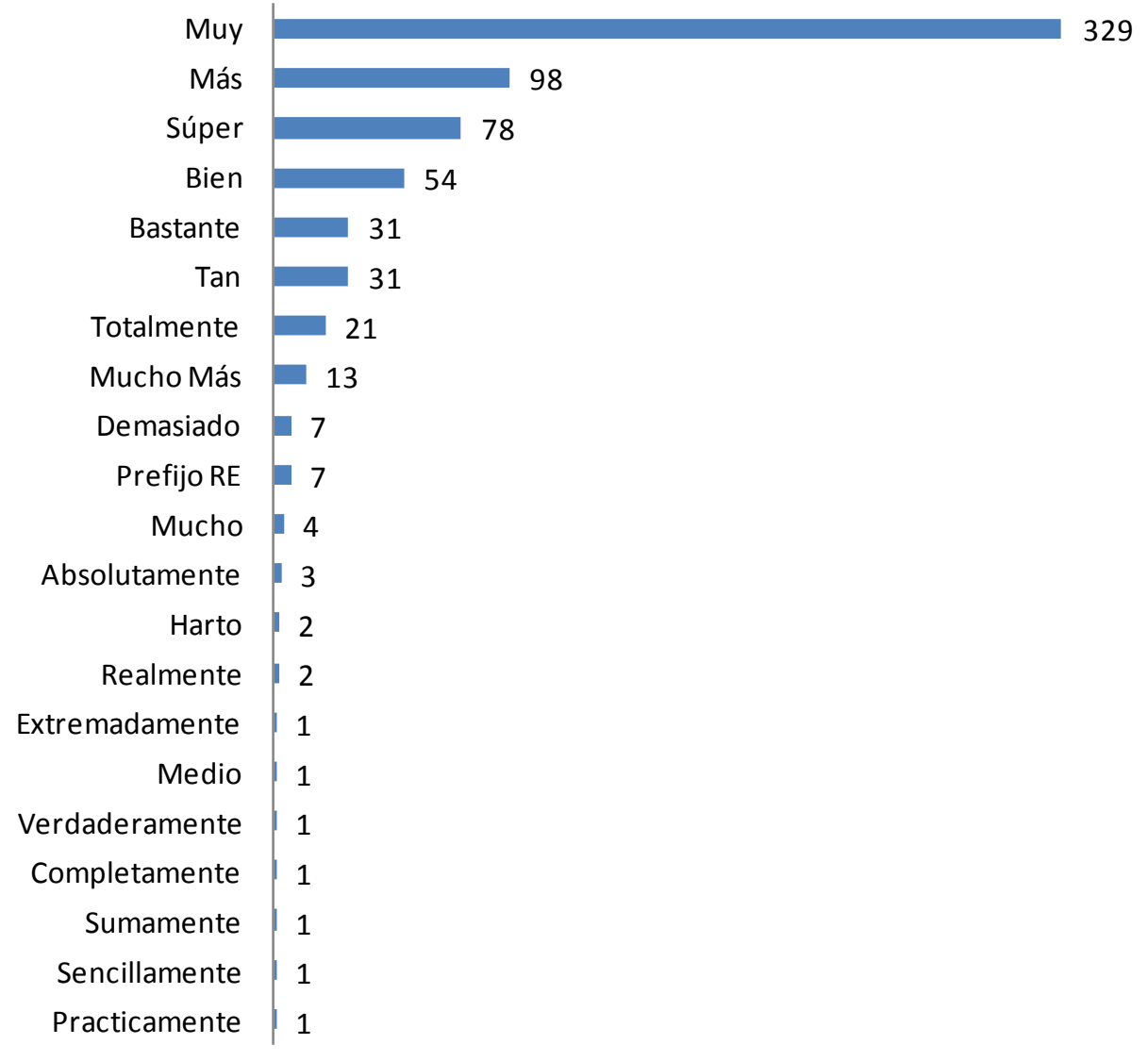

Figura 28. Número de cuantificadores usados en las entrevistas realizadas y su ocurrencia.

A continuación, se muestra la gráfica de cada uno de los 6 cuantificadores más utilizados según variable sexo, edad y nivel educacional.

\subsubsection{Cuantificador muy}

\subsubsection{Según variable sexo}

Este adverbio cuantificador, que es históricamente el de mayor uso en la lengua castellana, en las entrevistas realizadas también es el más usado por los hablantes. 
Al analizar el uso de este cuantificador según la variable sexo, se puede observar que los entrevistados de sexo femenino tienen un porcentaje mayor de uso (57\%) que los de sexo masculino (43\%). Estos porcentajes se representan en la Figura 29.

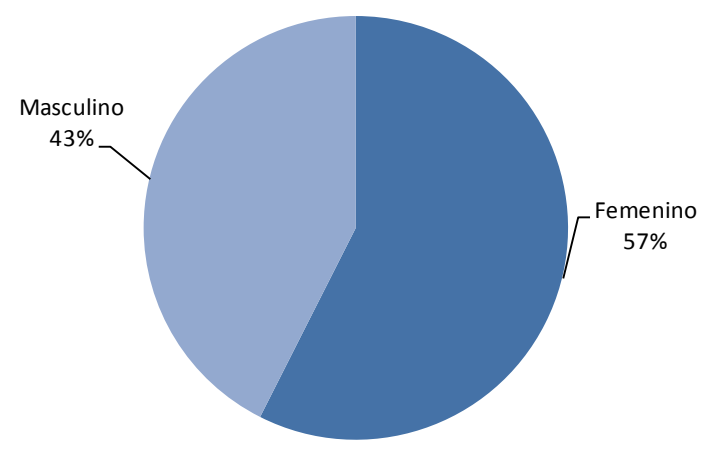

Figura 29. Porcentaje de uso de cuantificador muy en las entrevistas, según sexo.

\subsubsection{Según variable edad}

En relación con esta variable, se puede concluir que las personas entrevistadas de mayor edad (50 a 69 años) son los que registran un mayor uso de este cuantificador (35\%), mientras que los de rango etario medio (32 a 49 años) son los que tienen menor uso (31\%). Cabe señalar que la diferencia de uso entre los grupos etarios no es tan significativa como en la variable sexo. 


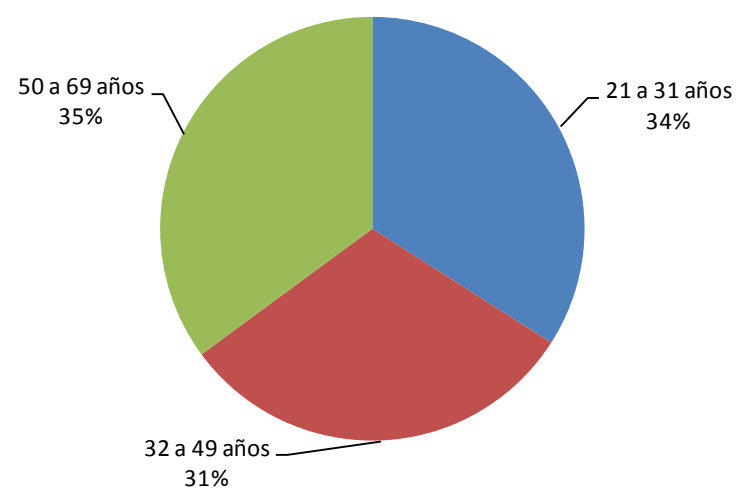

Figura 30. Porcentaje de uso de cuantificador muy, según rango etario.

\subsubsection{Según variable nivel educacional}

En el análisis de uso de este cuantificador, representado en la Figura 31, se constata que los entrevistados del nivel universitario tienen un mayor uso (42\%) y que los que hacen menor uso de él son los de nivel técnico (25\%).

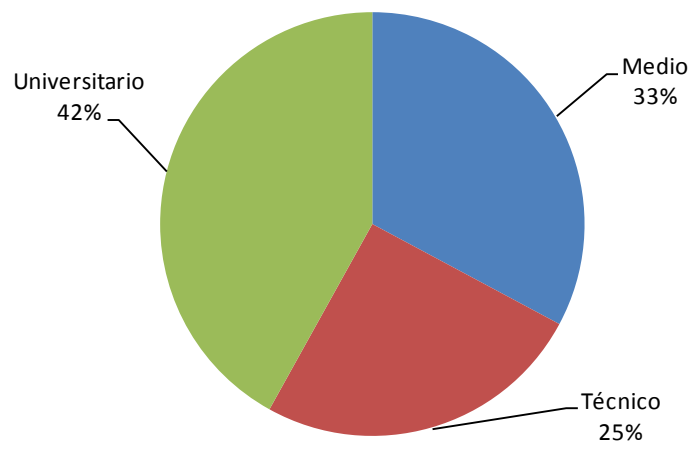

Figura 31. Porcentaje de uso de cuantificador muy en las entrevistas, según nivel educacional. 


\subsubsection{Cuantificador más}

8.1.2.1. Según variable sexo

De acuerdo con los resultados obtenidos, el cuantificador "más" ocupa el segundo lugar de uso en las entrevistas realizadas.

En cuanto a la variable sexo, el masculino presenta un mayor porcentaje de uso (56\%). El femenino registra 44\%. Estos resultados pueden observarse en la Figura 32.

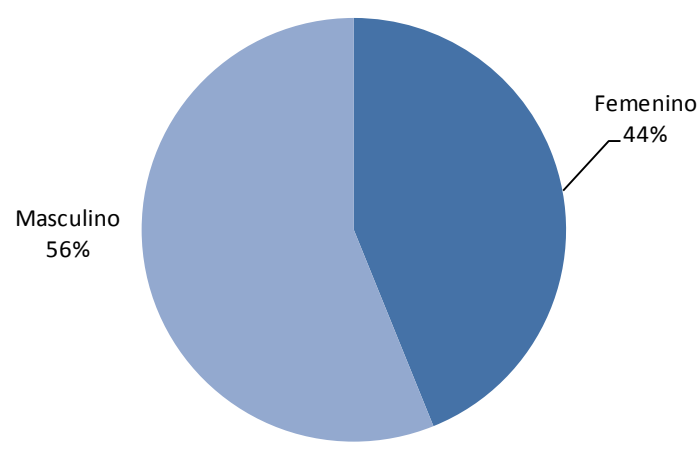

Figura 32. Porcentaje de uso de cuantificador más en las entrevistas, según sexo.

\subsubsection{Según variable edad}

De acuerdo con esta variable, se puede decir que el grupo etario correspondiente a los más jóvenes registra el mayor porcentaje de uso (48\%), mientras que el segundo grupo etario (32 a 49 años) tiene el menor porcentaje de uso (24\%). 


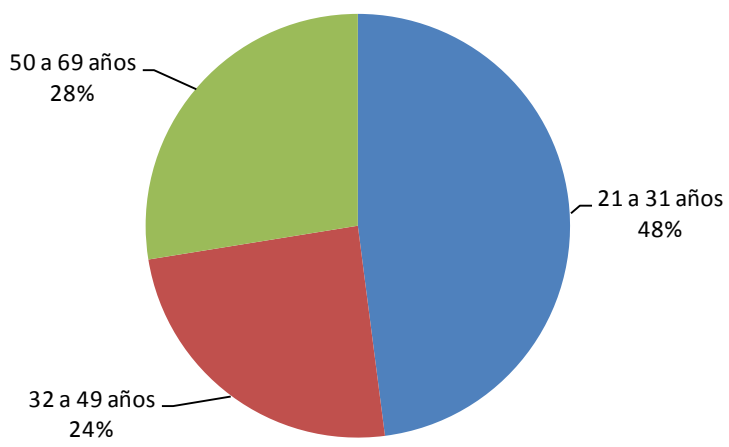

Figura 33. Porcentaje de uso de cuantificador más en las entrevistas, según rango etario.

8.1.2.3. Según variable nivel educacional

En el caso de esta variable, de acuerdo con los resultados representados en la Figura 34, los entrevistados de nivel universitario son los que registran el mayor porcentaje de uso (59\%). Los entrevistados de nivel técnico tienen el menor porcentaje de uso (20\%).

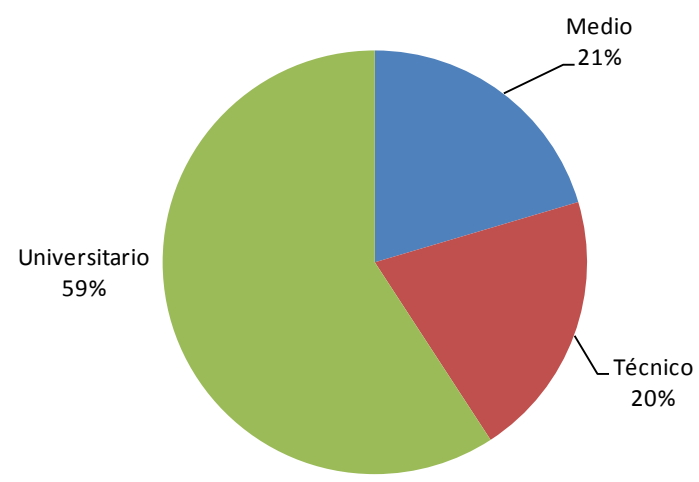

Figura 34. Porcentaje de uso de cuantificador más en las entrevistas, según nivel educacional. 


\subsubsection{Cuantificador súper}

\subsubsection{Según variable sexo}

El prefijo cuantificador "súper" tiene en el habla de Chile un uso recurrente. Como puede apreciarse en la Figura 35, registra un uso evidentemente mayor en los entrevistados de sexo femenino (79\%). En cambio, en el sexo masculino alcanza sólo un $21 \%$ de uso.

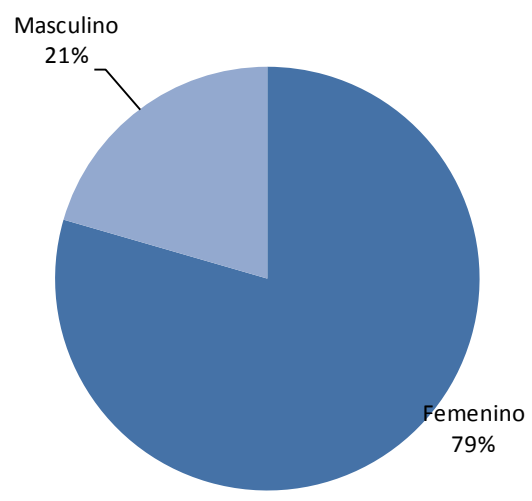

Figura 35. Porcentaje de uso de cuantificador súper en las entrevistas, según sexo.

\subsubsection{Según variable edad}

Los resultados obtenidos de acuerdo con esta variable demuestran que este cuantificador es usado mayoritariamente por los entrevistados de menor edad (21 a 31 años), con $67 \%$ de uso. El grupo etario correspondiente a los de más edad (50 a 69 años) registra el menor porcentaje, correspondiente a 8\%. (Figura 36). 


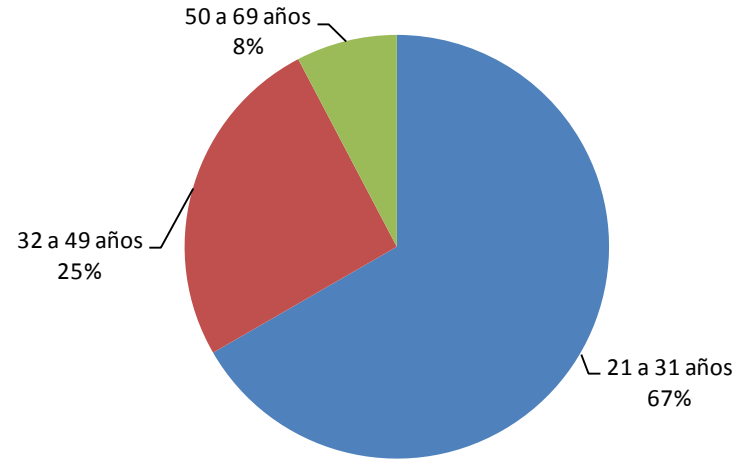

Figura 36. Porcentaje de uso de cuantificador súper en las entrevistas, según rango etario.

\subsubsection{Según Variable nivel educacional}

Al analizar los resultados de acuerdo con esta variable, se observa que sólo registran uso los entrevistados de los niveles educacionales técnico y universitario. De éstos, el nivel universitario es el que presenta mayor uso de este cuantificador (87\%), mientras que el nivel técnico sólo registra $13 \%$ de uso. Tal como puede observarse en la Figura 37, la diferencia de uso es bastante significativa.

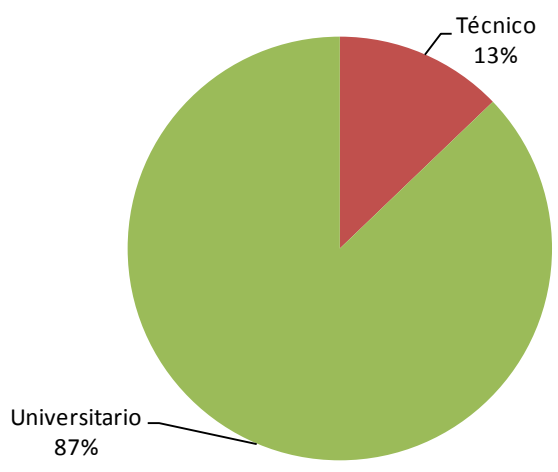

Figura 37. Porcentaje de uso de cuantificador súper en las entrevistas, según nivel educacional. 


\subsubsection{Cuantificador bien}

8.1.4.1. Según variable sexo

Este cuantificador tiene un uso mayor en las personas entrevistadas de sexo femenino (54\%), mientras que los pertenecientes al sexo masculino tienen $46 \%$ de uso. Estos resultados pueden observarse en la Figura 38.

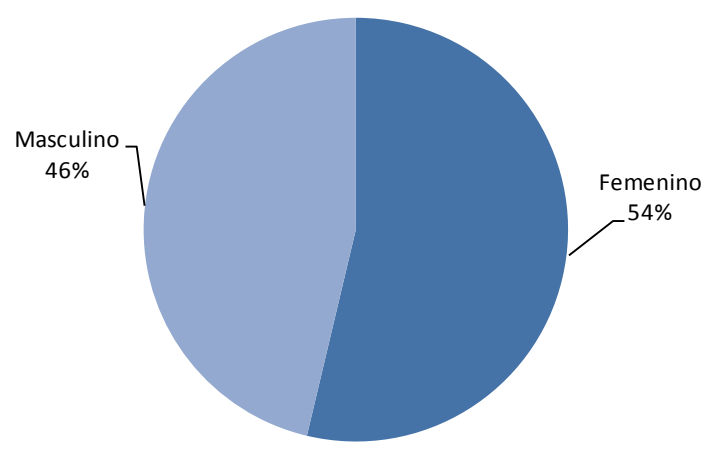

Figura 38. . Porcentaje de uso de cuantificador bien en las entrevistas, según sexo.

\subsubsection{Según variable edad}

Al analizar los resultados representados en la Figura 39, según esta variable, se puede decir lo siguiente:

1. Los entrevistados del segundo grupo etario son los que registran mayor porcentaje de uso de este cuantificador (46\%).

2. El grupo etario que corresponde a los entrevistados que tienen entre 32 y 49 años, son los que registran el segundo porcentaje de uso (37\%).

3. Los entrevistados de mayor edad (50 a 69 años) son los que menos usan este cuantificador (17\%). 


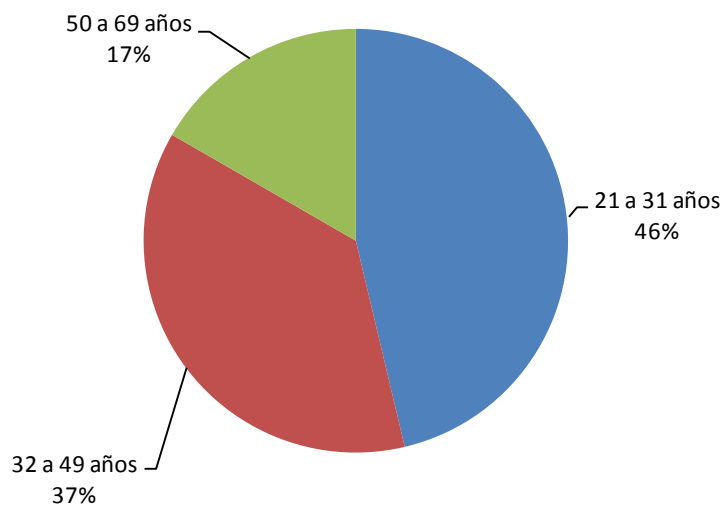

Figura 39. Porcentaje de uso de cuantificador bien en las entrevistas, según rango etario.

\subsubsection{Según variable nivel educacional}

Como puede observarse en la Figura 40, el nivel universitario es el que presenta un mayor porcentaje de uso del cuantificador bien, ya que registra $54 \%$ de uso; el nivel técnico tiene $26 \%$ de uso; y el nivel medio el menor porcentaje, correspondiente a $20 \%$.

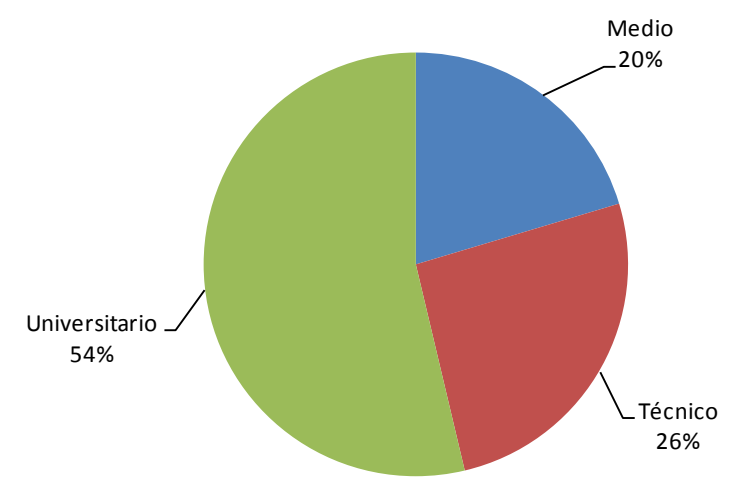

Figura 40. Porcentaje de uso de cuantificador bien en las entrevistas, según nivel educacional. 


\subsubsection{Cuantificador bastante}

8.1.5.1. Según variable sexo

Los resultados representados en la Figura 41 indican claramente que este cuantificador es usado preferentemente por los entrevistados de sexo masculino, con $65 \%$ del total de uso; mientras que el sexo femenino registra $35 \%$ de uso.

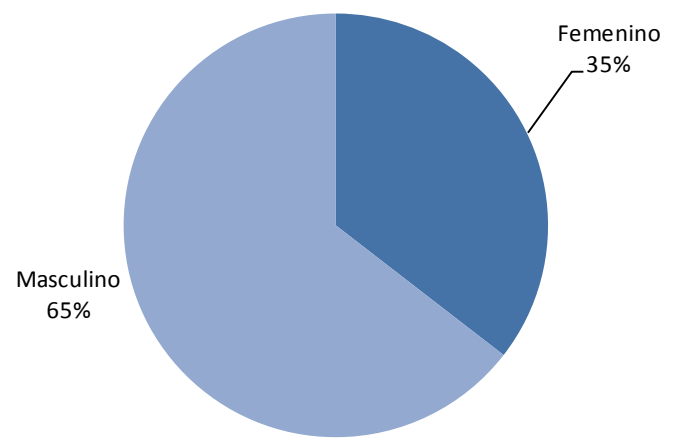

Figura 41. Porcentaje de uso de cuantificador bastante, según sexo.

\subsubsection{Según variable edad}

De acuerdo con los resultados que se representan en la Figura 42, se puede decir lo siguiente:

1. Los entrevistados que corresponden al grupo etario de los más jóvenes son los que hacen mayor uso de este cuantificador, ya que registran $48 \%$ de uso.

2. El segundo porcentaje corresponde al segundo grupo etario (32 a 49 años), pues registra $36 \%$ de uso.

3. El grupo de los de mayor edad registra el $16 \%$ del total de uso del cuantificador. 


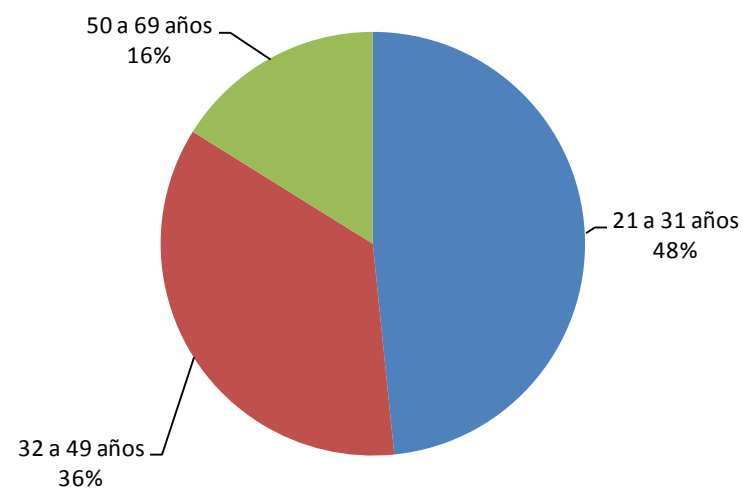

Figura 42. Porcentaje de uso de cuantificador bastante, según rango etario.

8.1.5.3. Según variable nivel educacional

Al analizar los resultados en el uso de este cuantificador, según el nivel educacional, se puede constatar que los niveles medio y universitario tienen una leve diferencia de uso, 36\% para el nivel medio y 35\% para el universitario; y el nivel técnico está cercano a los anteriores, con $29 \%$ de uso ( Figura 43).

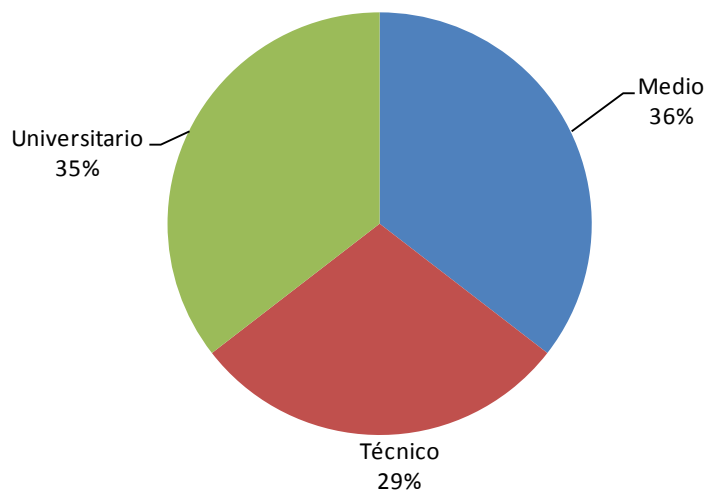

Figura 43. Porcentaje de uso de cuantificador bastante, según nivel educacional. 


\subsubsection{Cuantificador tan}

8.1.6.1. Según variable sexo

En el caso de este cuantificador, según la variable sexo, los resultados demuestran que los entrevistados de sexo masculino registran mayor uso (52\%), que los de sexo femenino (48\%). Sin embargo, la diferencia de uso no es tan significativa como en otros cuantificadores. Estos resultados se encuentran representados en la Figura 44.

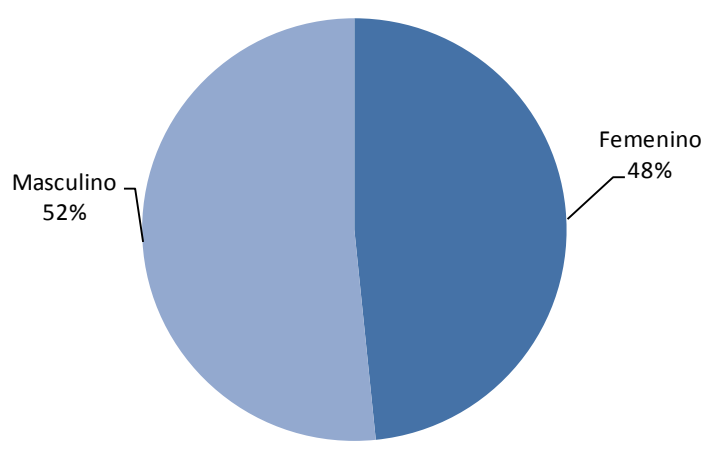

Figura 44. Porcentaje de uso de cuantificador tan, según sexo.

\subsubsection{Según variable edad}

El análisis de los resultados de acuerdo con la variable edad, representados en la Figura 45, demuestra lo siguiente:

1. El segundo grupo etario (32 a 49 años) es el que registra el mayor porcentaje de uso (55\%). 
2. El grupo etario de mayor edad tiene el segundo lugar en porcentaje de uso (29\%).

3. El grupo etario de los más jóvenes es el que registra el menor uso de este cuantificador (16\%).

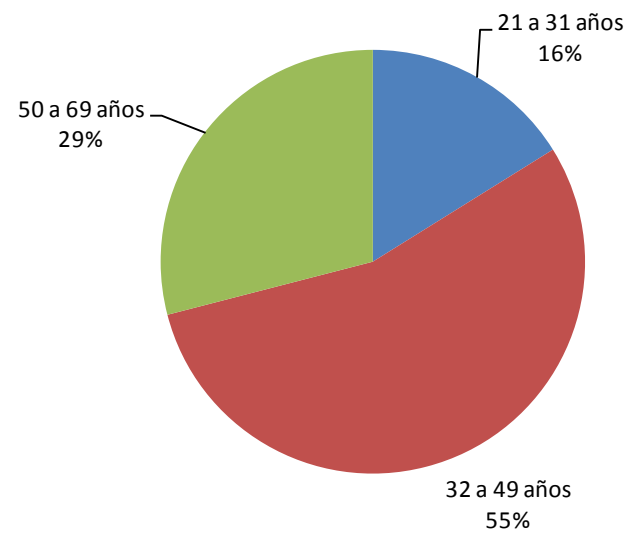

Figura 45. Porcentaje de uso de cuantificador tan en las entrevistas, según rango etario.

\subsubsection{Según variable nivel educacional}

En el uso de este cuantificador, el análisis de los resultados, según la variable nivel educacional, demuestra que el nivel universitario registra el mayor porcentaje de uso (55\%). Los otros dos niveles registran un porcentaje de uso muy cercano entre sí, pues el técnico tiene $23 \%$ y el medio, 22\% (Figura 46 ). 


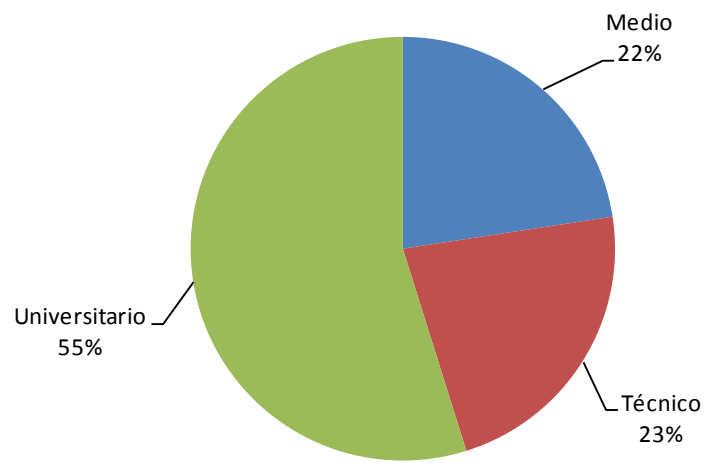

Figura 46. Porcentaje de uso de cuantificador tan en las entrevistas, según nivel educacional.

8.2. Uso de adjetivos y adverbios superlativos sintéticos y analíticos, según sexo, edad y nivel educacional

Se hará un análisis cuantitativo del uso de los adjetivos y adverbios elativos sintéticos y analíticos, usados por los entrevistados, de acuerdo con las variables sociolingüísticas consideradas en este trabajo: sexo, edad y nivel educacional.

\subsubsection{Según variable sexo}

Al analizar los resultados de la investigación, representados en la Tabla 7 y en la Figura 47, de acuerdo con esta variable sociolingüística, podemos decir que:

1. Las personas entrevistadas, pertenecientes al sexo femenino, hacen un mayor uso del superlativo, en los siguientes casos:

- Como adjetivo superlativo analítico, con un promedio de uso de 21.00.

- Como adverbio superlativo analítico, con un promedio de uso de 1.92. 
2. Las personas de sexo masculino tienen un mayor uso del adjetivo superlativo sintético (promedio de uso de 2.35).

3. Las personas entrevistadas de ambos sexos tienen el mismo promedio de uso del superlativo sintético adverbial (0.29).

En las siguientes gráficas, se muestran los resultados de uso de los adjetivos y adverbios sintéticos y analíticos en términos de medidas descriptivas, referidas al promedio, la desviación estándar y el coeficiente de variación.

Tabla 7. Medidas descriptivas de adjetivos y adverbios superlativos sintéticos y analíticos, según variable sexo.

\begin{tabular}{|c|c|c|c|c|}
\hline Superlativos & Medida Descriptiva & Femenino & Masculino & Total \\
\hline \multirow{3}{*}{ 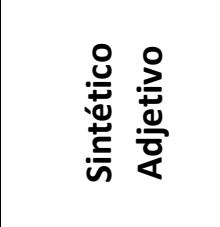 } & Promedio & 1.71 & 2.35 & 2.03 \\
\hline & Desviación Estándar & 1.86 & 2.34 & 2.11 \\
\hline & Coeficiente de Variación & 1.09 & 1.00 & 1.04 \\
\hline \multirow{3}{*}{ 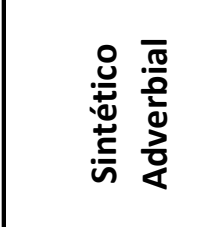 } & Promedio & 0.29 & 0.29 & 0.29 \\
\hline & Desviación Estándar & 0.69 & 0.77 & 0.72 \\
\hline & Coeficiente de Variación & 2.33 & 2.62 & 2.44 \\
\hline \multirow{3}{*}{ 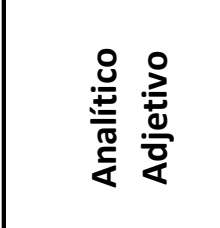 } & Promedio & 21.00 & 17.12 & 19.06 \\
\hline & Desviación Estándar & 11.07 & 8.12 & 9.76 \\
\hline & Coeficiente de Variación & 0.53 & 0.47 & 0.51 \\
\hline \multirow{3}{*}{ 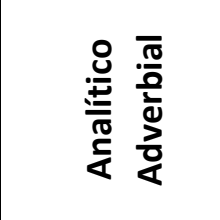 } & Promedio & 3.06 & 1.88 & 2.47 \\
\hline & Desviación Estándar & 1.92 & 1.50 & 1.80 \\
\hline & Coeficiente de Variación & 0.63 & 0.79 & 0.73 \\
\hline
\end{tabular}




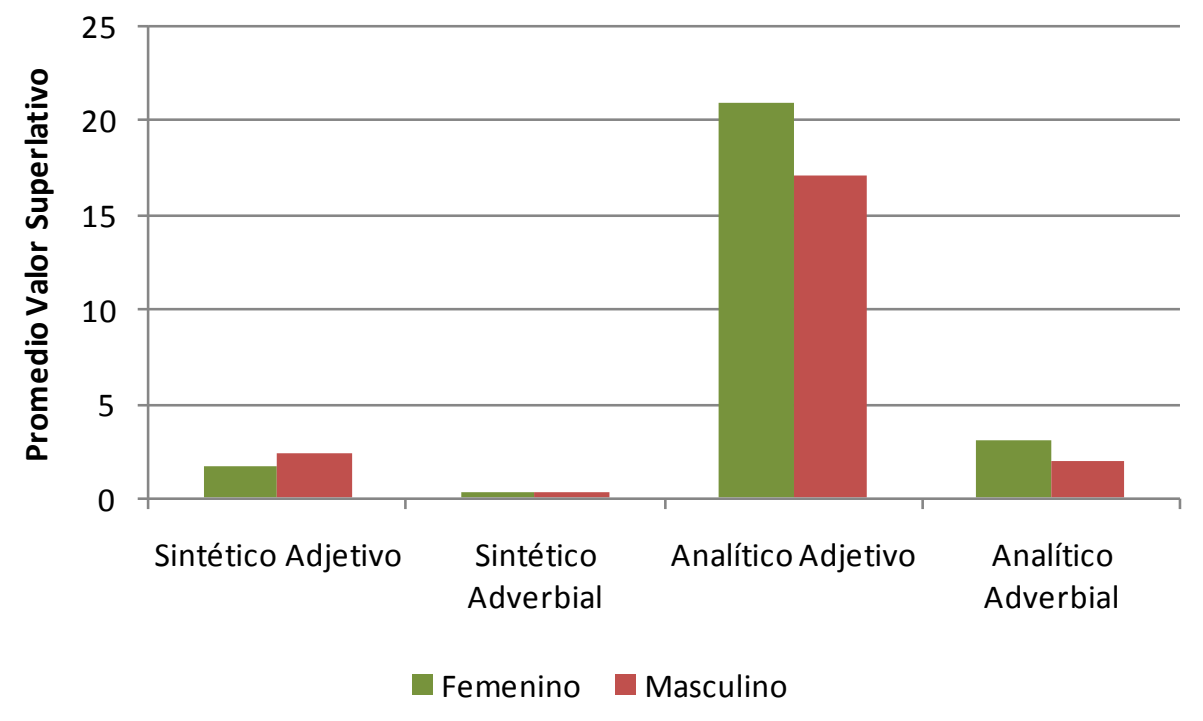

Figura 47. Promedio de uso del adjetivo y adverbio superlativo analítico y sintético, según variable sexo.

En las figuras siguientes, se expresan, en términos porcentuales, los resultados obtenidos, respecto del uso de los adjetivos y adverbios superlativos, tanto sintéticos como analíticos, por cada sexo.

\subsubsection{Sexo femenino}

De acuerdo con los resultados porcentuales, representados en la Figura 48, se puede decir lo siguiente:

1. En el sexo femenino, el mayor porcentaje de uso corresponde al adjetivo superlativo analítico, con $81 \%$.

2. El adverbio superlativo analítico registra el segundo porcentaje (12\%).

3. El adjetivo sintético tiene $6 \%$ de uso.

4. El adverbio superlativo sintético sólo alcanza $1 \%$ de uso. 


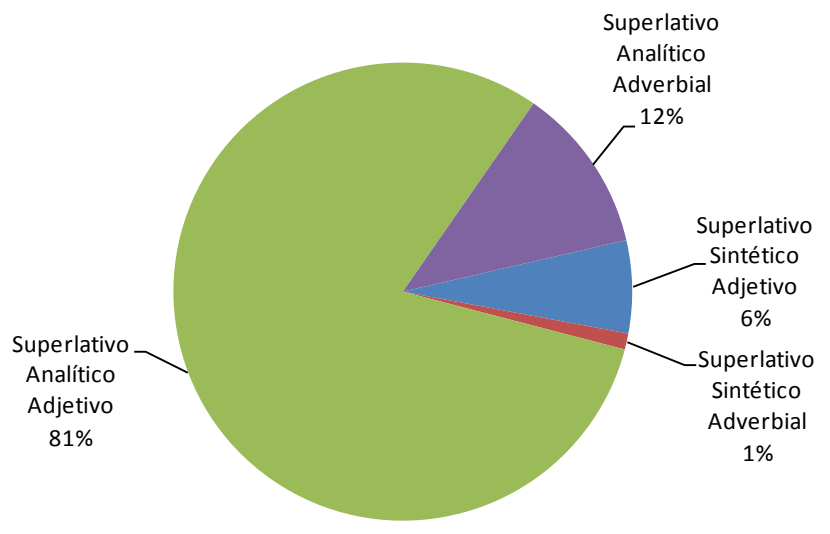

Figura 48. Porcentaje de uso de adjetivos y adverbios superlativos sintéticos y analíticos, según sexo femenino.

\subsubsection{Sexo masculino}

En el caso del sexo masculino, los resultados obtenidos son los siguientes:

1. El adjetivo superlativo analítico registra el mayor uso (79\%).

2. En segundo lugar de porcentaje, está el adjetivo superlativo sintético con $11 \%$ de uso.

3. El adverbio superlativo analítico tiene $9 \%$ de uso.

4. El adverbio superlativo sintético registra el mismo porcentaje que en el sexo femenino (1\%). 


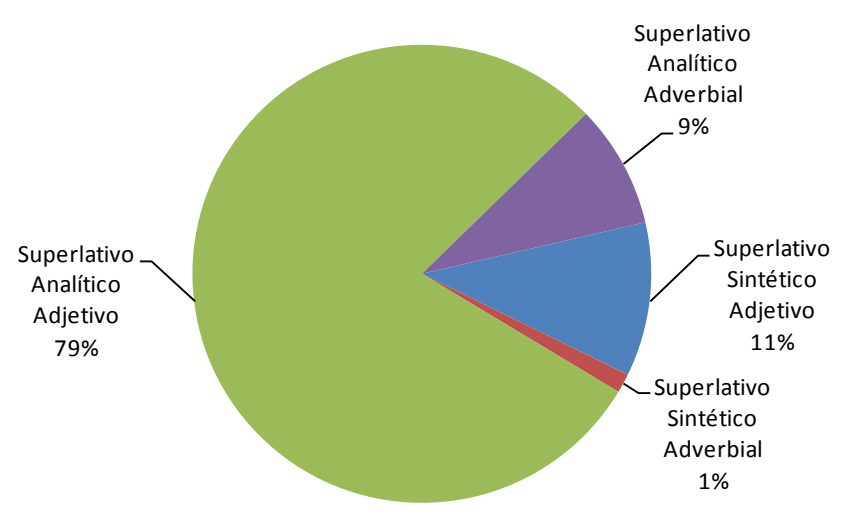

Figura 49. Porcentaje de uso de adjetivos y adverbios superlativos sintéticos y analíticos, según sexo masculino.

\subsubsection{Variable edad}

Los resultados obtenidos en las entrevistas sobre el uso que los hablantes hacen de adjetivos y adverbios superlativos sintéticos y analíticos, según la variable edad, nos muestran que:

1. Los adjetivos superlativos sintéticos, en el tercer grupo etario, que corresponde a los entrevistados de mayor edad, tienen el mayor promedio de uso (2.60), mientras que, en el grupo de los más jóvenes, se registra el menor promedio de uso (1.60).

2. Los adjetivos superlativos analíticos, en el segundo grupo etario tienen un mayor promedio de uso, correspondiente a 24.11. El grupo etario que registra menor promedio de uso (16.60) es el tercero. 
3. Los adverbios superlativos sintéticos registran, en el tercer grupo etario, el mayor promedio de uso (0.60) y el menor promedio corresponde al primero (los más jóvenes), con un promedio de 0.07 .

4. Los adverbios superlativos analíticos, tienen el mayor promedio de uso en el grupo etario número dos, con 2.89, y el menor promedio, en el primer grupo, con 2.07 .

Los resultados antes mencionados pueden observarse en la Tabla 8 y en la Figura 50.

Tabla 8. Medidas descriptivas de adjetivos y adverbios superlativos sintéticos y analíticos, según rango etario.

\begin{tabular}{|c|c|c|c|c|c|}
\hline Superlativos & Medida Descriptiva & 21 a 31 años & 32 a 49 años & 50 a 69 años & Total \\
\hline \multirow{3}{*}{ 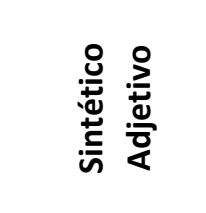 } & Promedio & 1.60 & 2.11 & 2.60 & 2.03 \\
\hline & Desviación Estándar & 1.35 & 2.32 & 2.84 & 2.11 \\
\hline & Coeficiente de Variación & 0.85 & 1.10 & 1.09 & 1.04 \\
\hline \multirow{3}{*}{ 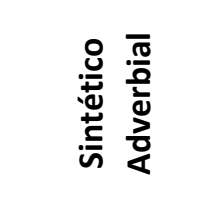 } & Promedio & 0.07 & 0.33 & 0.60 & 0.29 \\
\hline & Desviación Estándar & 0.26 & 0.71 & 1.07 & 0.72 \\
\hline & Coeficiente de Variación & 3.87 & 2.12 & 1.79 & 2.44 \\
\hline \multirow{3}{*}{ 总 } & Promedio & 17.67 & 24.11 & 16.60 & 19.06 \\
\hline & Desviación Estándar & 7.53 & 13.04 & 8.62 & 9.76 \\
\hline & Coeficiente de Variación & 0.43 & 0.54 & 0.52 & 0.51 \\
\hline \multirow{3}{*}{ 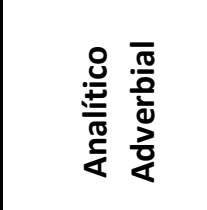 } & Promedio & 2.07 & 2.89 & 2.70 & 2.47 \\
\hline & Desviación Estándar & 1.67 & 2.20 & 1.64 & 1.80 \\
\hline & Coeficiente de Variación & 0.81 & 0.76 & 0.61 & 0.73 \\
\hline
\end{tabular}




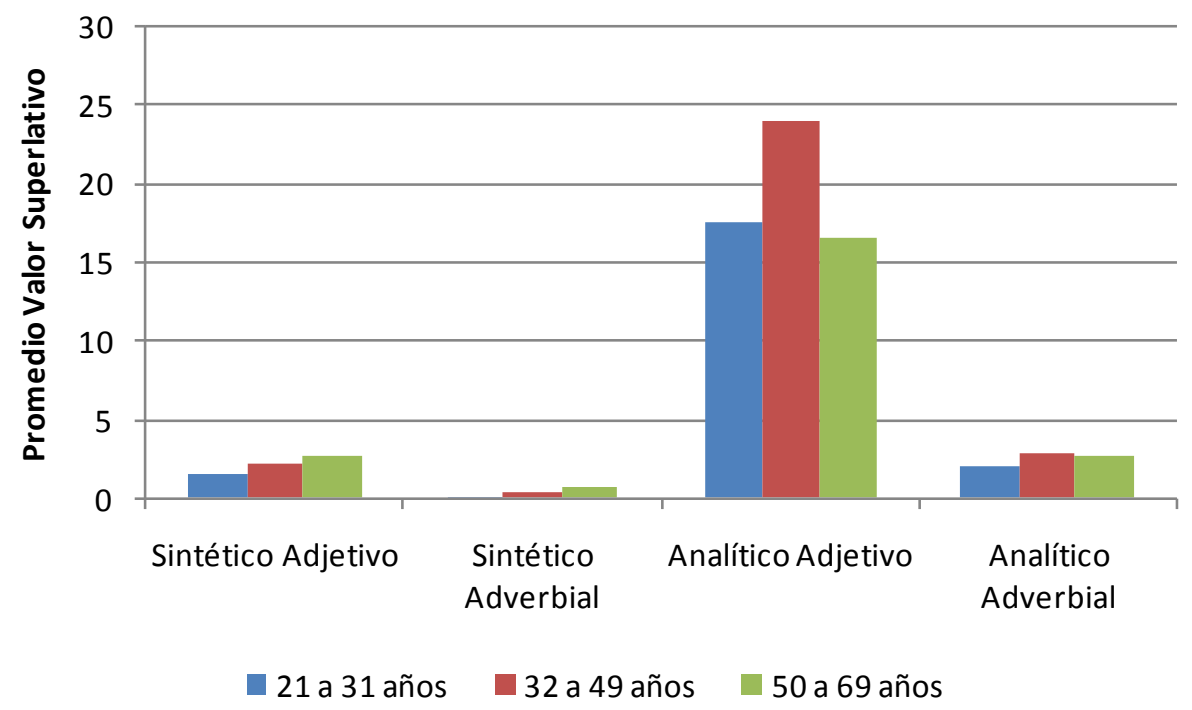

Figura 50. Promedio de uso de adjetivos y adverbios superlativos sintéticos y analíticos, según variable edad.

En cada uno de los grupos etarios, se observan los siguientes resultados de uso de los adjetivos y adverbios sintéticos y analíticos.

\subsubsection{Primer grupo etario.}

En el primer rango etario, correspondiente a los entrevistados cuyas edades median entre 21 y 31 años, los porcentajes de uso de estas formas superlativas, representados en la Figura 26, son los siguientes:

1. Adjetivo superlativo analítico $83 \%$

2. Adverbio superlativo analítico $10 \%$

3. Adjetivo superlativo sintético $7 \%$

4. Adverbio superlativo sintético $0 \%$ 
De acuerdo con estos resultados, se puede decir que el adjetivo superlativo analítico es el que tiene el mayor porcentaje de uso en este grupo etario, mientras que el adverbio superlativo sintético no registra porcentaje de uso.

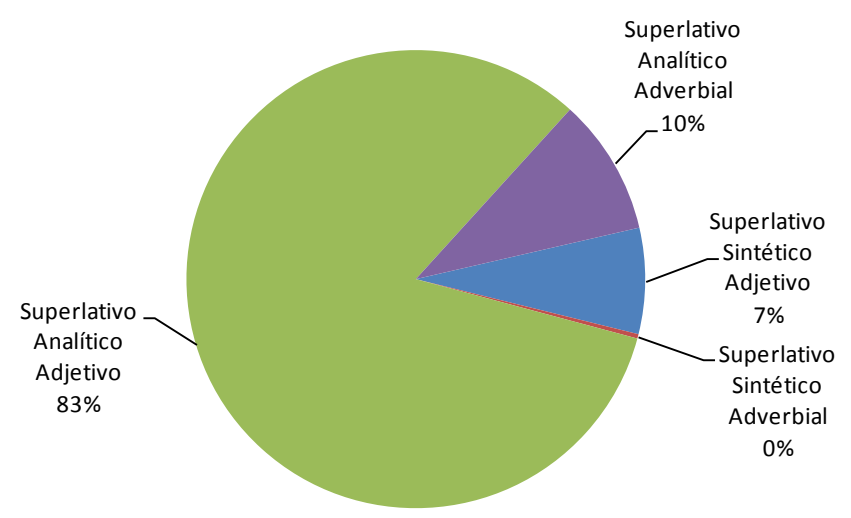

Figura 51. Porcentaje de uso de adjetivos y adverbios superlativos sintéticos y analíticos, según rango etario de 21 a 31 años.

\subsubsection{Segundo grupo etario}

En el segundo grupo etario, se observan resultados semejantes al del grupo anterior. La diferencia se establece en el caso del adverbio superlativo sintético, que registra un $1 \%$ de uso (Figura 52 ).

1. Adjetivo superlativo analítico $82 \%$

2. Adverbio superlativo analítico $10 \%$

3. Adjetivo superlativo sintético $\quad 7 \%$

4. Adverbio superlativo sintético $1 \%$ 


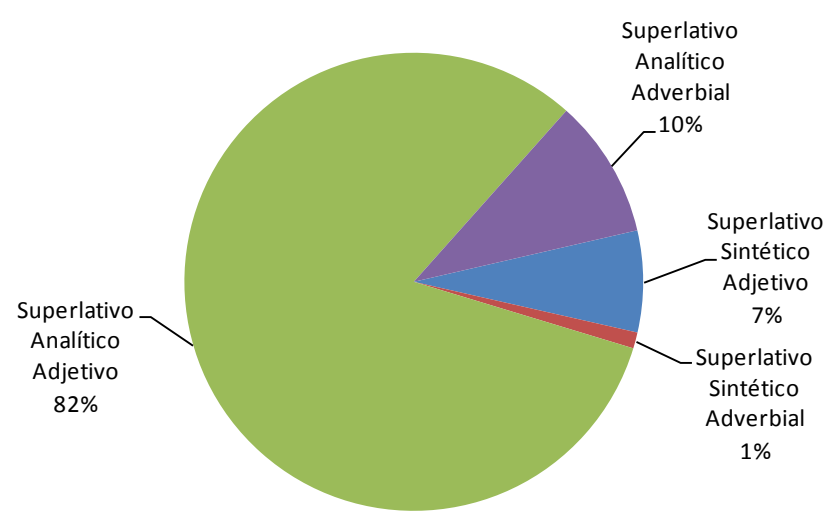

Figura 52. Porcentaje de uso de adjetivos y adverbios superlativos sintéticos y analíticos, según rango etario de 32 a 49 años.

\subsubsection{Tercer grupo etario}

En el último grupo etario, se observan diferencias con los grupos anteriores en cuanto al mayor porcentaje de uso del adjetivo superlativo sintético y del adverbio superlativo sintético (Figura 53).

1. Adjetivo superlativo analítico $74 \%$

2. Adverbio superlativo analítico $12 \%$

3. Adjetivo superlativo sintético $11 \%$

4. Adverbio superlativo sintético $3 \%$ 


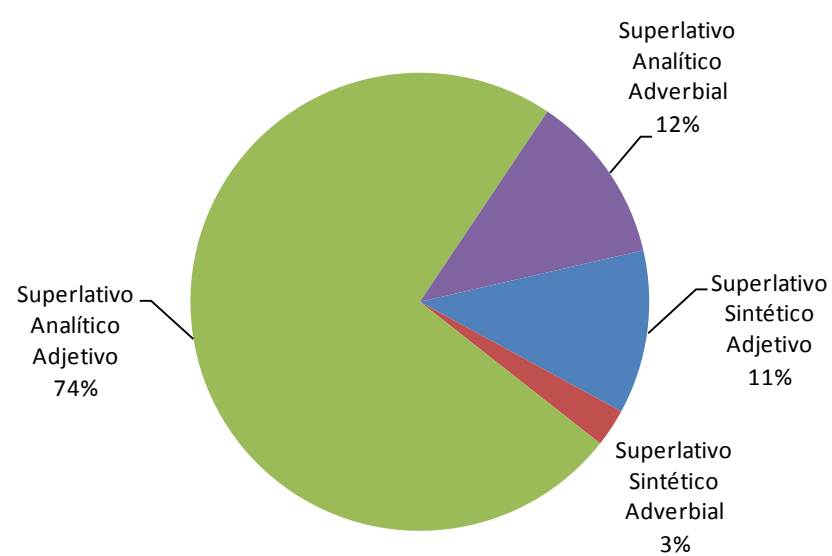

Figura 53. Porcentaje de uso de adjetivos y adverbios superlativos sintéticos y analíticos, según rango etario de 50 a 69 años.

\subsubsection{Variable nivel educacional}

Al analizar los resultados representados en la Tabla 9 y en la Figura 54, se puede observar lo siguiente:

1. Respecto del adjetivo superlativo analítico, el mayor promedio de uso corresponde al nivel educacional medio, con 21.14; y el menor promedio, al nivel universitario, con 18.37 .

2. En el adjetivo superlativo sintético, el mayor promedio de uso corresponde también al nivel medio, con 2.71, y el menor, al nivel técnico, con 1.50.

3. En el adverbio superlativo analítico, el mayor promedio corresponde al nivel universitario con 2.63, y el menor, al nivel medio, con 2.14.

4. La forma adverbial superlativa sintética sólo registra uso en el nivel medio y universitario. De estos niveles, el que tiene mayor promedio de uso es el universitario, con 0.42 . 


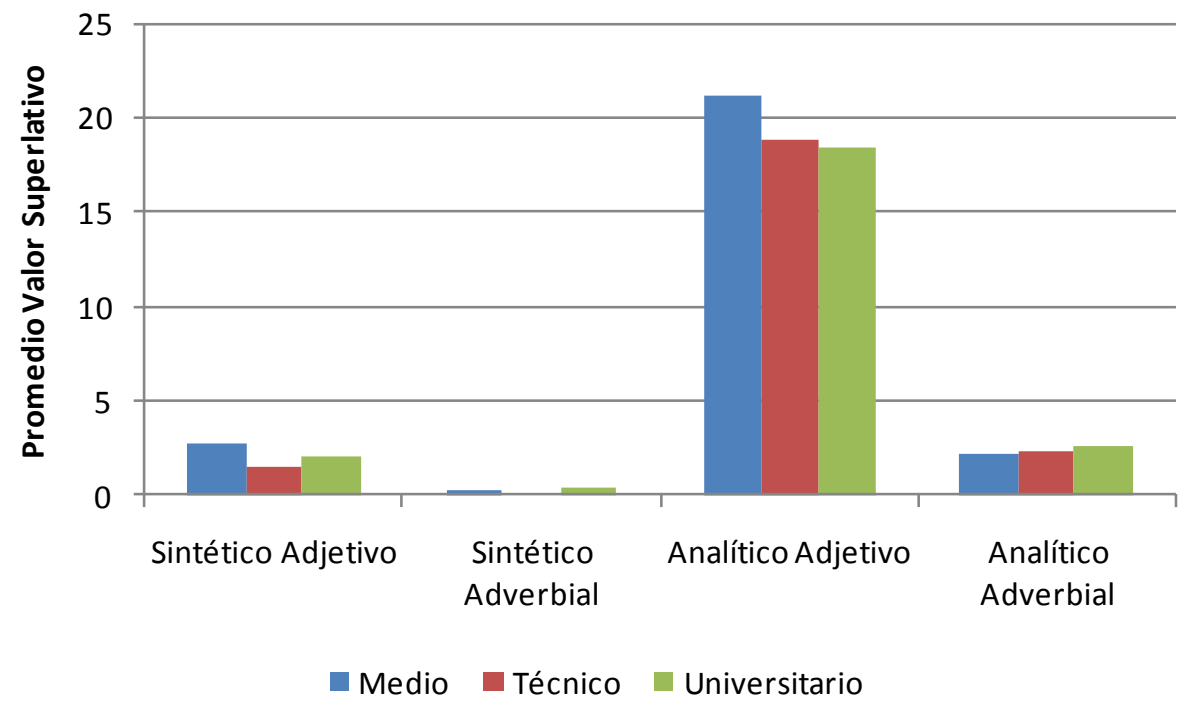

Figura 54. Promedio de uso de adjetivos y adverbios superlativos sintéticos y analíticos utilizados por las personas entrevistadas, según nivel educacional. 
Tabla 9. Medidas descriptivas de adjetivos y adverbios superlativos sintéticos y analíticos, según nivel educacional.

\begin{tabular}{|c|c|c|c|c|c|}
\hline Superlativos & Medida Descriptiva & Medio & Técnico & Universitario & Total \\
\hline \multirow{3}{*}{ 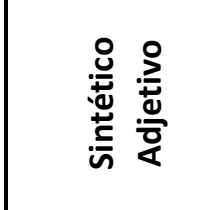 } & Promedio & 2.71 & 1.50 & 2.00 & 2.03 \\
\hline & Desviación Estándar & 2.43 & 1.69 & 2.19 & 2.11 \\
\hline & Coeficiente de Variación & 0.90 & 1.13 & 1.09 & 1.04 \\
\hline \multirow{3}{*}{ 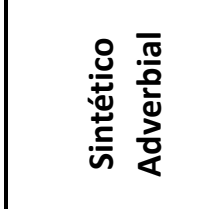 } & Promedio & 0.29 & - & 0.42 & 0.29 \\
\hline & Desviación Estándar & 0.76 & - & 0.84 & 0.72 \\
\hline & Coeficiente de Variación & 2.65 & - & 1.99 & 2.44 \\
\hline \multirow{3}{*}{ 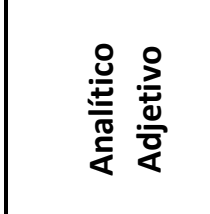 } & Promedio & 21.14 & 18.88 & 18.37 & 19.06 \\
\hline & Desviación Estándar & 8.49 & 8.66 & 10.91 & 9.76 \\
\hline & Coeficiente de Variación & 0.40 & 0.46 & 0.59 & 0.51 \\
\hline \multirow{3}{*}{ 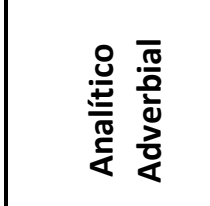 } & Promedio & 2.14 & 2.38 & 2.63 & 2.47 \\
\hline & Desviación Estándar & 1.21 & 2.00 & 1.95 & 1.80 \\
\hline & Coeficiente de Variación & 0.57 & 0.84 & 0.74 & 0.73 \\
\hline
\end{tabular}

Por cada uno de los niveles educacionales, los resultados son los siguientes:

\subsubsection{Nivel educacional medio.}

En este nivel educacional, los resultados graficados en la Figura 55, muestran lo siguiente:

1. El adjetivo superlativo analítico es el que registra el mayor porcentaje (81\%).

2. El adjetivo superlativo sintético tiene $10 \%$ de uso.

3. El adverbio superlativo analítico registra $8 \%$ de uso.

4. El adverbio superlativo sintético es el de menor uso en este nivel (1\%). 


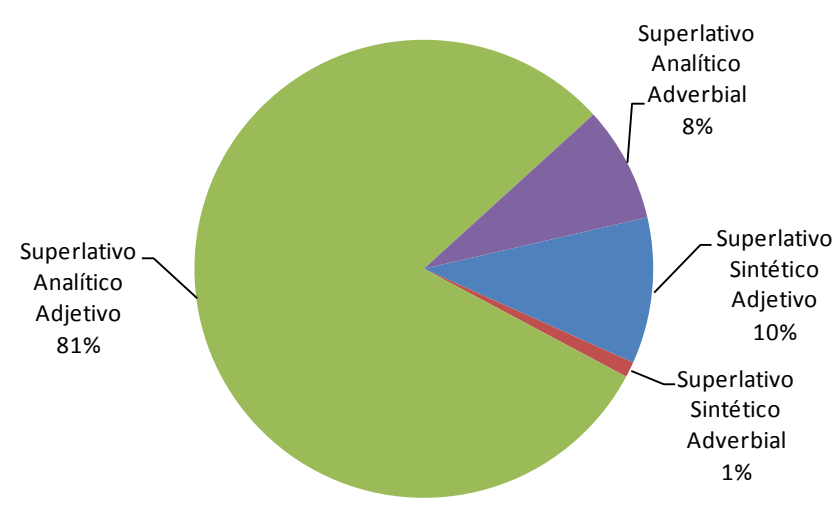

Figura 55. Porcentaje de uso de adjetivos y adverbios superlativos sintéticos y analíticos en entrevistados de nivel educacional medio.

8.2.3.2. Nivel educacional técnico.

De acuerdo con los resultados representados en la Figura 56, el porcentaje de uso es el siguiente:

1. El mayor porcentaje corresponde al adjetivo superlativo analítico con $83 \%$ de uso.

2. El adverbio analítico tiene $10 \%$ de uso.

3. El adjetivo superlativo sintético tiene $7 \%$ de uso.

4. El adverbio superlativo sintético no registra uso.

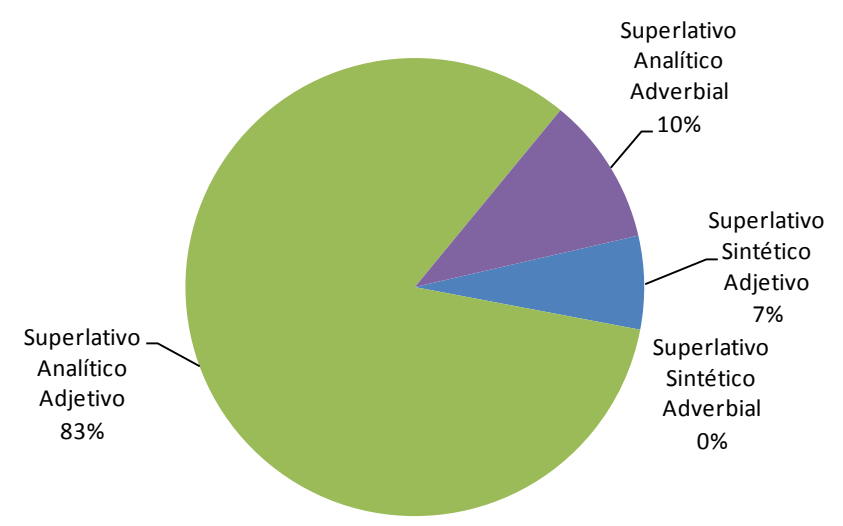

Figura 56. Porcentaje de uso de adjetivos y adverbios superlativos sintéticos y analíticos en entrevistados de nivel educacional técnico. 
8.2.3.3. Nivel educacional universitario.

En este nivel, los porcentajes de uso, representados en la Figura 57, son los siguientes:

1. El adjetivo superlativo analítico es el que registra mayor porcentaje de uso (78\%).

2. En segundo lugar, se encuentra el adverbio superlativo analítico, con $11 \%$ de uso.

3. El adjetivo superlativo sintético tiene $11 \%$ de uso.

4. El adverbio superlativo sintético registra $2 \%$ de uso.

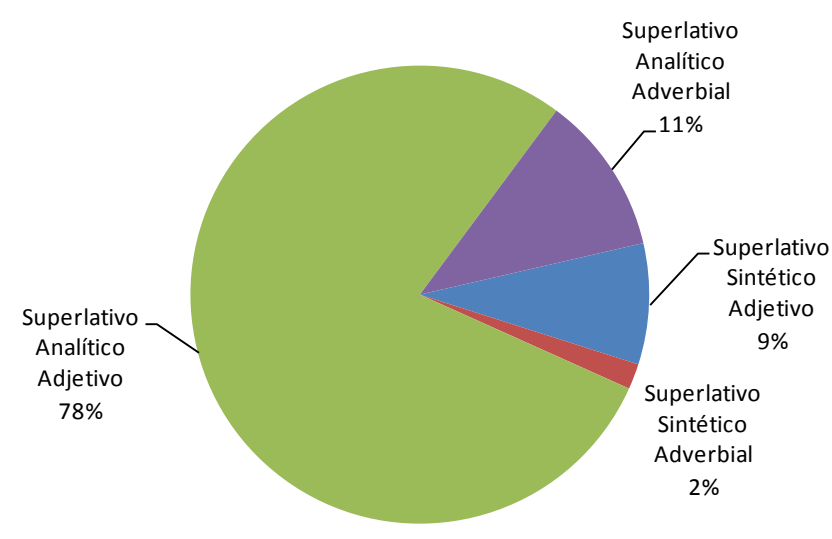

Figura 57. Porcentaje de uso de adjetivos y adverbios superlativos sintéticos y analíticos, según nivel educacional universitario. 


\section{USO DE LÉXICO CON VALOR SUPERLATIVO.}

En la elocución de los entrevistados, se suma, a los superlativos propiamente tales (adjetivos o adverbios), una serie de palabras que tienen un significado claramente superlativo. Entre estos vocablos, se encuentran sustantivos, adjetivos, adverbios y también locuciones adjetivas y adverbiales. Algunos de ellos están incluidos en el Diccionario de la Real Academia Española con este sentido de intensificación significativa, o bien se registra su valor superlativo en diccionarios de chilenismos o de americanismos.

El listado completo de las palabras que corresponden al léxico con valor superlativo se encuentra registrado como Anexo № 1, con la definición extraída de diccionarios y con un ejemplo de uso tomado de la elocución de los entrevistados.

En el corpus de la investigación, se registró un total de 248 palabras y locuciones usadas con este valor superlativo. En la tabla siguiente, se presenta el total de léxico de acuerdo con la categoría gramatical o con la indicación del tipo de locución (adjetiva o adverbial). 
Tabla 10. Número de palabras de léxico con valor superlativo, según categoría gramatical y tipo de locución.

\begin{tabular}{|l|r|}
\hline Función & No Palabras \\
\hline Adjetivo & 174 \\
\hline Adverbio & 52 \\
\hline Locución adjetiva & 2 \\
\hline Locución adverbial & 3 \\
\hline Sustantivo & 17 \\
\hline Total & $\mathbf{2 4 8}$ \\
\hline
\end{tabular}

De acuerdo con los resultados, cuyos porcentajes se representan en la Figura 58, se puede afirmar que los hablantes usaron, mayoritariamente, adjetivos para intensificar su elocución, ya que, de un total de 248 usos, 174 corresponden a adjetivos, lo que equivale a $70 \%$. En segundo lugar, se encuentran los adverbios, con $21 \%$; luego los sustantivos, con $7 \%$, y las locuciones, tanto adjetivas como adverbiales, con $1 \%$.

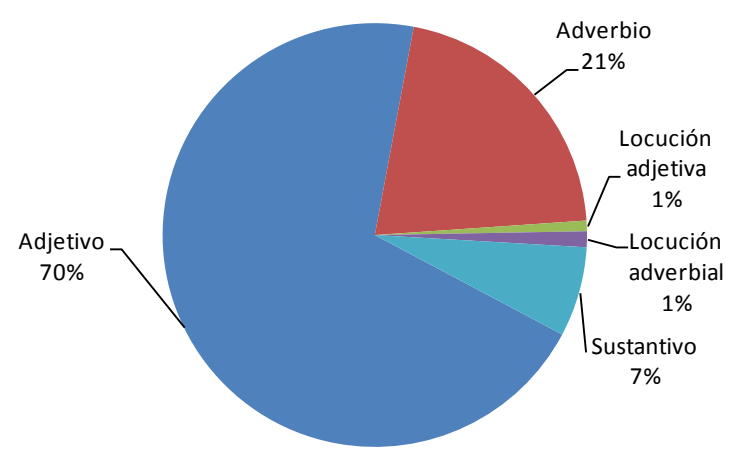

Figura 58. Porcentaje de palabras utilizadas por los entrevistados en léxico con valor superlativo. 
En el siguiente listado, se consignan todas las palabras con valor superlativo, utilizadas por los entrevistados, con la indicación de la categoría gramatical o tipo de locución correspondiente y el número de ocurrencia en las entrevistas.

\begin{tabular}{|l|l|l|}
\hline Palabra & $\begin{array}{l}\text { Categoría gramatical /Tipo de } \\
\text { locución }\end{array}$ & Ocurrencia \\
\hline Absoluto & adjetivo & 2 \\
\hline Amigote & sustantivo & 1 \\
\hline Asqueroso & adjetivo & 1 \\
\hline Atroz & adjetivo & 1 \\
\hline Bacán & adjetivo & 5 \\
\hline Bacán & adverbio & 1 \\
\hline Bastante & Adjetivo & 5 \\
\hline Bastante & Adverbio & 18 \\
\hline Brillante & adjetivo & 1 \\
\hline Brutal & adjetivo & 2 \\
\hline Buen(o) & adjetivo & 1 \\
\hline Caleta & adverbio & 2 \\
\hline Caótica & adjetivo & 1 \\
\hline Caracha & sustantivo & 1 \\
\hline Cataclismo & sustantivo & 1 \\
\hline Cero & adjetivo & 1 \\
\hline Completamente & adverbio & 1 \\
\hline Complicado & adjetivo & 9 \\
\hline Concho(a concho) & locución adverbial. & 1 \\
\hline Cuantioso & adjetivo & 1 \\
\hline Cuesco & sustantivo & 1 \\
\hline Demasiado & adverbio & 8 \\
\hline Demasiado & adjetivo & 2 \\
\hline Desastre & sustantivo & 1 \\
\hline Descueve & sustantivo & 3 \\
\hline Enorme & adjetivo & 1 \\
\hline Entero & adjetivo & 1 \\
\hline Escoba & sustantivo & 2 \\
\hline Espantoso & adjetivo & 1 \\
\hline Espectacular & adjetivo & 3 \\
\hline Estratosférico & adjetivo & 1 \\
\hline Estresante & adjetivo & 1 \\
\hline Estúpido & adjetivo & 1 \\
\hline Eterno & adjetivo & 6 \\
\hline Excelencia (de) & locución adjetiva & \\
\hline Excelente & adjetivo & 1 \\
\hline & & 1 \\
\hline
\end{tabular}




\begin{tabular}{|c|c|c|}
\hline Exorbitante & adjetivo & 1 \\
\hline Exquisito & adjetivo & 1 \\
\hline Extraordinario & adjetivo & 2 \\
\hline Fantástico & adjetivo & 3 \\
\hline Fome & adjetivo & 1 \\
\hline Flojaza & adjetivo & 1 \\
\hline Fundamental & adjetivo & 6 \\
\hline Gigante & adjetivo & 5 \\
\hline Gorilona & adjetivo & 1 \\
\hline Gran(grande) & adjetivo & 3 \\
\hline Grandota & adjetivo & 2 \\
\hline Hecho (tira) & locución adverbial & 1 \\
\hline Harto & adverbio & 20 \\
\hline Harto & adjetivo & 27 \\
\hline Heavy & adjetivo & 3 \\
\hline Histérica & adjetivo & 1 \\
\hline Horrible & adjetivo & 7 \\
\hline Increíble & adjetivo & 5 \\
\hline Infinita & adjetivo & 1 \\
\hline Inmensa & adjetivo & 2 \\
\hline Irrestricto & adjetivo & 1 \\
\hline Largo & adjetivo & 1 \\
\hline Maravilla & sustantivo & 1 \\
\hline Maravilloso & adjetivo & 4 \\
\hline Medio & adjetivo & 1 \\
\hline Millonada & sustantivo & 2 \\
\hline Mucho & adjetivo & 2 \\
\hline Mugre & sustantivo & 1 \\
\hline Multifacético & adjetivo & 2 \\
\hline Multifuncional & adjetivo & 1 \\
\hline Película (de) & locución adjetiva & 1 \\
\hline Perfecto & adjetivo & 1 \\
\hline Perfecto & adverbio & 1 \\
\hline Picante & adjetivo & 1 \\
\hline Precioso & adjetivo & 2 \\
\hline Principal & adjetivo & 1 \\
\hline Puro & adjetivo & 1 \\
\hline Raja (la) & locución adverbial & 1 \\
\hline Rico & adjetivo & 2 \\
\hline Ridículo & adjetivo & 2 \\
\hline Seco & adjetivo & 2 \\
\hline Talentoso & adjetivo & 3 \\
\hline Tanto & adverbio & 2 \\
\hline Terrible & adjetivo & 9 \\
\hline Titánico & adjetivo & 1 \\
\hline
\end{tabular}




\begin{tabular}{|l|l|l|}
\hline Total & adjetivo & 3 \\
\hline Totalmente & adverbio & 1 \\
\hline Traumático & adjetivo & 2 \\
\hline Tremendo & adjetivo & 9 \\
\hline Triple & sustantivo & 1 \\
\hline Trucho & adjetivo & 2 \\
\hline
\end{tabular}

\subsection{Léxico con mayor número de ocurrencia}

En la siguiente figura, se presentan las 20 palabras de mayor ocurrencia en las entrevistas realizadas. La mínima ocurrencia del vocablo considerada para el análisis es de 3 veces. Las restantes palabras usadas por los entrevistados con menos de tres ocurrencias se encuentran, como ya se ha dicho, en el listado de léxico con valor superlativo, incorporado como Anexo 1.

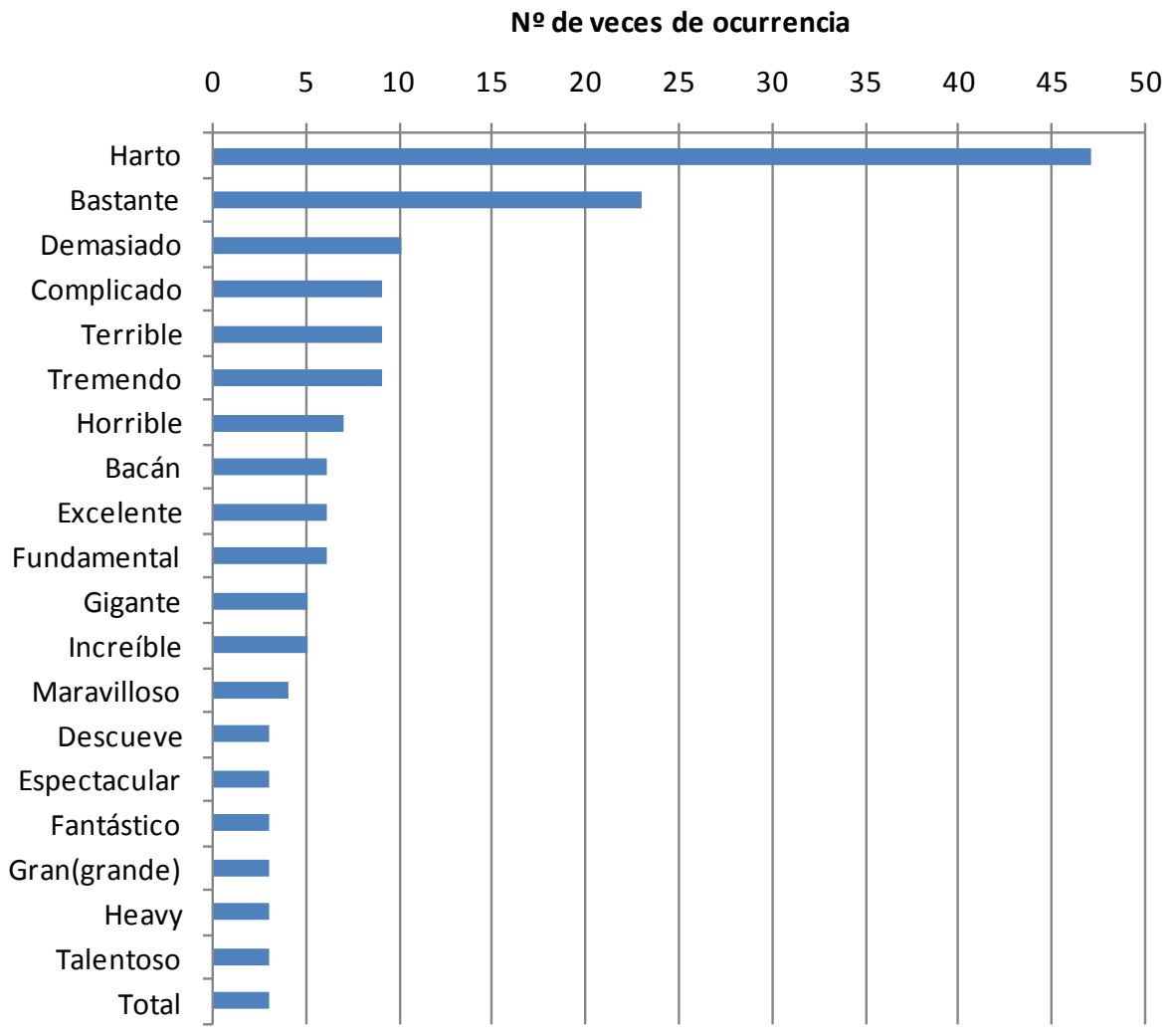

Figura 59. Palabras de léxico con valor superlativo más utilizadas por los entrevistados. 
A continuación, se realiza un análisis cuantitativo de cada uno de los 20 vocablos con valor superlativo más usados por los entrevistados.

\subsubsection{Harto}

Al observar los resultados representados en la Figura 59, se puede constatar que los hablantes de las entrevistas realizadas tienen una marcada preferencia por el uso de "harto". Como adjetivo es usado 27 veces y como adverbio, 20 veces. El valor superlativo de este vocablo se encuentra registrado en el DRAE y también en el DECH.

Harto, ta : *adj. //2. Bastante o sobrado (DRAE, pág. 696). Ej. "Aparte de que se hizo harta parafernalia con ; Vamos, Chile!, creo que la gente se paró. Me refiero a que la gente se unió." (Entrevista № 22).

* adv. cant. pond. coloq. Mucho o muy; con abundancia, en gran cantidad (Nuevo Diccionario Ejemplificado de Chilenismos, DECH, pág. 1334). Ej.: "Me ayudaron harto unos amigos míos y... uno de ellos también me dijo: yo prefiero que sufrai ahora... y que no seai un amargado toda la vida". (Entrevista № 9).

\subsubsection{Bastante}

Este vocablo registra un total de 23 usos: 18 como adverbio y 5 como adjetivo. Está definido en el Diccionario de la RAE como participio activo del verbo bastar y como adverbio. 
Bastante:* adj. p.a. de bastar. Que basta (DRAE, pág.170). Ej.: "Tengo bastante paciencia" (Entrevista № 13).

* adv. // 3. No poco (DRAE, pág. 170). Ej. "Ahora se ha perdido bastante el respeto a los papás sobre todo y a los adultos mayores en general". (Entrevista № 17).

\subsubsection{Demasiado}

Este término es usado por los entrevistados como adverbio 8 veces y como adjetivo, 2 veces. Su valor superlativo se registra en el DRAE.

Demasiado, -a: *adj. Que es en demasía o tiene demasía (DRAE, pág. 431). Ej.: “... o sea que es bastante poco pa' producciones como Machuca o como el mismo La Buena Vida que son películas que Andrés Wood gasta demasiada plata, demasiada y que yo creo que recupera un tercio si no un doceavo de todo lo que invirtió”..(Entrevista № 27).

* 3. Adv. c. en demasía. Ej. “...habían un... un dibujante que ponía los monos y los mandaban por Internet y todo el cuento, pero el de ella era demasiado pesado, se tuvo que quedar con el mono ahí nomás, porque era muy pesado, pesaba demasiado, pesaba cuatro veces más de lo que exigía". (Entrevista №1).

\subsubsection{Complicado}

Este adjetivo registra 9 usos por parte de los entrevistados. Su valor semántico está definido en el DRAE. 
Complicado,-da: adj. Enmarañado, de difícil comprensión. (DRAE, pág. 605). Ej.: "Eeh..., económicamente el país ha tenido altos, altos y bajos... Pienso, pienso que es un momento complicado el, el que se está viviendo," (Entrevista № 23).

\subsubsection{Terrible}

Adjetivo que los entrevistados usaron en 9 ocasiones y cuyo valor superlativo está registrado en el diccionario académico.

Terrible: //. adj. 3 Muy grande o desmesurado. (DRAE, pág. 1259). Ej.: "Terrible, terrible ha sido toda esta situación, porque estar lejos de la familia y haber conocido a alguien que falleció en ... con el tsunami, fue terrible". (Entrevista № 15).

\subsubsection{Tremendo}

Este adjetivo es usado por los entrevistados en 9 ocasiones. En su significado, ya aparece el valor superlativo con el que es usado en el habla coloquial.

Tremendo,-da. // 4. coloq. Muy grande y excesivo en su línea. (DRAE, pág. 2223). Ej.: "Por una bendición, eeh, no suficientemente agradecida, ellos se autosustentan, no digo económicamente, pero síi en cuanto a que no están inhabilitados, son autovalentes. $Y$ esa es una cuestión quee, ¡Uuuh!, es tremenda, o sea tremenda de valor, Ah!, uno no lo, no lo 
valora en tanto no viva lo contrario, o, o vea por lo menos a otro que vive lo contrario". (Entrevista № 30).

\subsubsection{Horrible}

Adjetivo que se encuentra usado 7 veces en la elocución de los entrevistados. El Diccionario de la RAE consigna su valor superlativo en el habla coloquial.

Horrible: adj. 2. coloq. Muy feo. /3. coloq. Muy intenso o acentuado. /4. coloq. Muy malo, pésimo. (DRAE. Ej.: "Fue una experiencia horrible, tuvimos que estar durmiendo como una semana en otra casa,...” (Entrevista № 6).

\subsubsection{Bacán}

Vocablo que es de uso habitual entre los hablantes chilenos jóvenes con el valor superlativo de algo "muy bueno". En las entrevistas, se registran 6 usos del término: una vez como adverbio y 5 veces como adjetivo.

Bacán,- na: I. 2. adj. Cu. Ec. Pe. Ch. juv. Referido a persona o cosa muy buena, estupenda. (Diccionario de Americanismos, pág. 189) Ej.: "Somos muy cariñosos, mantenemos una comunicación bacán" (Entrevista №31).

\subsubsection{Excelente}

Adjetivo considerado por la RAE dentro del grupo de adjetivos elativos léxicos. En la elocución de los entrevistados aparece usado 6 veces. 
Excelente: adj. Que sobresale en bondad, mérito o estimación entre las cosas que son buenas en su misma especie (DRAE, pág. 594). Ej.: "El compadre estudia y resulta que es un excelente historiador, está estudiando historia y el compadre es seco y gran profesor de historia..." (Entrevista № 27).

\subsubsection{Fundamental}

Este adjetivo registra 6 usos entre los entrevistados. Su valor superlativo se encuentra en la definición consignada en el diccionario.

Fundamental: adj. Que sirve de fundamento o es lo principal en una cosa (DRAE, pág. 642). Ej.: "...el estudiar turismo fue netamente, porque yo ya viví en otro país y sé lo que es el turismo y ya tengo idiomas, que es una parte fundamental en un país como que es Chile". (Entrevista № 6).

\subsubsection{Gigante}

Adjetivo usado 5 veces por los entrevistados y cuyo valor superlativo se encuentra lexicalizado.

Gigante: adj. Gigantesco //. 2. Mucho mayor que lo considerado como normal. (DRAE, pág. 1135). Ej.: "Entonces no, no, no muestran, no hay un cartel como poderoso afuera como hace el cine Hoyts, que pone unos lienzos gigantes "hoy miércoles, vuelve un clásico del cine a mil quinientos", o sea, ahí está el punto". (Entrevista №27). 
9.1.12. Increíble

Esta palabra es usada en 5 ocasiones por los entrevistados. La Gramática de la Real Academia lo considera elativo léxico y el diccionario lo registra con valor superlativo.

Increíble: adj. // 2. Muy difícil de creer. (DRAE, pág. 1264). Ej.: "Porque no le prestó atención, le tiró un jarro con agua a la autoridad. O sea, la falta de respeto increíble”. (Entrevista № 21).

\subsubsection{Maravilloso}

Adjetivo que registra 4 usos en la elocución de los entrevistados. La GRAE lo incluye en el grupo de los adjetivos elativos léxicos.

Maravilloso, sa. (De maravilla). adj. Extraordinario, excelente, admirable (DRAE, pág.1450). Ej.: "Casada dos veces, tengo dos hijos maravillosos: uno de 19, estudia Pedagogía en Inglés, en la Viña del Mar, y otro de 13, está en $8^{\underline{a}}$ Básico en el Colegio San Nicolás, que llenan mi vida, son mi orgullo completamente”(Entrevista № 21).

\subsubsection{Descueve}

Este sustantivo masculino es usado, en el habla coloquial de Chile, con un claro valor superlativo. En las entrevistas, es usado en 3 oportunidades. Su significado está registrado en el Nuevo Diccionario Ejemplificado de Chilenismos (DECH). 
Descueve (el): m. sing. fig. pond. coloq. El colmo, el sumo, el grado más alto al que se puede llegar una cosa, como para producir notable impresión. (Nuevo Diccionario Ejemplificado de Chilenismos, DECH, pág. 877). Ej. “, pero este gallo era en realidad el descueve". (Entrevista N5).

\subsubsection{Espectacular}

Es un adjetivo que los hablantes usan con un valor claramente superlativo. Se registran 3 usos de él.

Espectacular: adj. fig. coloq. Maravilloso, magnífico, sorprendente. (Nuevo Diccionario Ejemplificado de Chilenismos, DECH, pág.1064). Ej.: "Pero, finalmente tú puedes decir, ya pero como museos son espectaculares, ¿cachai?, son espectaculares, no sé, yo nunca he ido, ¿cachai?”. (Entrevista № 28).

\subsubsection{Fantástico}

Adjetivo que es usado en 3 ocasiones por los entrevistados y cuyo valor superlativo está consignado en el Diccionario de la RAE.

Fantástico, -a: adj.// 4. coloq. Magnífico, excelente. (DRAE, pág. 1039). Ej. “Tengo tres nietos fantásticos". (Entrevista №29).

9.1.17. Gran (grande) 
Este adjetivo es usado en 3 ocasiones por los entrevistados. Se registra tanto en la forma apocopada como no apocopada.

Gran(de):adj. que excede a lo común y regular (DRAE, pág. 675).Ej. “...me preparé yo, o sea, egresé del Colegio Rubén Castro y el Colegio Rubén Castro me dio la gran oportunidad de ver en qué consistía la parte administrativa,..." (Entrevista №23).

9.1.18. Heavy

Dentro del grupo de palabras con este valor superlativo, se registra el uso de palabras de origen extranjero que los hablantes utilizan en su habla coloquial. Tal es el caso de "heavy", anglicismo que los entrevistados usan en 3 ocasiones, con el significado de extraordinario, muy bueno, tremendo, etc. Este adjetivo es definido por el Diccionario de Americanismos, como una voz inglesa usada en el habla juvenil de Chile, con un claro valor ponderativo.

Heavy: adj. 1. Pesado, de mucho peso. // 7. Grave, serio; de peso, importante, considerable. (International Dictionary English/Spanish, pág.935).

Heavy: Voz inglesa. I. 1. adj. Ch. juv. referido a cosa, muy buena, excelente. (Diccionario de Americanismos, pág. 1134). Ej.: "Ahora trato de no hacerlo tanto, disfrutar el día a día, peroooo, pero no sé, por el momento me veo obviamente con, con mi pololo, con el Enrique, juntos yyy, no sé, eeh, espero 
con una pega heavy, que sea estable, que no tenga que estar estresada,..." (Entrevista 31).

9.1.19. Talentoso

Adjetivo usado en 3 ocasiones, con valor superlativo equivalente a "con muchísimo talento".

Talentoso, sa: adj. Que tiene talento, ingenio, capacidad y entendimiento (DRAE, pág. 1239). Ej.: "Armamos un equipo pero pa`qué te digo que el descueve, gente talentosa..." (Entrevista № 5).

\subsubsection{Total}

Adjetivo que es usado 3 veces. Su valor superlativo se encuentra registrado en el Diccionario de Chilenismos de Félix Morales Pettorino, como una palabra de uso ponderativo en el habla coloquial.

Total: adj. pond. coloq. Absoluto, extremo, categórico (Nuevo Diccionario Ejemplificado de Chilenismos, $\mathrm{DECH}$, pág. 3042). Ej.: “..., cuando yo llegué, era un desorden total, así muy, muy desordenado". (Entrevista № 8). 
9.2. Léxico con valor superlativo según variables sociolingüísticas de sexo, edad y nivel educacional

Se realiza a continuación un análisis cuantitativo de uso del léxico con valor superlativo, en primer lugar, de acuerdo con la variable sexo; luego, según la variable edad; y, por último, de acuerdo con el nivel educacional de los entrevistados.

\subsubsection{Variable sexo.}

Según los resultados obtenidos, se puede afirmar que las mujeres entrevistadas registran un porcentaje mayor de uso de palabras con valor superlativo que los hombres. Como puede observarse en la Figura 60 , el sexo femenino registra $58 \%$ de uso, mientras que el masculino $42 \%$.

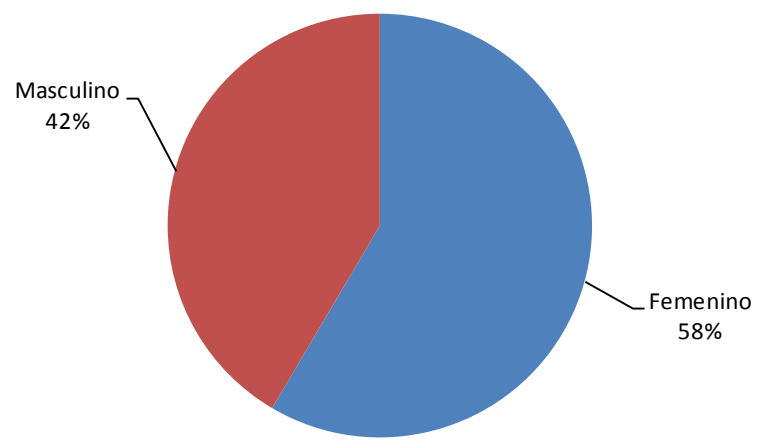

Figura 60. Porcentaje de palabras de léxico con valor superlativo utilizadas por los entrevistados, según sexo.

El uso por cada una de las categorías gramaticales de acuerdo con la variable sexo se representa en la siguiente figura. 


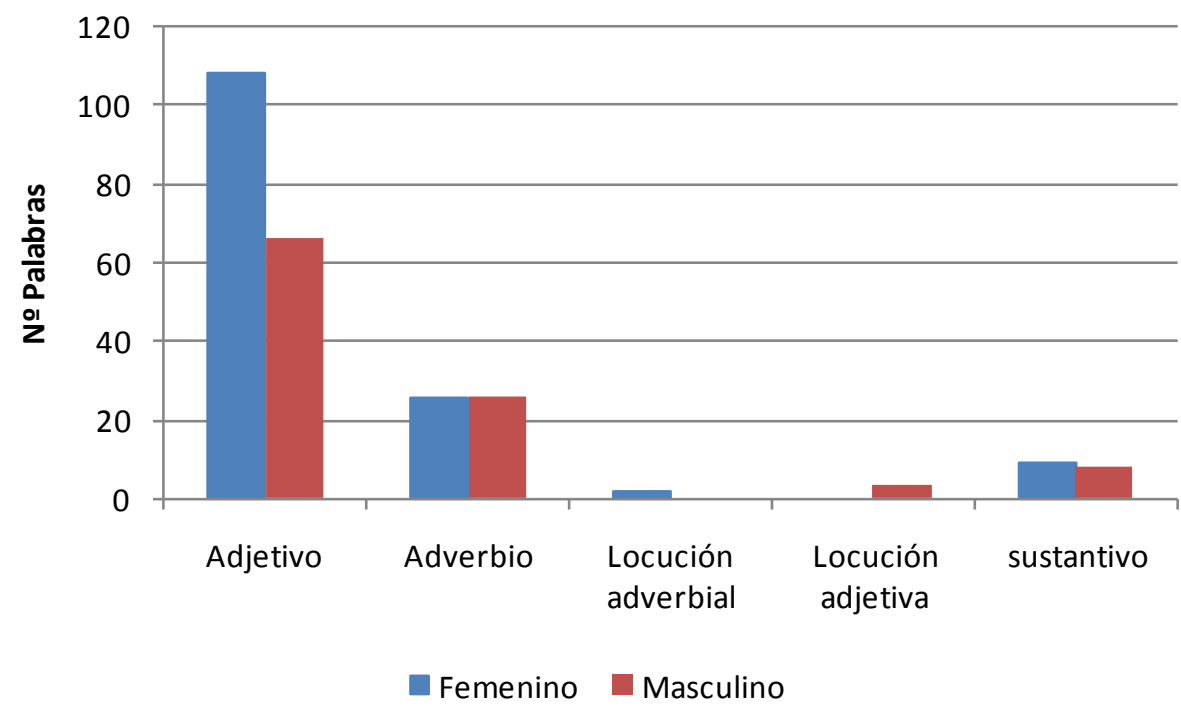

Figura 61. Número de palabras de léxico con valor superlativo, según categoría gramatical y variable sexo.

En concordancia con la estadística presentada, se puede decir lo siguiente:

1. Las personas de sexo femenino tienen mayor uso de léxico con valor superlativo correspondiente a las categorías de adjetivo y sustantivo.

2. El léxico con valor superlativo correspondiente a la categoría adverbio registra la misma cantidad de uso por hombres y por mujeres.

3. La locución adverbial es usada sólo por el sexo femenino.

4. La locución adjetiva es sólo usada por el sexo masculino.

\subsubsection{Variable edad}

Al realizar el análisis estadístico del léxico con valor superlativo, de acuerdo con la variable edad, se obtienen los siguientes porcentajes de uso, por cada uno de los grupos etarios. Estos porcentajes se encuentran representados en las figuras correspondientes. 


\subsubsection{Primer grupo etario}

1. En este grupo, los adjetivos con valor superlativo tienen claramente el mayor porcentaje de uso (75\%).

2. El adverbio con valor superlativo alcanza $18 \%$.

3. El sustantivo con valor superlativo registra $4 \%$ de uso.

4. Las locuciones adverbiales y adjetivas registran un porcentaje menor ( $2 \%$ y $1 \%$ respectivamente).

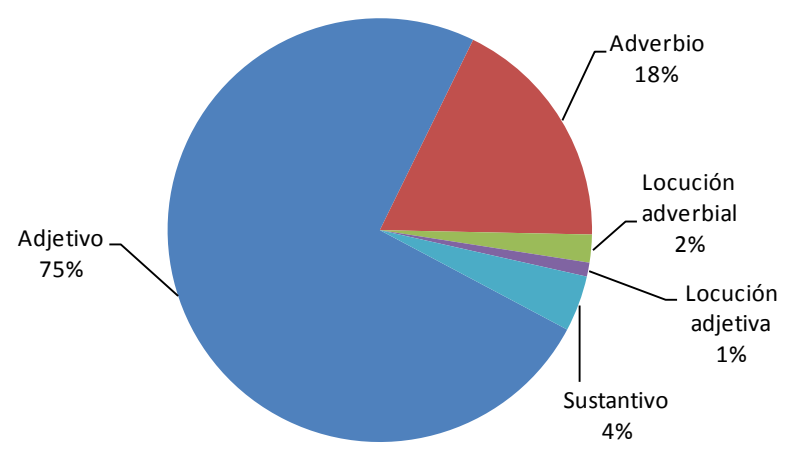

Figura 62. Porcentaje de léxico con valor superlativo utilizado por entrevistados con rango etario 21 a 31 años.

\subsubsection{Segundo grupo etario}

1. Los entrevistados de este grupo etario registran el mismo porcentaje de uso de adjetivos con valor superlativo que el primer grupo (75\%).

2. El adverbio con valor superlativo tiene $21 \%$ de uso.

3. El sustantivo con este valor alcanza sólo $4 \%$ de uso.

4. Las locuciones adjetivas y adverbiales no son usadas por los entrevistados de este grupo etario. 


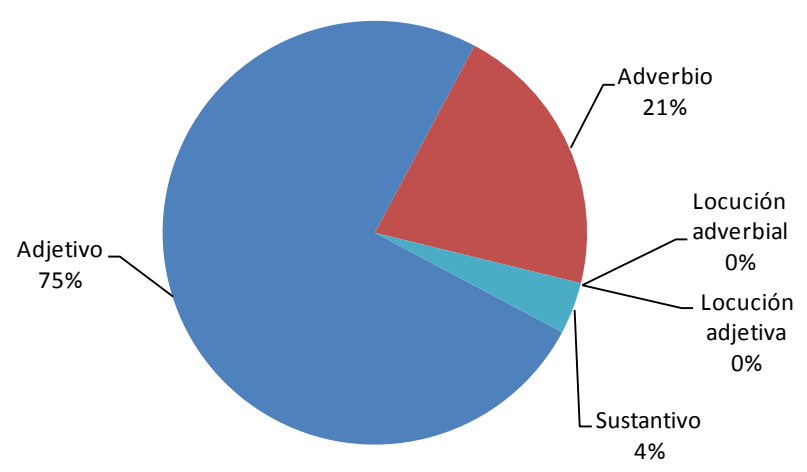

Figura 63. Porcentaje de Léxico con valor superlativo utilizado por entrevistados con rango etario 32 a 49 años.

\subsubsection{Tercer grupo etario}

1. En este grupo etario, el adjetivo tiene $60 \%$ de uso.

2. El adverbio registra $24 \%$ de uso.

3. El sustantivo tiene $13 \%$ del total de uso.

4. La locución adjetiva tiene $3 \%$ de uso.

5. La locución adverbial no es usada por los entrevistados de este grupo etario.

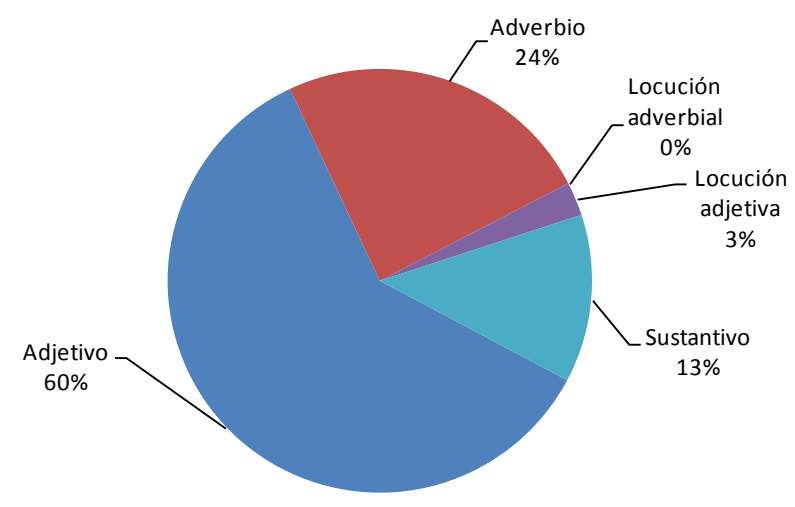

Figura 64. Porcentaje de léxico con valor superlativo utilizado por entrevistados con rango etario 50 a 69 años. 
9.2.13. Variable nivel educacional

El análisis de los datos de acuerdo con la variable nivel educacional proporciona los siguientes resultados por cada nivel educacional.

\subsubsection{Nivel medio}

1. Los entrevistados de este nivel educacional tienen un uso mayoritario de adjetivos con valor superlativo (62\%).

2. En segundo término, emplean los adverbios con valor superlativo (33\%).

3. El sustantivo registra un uso de $5 \%$.

4. Las locuciones, tanto adverbiales como adjetivas no registran uso en este nivel educacional.

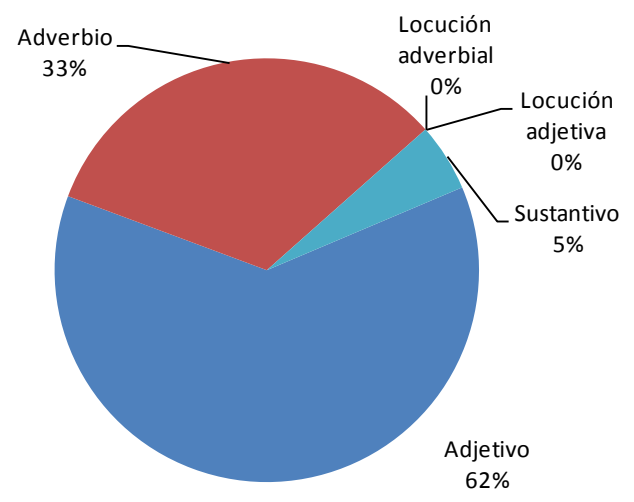

Figura 65. Porcentaje de léxico con valor superlativo utilizado por entrevistados con nivel educacional medio.

\subsubsection{Nivel técnico}

1. En este nivel, el adjetivo con valor superlativo es el que registra el mayor porcentaje de uso (69\%). 
2. El adverbio registra $25 \%$ de uso.

3. El sustantivo con valor superlativo tiene $4 \%$ de uso.

4. La locución adjetiva registra $2 \%$.

5. Los entrevistados de este nivel no usan la locución adverbial.

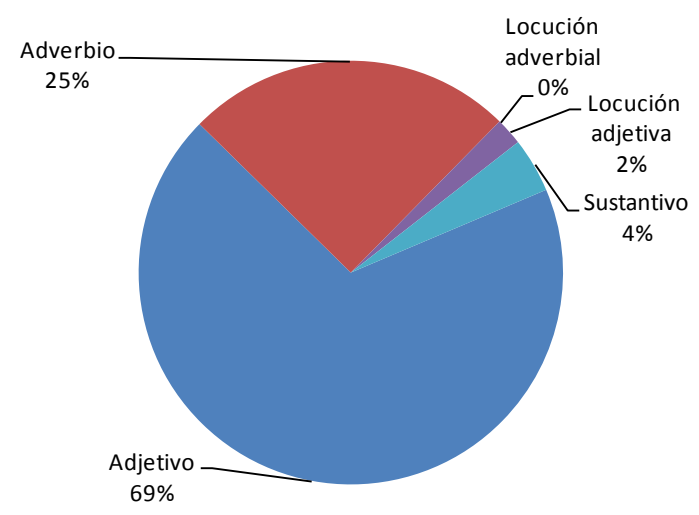

Figura 66. Porcentaje de léxico con valor superlativo utilizado por entrevistados con nivel educacional técnico.

\subsubsection{Nivel universitario}

1. En este nivel, el adjetivo con valor superlativo tiene el mayor porcentaje (74\%).

2. El adverbio con valor superlativo alcanza un $15 \%$.

3. El sustantivo con valor superlativo tiene $9 \%$ de uso.

4. Las locuciones, tanto adjetivas como adverbiales, no registran usos. 


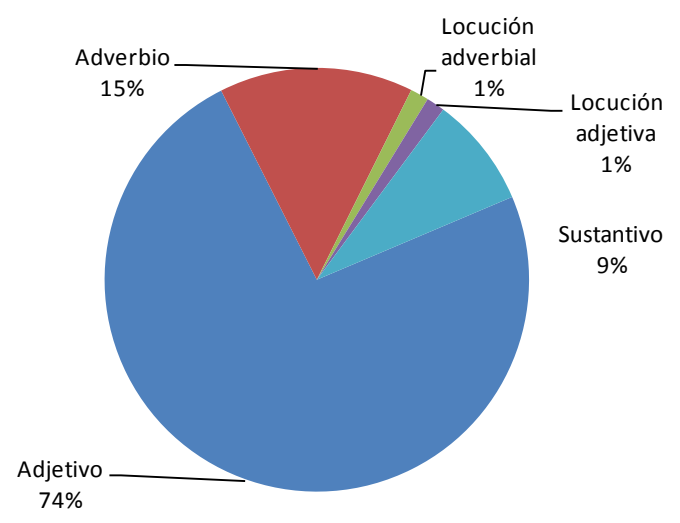

Figura 67. Porcentaje de léxico con valor superlativo utilizado por entrevistados con nivel educacional universitario. 


\section{RECURSOS ESTILÍSTICOS CON VALOR SUPERLATIVO}

Dentro de los recursos estilísticos usados por los hablantes de las entrevistas realizadas, se encuentran reiteraciones, hipérboles, metáforas y comparaciones. Estos

recursos son empleados por los entrevistados con la intención de dar mayor énfasis a lo expresado.

Los 106 recursos utilizados en las 34 entrevistas se registran en la siguiente tabla, con la especificación del tipo de recurso empleado. 
10.1. Listado de recursos estilísticos con valor superlativo.

LISTADO DE RECURSOS REGISTRADOS

1. Unos poemas horribles, horribles

2. Ella era un ostracismo

3. La gente cabezona, cabezona

4. Intelectual, intelectual

5. Va a ser puro puro

6. Formato original original

7. Personas bastante, bastante amplias

8. Millones y millones

9. Es grito y plata

10. Era para llorar

11. Es pero ya pa' decir basta

12. Harto, harto profe gringo

13. Es escoger con pinzas

14. Yo era chico, chico

15. Una cosa como de segundos

16. Una profesora francesa francesa

17. Es como más

18. Era como bien diverso

19. Es más cerrado, más cerrado

20. Pero está a punto

21. Una experiencia que no se la doy a nadie

22. Yo ya estaba ya agotado
TIPO DE RECURSO

Reiteración

Metáfora

Reiteración

Reiteración

Reiteración

Reiteración

Reiteración

Reiteración

Metáfora

Hipérbole

Hipérbole

Reiteración

Hipérbole

Reiteración

Comparación

Reiteración

Comparación

Comparación

Reiteración

Hipérbole

Hipérbole

Reiteración 
23. Es muy... es muy...

Reiteración

24. Pero hasta con cinco candados.

Hipérbole

25. Bien así... car'e palo

Metáfora

26. Se sentía como orgullosa

Comparación

27. Así muy, muy desordenado

Reiteración

28. Me sacrificaba mucho, mucho, mucho.

Reiteración

29. Era un bastión pa‘mí

Metáfora

30. Costó harto, costó harto

Reiteración

31. Era como que había tocado fondo

Comparación

32. Entonces hay harto, harto trabajo

Reiteración

33. Estaba muy, muy feliz

Reiteración

34. Era un canguro saltando

Metáfora

35. Era una pulga todo el día

Metáfora

36. Yo corría y corría y corría

Reiteración

37. Como tres horas puro corriendo

Hipérbole

38. Yo quedaba muerta, muerta

Reiteración

39. Mi hermana también un pan de Dios.

Metáfora

40. Se te achicó así ( el sueldo)

Hipérbole

41. Está con su problema hasta más arriba

Hipérbole

42. Estar muy agradecida, muy, muy agradecida

Reiteración

43. Súper, súper fuerte

Reiteración

44. Es increíble, increíble

Reiteración

45. Quedó para la historia

Hipérbole

46. Casi me morí

Hipérbole

47. Estaba solita, estaba solita

Reiteración 
48. Hace muchos, muchos años

49. Es muy negativo, muy negativo

Reiteración

50. Es muy raro, muy raro

Reiteración

51. Yo le agradezco mucho, mucho

Reiteración

52. Me da un miedo terrible, terrible, terrible, terrible

Reiteración

53. Estaban muy buenos médicos, muy buenos

Reiteración

54. Fue muy, muy molesto

Reiteración

55. Yo sufrí mucho, mucho, mucho

Reiteración

56. Quedaba muerta de hambre

Hipérbole

57. Eran súper carnívoros, carnívoros

Reiteración

58. Es lo más madura del mundo

Hipérbole

59. Muchas alegrías, muchas alegrías

Reiteración

60. Lo tomé muy a pecho

Metáfora

61. Me lo tomé muy a pecho

Metáfora

62. Se fuera a acabar el mundo

Hipérbole

63. Es una cosa increíble, es una cosa increíble

Reiteración

64. Que son muy buenos, que son muy buenos

Reiteración

65. Si uno no está muy, muy, como muy claro

Reiteración

66. Se cayó un edificio completo, completo

Reiteración

67. Es una de las grandes, grandes industrias

Reiteración

68. Es fundamental, es fundamental la parte deportiva.

Reiteración

69. Trabajando hasta las últimas consecuencias

Hipérbole

70. Lo lamento demasiado, lo lamento demasiado.

Reiteración

71. Cumplir mil requisitos

Hipérbole

72. Esos tremendos monstruos oruga

Metáfora 
73. Alguien era la vergüenza del colegio

Metáfora

74. Los atienden como el hoyo

Comparación

75. Es muy, muy parecido

Reiteración

76. Director favorito, favorito

Reiteración

77. Es una monada

Metáfora

78. Son muy, muy violentos

Reiteración

79. Mi vida es más, más plena, más conforme

Reiteración

80. Todo bellísimo, bellísimo

Reiteración

81. Todo tan, tan natural

Reiteración

82. Pude comprar todo en un dos por tres

Hipérbole

83. Tiene harto, harto ganado

Reiteración

84. Cien por ciento sibarita

Hipérbole

85. Persona muy, muy, muy desvalida

Reiteración

86. Fue muy, muy pesado

Reiteración

87. Muy, muy dados a entregar

Reiteración

88. Salía muy, muy temprano.

Reiteración

89. Harto viaje, harto viaje.

Reiteración

90. Harto, harto ruido.

Reiteración

91. Mucha, mucha suerte.

Reiteración

92. Técnicos, técnicos.

Reiteración

93. ¡Grito y plata!

Metáfora

94. Muy, muy completos.

Reiteración

95. Muy motivado, muy, muy...

Reiteración

96. Una actividad muy, muy, muy fuerte.

Reiteración

97. Eso fue muy, muy interesante.

Reiteración 
98. Son muy, muy loquillos.

Reiteración

99. Somos muy irresponsables, ¿ya?, muy irresponsables

Reiteración

100. (una niñez) pero muy, muy feliz.

Reiteración

101. Una ciudad muy limpia, muy limpia.

Reiteración

102. Estoy completamente de acuerdo, completamente de acuerdo.

Reiteración

103. ... las relaciones universitarias son como bien, bien al lote

Reiteración

104. Son de por vida

Hipérbole

105. Soy muy, muy cercana.

Reiteración

106. Una relación muy, muy cercana.

Reiteración

10.2. Ocurrencia de los recursos estilísticos en las entrevistas

La ocurrencia de los recursos con valor superlativo, en la elocución de los 34 entrevistados, se representa porcentualmente en la siguiente figura:

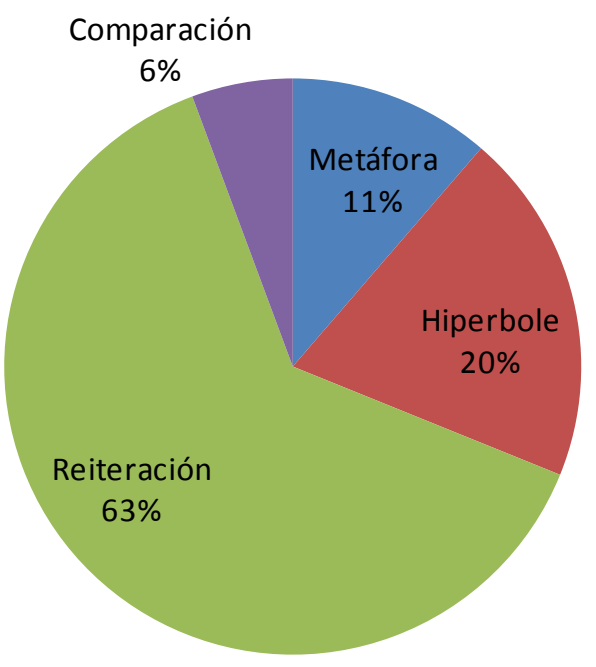

Figura 68. Porcentaje de ocurrencias de recursos en las entrevistas realizadas. 
De acuerdo con los porcentajes representados en la Figura 68, se puede decir lo siguiente:

1. La reiteración es el recurso con mayor ocurrencia en las entrevistas realizadas (63\%).

2. La hipérbole ocupa el segundo lugar en la elocución de los entrevistados (20\%).

3. El recurso metafórico tiene $11 \%$ de ocurrencia.

4. La comparación es el recurso con menor ocurrencia (6\%).

Los resultados demuestran que los hablantes de las entrevistas usan los recursos estilísticos que les permiten expresar con mayor énfasis lo que quieren decir, esto es, la reiteración y la hipérbole. Estos dos recursos suman $83 \%$ del total de recursos registrados.

10.3. Análisis cuantitativo de los recursos estilísticos según sexo, edad y nivel educacional.

Para el análisis cuantitativo de acuerdo con las variables sociolingüísticas de sexo, edad y nivel educacional, se ha realizado un estudio por cada uno de los recursos, según la ocurrencia de éste en la elocución de los entrevistados. 
10.3.11. Recursos según variable sexo

\subsubsection{Metáfora}

De acuerdo con los resultados obtenidos, se puede decir que la ocurrencia de este recurso es mayor en el sexo femenino que en el masculino, ya que 5 de las 17 entrevistadas ocuparon este recurso (tres de ellas la ocuparon una vez; una, dos veces; y una, tres veces). En cambio, sólo 3 de los entrevistados de sexo masculino usaron metáfora (dos de ellos la usaron una vez y uno, dos veces. Estos resultados pueden observarse en la Tabla 11 y en la Figura 69.

Tabla 11. Número de personas entrevistadas, según ocurrencia de metáfora y variable sexo.

\begin{tabular}{|l|c|c|r|}
\hline Ocurrencias & Femenino & Masculino & Total \\
\hline Nunca & 12 & 14 & 26 \\
\hline Una vez & 3 & 2 & 5 \\
\hline Dos veces & 1 & 1 & 2 \\
\hline Tres veces & 1 & & 1 \\
\hline Total & $\mathbf{1 7}$ & $\mathbf{1 7}$ & $\mathbf{3 4}$ \\
\hline
\end{tabular}

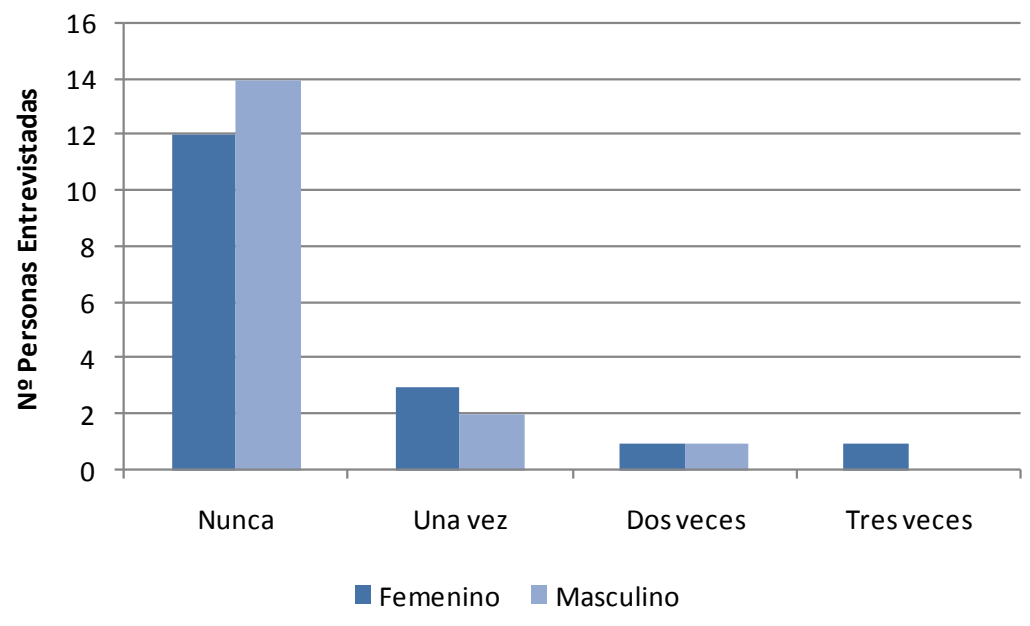


Figura 69. Número de personas entrevistadas, según ocurrencia de metáfora y variable sexo.

En la Figura 70, se registra el porcentaje de ocurrencia de este recurso, tanto en la elocución de los entrevistados de sexo masculino como de sexo femenino. Según estos resultados, se puede decir lo siguiente:

1. La mayoría de los entrevistados no utiliza el recurso metáfora (76\%).

2. El $15 \%$ de ellos la utiliza una vez.

3. En dos ocasiones, la usan 2 entrevistados, que corresponde a $6 \%$.

4. Es usada en tres oportunidades por una persona, lo que corresponde a $3 \%$.

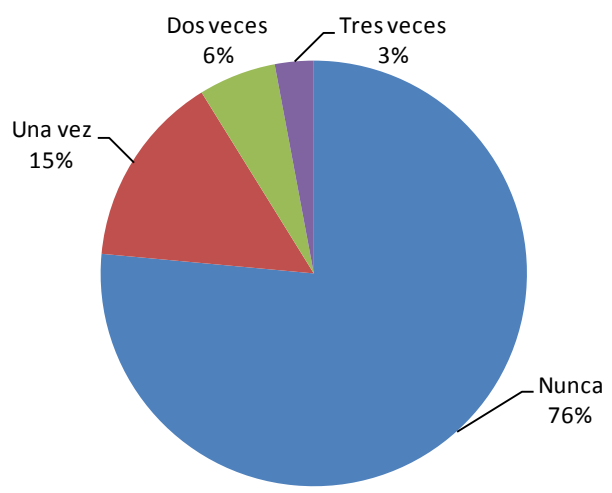

Figura 70. Porcentaje de ocurrencia de metáfora, según variable sexo.

\subsubsection{Hipérbole}

En el uso de este recurso hay una leve diferencia entre ambos sexos, pues 6 mujeres entrevistadas registran su uso (dos la usaron una vez, y cuatro de ellas, dos veces), mientras que 5 hombres la emplean (4 de ellos en una oportunidad y uno, dos 
veces). Los resultados de la ocurrencia de hipérbole en la elocución de los 34 entrevistados se expresan en la Tabla 12 y en la Figura 71.

Tabla 12. Número de personas entrevistadas, según ocurrencia de Hipérbole y variable sexo.

\begin{tabular}{|l|c|c|r|}
\hline Ocurrencias & Femenino & Masculino & Total \\
\hline Nunca & 11 & 11 & 22 \\
\hline Una vez & 2 & 4 & 6 \\
\hline Dos veces & 4 & 1 & 5 \\
\hline Tres veces & & & \\
\hline Cuatro Veces & & & 1 \\
\hline Cinco veces & & 1 & $\mathbf{3 4}$ \\
\hline Total & $\mathbf{1 7}$ & $\mathbf{1 7}$ & \\
\hline
\end{tabular}

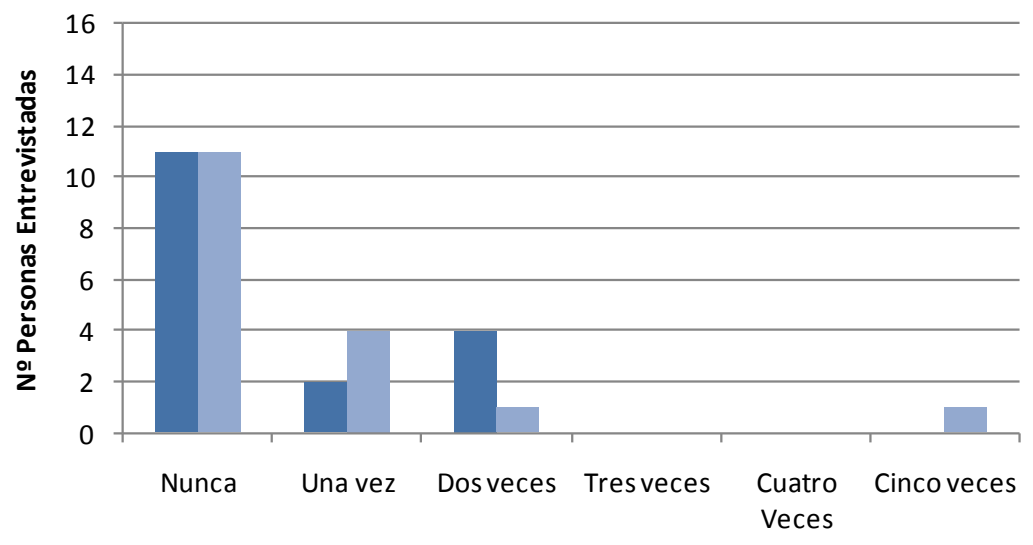

Femenino Masculino

Figura 71. Número de personas entrevistadas, según ocurrencia de hipérbole y variable sexo. 
En la Figura 72, se representan los porcentajes de ocurrencia de hipérbole en la elocución de los 34 entrevistados. De acuerdo con estos resultados, se puede decir lo siguiente:

1. El $65 \%$ de los entrevistados no utiliza la hipérbole en su elocución.

2. $17 \%$ de ellos la utiliza una vez.

3. Dos veces es utilizada por $15 \%$ de los entrevistados.

4. Cinco veces es usada por $3 \%$ de los entrevistados.

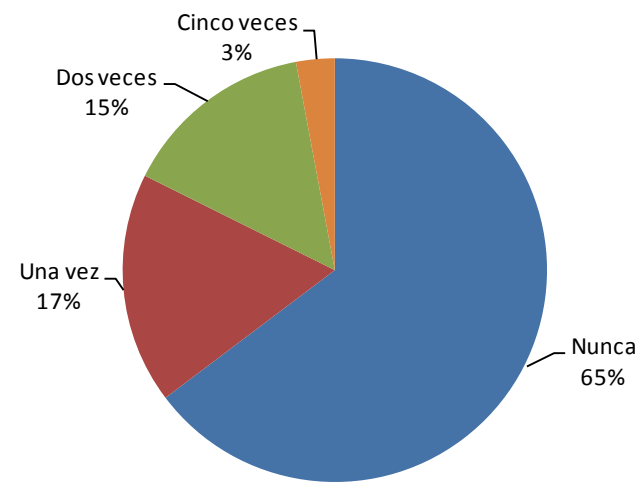

Figura 72. Porcentaje de ocurrencia de hipérbole, según variable sexo.

\subsubsection{Reiteración}

La reiteración es uno de los recursos más empleados por las personas entrevistadas. Según los datos estadísticos expresados en la Tabla 13 y en la Figura 73, existe mayor uso en las personas de sexo femenino, ya que 14 de las 17 entrevistadas registran uso del recurso, con una ocurrencia que va desde una vez hasta ocho veces. Por su parte, 11 de los 17 entrevistados de sexo masculino usan la reiteración, con una ocurrencia que va desde una a cinco veces. 
Tabla 13. Número de personas entrevistadas según ocurrencia de reiteración y variable sexo.

\begin{tabular}{|l|c|c|r|}
\hline Ocurrencias & Femenino & Masculino & Total \\
\hline Nunca & 3 & 6 & 9 \\
\hline Una vez & 2 & 3 & 5 \\
\hline Dos veces & 6 & 4 & 10 \\
\hline Tres veces & 3 & 3 & 6 \\
\hline Cuatro Veces & 1 & & 1 \\
\hline Cinco veces & & 1 & 1 \\
\hline Seis veces & & & 1 \\
\hline Siete veces & 1 & & 1 \\
\hline Ocho Veces & 1 & & $\mathbf{3 4}$ \\
\hline Total & $\mathbf{1 7}$ & $\mathbf{1 7}$ & \\
\hline
\end{tabular}

En la siguiente figura, se representan los porcentajes de ocurrencia de la reiteración (de 0 a 8 veces), en la elocución de los 34 entrevistados

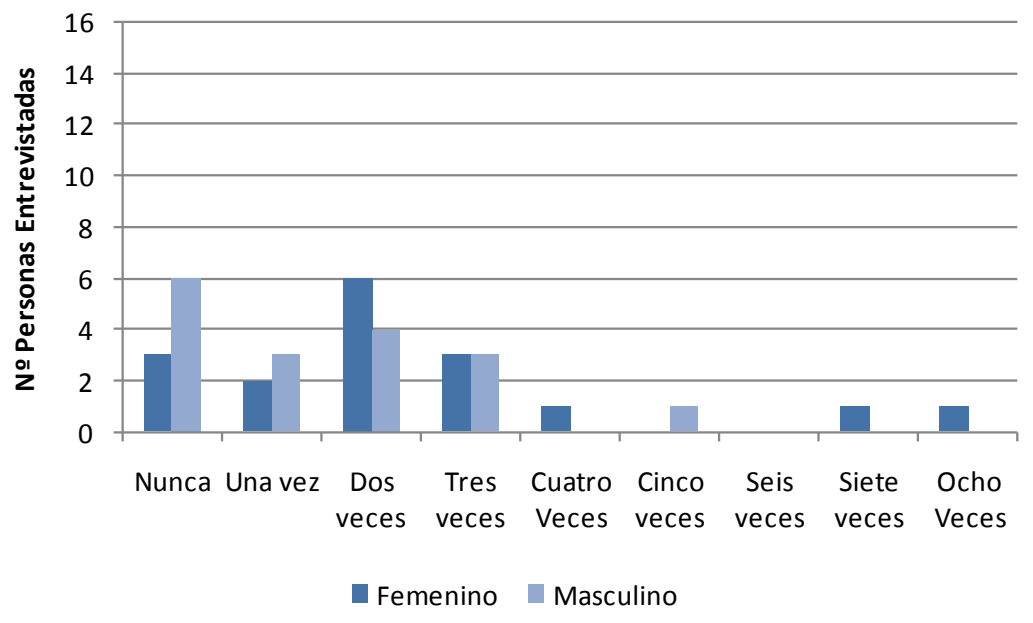

Figura 73. Número de personas entrevistadas, según ocurrencia de reiteración y variable sexo.

. Según los datos obtenidos, se puede concluir lo siguiente:

1. Nueve de los entrevistados nunca usaron reiteración (26\%). De éstos, 6 son del sexo masculino y 3 del femenino. 
2. Cinco entrevistados la usaron una vez (15\%). Dos de éstos son de sexo femenino y tres, masculino.

3. $29 \%$ de los entrevistados usó reiteración 2 veces (10 entrevistados). De ellos, $60 \%$ corresponde al sexo femenino.

4. Tres veces fue usada por $18 \%$ de los entrevistados (tres hombres y tres mujeres).

5. Cuatro veces la usó una entrevistada, lo que corresponde a 3\%.

6. Cinco veces la usó un entrevistado (3\%).

7. La ocurrencia de siete y ocho veces tiene $3 \%$ de uso, que corresponde a una entrevistada.

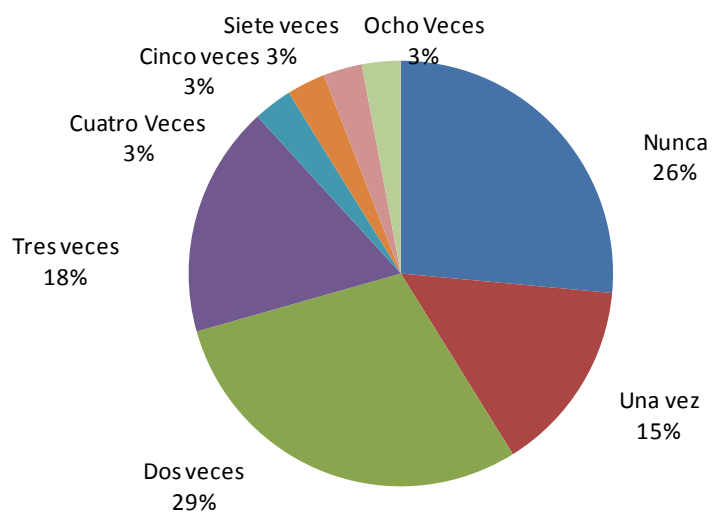

Figura 74. Porcentaje de ocurrencia de reiteración, según variable sexo.

\subsubsection{Comparación}

Este recurso estilístico sólo registra uso en la elocución de los entrevistados de sexo masculino. Tres entrevistados la utilizan una vez, y uno de ellos, en tres oportunidades. Estos resultados se representan en la Tabla 14 en la Figura75. 
Tabla 14. Número de personas entrevistadas según ocurrencia de comparación y variable sexo.

\begin{tabular}{|l|c|c|r|}
\hline Ocurrencias & Femenino & Masculino & Total \\
\hline Nunca & 17 & 13 & 30 \\
\hline Una vez & & 3 & 3 \\
\hline Dos veces & & & 1 \\
\hline Tres veces & & 1 & $\mathbf{3 4}$ \\
\hline Total & $\mathbf{1 7}$ & $\mathbf{1 7}$ & \\
\hline
\end{tabular}

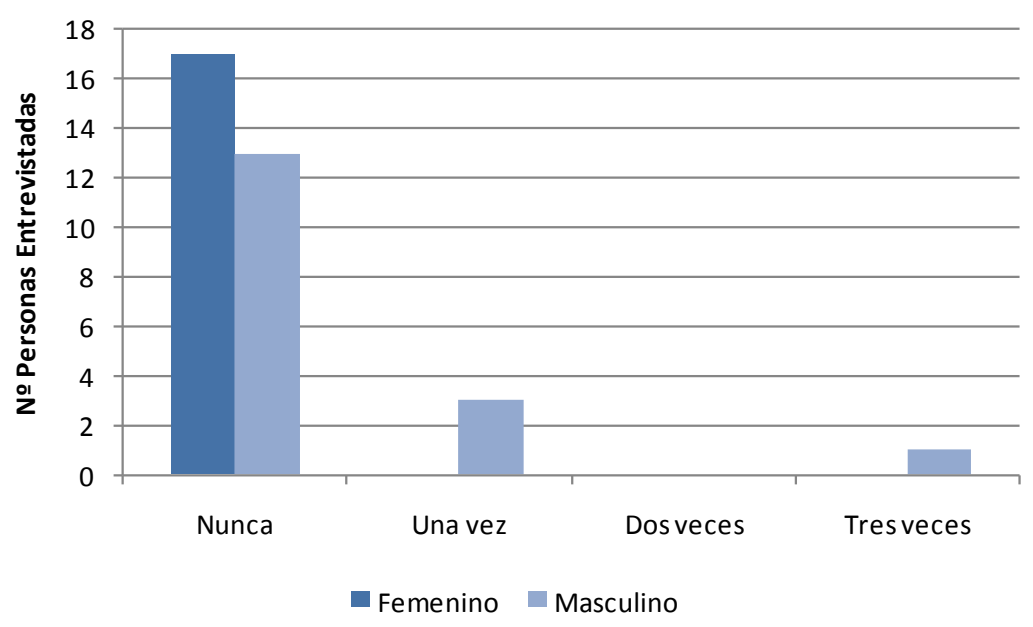

Figura 75. Número de personas entrevistadas, según ocurrencia de comparación y variable sexo.

En la Figura 75, se representan los porcentajes de ocurrencia de este recurso. De acuerdo con los datos obtenidos, se puede decir que:

1. $88 \%$ de los entrevistados no usa el recurso comparación (30 personas).

2. Tres personas de sexo masculino la usan una vez (9\%).

3. Un entrevistado (sexo masculino) la usa 3 veces (3\%). 


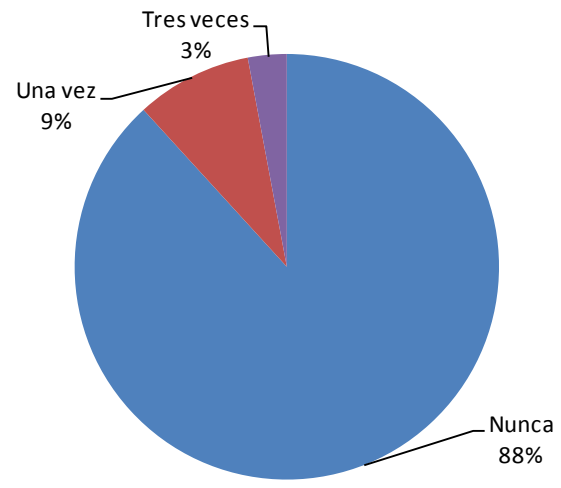

Figura 76. Porcentaje de ocurrencia de comparación, según variable sexo.

10.3.12. Recursos según variable edad

\subsubsection{Metáfora}

Este recurso es menos usado por el grupo etario de los más jóvenes (solo una persona). Registra un mayor uso en el tercer grupo etario (4 personas). Estos resultados se representan en la Tabla 15.

Tabla 15. Número de personas entrevistadas, según ocurrencia de metáfora y rango etario.

\begin{tabular}{|l|c|c|c|r|}
\hline Ocurrencias & 21 a 31 años & 32 a 49 años & 50 a 69 años & Total \\
\hline Nunca & 14 & 6 & 6 & 26 \\
\hline Una vez & 1 & 1 & 3 & 5 \\
\hline Dos veces & & 1 & 1 & 2 \\
\hline Tres veces & & 1 & & 1 \\
\hline Total & $\mathbf{1 5}$ & $\mathbf{9}$ & $\mathbf{1 0}$ & $\mathbf{3 4}$ \\
\hline
\end{tabular}

A continuación, se presentan los datos de ocurrencia del recurso metáfora de acuerdo con cada grupo etario. 
$\underline{\text { Primer grupo etario }}$

1. El $93 \%$ de los entrevistados no usa este recurso.

2. Un entrevistado usa una vez el recurso (7\%).

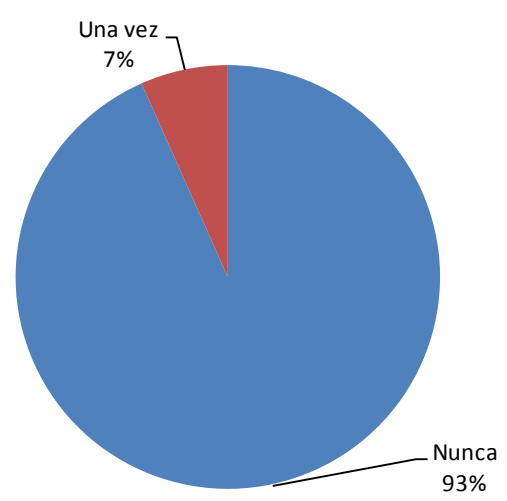

Figura 77. Porcentaje de ocurrencia de metáfora en rango etario entre 21 a 31 años.

\section{$\underline{\text { Segundo grupo etario }}$}

1. $67 \%$ de los entrevistados no usa este recurso.

2. $11 \%$ usa el recurso una vez.

3. Tres veces lo usa el $11 \%$ de los entrevistados.

4. $11 \%$ lo usa dos veces.

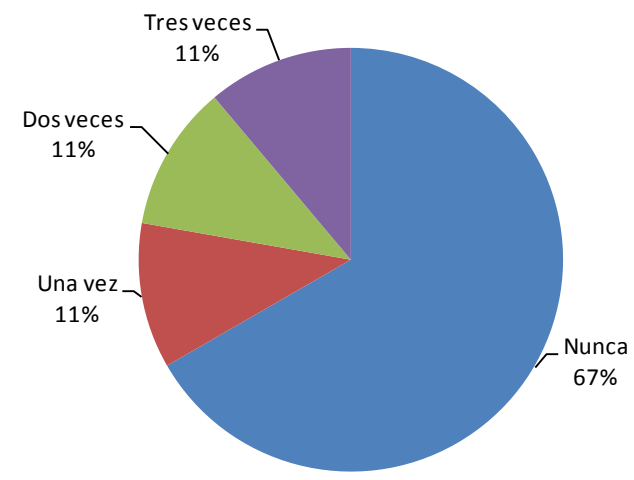

Figura 78. Porcentaje ocurrencia de metáfora en rango etario entre 32 a 49 años. 


\section{$\underline{\text { Tercer grupo etario }}$}

1. En este grupo, $60 \%$ de los entrevistados nunca usa este recurso.

2. Una vez lo usa el $30 \%$ de los entrevistados.

3. Dos veces es utilizado por el $10 \%$ de los entrevistados.

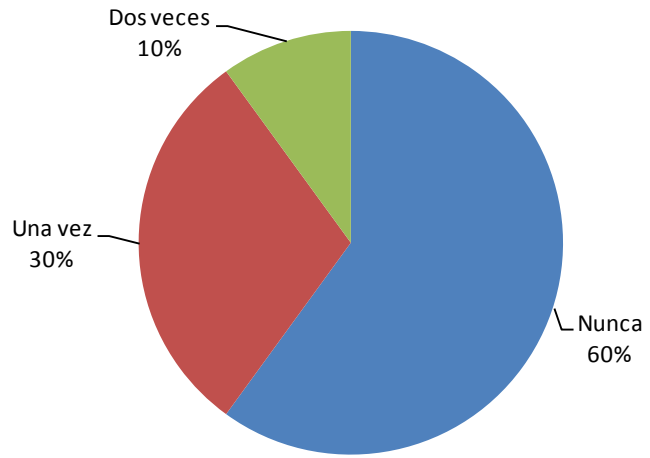

Figura 79. Porcentaje de ocurrencia de metáfora en rango etario entre 50 a 69 años.

\subsubsection{Hipérbole}

Este recurso registra lo usan 4 entrevistados del primer grupo etario, 3 en el segundo y 4 en el último grupo (Tabla 16).

Tabla 16. Número de personas entrevistadas según ocurrencia de hipérbole y rango etario.

\begin{tabular}{|l|c|c|c|r|}
\hline Ocurrencias & 21 a 31 años & 32 a 49 años & 50 a 69 años & Total \\
\hline Nunca & 11 & 6 & 5 & 22 \\
\hline Una vez & 1 & 3 & 2 & 6 \\
\hline Dos veces & 3 & & 2 & 5 \\
\hline Tres veces & & & & \\
\hline Cuatro veces & & & & 1 \\
\hline Cinco veces & & & 1 & $\mathbf{3 4}$ \\
\hline Total & $\mathbf{1 5}$ & $\mathbf{9}$ & $\mathbf{1 0}$ & \\
\hline
\end{tabular}


En cada grupo etario, los resultados de uso de la hipérbole son los siguientes:

\section{Primer grupo etario}

1. En este grupo, $73 \%$ de los entrevistados no usa hipérbole ( 11 personas).

2. $20 \%$ de los entrevistados del grupo etario usan el recurso dos veces.

3. La hipérbole es usada una vez por $7 \%$ de los entrevistados.

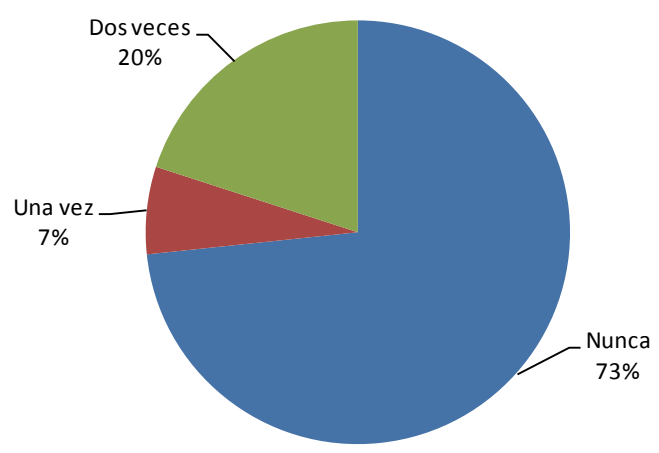

Figura 80. Porcentaje de ocurrencia de hipérbole en rango etario entre 21 a 31 años.

$\underline{\text { Segundo grupo etario }}$

1. En este grupo, $67 \%$ de los entrevistados no usa la hipérbole.

2. Una vez es usada por $33 \%$ de los entrevistados. 


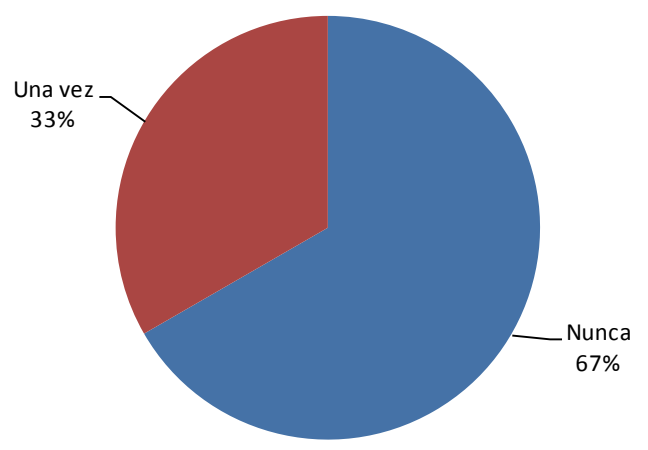

Figura 81. Porcentaje de ocurrencia de hipérbole en rango etario entre 32 a 49 años.

\section{$\underline{\text { Tercer grupo etario }}$}

1. En este grupo, $50 \%$ de los entrevistados no usa la hipérbole.

2. Una vez la usa el $20 \%$ de los entrevistados de este grupo.

3. Dos veces es usada por $20 \%$ de los entrevistados.

4. Cinco veces es usada por $10 \%$ de los entrevistados.

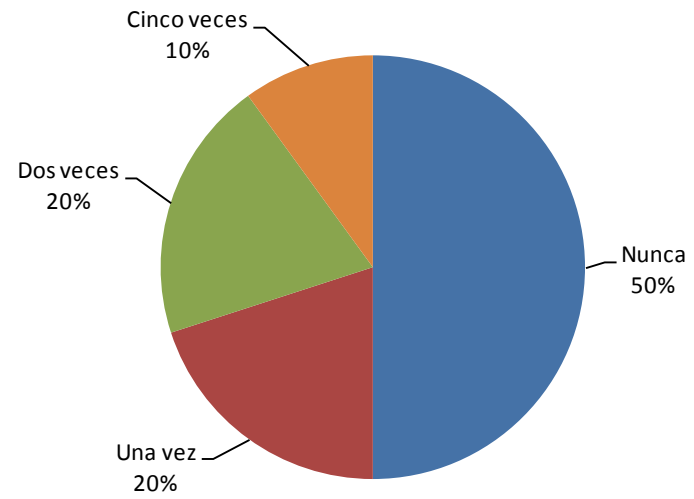

Figura 82. Porcentaje de ocurrencia de hipérbole en rango etario entre 50 a 69 años. 


\subsubsection{Reiteración}

La reiteración es el recurso más usado por los entrevistados, ya que el $80 \%$ de ellos registra uso en su elocución. La ocurrencia de este recurso es de una hasta ocho veces. En los tres grupos etarios, se encuentra el uso de este recurso.

En la Tabla 17, se presenta la ocurrencia de la reiteración, según los tres rangos etarios.

Tabla 17. Número de personas entrevistadas, según ocurrencia de reiteración y rango etario.

\begin{tabular}{|l|c|c|c|r|}
\hline Ocurrencias & 21 a 31 años & 32 a 49 años & 50 a 69 años & Total \\
\hline Nunca & 3 & 2 & 4 & 9 \\
\hline Una vez & 4 & & 1 & 5 \\
\hline Dos veces & 5 & 4 & 1 & 10 \\
\hline Tres veces & 3 & 2 & 1 & 6 \\
\hline Cuatro veces & & & 1 & 1 \\
\hline Cinco veces & & 1 & & 1 \\
\hline Seis veces & & & & 1 \\
\hline Siete veces & & & 1 & 1 \\
\hline Ocho Veces & & & 1 & $\mathbf{3 4}$ \\
\hline Total & $\mathbf{1 5}$ & $\mathbf{9}$ & $\mathbf{1 0}$ & \\
\hline
\end{tabular}

Por cada grupo etario, los resultados de ocurrencia de reiteración son los siguientes:

\section{Primer grupo etario}

1. En este grupo, el $20 \%$ de los entrevistados nunca usó la reiteración.

2. $27 \%$ de los pertenecientes a este grupo la usó una vez.

3. Dos veces fue usada por $33 \%$ de los entrevistados.

4. Tres veces fue usada por $20 \%$ de los entrevistados. 


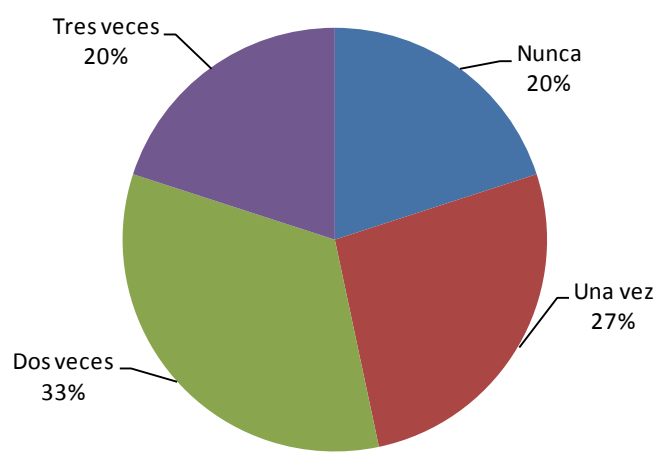

Figura 83. Porcentaje de ocurrencia de reiteración en rango etario entre 21 a 31 años.

Segundo grupo etario

1. En este grupo, $22 \%$ de los entrevistados no usó de este recurso.

2. $45 \%$ de los pertenecientes a este grupo la usó dos veces.

3. Tres veces fue usada por $22 \%$ de los entrevistados.

4. Cinco veces fue usada por $11 \%$ de los integrantes de este grupo etario.

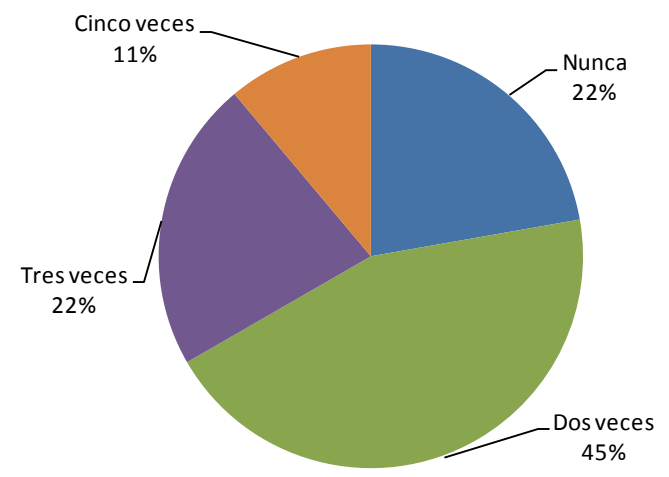

Figura 84. Porcentaje de ocurrencia de reiteración en rango etario entre 32 a 49 años. 
$\underline{\text { Tercer grupo etario }}$

1. El $40 \%$ de los entrevistados de este grupo etario no usó la reiteración.

2. El $60 \%$ del grupo usó este recurso en una ocurrencia que va de una hasta ocho veces.

3. Cada una de las ocurrencias (de una a ocho veces) tiene un porcentaje de $10 \%$.

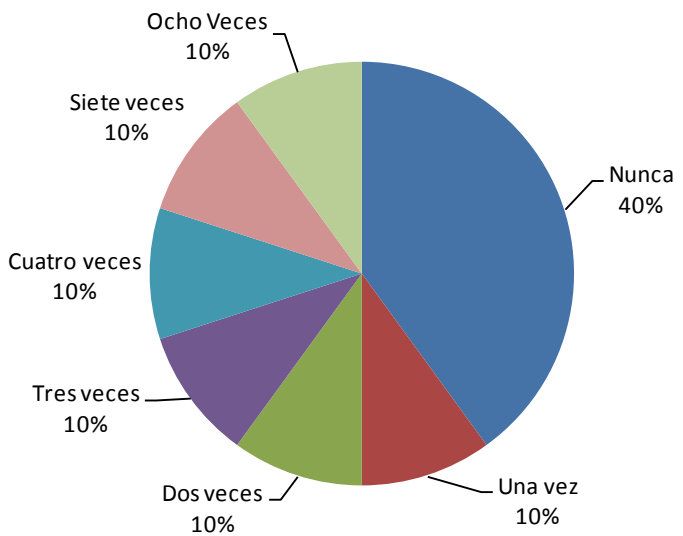

Figura 85. Porcentaje de ocurrencia de reiteración en rango etario entre 50 a 69 años.

\subsubsection{Comparación}

Este es el recurso menos usado por los entrevistados de los grupos generacionales. Tal como puede observarse en la Tabla18, sólo 4 personas la usan. La ocurrencia va de una hasta tres veces. 
Tabla 18. Número de personas entrevistadas, según ocurrencia de comparación y rango etario.

\begin{tabular}{|l|c|c|c|r|}
\hline Ocurrencias & 21 a 31 años & 32 a 49 años & 50 a 69 años & Total \\
\hline Nunca & 12 & 8 & 10 & 30 \\
\hline Una vez & 2 & 1 & & 3 \\
\hline Dos veces & & & & 1 \\
\hline Tres veces & 1 & & & $\mathbf{3 4}$ \\
\hline Total & $\mathbf{1 5}$ & $\mathbf{9}$ & $\mathbf{1 0}$ & \\
\hline
\end{tabular}

El análisis de la ocurrencia de comparación por cada grupo etario es el siguiente:

\section{Primer grupo etario}

Si se comparan los tres grupos etarios, este grupo es el que registra mayor uso del recurso, sin embargo, la ocurrencia se presenta sólo en 3 entrevistados del total de 15.

Los resultados de ocurrencia, en términos de porcentaje, son los siguientes:

1. El $80 \%$ de los entrevistados nunca usó el recurso.

2. Una vez la usó el $13 \%$ de los entrevistados.

3. Tres veces sólo fue usada por un entrevistado (7\%). 


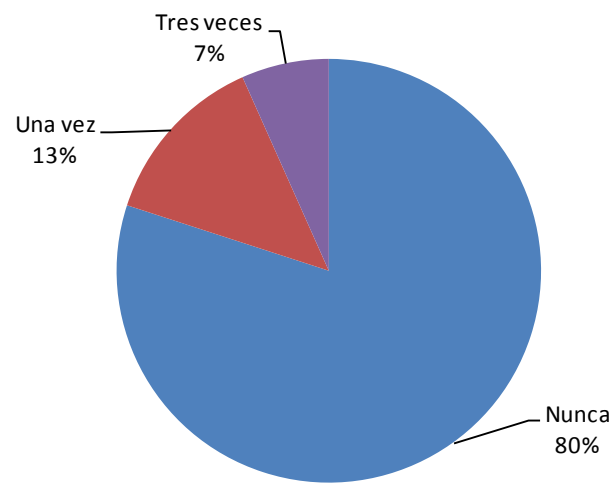

Figura 86. Porcentaje de ocurrencia de comparación en rango etario entre 21 a 31 años.

\section{Segundo grupo etario}

En el segundo grupo etario, $89 \%$ de los entrevistados nunca usó este recurso, según se grafica en la Figura 87 . Sólo la usa una vez uno de los hablantes (11\%).

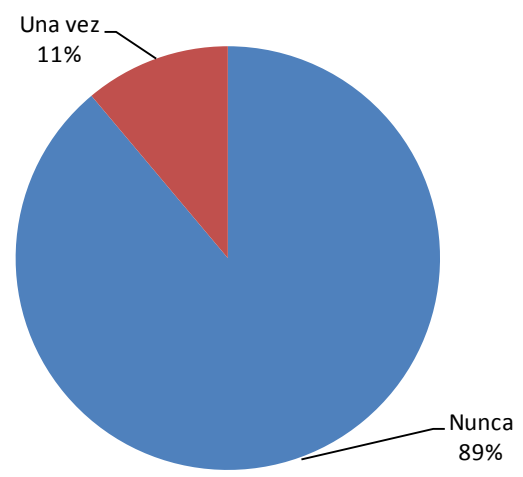

Figura 87. Porcentaje de ocurrencia de comparación en rango etario entre 32 a 49 años.

\section{Tercer grupo etario}

Este grupo no hace uso de la comparación en la entrevistas. Como puede observarse en la Figura 88, 100\% de los entrevistados nunca la usó. 


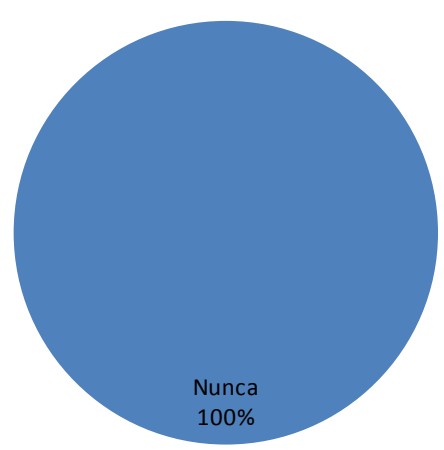

Figura 88. Porcentaje de ocurrencia de comparación en rango etario entre 50 a 69 años.

10.3.13. Recursos según variable nivel educacional

\subsubsection{Metáfora}

Este recurso registra ocurrencia en los tres niveles educacionales, desde una a tres veces, como puede observarse en la siguiente tabla.

Tabla 19. Número de personas entrevistadas, según ocurrencia de metáfora y nivel educacional.

\begin{tabular}{|l|c|c|c|r|}
\hline Ocurrencias & Medio & Técnico & Universitario & Total \\
\hline Nunca & 5 & 7 & 14 & $\mathbf{2 6}$ \\
\hline Una vez & 1 & 1 & 3 & $\mathbf{5}$ \\
\hline Dos veces & 1 & & 1 & $\mathbf{2}$ \\
\hline Tres veces & & & 1 & $\mathbf{1}$ \\
\hline Total & $\mathbf{7}$ & $\mathbf{8}$ & $\mathbf{1 9}$ & $\mathbf{3 4}$ \\
\hline
\end{tabular}


$\underline{\text { Nivel educacional medio }}$

Los resultados de ocurrencia de metáfora, representados en la Figura 89, son los siguientes:

1. $72 \%$ de los entrevistados de este nivel nunca usó la metáfora.

2. Un entrevistado la usa una vez (14\%).

3. Un entrevistado la usa dos veces (14\%).

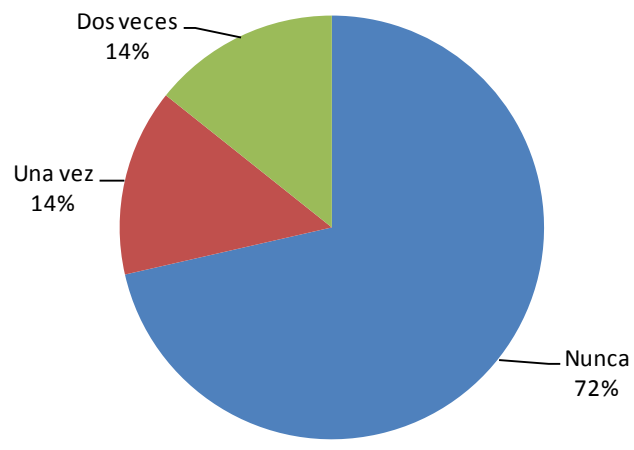

Figura 89. Porcentaje de ocurrencia de metáfora en nivel educacional medio.

\section{Nivel educacional técnico}

Según los resultados, se puede decir que los entrevistados de este nivel mayoritariamente no usan la metáfora (87\%).

Solo uno de los entrevistados de este nivel la usa una vez (13\%). 


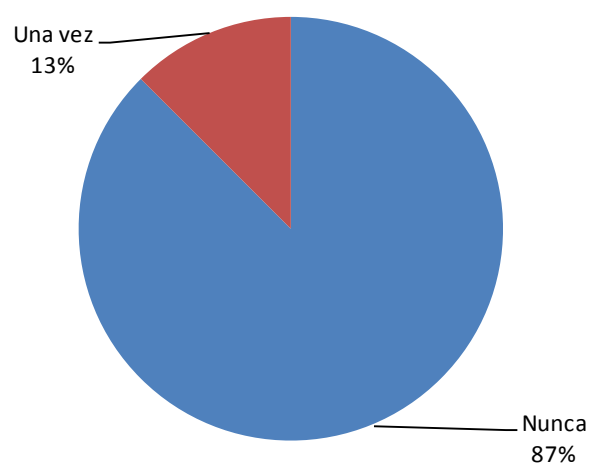

Figura 90. Porcentaje de ocurrencia de metáfora en nivel educacional técnico.

\section{$\underline{\text { Nivel educacional universitario }}$}

1. En este nivel educacional, $74 \%$ de los entrevistados no usó la metáfora.

2. Una vez la usó el $16 \%$ de los entrevistados.

3. Dos veces fue usada por un entrevistado (5\%).

4. Tres veces fue usada por un entrevistado (5\%).

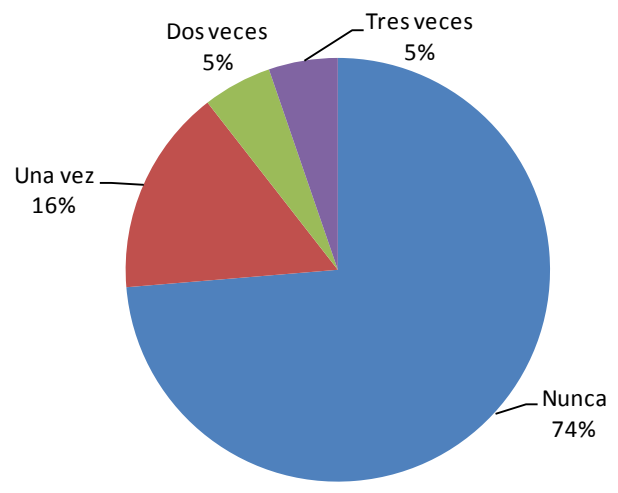

Figura 91. Porcentaje de ocurrencia de metáfora en nivel educacional universitario.

10.3.13.2. Hipérbole.

Este recurso registra uso en los tres niveles educacionales. Los resultados de ocurrencia de hipérbole se representan en la Tabla 20. 
Tabla 20. Número de personas entrevistadas, según ocurrencia de hipérbole y nivel educacional.

\begin{tabular}{|l|c|c|c|r|}
\hline Ocurrencias & Medio & Técnico & Universitario & Total \\
\hline Nunca & 3 & 5 & 14 & $\mathbf{2 2}$ \\
\hline Una vez & 3 & 1 & 2 & $\mathbf{6}$ \\
\hline Dos veces & 1 & 2 & 2 & $\mathbf{5}$ \\
\hline Tres veces & & & & $\mathbf{1}$ \\
\hline Cuatro veces & & & & $\mathbf{3 4}$ \\
\hline Cinco veces & & & 1 & $\mathbf{1 9}$ \\
\hline Total & $\mathbf{7}$ & $\mathbf{8}$ & & \\
\hline
\end{tabular}

El análisis de ocurrencia de Hipérbole por cada uno de los niveles educacionales es el siguiente:

Nivel educacional medio

En este nivel, 57\% de los entrevistados usó hipérbole. De acuerdo con los resultados representados en la Figura 92, la ocurrencia del recurso es la siguiente:

1. Una vez la usó $43 \%$ de los entrevistados.

2. $14 \%$ la usó dos veces.

3. $43 \%$ no hizo uso de hipérbole. 


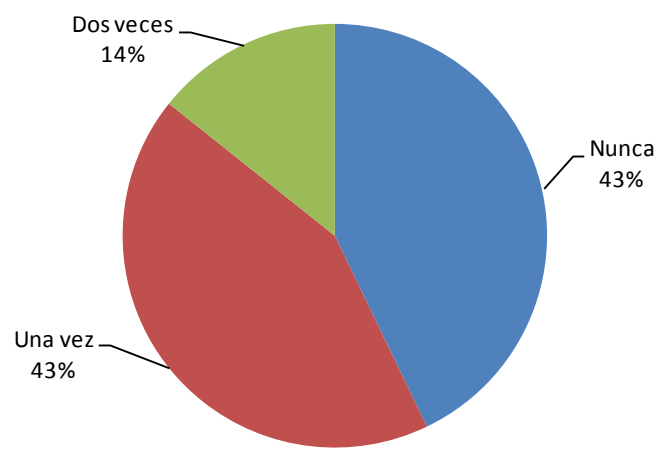

Figura 92. Porcentaje de ocurrencia de hipérbole en nivel educacional medio.

Nivel educacional técnico

1. En este nivel, $62 \%$ no usó la Hipérbole.

2. Dos veces fue usada por $25 \%$ de los entrevistados del nivel.

3. Un entrevistado la usó una vez (13\%).

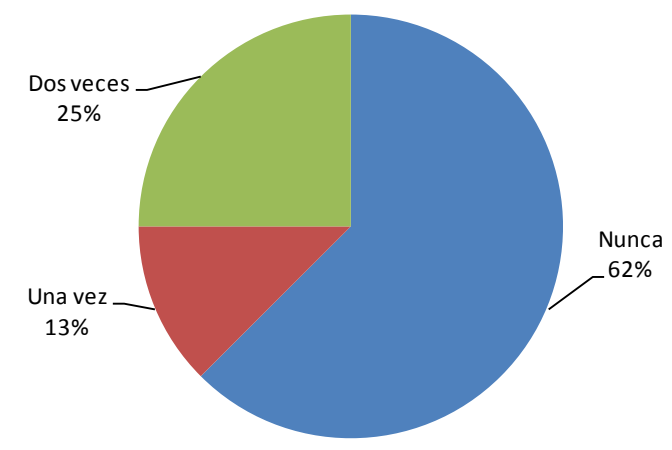

Figura 93. Porcentaje de ocurrencia de hipérbole en nivel educacional técnico. 
Nivel educacional universitario

1. $74 \%$ de los entrevistados de este nivel no hace uso de la hipérbole.

2. Dos veces la ocupa el $11 \%$.

3. Una vez es usada por $10 \%$ de los entrevistados del nivel.

4. $5 \%$ de los de este nivel la ocuparon 5 veces.

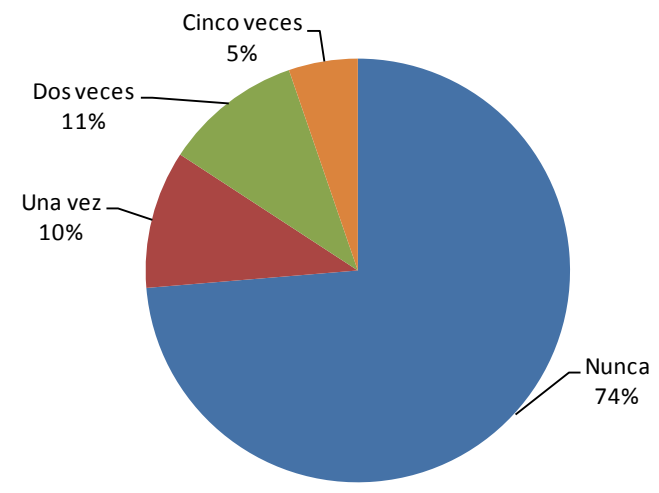

Figura 94. Porcentaje de ocurrencia de hipérbole en nivel educacional universitario.

10.3.13.3.Reiteración

Este recurso registra uso en los tres niveles educacionales, como puede observarse en la Tabla 21.

La reiteración tiene un registro de uso de hasta ocho veces. La mayor ocurrencia corresponde a 2 veces (registrada en 10 de las personas entrevistadas).

Tabla 21. Número de personas entrevistadas, según ocurrencia de reiteración y nivel educacional. 


\begin{tabular}{|l|c|c|c|r|}
\hline Ocurrencias & Medio & Técnico & Universitario & Total \\
\hline Nunca & 1 & 3 & 5 & $\mathbf{9}$ \\
\hline Una vez & & 1 & 4 & $\mathbf{5}$ \\
\hline Dos veces & 2 & 1 & 7 & $\mathbf{1 0}$ \\
\hline Tres veces & 2 & 2 & 2 & $\mathbf{6}$ \\
\hline Cuatro veces & & 1 & & $\mathbf{1}$ \\
\hline Cinco veces & 1 & & & $\mathbf{1}$ \\
\hline Seis veces & & & & $\mathbf{1}$ \\
\hline Siete veces & & & 1 & $\mathbf{1}$ \\
\hline Ocho Veces & 1 & & & $\mathbf{3 4}$ \\
\hline Total & $\mathbf{7}$ & $\mathbf{8}$ & $\mathbf{1 9}$ & \\
\hline
\end{tabular}

El análisis de la ocurrencia de reiteración por cada nivel educacional es el siguiente:

Nivel educacional medio

1. Solo una persona de este nivel nunca usó el recurso, lo que equivale a 14\%.

2. Dos veces fue ocupada por $29 \%$ de los entrevistados.

3. La ocurrencia de tres veces corresponde a $29 \%$.

4. Cinco veces fue usada por $14 \%$ de los entrevistados.

5. Ocho veces, la máxima ocurrencia, corresponde a una persona (14\%).

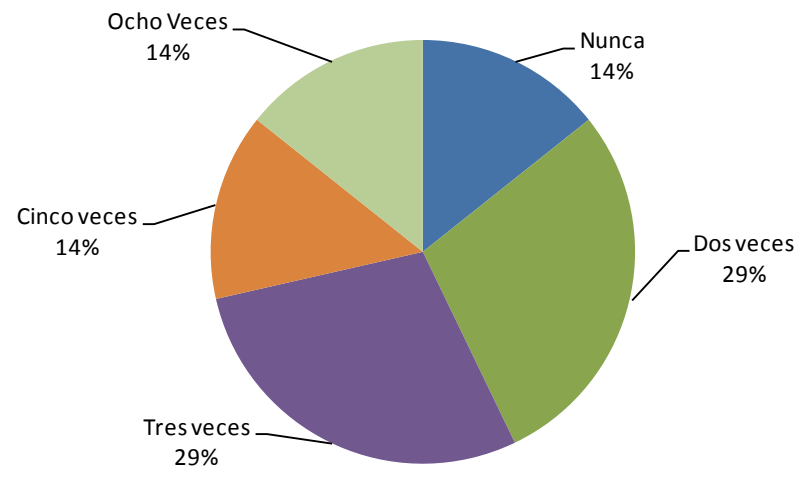

Figura 95. Porcentaje de ocurrencia de reiteración en nivel educacional medio. 
$\underline{\text { Nivel educacional técnico }}$

En este nivel, los resultados de ocurrencia de reiteración representados en la Figura 96, son los siguientes:

1. $37 \%$ de los entrevistados del nivel nunca usaron este recurso.

2. Una vez la usó el $12 \%$ de los entrevistados.

3. $13 \%$ la usó dos veces.

4. La ocurrencia de tres veces corresponde a $25 \%$ de los entrevistados del nivel.

5. Cuatro veces corresponde a $13 \%$.

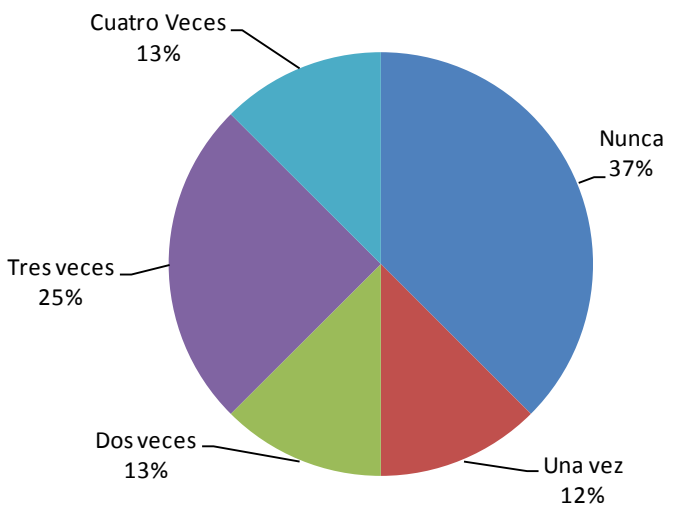

Figura 96. Porcentaje de ocurrencia de reiteración en nivel educacional técnico.

Nivel educacional universitario

1. $26 \%$ de los entrevistados nunca usó el recurso.

2. Una vez la usó $21 \%$ de los entrevistados.

3. El mayor porcentaje de ocurrencia corresponde a dos veces (37\%).

4. Tres veces la usó el $11 \%$.

5. El mayor número de ocurrencia (7) registra 5\%. 


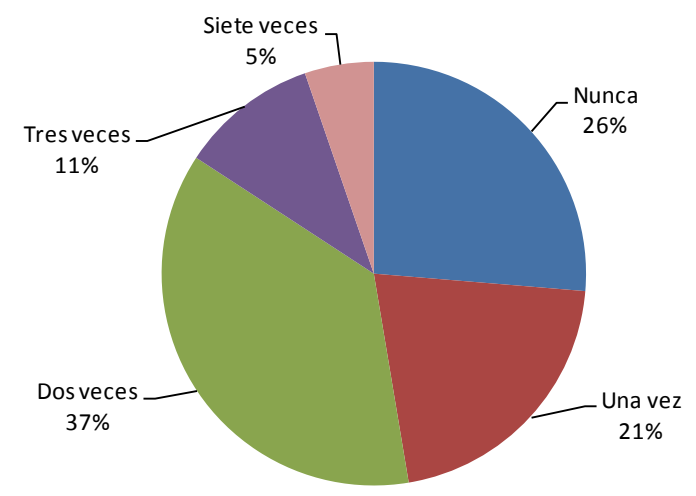

Figura 97. Porcentaje de recurrencia de reiteración en nivel educacional universitario.

\subsubsection{Comparación}

La comparación es el recurso de menor uso en las entrevistas realizadas. Los resultados de ocurrencia en cada uno de los niveles educacionales, se representan en la Tabla 22.

Tabla 22. Número de personas entrevistadas, según ocurrencia de comparación y nivel educacional.

\begin{tabular}{|l|c|c|c|r|}
\hline Ocurrencias & Medio & Técnico & Universitario & Total \\
\hline Nunca & $\mathbf{7}$ & 5 & 18 & $\mathbf{3 0}$ \\
\hline Una vez & & 2 & 1 & $\mathbf{3}$ \\
\hline Dos veces & & & & $\mathbf{1}$ \\
\hline Tres veces & & 1 & & $\mathbf{3 4}$ \\
\hline Total & $\mathbf{7}$ & $\mathbf{8}$ & $\mathbf{1 9}$ & \\
\hline
\end{tabular}

A continuación, se analiza la ocurrencia de Comparación en cada nivel educacional. 
$\underline{\text { Nivel educacional medio }}$

En este nivel educacional, el 100\% de los entrevistados no usó del recurso comparación, tal como puede observarse en la Figura 98.

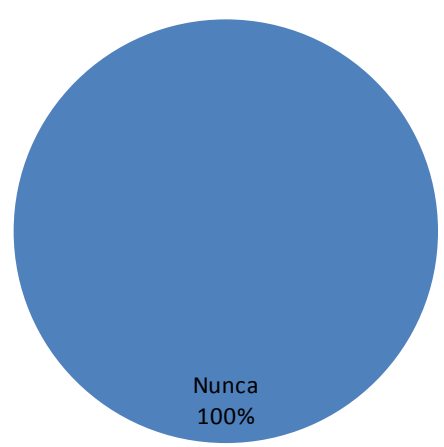

Figura 98. Porcentaje de ocurrencia de comparación en nivel educacional medio.

Nivel educacional técnico

1. $62 \%$ de los entrevistados del nivel no usó la comparación.

2. Dos entrevistados la usaron una vez (25\%).

3. Tres veces fue usada por una persona entrevistada (13\%).

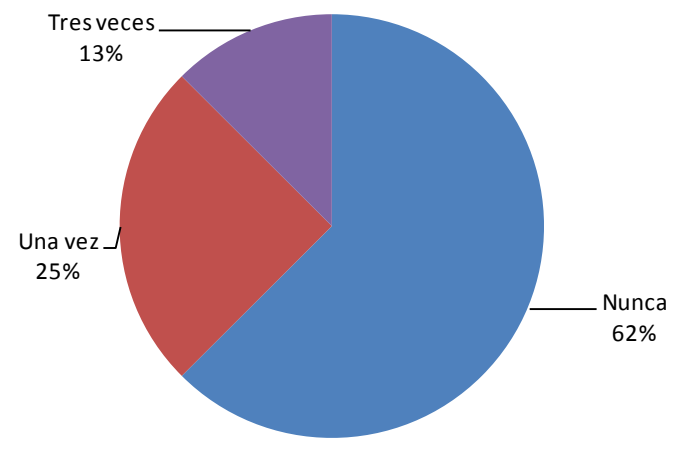

Figura 99. Porcentaje de ocurrencia de comparación en nivel educacional técnico. 
Nivel educacional universitario

1. En este nivel, el 95\% de los entrevistados no usó la comparación.

2. Una persona entrevistada del nivel la usó una vez (5\%).

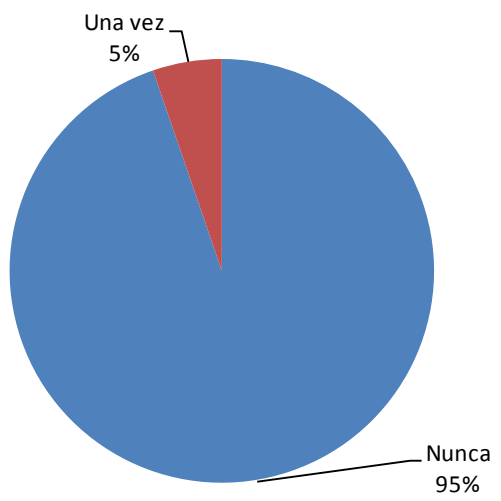

Figura 100. Porcentaje de ocurrencia de comparación en nivel educacional universitario. 


\section{ASPECTOS PRAGMÁTICOS: EL ÉNFASIS Y LA POSICIÓN DEL SUPERLATIVO.}

En este trabajo sociolingüístico, he considerado sólo dos elementos pragmáticos relativos al uso que los entrevistados hacen del superlativo: el énfasis o intensificación de la expresión y la posición que tienen estas formas superlativas en la elocución de los hablantes, pues tanto la ponderación de lo que se manifiesta como la organización de los elementos en el discurso de los hablantes tienen directa relación con la intención comunicativa subjetiva de quien habla.

\section{1. ÉNFASIS EN LA EXPRESIÓN DEL SUPERLATIVO}

El superlativo, por definición, es uno de los medios que posee el idioma español para intensificar o atenuar la cualidad que significa el adjetivo. Para la expresión de lo superlativo, nuestra lengua se vale de elementos morfológicos, sintácticos, léxicos, fonéticos y también de recursos estilísticos portadores de esta significación enfática.

Briz (1998) señala que intensificar es hacer que una cosa adquiera mayor intensidad, a través del énfasis o fuerza de la expresión, de la entonación o de los gestos. En este sentido, se resalta el carácter pragmático de la intensidad, frecuente en el español, unas veces para destacar el papel del yo y su deseo de expresar vehementemente sus sentimientos, con el fin de impresionar o provocar un mayor interés en lo expresado; en otras, para implicar al interlocutor y persuadirlo, imponiéndole su actitud, su propio punto de vista.

J. Martín García (1998) considera que la intensidad supone una mayor carga intencional, emotiva o cuantitativa del contenido significativo de una palabra, por lo que 
la intensificación se enmarca dentro de la subjetividad del hablante y añade rasgos connotativos al significado denotativo de una palabra. Entonces, esta intensificación de lo dicho por un hablante puede expresarse, lógicamente, por un superlativo en grado extremo (adjetivo o adverbio), cuya forma puede ser sintética o analítica.

En el estudio realizado sobre la intensificación semántica, Marta Albelda (1997: 25) manifiesta que los autores han usado distinta terminología para referirse a aquellas formas que los hablantes utilizan en la conversación coloquial, para dar mayor intensidad a lo que dicen. Entre los términos usados por algunos autores, están los siguientes: énfasis (González Calvo 1984-1988, Portero 1997), expresividad (Seco 1970, Vigara Tauste 1992), expresión afectiva (Beinhauer 1991), realce lingüístico (Seco 1970, Vigara Tauste 1992), elativización (González Calvo 1984-1988, GarcíaPage 1990), superlación (González Calvo 1984-1988), gradación (Bolinger 1972, Portero 1997), reforzamiento (Oster 1951, Penas Ibáñez 1993-1994), puesta en relieve (Lamíquiz 1971, Cisneros 1966), recalcamiento (Oster 1951), ponderación (Herrero 1991, Krüger 1960). Albelda (1997) sostiene que estos conceptos coinciden en algunos aspectos, pero difieren en otros y que los propios autores usan tanto unos como otros, porque no hay una clara delimitación de los conceptos usados.

Briz (1998) considera que los intensificadores constituyen en la conversación una categoría pragmática relacionada con la actividad retórica del que habla en relación a un tú no siempre implicado activamente. El yo utiliza el intensificador para reforzar la verdad de lo expresado y, en ocasiones, para hacer valer su intención de habla. Es un modo de valorar, pero también de persuadir. Esta intensificación se logra mediante recursos morfológicos, sintácticos, léxicos y fonéticos, y, con frecuencia, 
combinando varios. Cualquier categoría léxica puede verse afectada por este realce pragmático u operador de intensificación.

En su estudio, Briz (1998) considera varios modos de intensificar en la conversación coloquial, y para ejemplificar estos modos se vale de lo registrado por él en conversaciones de hablantes españoles. Entre estos modos, considera los siguientes:

- Por modificación interna (uso del sufijo aumentativo o de prefijos intensificadores como son re (que (te) -, súper, etc.

- Por modificación externa, bien a través de cuantificadores, de sintagmas especificativos con valor intensificador.

- Por medio de otros recursos sintácticos como los siguientes:

- Artículo + sustantivo + que (oración de relativo). Para ilustrar, cita el siguiente ejemplo: Las juergas que se corría el tío.

- (prep.) Artículo + lo + Adj./Adv. + que. Por ejemplo: Lo bueno que es.

- (prep.) Artículo + que + verbo. Ej.: Lo que estudiaba el tío.

- Artículo + de + sustantivo (frecuentemente en plural). Ej.: La de veces que te lo he dicho.

- Artículo un + sustantivo (valorativo). En construcciones atributivas. Ej.: Es un burro.

- Verbo + de + sustantivo. Ej.: Va de gente a esa verbena.

- Verbo + que + (te) verbo. Ej.: Mira que te mira

- Con el empleo de modos cuasiconsecutivos. Ej.: Está que se sube por las paredes. 
- Con estructuras comparativas. Ej.: Son como dos gotas de agua.

- Con enunciados exclamativos: Ej.: ¡Anda la mosquita muerta!

- Con el uso de enumeraciones, un procedimiento muy empleado para dar relieve a lo dicho.

- Por medio de recursos fraseológicos (locuciones adnominales y adverbiales). Ej.: Lo pasamos de muerte; también con algunas unidades sintagmáticas verbales. Ej.: Estar para chuparse los dedos.

- Por medio de recursos léxicos, como la repetición directa, inmediata, o indirecta, a través de partículas de refuerzo (pero que, más que, no, etc.). Ej.: Es tarde tarde; bobo más que bobo.

- Mediante frases o lexemas semánticamente intensos (adjetivos, sustantivos, verbos o adverbios). Ej.: terrible, horrible, porrada (de), me chiflan, etc.

- Por medio de otros recursos semánticos, como la ironía (Tienes tan poco dinero) y la metáfora hiperbólica (Vaya una empanada mental).

- Por medio de recursos suprasegmentales, que ocupan un lugar fundamental en los procesos intensificadores de la conversación coloquial, pues con la pronunciación, en general, podemos maximizar la expresión con intenciones diversas. Algunos de los recursos suprasegmentales señalados por Briz (1998) son los siguientes:

- el tono o pronunciación marcados. Ej.: Es LENTO.

- la pronunciación silabeada. Ej.: ES PE - SA - DO.

- El alargamiento vocálico. Ej.: No estaba bueno / estaba buenísimo. 
Al referirse a las denominadas por Briz (1998) unidades fraseológicas intensificadoras, Zuluaga (1980) las llama locuciones elativas que pueden intensificar a un verbo (corría como loco), a un sustantivo (vivía entre un mar de libros), a un adjetivo (terco como él solo), e indica que la mayoría de estas expresiones equivalen a un cuantificador como mucho, muy, - ísimo. Estas expresiones se usan preferentemente en el habla popular y coloquial e intensifican la cantidad y la cualidad en grado superlativo.

Briz (1998) señala que, según lo manifestado por otros autores, entre éstos, Beinhauer (1978), muchos de estos intensificadores son usados tanto para la cantidad como para la cualidad. Los signos de intensificación de la cantidad y de la cualidad constituyen un rasgo característico de la conversación coloquial, no sólo por su frecuencia de uso, sino por los numerosos recursos que transmiten la citada intensidad. En este tipo de conversación, junto con los intensificadores gramaticales (comparativos, superlativos, cuantificadores en general), se encuentran muchas formas de expresión verbal y no verbal que aumentan expresivamente la intensidad de lo dicho.

González Calvo (1984: 173) plantea que el español posee abundantes medios para ponderar, enfatizar o intensificar la afirmación y la negación, con el fin de exagerar cantidades o de hiperbolizar la intensidad. Entre estos medios, están morfemas, palabras, sintagmas, oraciones y textos, que se relacionan con el contenido de "muy", que es el denominador común significativo de todo lo que tiene o puede tener valor superlativo (zona máxima positiva o negativa de la cantidad o la cualidad). 
En este trabajo, se analizará, entonces, el uso de las diferentes formas de expresión de lo superlativo, en las entrevistas realizadas, para lograr el mayor énfasis de lo expresado.

11.1.11. El énfasis en los superlativos formados con el sufijo -ísimo

- $\underline{\text { Adjetivos }}$

Estos superlativos tienen, en las entrevistas, un menor uso por parte de los hablantes, en comparación con las otras formas de realización del superlativo. Tal como se ha dicho anteriormente, el hecho de transformar al adjetivo o al adverbio en palabras esdrújulas con el sufijo -ísimo, la intensidad se centra principalmente en estos términos. El hablante entrevistado expresa con mayor énfasis la cualidad que quiere resaltar con el adjetivo. Algunos ejemplos que ilustran lo dicho son los siguientes:

a. "Vivimos una grandísima crisis valórica". (Entrevista 25).

b. “... sé que es un país carísimo...”. (Entrevista $\left.N^{\circ} 6\right)$.

c. "Ellos han sido un apoyo importantísimo hasta el día de hoy". (Entrevista No 21).

d. "A mí, por ejemplo, me da muchísima pena la falta de respeto que hay". (Entrevista №21).

En estos ejemplos notamos el énfasis del adjetivo superlativo, independientemente de ser un calificador antepuesto o pospuesto al sustantivo. 
Algunas veces, la sola expresión del superlativo morfológico no basta para el énfasis que se quiere dar a la expresión y se recurre a otros elementos enfatizadores, junto con el superlativo flexivo.

“... lamentablemente, el Rector tuvo que tomar la, la determinación dee eliminar en unn, enn plazo pero brevísimo eliminar un curso". (Entrevista $\mathrm{N}^{\circ} 23$ ).

En este caso, "pero" pierde su valor conjuntivo para transformarse sólo en un elemento enfatizador de la característica enunciada por el adjetivo "brevísimo". Hay, entonces, en la expresión, un doble énfasis. Así aparece indicado este valor de énfasis de pero en la Gramática Funcional del Español de César Hernández Alonso (1984/1996: 302): “...cuando un pero encabeza una oración y no tiene un primer elemento que coordinar, ese conector deja de serlo, se convierte en pleonástico y en consecuencia, enfático". EI DRAE, consigna este valor de pero del modo siguiente: "Empléase a principio de cláusula sin referirse a otra anterior, sólo para dar énfasis o fuerza de expresión a lo que se dice". También el Diccionario de María Moliner da cuenta de este valor de pero, al definirlo como "una partícula expletiva o enfática usadísima".

\section{- $\underline{\text { Adverbios }}$}

El uso de adverbios superlativos flexivos es menor en relación con la forma adjetiva. Se usan especialmente adverbios de cantidad. Algunos ejemplos son los siguientes.

a. “... y se preocupan muchísimo de su familia." (Entrevista $\left.\mathrm{N}^{\circ} 25\right)$.

b. “... en vez de disminuir le aumentó muchísimo su deuda...". (Entrevista № 25). 
11.1.12. El énfasis en los superlativos formados con prefijo enfatizador:

El uso de prefijos para enfatizar la expresión es escaso en la elocución de los entrevistados. Sólo se registran 7 casos de "re" como enfatizador. En la expresión de los entrevistados, "re" concentra el énfasis y se manifiesta separadamente del adjetivo al que intensifica.

En los siguientes ejemplos, se aprecia claramente el valor enfático, equivalente a "muy" o "excesivamente" de "re-". En el primero de ellos, el uso coloquial del prefijo referido al participio pasado "movido" de "mover" (con significado de muy dinámico), es notoriamente separado y con carácter ponderativo, diferente del participio de removido del verbo remover.

a. "Mmm, bastante dinámico, re movido (el trabajo). Eeeh, no es rutinario como en otras áreas de la kinesiología". (Entrevista № 31).

b. “...,casi como ese problema aritmético que se hizo re famoso en la Vida es Bella, la película, ¿se acuerdan?”. (Entrevista № 5).

c. "Tenía como dos años y empezó a preocuparse si le faltaban pañales..., porque igual vio la situación re complicada,..." (Entrevista № 11).

Se encuentra usado "re" una sola vez para enfatizar la función adverbial del superlativo.

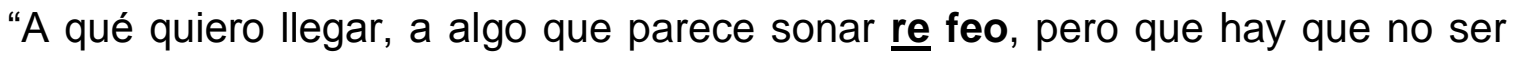
tan cínicos, pero entenderlo con pinzas...". (Entrevista № 5). 
11.1.13. El énfasis en los superlativos formados con cuantificadores adverbiales

Como ya se ha afirmado en las páginas anteriores, los superlativos formados por adverbios cuantificadores son los de mayor ocurrencia en la elocución de los entrevistados. El énfasis en la frase formada por el cuantificador y su núcleo adjetivo o adverbio está en el primero de estos elementos gramaticales.

Para la construcción de la frase superlativa (adjetiva o adverbial), se usan distintos cuantificadores. De éstos, el más recurrente en las entrevistas es "muy". Se citan los siguientes ejemplos de frases adjetivas y adverbiales:

a. “...bueno me separé de la mamá, fue un golpe duro para él, yo pienso, bueno para mí, porque con ella tuve una historia muy larga, casi desde niños". (Entrevista № 9).

b. "Hacíamos las orinas, en ese tiempo había gente muy especializada de los paramédicos, porque les enseñaban los médicos". (Entrevista $\left.N^{\circ} 12\right)$.

c. "Ése es como mi gran sueño ahora: tener mi casa; pero... no, de lo que llevo hasta el momento estoy muy contenta". (Entrevista № 13).

d. “... estructuralmente, Japón resistió muy bien, cosa que no nos pasó a nosotros, porque creo que hay normativas y las normativas se cumplen". (Entrevista № 32).

En algunos casos, el énfasis del cuantificador se expresa con la reiteración de éste, 2 o más veces. Por ejemplo:

a. "No, yo creo que a lo mejor aunque no siga con él..., con el papá de mi hijo, siempre les voy a estar muy agradecida, muy, muy agradecida ". (Entrevista № 13). 
b. “..., porque por mis hiiijos, lo que informó en la televisión, que empieza a bombardearnos un poco con información y si uno no está muy, muy, como muy claro,...". (Entrevista №22).

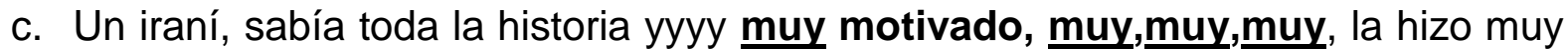
propia". (Entrevista $\left.\mathrm{N}^{\circ} 30\right)$.

Hay también ejemplos de uso de la frase superlativa formada con otros cuantificadores como bien, absolutamente, bastante, súper, más, etc.

a. "Yo ante eso tengo una postura bien especial". (Entrevista № 32).

b. "Ahora todas las comunicaciones es manejada, absolutamente manejada (sic)". (Entrevista №33).

c. "Yo sentía como que después de eso podíamos superar juntos cualquier cosa que se nos viniera. Así que no, ha sido súper lindo,...”. (Entrevista № 34).

d. "... esto de lo intercultural dentro del programa, entonces se vuelve $\underline{\text { bastante }}$ interesante”. (Entrevista №3).

e. "Así que no, no tengo problema con eso, creo que soy una persona completamente sociable, o sea...". (Entrevista $\left.N^{\circ} 6\right)$.

f. "Mira, yo me fui a Valparaíso con unas expectativas totalmente diferentes a lo que llegué a vivir, ...". (Entrevista $\left.N^{\circ} 8\right)$.

g. "Entonces ahí hay una influencia bastante fuerte, sobre todo por el cómic japonés...". (Entrevista № 17).

h. "Le preguntan, además, por qué cree él que está sucediendo lo que sucedía en París en esos momentos: la quema de autos y la violencia tan grande". (Entrevista №25). 
i. "Eso es lo, lo que a uno le llama la atención, y uno trabaja más tranquilo el hombre". (Entrevista N²6).

j. "Lo que pasa que en Japón, yo por lo que yo leo, en Japón las normas de seguridad, de responsabilidad son sumamente estrictas y son de por vida,...". (Entrevista Nº 32).

\subsubsection{El énfasis en los superlativos léxicos}

Existe en el corpus de la investigación una gran cantidad de palabras que se emplean con valor superlativo. Estas palabras o frases tienen ya registrado en el diccionario el valor superlativo. Muchas de ellas pertenecen al habla coloquial que le ha ido otorgando este carácter enfático a dichos vocablos. Entre ellos, encontramos adverbios, sustantivos, adjetivos y también frases adjetivas y adverbiales, que son usados para expresar enfáticamente lo que los hablantes quieren manifestar. Se citan algunos ejemplos, según se quiera enfatizar la cualidad o la cantidad de lo dicho.

Para expresar enfáticamente que una persona o una cosa posee cualidades que la destacan, se emplean adjetivos, sustantivos o locuciones como excelente (adjetivo), descueve (sustantivo), seco (adjetivo), de excelencia (locución adjetiva), de película (locución adjetiva), etc.

a. "El decano de Arquitectura, nombres dan lo mismo, pero este gallo era en realidad el descueve,,... . (Entrevista № 5).

b. "Bueno, en Cuba el cuento es ese; claro es lo ideal en la medida en que los gallos, los médicos, ejemplo típico, son de excelencia, o sea, de película,...". (Entrevista № 5). 
c. "El compadre estudia y resulta que es un excelente historiador, está estudiando historia y el compadre es seco y gran profesor de Historia". (Entrevista № 27).

Para manifestar el horror frente a una realidad, se emplean adjetivos como terrible, espantoso, horrible, etc.

a. "Como somos todos adultos, esta niñita creció, se me habían olvidado los problemas que tenía la adolescencia, que son terribles a mi modo de ver". (Entrevista № 1).

b. “... y está muy bien como está, porque antes ni siquiera podía dormir, era algo espantoso... terrible de tensa..." (entrevista $N^{0} 1$ ).

c. "Yo me volví a San Antonio, después ya no teníamos tiempo para juntarnos, el profesor que nos tocó... bueno que nosotros elegimos el profesor guía... fue horrible, había que andarlo llamando...". (Entrevista № 8).

Para ponderar lo agradable, muy bueno, grandioso o hermoso, se usan las siguientes palabras: precioso (adjetivo), maravilloso (adjetivo), bacán (adjetivo), espectacular (adjetivo), heavy (adjetivo), medio (adjetivo), la raja (locución adverbial de modo).

a. “... y el Tommy solo fue y se puso a escribir y después yo vi el mensaje, era precioso todo lo que había puesto". (Entrevista Nº 34 ).

b. "Me siento protegida, muy regaloneada, muy querida por mis hijos. Tengo un esposo maravilloso." (Entrevista $\left.\mathrm{N}^{\circ} 21\right)$.

c. "¡Aah!, eso fue muy, muy interesante, eeh, fue ¡El medio viaje, porque, bueno y fue súper,eeh, en corto tiempo, eeh, conocí muchos lados". (Entrevista № 31). 
d. "... y ahí mi mamá prepara una cenas heavy, bacanes de ricas. Eso". (Entrevista № 31).

e. "Estar ahí relajados, con un clima distinto, eeh, guatita al sol todo el día, comiendo bacán, sí, la raja, pero faltó el carrete no más, eeh, en las discoteques de allá, pero era muy chica todavía así que no podía salir sola".(Entrevista №31).

La cantidad excesiva de una realidad se expresa con adverbios y adjetivos que se usan recurrentemente en el habla chilena, como bastante, harto, demasiado, caleta, tremendo, gigante, bueno. El adjetivo bueno, en el habla coloquial, adquiere la connotación de cantidad muy grande, lo que puede constatarse con el primer ejemplo citado.

a. "...; entonces, no sé poh, yo me acuerdo que estaba comiendo y... comía puras papas y tomates... y todos los demás comiéndose su buen pedazo de carne, y obviamente yo comí, porque tenía hambre,...”.(Entrevista $\left.\mathrm{N}^{\circ} 20\right)$.

b. "Tenía cincuenta años. Eh..., eso me preocupó bastante, porque sentía yo que me habían sacado como la matriz, para mí era tan importante esa parte....." (Entrevista $\left.\mathrm{N}^{\circ} 18\right)$.

c. "La perrera era fuerte por un tema que se trató en los años... principio de los ochenta... setenta, entonces, se trató de cambiar el tema, se trató de trabajar harto con que... con que la gente sea responsable de sus mascotas, entonces se recogió harto perro en ese tiempo...".(Entrevista №9). 
d. "... o sea que es bastante poco pa`producciones como Machuca o como el mismo La Buena Vida que son películas que Andrés Wood gasta demasiada plata, demasiada, y yo creo que recupera un tercio...". (Entrevista $\left.N^{\circ} 27\right)$.

e. “¿Cómo se llaman estos jóvenes que trabajan en los, en los, en los bu, en los barcos de turismo del Mediterráneo? Y bueno y viaja por Grecia, y ha viajado caleta". (Entrevista №30).

f. Nos pegamos un pique tremendo con mis compañeros de la universidad. Caminamos caleta por Francia, principalmente, eeh, aprovechamos de subir a la Torre Eiffel..." (Entrevista № 31).

g. "Yo creo que en tu área también puede funcionar, no sé si la lengua, no sé, me estoy mandando un carril gigante, tal vez las últimas modificaciones de las letras de la RAE...".(Entrevista $\left.\mathrm{N}^{\mathrm{a}} 28\right)$.

Lo que tiene muy poco valor para los hablantes es calificado con vocablos que denotan ausencia o carencia. Entre éstos, están los sustantivos mugre, caracha, cero. En los diccionarios, caracha no registra el valor con que se usa en el habla coloquial de Chile, referido a algo sin valor alguno, sinónimo de "mugre".

a. “..., pero cuando tú vas a jubilar te toman, no te toman el total de haberes, sino que te toman el sueldo base, que es una caracha ". (Entrevista $\mathrm{N}^{\circ}$ 12).

b. "Si tú vieras el sueldo base que ganan nuestros compañeros de trabajo y son auxiliares de servicio, es una mugre”. (Entrevista № 12). 
c. "Y retribución cero. Así que viajé a Valparaíso a la entrevista y claro, pedí un poco más de plata, yo más o menos saqué la cuenta de cuánto iba a gastar en arriendo allá y tomé la decisión...”. (Entrevista Nº8).

Adjetivos como asqueroso y picante son utilizados por los entrevistados para manifestar lo que es considerado muy malo, muy feo o de muy bajo nivel. Por ejemplo:

a. “..., estaba muy mal hecho el programa, los fotógrafos eran asquerosos, entonces en sí no desde mi punto de vista, creo que todas las copias que se han hecho en Chile y en Argentina son pésimas respecto a los originales". (Entrevista № 3).

b. "Esas películas picantes". (Entrevista № 14).

Para denotar el descuido en grado sumo, la falta de interés en los estudios, se utiliza el aumentativo de flojo.

"Sí. Es que a ella no le gusta leer los libros, noticias, los diarios, es flojaza para leer...". (Entrevista № 1).

Para la expresión de lo descomunal, de aquello que sobrepasa la estatura habitual de las personas, el entrevistado № 28 usa un aumentativo inexistente en la lengua española: gorilona.

"Entonces él decía, ya mira, el hombre mide 1 metro 70, no sé, en el caso de mis compañeras escandinavas son 2 metros 47 - gorilonas, gorilonas -, y emmm, él hacía techos muy bajos, perdón, cielos muy bajos,...”. (Entrevista №28). 
El adjetivo aumentativo cabezona se utiliza para expresar la capacidad intelectual de una persona que es inteligentísima.

"Sí, la Santa María, pero es que ahí van los...la gente cabezona cabezona, intelectual intelectual, ese es el sueño, pero si es alguna ingeniería podría ser ahí..." (Entrevista №1).

11.1.15. El énfasis en los recursos estilísticos

El uso de recursos estilísticos en el habla oral tiene una clara intención intensificadora de aquello que dicen los hablantes.

En el corpus de la investigación, se registran 106 recursos estilísticos. De éstos, el de mayor ocurrencia es la reiteración (63\%); luego, la hipérbole con $20 \%$ de los usos; la metáfora, con $11 \%$, y la comparación, con $6 \%$.

\subsubsection{El énfasis en la reiteración}

Como ya se ha dicho, éste es el recurso más utilizado por los entrevistados para enfatizar la expresión. Se reiteran cuantificadores, palabras, frases y hasta oraciones, como una forma de los hablantes para hacer más intenso aquello que expresan.

Reiteración de adjetivos

En la reiteración de esta categoría gramatical, se producen dos situaciones de enunciación por parte de los entrevistados. La primera corresponde a una expresión en 
que cada adjetivo tiene el mismo énfasis, como puede observarse en los siguientes ejemplos:

a. "Se comunicaba solamente con dibujos, y poemas, pero escribía unos poemas horribles, horribles...poemas oscuros, de la Edad Media, esas cosas góticas, una tristeza pero infinita del alma, pero ella no decía lo que le pasaba,... (Entrevista №1).

b. "Y junto con eso, la modalidad de los profesores invitados, pero o sea, harto, harto profe gringo, invitados, o de afuera mismo, que dictaba módulos,..." (Entrevista №5).

c. "París, París, con la Torre Eiffel, con, con todo lo que eso significa. Eeh, el Museo Erótico, todo el Barrio Rojo, todo, todo, todo, bellísimo, bellísimo; los Campos Elíseos, o sea, es realmente bien". Entrevista № 29).

La segunda situación de enunciación es que no haya separación entre los adjetivos reiterados. El énfasis, en este caso, se produce en el segundo elemento. Esta es una particular forma de expresión de lo superlativo en el habla coloquial.

Algunos ejemplos son los siguientes:

a. "Me enseñaron, porque me metieron a un..., a una secundaria, a la secundaria que todo el mundo iba y ahí te nivelaban, eh, te ponen en un curso de acogida, según tus notas, durante el año, pasas al, al segundo año te nivelan al curso que tú deberías ir. Y eso, y ahí tenía una profesora que era francesa francesa, que impartía el francés quebecuas...". (Entrevista $\left.\mathrm{N}^{\circ} 6\right)$.

b. "Creo que, o sea, por supuesto que estas cosas siempre van cambiando, nunca tienes como un favorito o, no sé, considero que uno nunca tiene algo como favorito y que sea como posiblemente eterno. Aparte no tiene nunca el control 
de las cosas, pero a mí parecer mi director favorito favorito sería, ahora, Darkovsky que lo estoy como empezando a analizar". (Entrevista $\left.N^{\circ} 28\right)$.

c. Sí, la Santa María, pero es que ahí van los...la gente cabezona cabezona, intelectual intelectual, ese es el sueño, pero si es alguna ingeniería podría ser ahí... (Entrevista No1).

También se registra la reiteración de sustantivos, enunciados sin separación y con énfasis en el segundo, como puede observarse en el siguiente ejemplo:

“... e impartía el francés francés. La idea era aprender el francés quebecuas, porque el francés es diferente del francés original, como..., es como el chileno con el español, una cosa así. Se habla..., es como más mal, es más malo el francés de Canadá". (Entrevista № 6).

Beinhauer (1958/1978: 275) considera "curiosa" la duplicación de un mismo sustantivo en el español coloquial para ponderar la pureza y autenticidad del ser a que da nombre, y más aún si se repite tres veces el vocablo.

Reiteración de cuantificadores

Se enfatiza la expresión superlativa con la reiteración del cuantificador. Cada uno de los cuantificadores reiterados asume el énfasis correspondiente. Algunos ejemplos con diferentes cuantificadores reiterados son los siguientes:

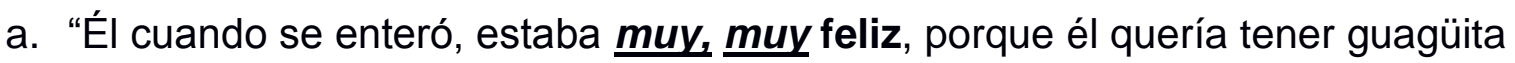
poh...". (Entrevista $\left.N^{\circ} 10\right)$.

b. "Entonces, cuando tú te das cuenta que aunque sea mínimo, mínimo lo que aprenda, eh, es valorable, porque ellos traen una carga social súper grande, 
algunos claro, no todos, pero hay algunos niños que traen una carga social súper fuerte de la casa, súper, súper fuerte". (Entrevista № 13).

c. "Me gusta, eh, San Andrés, San Andrés, Colombia, ahí donde los nativos y todas las playas con sus corales, sus peces, todo $\underline{\tan } \underline{\tan }$ natural, eh, qué más, ¿Qué más vas a ver? Y ahora que voy a Brasil, poh, la próxima semana" (Entrevista № 29).

Reiteración de frases sustantivas

En estas estructuras, siempre tiene el énfasis el adjetivo que va antepuesto al sustantivo.

a. "Y bueno, y en Brasil hemos estado con los, con los, con los tres: con Jorge, con Pablo y con Enrique. Pagamos todo el año eso. Eeh, claro. Eeh, así quee bueno, harto viaje, harto viaje $_{2}$ hartos lugares, pero siempre es como poco cuando uno se da cuenta que en realidad,..." (Entrevista $\left.N^{\circ} 30\right)$.

b. "Eeeh, altos: he pasado $\underline{\text { muchas }}$ alegrías, $\underline{\text { muchas }}$ alegrías. Alegría familiar, por una parte, pero, a la vez, bajos cuando en un momento me casé por segunda vez y después, cuando nació mi hijo, mi mamá tomó la decisión de demandarme". (Entrevista N²1).

Reiteración de frases adjetivas

En estas frases, hay un mayor énfasis en el adverbio que sirve de cuantificador del adjetivo. 
a. "Yo creo que sí, porque hay un antes y un después. El antes era que...igual uno es más cerrado, es más cerrado, teni..., uno no tiene la misma mente que la gente..., eh, no quiero denigrar a los de San Antonio ni mucho menos, pero cuando tú conoces otro país y ves otras cosas, ya la mente se te amplía, eh, de hecho, las cosas sexuales, los gays, las lesbianas y qué sé yo, ni un drama con eso, ni un atado, tengo hartos amigos que lo son y somos re amigos...". (Entrevista № 6).

b. "No, es $\underline{\text { muy }}$ negativo, $\underline{\text { muy }}$ negativo, por el aspecto de que, eh..., uno es papá, no amigo de los hijos. Cuando uno pasa a ser amigo y entre comillas, amigote de los hijos ya...deja de ser papá, entonces en un momento dado, tú le quieres aplicar un respeto al hijo, que te respete y no te va a respetar, porque tú eres el amigo, no el papá”. (Entrevista № 17).

Reiteración de oraciones

En la reiteración de oraciones, algunas veces la carga enfática la tienen los adverbios que modifican a los verbos; en otras, la acción misma expresada por el verbo; o, en los casos de construcciones con verbos copulativos, los adjetivos que funcionan de atributo.

a. "Eso nosotros nos dedicamos a inculcar en la gente el tema de la tenencia responsable, de generar la...la consciencia necesaria... costó harto, costó harto también porque fuimos muy vilipendiados por el tema de la perrera, que nosotros le cambiamos al eufemismo de decirle móvil de protección canina". (Entrevista № 9). 
b. ."¡Pero!, lamentablemente, estamos en un país subdesarrollado en el cual nosotros necesitamos trabajar y de alguna forma, como lo dicen estas propias personas, llevar el sustento a su casa, yyy, lamentablemente, ellos tenían que arriesgar su vida, sabían en qué condiciones estaban trabajando...y lo lamento demasiado, lo lamento demasiado;...". (Entrevista № 23).

c. "y después veo a la Natalia en el velorio y estaba solita, estaba solita ella con todos los familiares de él, y nos vio y se puso a llorar y ahí nos contó todo". (Entrevista № 15).

d. "No, yo vivía en Santiago, vivía en Ñuñoa, específicamente en Ñuñoa, e iba al Estadio Nacional, y me ponían en una pista a correr: yo corría y corría y corría.... y corría. Como tres horas puro corriendo...". Entrevista № 11).

\subsubsection{El énfasis en la hipérbole.}

Al usar recursos como la hipérbole, cuyo valor significativo es claramente hacer que la realidad sea exageradamente representada, lo que el hablante quiere es justamente resaltar, enfatizar lo dicho.

En las entrevistas realizadas, son numerosos los usos de este recurso estilístico. El énfasis se produce en algunos de los elementos gramaticales que contiene la hipérbole (verbos, adjetivos, adverbios o locuciones adverbiales). Algunos ejemplos son los siguientes:

a. "Y ahí casi me morí poh, le conté a mi mamá, mi mamá se puso a llorar y todo y llamamos a Felipe y el Felipe ya no tenía teléfono poh, así que no 
sabíamos cómo ubicarlo, porque no sabíamos dónde estaba, aparte con el miedo de las réplicas, ese día sábado no hicimos mucho". (Entrevista № 15).

b. " ..., porque cuando yo estaba chica o estaba en el colegio, si no comía carne, no comía, o sea, mis papás me obligaban a comer carne, porque o me daban arroz con carne o puré con carne o lo que sea, entonces si yo comía, comía tres cucharadas de puré y quedaba muerta de hambre y no me hacían comida especial y me decían que me tenía que alimentar sí o sí". (Entrevista № 20).

c. "No sé, los nuevos procesos, los, esos sistemas que vienen ahora para instalar que le cambian la vida a uno, que le enseñan. que, en un dos por $\underline{\text { tres, }}$ uno está en contacto con los bancos, puede comprar todo". (Entrevista № 29).

\subsubsection{El énfasis en la metáfora.}

En este recurso, el énfasis se centra en los elementos nominales con que se representa figuradamente la realidad.

Algunos ejemplos de metáforas con valor superlativo son los siguientes:

a. "Ahí empezaba la historia como de mi hiperactividad..., entonces, me llevaron a los médicos, porque la niña no se podía quedar quieta, era un canguro saltando, una pulga todo el día. No encontraron nada más constructivo que a mi papá le dijeron que me iban a dar...en ese tiempo ocupaban mucho el Ritalín....(Entrevista №11). 
b. "Llevaba dos años y medio más o menos entre intermitencia. El año 2000 nació el niño, y ese mismo año, a su vez, el año anterior, el 99' murió mi abuela, que también era un bastión pa' mí, en cuanto a apoyo...." (Entrevista № 9).

c. "Entonces como...oh, qué onda estos huevones, cachay. Y..., ellos te trabajaban la mente, eh, así...bien estricta, bien así...care' palo poh". (Entrevista № 7).

d. "No, los demás son un pan de Dios, mi mamá los tenía que cachetear para que se movieran. No, yo salí con toda la hiperactividad y después salió mi hermana, también un pan de $\underline{\text { Dios, }}$ mi hermana era lo más, lo más tranquilo que había..., iban todos y a la única que amarraban de la mano era a mí...”. (Entrevista №11).

\subsubsection{El énfasis en la comparación.}

En este recurso, el énfasis se centra en el comparando de la expresión. En algunos casos, el elemento sustantivo se halla elíptico, por lo que la frase adjetiva asume el énfasis en la comparación.

Uno de los ejemplos registrado en las entrevistas es la locución lexicalizada "como el hoyo", con el valor superlativo de "muy mal", "de manera pésima", que según el Diccionario de Americanismos corresponde al ámbito vulgar y popular en Chile. En esta locución, el énfasis está centrado en el sustantivo hoyo.

"O sea, vemos grupos que salen, no sé, van a tocar a un pub, van a tocar, hacen una tocata, tipos re buenos, entonces, pero resulta que los tipos los 
atienden como el hoyo, les va mal, no va gente, entonces los tipos se desmotivan y dejan la cuestión botada". (Entrevista № 27).

En otras expresiones comparativas, como se explicó anteriormente, el elemento comparando se halla elíptico, en consecuencia, el énfasis se centra en la frase adjetiva que califica al elemento nominal tácito.

a. "En realidad, en mi familia, mi mamá era la que estaba más como..., como..., se sentía como orgullosa, pero mi papá no, siempre nos dijo:...". (Entrevista № 7).

b. "El colegio fue, fue todo un trauma, porque estaba..., yo estudiaba en San Antonio, acá en el colegio Pompeya, eh, y me fui en octavo básico, había pasado a octavo básico, en la mitad de octavo básico me dicen: sabes que te vai a mitad de..., te vai en Junio y no te dai ni cuenta y el 31 de Junio estaba en Canadá, te vai el 29 y el 31 ya estay allá, o sea, fue una cosa de, por decirlo así como de segundos". (Entrevista Na 6).

\subsection{POSICIÓN DE LOS SUPERLATIVOS}

El orden en que aparezcan los elementos oracionales en el discurso de los hablantes está íntimamente relacionado con su personal estilo y el énfasis que ese hablante quiera imprimirle a su expresión.

Gili y Gaya (1961/1964: 81) explica que en el orden de los elementos constitutivos de una oración intervienen factores expresivos ajenos a las leyes del juicio lógico, ligados a la atención más o menos tensa hacia determinados elementos 
oracionales, a la voluntad de destacar unos o atenuar otros, a la intensificación y calidad afectiva de algunos. Este ordenamiento de los elementos está determinado por la situación comunicativa y el estilo personal del hablante.

Andrés Bello (1928) analizó la posición del adjetivo interpretándola desde una perspectiva lógica. Según este criterio, el adjetivo pospuesto determina o restringe la extensión del sustantivo, mientras que antepuesto añade al sustantivo "una nota o cualidad que desenvuelve la imagen, pero no la limita. Para este gramático, el adjetivo antepuesto es explicativo, y el pospuesto es especificativo.

Al analizar la expresividad, se habla de la voluntad de destacar o atenuar determinados elementos oracionales, de la intensificación y calidad afectiva de algunos elementos, de la necesidad y hábitos rítmicos de la comunidad lingüística, del estilo personal del que habla o escribe, etc. Su propósito principal será, pues, fijar el valor expresivo que resulta de la colocación de estos elementos en la oración, relacionando, como se ha dicho, expresividad y posición (X. Padilla, 2001: 33).

En relación con la posición del adjetivo en el grupo nominal, se puede decir que existen muchos factores que influyen en ella. En español, a diferencia de otras lenguas, el adjetivo calificativo puede usarse antepuesto o pospuesto al sustantivo. En el registro coloquial, la anteposición o posposición no tiene mayormente incidencia en el valor semántico de la expresión, pero sí tiene una valoración enfática.

Desde una perspectiva pragmática, la posición que tenga el adjetivo superlativo dice relación directa con la intención del emisor de intensificar aquello que dice del sustantivo poseedor de la cualidad.

S. Fernández (1986) afirma que, en el sintagma nominal, la posposición del adjetivo es el orden que predomina en español. El adjetivo va antepuesto al sustantivo para 
expresar afectividad, subjetividad o síntesis; en cambio, cuando va pospuesto expresa objetividad y análisis y restringe la extensión del sustantivo.

La anteposición supone, por parte del que habla, mayor atención hacia la cualidad que al propio sustantivo; en la posposición, el sustantivo asume el interés principal. Por eso se dice que el adjetivo antepuesto tiene carácter subjetivo o afectivo y el pospuesto, que expresa una cualidad más o menos característica del sustantivo, sin realzarla, tiene carácter objetivo.

La preferencia por una u otra posición cuando las condiciones lógicas o el uso no exigen colocación fija, es un elemento de caracterización de un estilo (Gili y Gaya, 1964: 218).

En el habla literaria, sin embargo, la posición que tenga el adjetivo dentro del grupo nominal es muy importante. El poeta Pedro Salinas (1967: 189) considera que la diferencia entre el adjetivo antepuesto y el adjetivo pospuesto está en que el primero encierra un "atributo afectivo", mientras que el segundo, una "distinción lógica". Para él, el adjetivo antepuesto representa la intervención del elemento humano, del sentimiento en el mundo de valores objetivos representados por los sustantivos. Concluye que los adjetivos antepuestos representan la manera de sentir las realidades del mundo por parte del hablante.

En este trabajo, se aborda el tema de la posición del superlativo en la elocución de los entrevistados, considerando tanto las formas adjetivas como adverbiales, expresadas en forma sintética y analítica.

Los adjetivos se analizan de acuerdo con la función desempeñada, esto es, adyacente, atributo y complemento predicativo 


\subsubsection{Posición del adjetivo superlativo adyacente}

El adjetivo calificativo adyacente, como un elemento caracterizador del sustantivo, tiene en la elocución de los hablantes, una posición antepuesta al nombre o pospuesta a él, sin que se modifique su valor semántico, en la mayor parte de los casos.

Matte Bon (2002: 185) dice, respecto de la 'posición del adjetivo, que "cuando el adjetivo va junto al sustantivo puede ir inmediatamente antes o inmediatamente después", y agrega que puede tener matices expresivos "ligeramente" distintos según la posición que tenga. Cuando va después, el adjetivo constituye generalmente una información nueva respecto del sustantivo y esto hace que tenga un relieve mayor., por ejemplo: Acabo de leer una novela muy interesante o Vivo en una casa modernísima. En cambio, el adjetivo en posición antenominal, ya no es nuevo con respecto al sustantivo, y junto con él forma un bloque.

Sobre el valor del adjetivo en función de adyacente directo del sustantivo, César Hernández (1984/1996: 555) expresa que está mediatizado por su posición dentro del sintagma y que puede anteponerse o posponerse al nombre, pero que expresa diferentes valores en cada caso. El adjetivo antepuesto tiene generalmente valor explicativo, mientras que pospuesto sin pausa es determinativo o especificativo, esto es, que concreta, restringe o precisa el contenido del núcleo al que modifica. Si va antepuesto por la importancia estilística de esa posición, al adjetivo atrae la atención del hablante y del oyente, es decir, se manifiesta con valor subjetivo y afectivo; en él se enfatiza la cualidad. Cuando se pospone al nombre, el sintagma adquiere un carácter más descriptivo y objetivo.

La colocación del adjetivo tiene gran importancia en lo que se refiere a su manera de significar. El mismo adjetivo, según el lugar donde aparezca, puede tener una 
función estructural, como elemento constructivo en el enunciado o puede ser simplemente un elemento decorativo, cumpliendo tan sólo una función ornamental.

Autores como Bello (1958), Lenz (1925), Bolinger (1972), afirman que el adjetivo que aparece después del sustantivo, 'especifica', diferencia al sustantivo, mientras que el adjetivo que se antepone 'explica' o 'realza' al sustantivo.

\subsubsection{Anteposición del adjetivo superlativo}

El adjetivo antepuesto al sustantivo, en la mayoría de los casos, aporta un sentido valorativo, ponderativo de la cualidad expresada por el adjetivo. En este caso, se interpreta el sustantivo como fundamentalmente poseedor de la propiedad significada por el adjetivo. Con frecuencia, tiene un papel meramente ornamental, sobre todo cuando expresa cualidades inherentes al sustantivo. A este adjetivo se le llama "epíteto" y es de uso recurrente en el habla literaria.

\section{Adjetivo superlativo sintético}

En las entrevistas realizadas, el adjetivo superlativo sintético tiene tanto posición antepuesta como pospuesta al sustantivo que califica, sin embargo, la anteposición es la de mayor ocurrencia en la elocución de los entrevistados. Dado el carácter esdrújulo de este superlativo, con la anteposición, se produce una mayor carga tonal en él y, por supuesto, un mayor valor enfático en la cualidad expresada.

Algunos ejemplos de anteposición del superlativo sintético son los siguientes:

a. "Vivimos una grandísima crisis valórica. (Entrevista № 25). 
b. "Dicho de otra manera, existen dos frentes relacionados con la economía: los imperios económicos, que están preocupadísimos sólo de ellos mismos sin importarles el medio natural: daño a la naturaleza, manifestado en la altísima contaminación, depredación de gran cantidad de especies, cambio climático, etc.". (Entrevista № 25).

c. "Cada año vemos que las grandes potencias se reúnen con dispositivos de altísima seguridad, debido a que son rechazados por la gran mayoría los acuerdos que asumen, los que generan más desestabilización en el planeta". (Entrevista № 25).

Se registran algunos ejemplos de adjetivos superlativos sintéticos correspondientes a adjetivos numerales, cuya posición es siempre antepuesta al sustantivo.

a. "Así que cuando se trata de películas cómicas y simpáticas, ahí estoy en primerísima (fila)”. Entrevista № 29.

b. "Pero, para mí, en primerísimo lugar está el respeto. Si yo te estoy formando, te estoy enseñando". (Entrevista N²1).

También se encuentra el uso de adjetivos superlativos sintéticos antepuestos, provenientes de adjetivos indefinidos, cuya posición natural en la lengua española es ésta. Por ejemplo:

a. "A mí, por ejemplo, me da muchísima pena la falta de respeto que hay". (Entrevista № 21).

b. "Es vergonzoso y lastimero decirlo que hay gente que ocupa cargos de muchísima responsabilidad, ¿No?, y confiabilidad, y lo único que hacen es 
meterse la plata para proyectos en el bolsillo, o inventan proyectos y se la meten en el bolsillo". (Entrevista $\left.\mathrm{N}^{\circ} 25\right)$.

Los superlativos clásicos de origen latino como mejor, peor, pésimo, máximo, etc., que hoy la RAE considera superlativos léxicos, tienen, en las entrevistas, un mayor uso como elemento antepuesto a un sustantivo. Por ejemplo:

a. "O sea, si los tipos dicen vamos a lanzar un fondo concursable pa'radios y le vamos a dar a toda la radio que den música chilena y la vamos a hacer competir pa`quien presenta un mejor proyecto...". (Entrevista № 27).

b. “... y aquí estoy, terminé la carrera, fueron dos años, dos años y medio, ahora tengo que terminar mi práctica y fueron los mejores años de mi vida, la experiencia más gratificante,..." (Entrevista № 6$)$.

c. "En el caso de los Transformers, porque es muy mala, es pésima, tiene una fotografía muy saturada, la uno, la dos no estoy ni ahí con verla, pero me gustó la fotografía, pero es lo único que apreciar de una película así, que tiene un mal guión, tiene un pésimo director,..." (Entrevista $\mathrm{N}^{\circ}$ 14).

Adjetivo superlativo analítico antepuesto

La anteposición del adjetivo superlativo analítico es menos frecuente en la elocución de los entrevistados. La forma superlativa se construye con diferentes cuantificadores, principalmente con "muy", que es el más recurrente. Ejemplos con "muy": 
a. "No tengo idea, pero mi hermana conversó... y él y su familia... la señora, me parece, y el hijo que es profesor... muy buena persona y lo hace gratis, ..." (Entrevista № 1).

b. "Claro, tenía un promedio 6.1, que en eesa época, se les exigía a los deportistas tener buenos promedios de ... de la enseñanza media, tenías que tener muy buenos promedios para seguir de seleccionado nacional, si no tenías promedios buenos, tú te ibas". (Entrevista No 11).

c. “..., por el tema del mismo ámbito donde viven, de repente el padre es alcohólico o hay problemas económicos en la casa, que los chicos no asisten a clases, entonces, ese chico no va a poder ser nunca un buen estudiante, o sea, es...son muy raras ocasiones de que él, por sacrificio personal del niño, que pueda salir adelante, pero es muy raro, muy raro ...”. (Entrevista №17).

d. "Por ejemplo, en el cine lo que aprecio de manera directa e indirectamente, porque igual estoy viendo y estoy preocupado de la trama, porque siempre me fijo en la fotografía, en los buenos guiones me gustan, los efectos a veces no los tomo en cuenta, hay películas con muy malos efectos, pero son muy buenas “. (Entrevista N¹4).

Además del cuantificador "muy", se usan otros, como "bien”, "más” "súper", entre otros, para construir la forma superlativa analítica. Algunos ejemplos son los siguientes: 
a. "La cuestión es quee del SOCA me llamaron entremedio digamos, pa`decirme que algo así como bien educadita la respuesta que cumplía con todos los requisitos, pero era mujer". (Entrevista $\left.\mathrm{N}^{\circ} 30\right)$.

b. "En general, mis promedios fueron todos sobre cinco, tuve que dar súper pocos exámenes... no, me fue súper bien". (Entrevista № 8).

c. La familia estaba ahí sin agua, sin luz, y, además la Javi, mi sobrina, que estaba chiquitita, así que bien estresante, la verdad, la experiencia, y después me tocó el tema de las réplicas". (Entrevista №31).

d. Tenía los más diversos proyectos, igual, pero era una cuestión así como es, o sea, totalmente, eeh, en el aire, digamos, así, ni siquiera honorarios, era pago por hora". (Entrevista Nº 30).

\subsubsection{Posposición del adjetivo superlativo adyacente}

El adjetivo pospuesto al sustantivo conserva su significación denotativa. Su calificación es objetiva. Estos adjetivos tienen, como ya se ha dicho, un valor especificativo, ya que suponen la elección de una opción entre varias posibles. Por esta razón, no es prescindible. Su presencia es necesaria para la caracterización del sustantivo.

La posición posnominal del adjetivo superlativo adyacente es la más recurrente en la elocución de los entrevistados, tanto en su forma sintética como analítica. 
Adjetivo superlativo sintético pospuesto

Como ya se ha dicho, la mayor cantidad de los superlativos sintéticos adyacentes tiene una posición posnominal. Algunos de los ejemplos registrados en las entrevistas son los siguientes:

a. "O sea, si sumamos los factores: la universidad privada se rige por los capitales, por plata, por aranceles caros, carísimos, si para preparar la PSU es casi necesidad ir al Pedro de Valdivia,..."(Entrevista $\left.N^{\circ} 5\right)$.

b. "No obstante, todo es producto del apoyo de una inmensa población compradora: caso conocidísimo como es la Teletón". (Entrevista № 25).

c. “... o sea, ponte tú, la Daniela gasta 150 lucas por proyecto, en la sola presentación de las láminas, tú la hai visto.... Eso no lo pone la U, por eso, es una carrera carísima para los alumnos, pero para la universidad es grito y plata". (Entrevista № 5).

d. "Y no poh, darme un buen gusto de conocer Inglaterra, sé que es un país carísimo, pero me gustaría conocerlo ya en un momento de mi vida cuando ya tenga todo,..... (Entrevista $\left.\mathrm{N}^{\circ} 6\right)$.

e. "El transporte escolar lo iba a buscar, lo iba a dejar. Me lo dejaba en casa de mi suegra, que vivíamos relativamente cerca. Ellos siempre han sido un apoyo importantísimo hasta el día de hoy”. (Entrevista №21).

f. "Eeeh, en ese sentido, se le dio la oportunidad a todo el mundo yyy, lamentablemente, el Rector tuvo que tomar la determinación dee eliminar en unn enn, plazo, pero brevísimo, eliminar aproximadamente un curso". (Entrevista № 23). 
g. "Génova con sus múltiples eh, parajes históricos, sus cementerios hermosísimos, en Venecia, puuff, Venecia era un sueño". (Entrevista № 29).

Si bien la mayoría de los adjetivos superlativos léxicos de origen latino tiene una posición adnominal, se registran, en las entrevistas, algunos casos de posposición de estos adjetivos.

a. “..., pero yo creo que se debe también a que yo no estuve en un tiempo, y ahora que yo estoy todo el tiempo, es muy fundido conmigo, pero sigue siendo, eh, el fundimiento máximo de mi mamá". (Entrevista Nº13).

b. "Pero fueron y uno las ve ahora y son películas que tú me dices y "esta cuestión", las actuaciones pésimas eeeh, excepto que de Johnny Cien Pesos que yo creo que está muy bien lograda". (Entrevista № 27).

Adjetivo superlativo analítico pospuesto

La posición posnominal del adjetivo superlativo analítico es la que registra mayor cantidad de usos. Para la construcción de esta frase adjetiva superlativa, los entrevistados emplean, principalmente el cuantificador "muy". Algunos ejemplos son los siguientes:

a. “... y ella se vio sola, porque yo siempre la acompañaba, pero por cuidar a su abuela, yo la dejé a un lado, y... y fue una cosa muy negra, y muy oscura, y muy triste". (Entrevista №1).

b. "Entonces los cabros, las chiquillas también llegaban en su auto, eh..., sobre todo la facultad quedaba en un lugar muy lejano, y... queda en la Pintana, 
lugares que muchos de ellos ni siquiera habían conocido en su vida,...". (Entrevista № 9).

c. "No, buena experiencia, sí: La gente muy simpática, amena, jajaja. No, y ha sido buena...". (Entrevista Na10).

d. "Estoy frente a una, a esas mujeres muy jóvenes, o profesionales; me toca atender profesoras, médicos, abogados". (Entrevista № 29).

e. "'Nosotros fuimos amigos primero, entonces de ahí yo empecé a ver de a poco que tenía todas las características que yo había buscado siempre, que era una tremenda persona, un tremendo corazón, que tenía muy buenos sentimientos, que era un hombre muy inteligente, que a mí me hace admirarlo". (Entrevista № 34).

Los entrevistados usan también otros cuantificadores para formar la frase adjetiva superlativa, como "más", súper", "tan”, "totalmente", "bastante”, "bien”, etc.

A continuación, se ejemplifica el uso de algunos de estos cuantificadores. Con cuantificador "más"

a. "...y necesita de apoyo familiar, de apoyo de psicólogo, de apoyo de psiquiatra y ella siempre en su fuero más interno, y aunque lo niegue, delante de la sociedad y trate de autoconvencerse de que era lo mejor. Que era el único camino, en su fuero interno sabe que asesinó a un ser vivo que no podía defenderse,,... . (Entrevista $\left.\mathrm{N}^{\circ} 4\right)$.

b. "Más acceso al consumo de drogas más fuertes". (Entrevista № 17).

Con cuantificador "súper" 
a. "O sea, trabaja para la Municipalidad, eh, con Salud Mental y con las personas que son pacientes derivados de depresión, trabaja con ellos, y yo, así como en el área de lenguaje, como profesora, trabajos súper distintos, pero tenemos gustos en común...”. (Entrevista № 16).

b. "Entonces, cuando tú te das cuenta que aunque sea mínimo mínimo lo que aprenda, eh, es valorable, porque ellos traen una carga social súper grande, algunos claro, no todos...". (Entrevista № 13).

\section{Con cuantificador "bastante"}

a. "No, trabajaba en una constructora. Trabajaba en una constructora entonces tenía un horario bastante extenso, y yo me dedicaba a trabajar y a mi hijo...". (Entrevista № 21).

b. "Si no me recuerdo como se llamaba el nombre de esas cartas. Entonces ahí hay una influencia bastante fuerte, sobre todo el cómic japonés, porque hoy día, no sé poh, si ven Tom y Jerry o el Chavo del Ocho, a lo mejor lo van a encontrar ridículo". (Entrevista № 17).

\section{Con cuantificador "bien"}

a. "Era difícil a veces, porque muchos de ellos vivían en pensión. Con los que más me juntaba y también era una realidad como bien especial de que llegué ahí, porque, por ejemplo lo que fue la USACH, era una clase socioeconómica bastante media". (Entrevista № 9).

b. “... porque digan lo que digan, acá en Chile se discrimina bastante cuando se ve a un joven de corbatita, bien arregladito, o a uno todo desordenado y chascón, aunque sea muy inteligente". (Entrevista $\left.\mathrm{N}^{\circ} 17\right)$. 
Con otros cuantificadores

a. "Y ahí es donde uno quisiera entregarle mucho cariño, tampoco se dejan, porque están en una edad difícil, mimarlos como cuando estaban chicos, darles besos, cariños, caricias, porque les da vergüenza... entonces la cosa se va poniendo ya más complicada... eh... yo encuentro que es un período demasiado difícil..."(Entrevista № 1).

b. "con él pudimos clasificar todos estos motivos en cinco grandes ítems, o categorías que eran una cesárea solicitada por el paciente, una cesárea verdaderamente justificada en la clínica...”. (Entrevista № 2).

c. "No obviamente que tiene que haber confianza, eso es..., es que son cosas totalmente diferentes...". (Entrevista $\left.N^{\circ} 17\right)$.

d. “... cuando al tercer día ya no tenía, eh..., me iba a venir, me vino una hipocalcemia..., me dejó totalmente sin movimiento, los músculos totalmente duros y el del corazón comenzó a paralizarse “. (Entrevista № 18).

e. "El que está arriba siempre protege a los de más abajo, trata de ocultarlo para que no sea un escándalo tan grave". (Entrevista №33).

11.2.12. Posición del adjetivo superlativo en función atributiva

El atributo predicativo es una función sintáctica que cumple el adjetivo en oraciones construidas con verbos copulativos o atributivos. En este tipo de oraciones, la posición del adjetivo superlativo (analítico o sintético) es, en la lengua española, naturalmente posverbal. 
Gili y Gaya (1964: 86)) señala que en la oración de predicado nominal (al igual que en los casos de unión de sustantivo y adjetivo atributo sin verbo copulativo), el adjetivo pospuesto realiza el orden lineal, en que el determinante sigue al determinado (esta tendencia lineal o progresiva es una característica de la lengua española y también de otras lenguas modernas); el adjetivo antepuesto responde al orden envolvente, es decir, el determinante se anticipa.

Según Marcos Marín (1998: 32), por regla general, el orden de los constituyentes de la construcción atributiva es sujeto + verbo copulativo + atributo. Pero la lengua española tiene flexibilidad suficiente para permitir el cambio de orden. La anteposición del atributo al verbo, que algunos gramáticos llaman dislocación, es un procedimiento para marcar relevancia de este constituyente En este caso, el atributo se destaca enfáticamente y es considerado como el elemento más importante del enunciado

El adjetivo superlativo en función de atributo de los verbos ser y estar es el que registra el mayor uso en la elocución de los entrevistados, tanto expresado en forma sintética como analítica.

Adjetivos superlativos sintéticos en función atributiva

Como se ha dicho anteriormente, se registran algunos casos de uso de la función atributiva de superlativos sintéticos, tanto con el verbo "ser" como con el verbo "estar".

Ejemplos de superlativo sintético atributo del verbo "ser":

a. "No, si por eso te digo que fue complicadísimo, porque tuve que pagarme el hospital, tuve que pagarme todo". (Entrevista N 11). 
b. "Esto último es un robo de hormiga, pero actúan protegidos por la ley y sus ganancias son altísimas, pudiendo ser más criteriosas, y con ello favorecer a una amplia cantidad de personas que somos clientes". (Entrevista № 25).

c. "Sí, al lugar que yo iría, sería Génova y Asís. Italia, Italia me seduce como su gente, su entorno, eh. Es todo hermosísimo". (Entrevista № 29).

d. "Y la idea de taller es la construcción de uno, siempre tiene como la misma unidad en cierta manera, siempre la formalidad es tender al uno, ¿Cachai?, la forma tiene que ser una unidad, el taller tiene que ser uno, un cuerpo y el cuerpo tiene que ser uno Tiene que funcionar como colectivo y eso es complicadísimo". (Entrevista N²28).

Ejemplos de superlativo sintético atributo del verbo "estar":

a. "Lo tomé así como hobby los fines de semana..., o cuando me llamaban, que iba a haber una competencia ah, ahí iba..., pero no tanto, porque igual había que sacar pañales de por medio, había que...de que..¿¿cómo es que se llama? El niño tenía que tomar leche, darle de comer, así que estaba complicadísimo". (Entrevista № 11 ).

b. "Dicho de otra manera, existen dos frentes relacionados con la economía: los imperios económicos, que están preocupadísimos sólo de ellos mismos, sin importarles el medio natural...”. (Entrevista № 25).

c. "Creo que están lejísimos, el valor de la afectividad y la solidaridad. Muestra de ello es la inmensa cantidad recaudada por las grandes empresas que donan porque ello les permite descontar impuestos". (Entrevista $\left.\mathrm{N}^{\circ} 25\right)$. 
d. "Bien, súper bien. Estuvo buenísima la fiesta, porque tuvimos el bautizo de la pequeña y hizo una ceremonia muy bonita, eeh, y ahí estuvo festejando con unas comida exquisita, así que eso". (Entrevista № 31 ).

También se registran algunos usos de superlativos clásicos como atributos, especialmente con el verbo ser.

Ejemplos con el verbo ser:

a. "Puede que las soluciones, a lo mejor, no sean las óptimas, pero no me quedo en la, en en solamente en, en la crítica, ¿ya? Eeh, eso". (Entrevista № 30).

b. "Creo que todas las copias que se han hecho en Chile y en Argentina son pésimas respecto a los originales". (Entrevista №3).

c. "Entonces, cuando tú te das cuenta que aunque sea mínimo, mínimo lo que aprenda, eh, es valorable, porque ellos traen un carga social súper grande, algunos, claro, no todos,...". (Entrevista №13).

Sólo un entrevistado usa, como atributo, el adjetivo superlativo léxico con el verbo estar.

"Es un tema laargo, no es algo que se va a solucionar de un día para otro, porque cada vez se levanta una piedra y salen más niños delincuentes. Cada día la cosa está peor". (Entrevista № 21).

Adjetivos superlativos analíticos en función atributiva

Las oraciones copulativas construidas con los verbos ser y estar, con el atributo predicativo expresado de forma analítica, son recurrentemente usadas por los 
entrevistados. Para la estructura de este superlativo, los hablantes usan variados cuantificadores.

Puesto que la mayor cantidad de superlativos analíticos usados por los entrevistados corresponde a aquellos que funcionan como atributos de verbos copulativos, se consideran, para ilustrar el uso, algunos ejemplos, según el cuantificador que se emplea para la estructura.

Los adjetivos superlativos en función atributiva con verbo "ser" son los de mayor ocurrencia.

Ejemplos con cuantificador "muy" (el más recurrente):

a. "... si poh, hay gente buena, de buen corazón, que hace estas obras tremendas para la gente que no tiene plata, y él, porque él dice le contaba a mi hermana que ellos eran muy pobres, y... él salió adelante...”. (Entrevista $\mathrm{N}^{0} 1$ ).

b. "Llega la venta de hamburguesas, se llenan las hamburguesas. Eeh, somos muy consumistas de experiencias extranjeras por, y creo que se basa justamente en lo mismo, en el hecho de querer ser o parecernos a los que nosotros suponemos que son triunfadores..."(Entrevista $\left.\mathrm{N}^{\circ} 32\right)$.

Ejemplos con cuantificador "bastante":

a. "Estaba recién empezando eso. Tomé todos los ramos del plan común, era bastante bueno,... realmente me gustó". (Entrevista № 9).

b. "Entonces puede que la cartelera esté mala y la gente se queja porque hay etapas del cine del año, en que el cine es bastante fome para uno, no estoy diciendo que sea fome para todos, ..."(Entrevista №27). 
Ejemplos con cuantificador "bien":

a. "...y los quebecuas son bien simpáticos, no como los gringos, como los franceses que como que te ignoran, no, estos son bien acogedores,...". (Entrevista №6).

b. "Claro, claro. Mi vida, la verdad, ha sido bien movida, ha sido bien vivida, a Dios gracias". (Entrevista № 21).

Ejemplos con cuantificador "súper":

a. "Darkovsky tenía, no sé, algo como de intentar liberar el espíritu, tal vez, aparte que es súper religioso. Como todos (ríe)". (Entrevista № 28).

b. "Entonces yo me doy cuenta de las diferencias entre una crianza y la otra; uno se da cuenta porque yo creo que soy como bien crítico, eh, soy súper crítico de mí y de mi gente". (Entrevista №32).

Ejemplos con cuantificador "tan":

a. "Yo considero, creo que debe ser porque es más fácil poner el listón entero, o sea, el pie derecho entero, a estarlo cortando. Es una teoría que creo que no estoy tan equivocado".(Entrevista № 28).

b. "Me gustan las películas de niños, me encantan. Las películas de adultos que he visto realmente son tan terribles que evito ir al cine a ver desastres". (Entrevista № 29). 
Ejemplos con cuantificador "más":

a. "También yo he sabido casos de otros tribunales en que los jueces son más complicados o menos afectivos. Este caballero es una persona bien cercana, así que no, bien también con él”. (Entrevista Nº 34).

b. "De repente la micro pasaba y eran cinco centímetros de diferencia a cada lado de espacio. Así que ese segundo mes fue más entretenido, porque allí ya estábamos viviendo con otras, con españolas, entonces, fue como más interesante compartir con una cultura distinta que, si bien hablan español, es una cuestión completamente diferente. Y eso". (Entrevista Nº 31).

Ejemplos con otros adverbios cuantificadores:

a. Lo que pasa que en Japón, yo por lo que yo leo, en Japón las normas de seguridad, de responsabilidad son sumamente estrictas y son de por vida, 0 sea, no porque usted cierra la constructora deja de ser responsable..." (Entrevista № 32).

b. "Ahora, si eso lo llevamos a Chile, crear una planta nuclear en Chile es muy difícil aún, porque, primero, son extremadamente caras y controlar una planta nuclear y mantenerla es sumamente caro". (Entrevista $\mathrm{N}^{\circ} 33$ ).

c. "Ahora, no estoy diciendo que sea negativo, al contrario, una planta nuclear es absolutamente positivo, pero con la plata que se utilizaría en hacer un planta nuclear con todo el espacio que tenimos y con toda la capacidad de generar 
energías renovables, tenemos muchas otras cosas que utilizar antes que una planta nuclear".(Entrevista $\left.\mathrm{N}^{\circ} 33\right)$.

Adjetivos superlativos analíticos en función atributiva con verbo estar.

La función atributiva del superlativo con el verbo estar registra menor uso en la elocución de los entrevistados. Algunos ejemplos con diferentes cuantificadores son los siguientes:

a. "Entonces, en ese sentido, yo creo que los valores del, del matrimonio están muy bajos". (Entrevista № 26).

b. "O sea, está muy bien equilibrado en ese sentido, pero no es una trama novedosa, pa`que quede bien en claro, o sea, muchas veces aquí en el cine chileno se intenta poner de toda en una película, por ejemplo, acción, drama, muchas veces comedia...". (Entrevista N²7).

c. "Hoy día, eeh, uno mira, eeh, la cosa valórica y está totalmente trastrocada, no es lo que nosotros tuvimos como formación, como valor" (Entrevista $\left.\mathrm{N}^{\circ} 24\right)$.

d. "En ese diario de vida, ella se desahoga, o cuando está muy sola, se pone a hacer, porque ya, porque en período de vacaciones, ya queda sola porque como son las amigas compañeras de colegio". (Entrevista $\left.N^{0} 1\right)$.

e. “..., y esas sensaciones, esas vivencias están en el cerebro, si bien las células propiamente tal tienen capacidad de almacenar información, de memoria, no creo, o sea, posiblemente sea alguna tendencia, pero no está totalmente corroborada o certificada por el ámbito médico". (Entrevista № 2). 
f. "Entonces, a esa gente nosotros la defendíamos igual, para esa persona que estaba, hoy tan angustiada, con tanto estrés esa sobrecarga emocional tan grande.....(Entrevista №12).

g. "Y eso es lo que, en verdad, la funcionalidad y eficiencia, términos que están súper prostituidos, son como el signo de los tiempos, finalmente, poh". (Entrevista № 28).

h. "Yo, cuando pasaba períodos difíciles. Por ejemplo, cuando mi papá se enfermó del infarto, ellas siempre se han preocupado de estar bien presentes y entre todas nos cuidamos, nos preocupamos de los demás". (Entrevista № 34 ).

i. "Siempre se hablaba de este problema a nivel europeo, a nivel americano, eeh, estaba hablando de Estados Unidos específicamente, pero no acá en Sudamérica, y, con el tiempo, bueno, llegó esto acá y pienso quee, eeh, entró muy fuertemente yyy en la generación está pero realmente complicada en ese sentido, porque se metió demasiado". (Entrevista $\left.\mathrm{N}^{\circ} 23\right)$.

11.2.13. Posición de adjetivos superlativos en función de complemento predicativo El uso menos recurrente del adjetivo superlativo entre las personas entrevistadas es en la función de predicativo, tanto referido al sujeto como al objeto directo. Sólo se registra su uso en forma analítica, y construida principalmente con el cuantificador "muy".

Según la GRAE (2010), el complemento predicativo del sujeto puede ocupar varias posiciones dentro del grupo verbal: tras el complemento directo si es que existe (José escribió la carta sumamente preocupado), o bien ante él (Miraba distraído las 
hojas de los árboles). Con los verbos que se construyen con complemento directo e indirecto, el predicativo aparece normalmente a la derecha del verbo (La presidenta entregó complacida el premio a los ganadores). Raras veces el complemento predicativo se coloca tras este, a no ser que el sujeto aparezca pospuesto por otras razones (Si llega tu mamá cansada).

La posición del predicativo referido al sujeto tiene en la elocución de los entrevistados una posición posverbal.

Se registran, en las entrevistas realizadas, predicativos referidos al sujeto con verbos como sentirse, quedar, hacer, verse, tener, trabajar, entre otros.

Ejemplos de superlativos predicativos referidos al sujeto:

a. Eeh, me siento muy intrigada con mi entorno, con mi familia, mis cercanos, mis amigos. Disfruto cada día; me siento bien con mis hijos, con mis nietos, eeh, me gusta, me gusta estar viva". (Entrevista № 29).

b. "Es jefe de servicio de una línea, de una línea de... de... de barcos, porque lleva mucho tiempo en el tema, por eso que ascendió, digamos, eeh, lo he visto de uniforme, se ve precioso, se ve muy lindo". (entrevista № 30).

c. "A causa de que su padre estaba ausente, su abuela estaba enferma, entonces ella le gatilló una depresión aguda... debido a eso mismo, nosotros nos vimos muy afectados,...". (Entrevista $\left.\mathrm{N}^{\circ} 1\right)$.

Los complementos predicativos del objeto directo pueden estar constituidos por adjetivos (Lo compraste muy caro), sustantivos (Lo eligieron alcalde), grupos 
preposicionales (Envió la carta sin estampilla), locuciones adjetivas o adverbiales (La llevaba en volandas) y también por oraciones (Lo quiero que tenga aire acondicionado).

La posición de los complementos predicativos del complemento directo es tras el verbo (Alquilé amueblado el departamento), o tras el propio complemento (Alquilé el departamento amueblado), aunque en estos casos, como señala la GRAE (2010), puede producirse ambigüedad en la expresión (si amueblado es predicativo o modificador del sustantivo).

Los entrevistados usaron adjetivos superlativos en función de predicativo referido al complemento directo con verbos como encontrar, hacer, tener.

Ejemplos de superlativos predicativos referidos al objeto directo:

a. "Si bien valoro mucho el hecho de que esté haciendo películas con el formato digital, que gasta mucho menos, por ejemplo, el director de Mandrill, de Mirageman y de Quiltro, es un tipo que yo nunca he simpatizado con sus películas, porque las encuentro demasiado banales". (Entrevista № 27).

b. "Un iraní, sabía toda la historia yyy y muy motivado, muy, muy, la hizo muy propia, claro, un tipo sabía mucho."(Entrevista $\left.\mathrm{N}^{\circ} 30\right)$.

c. "Aquí nosotros nos llega la tecnología, la televisión muestra que tal o cual artista o persona en el extranjero usa un collar que se le prenden las luces y aquí al mes andan todos con el collar que se le prenden las luces, o sea, creo que tenemos poco, eeh, somos muy consumistas de televisión basura como le digo yo, de hecho, por eso a mis hijos les tengo súper regulado el tema de televisión y computador...". (Entrevista $\left.\mathrm{N}^{\circ} 32\right)$. 


\subsubsection{Posición del adverbio superlativo}

El adverbio superlativo es, en general, poco usado por los entrevistados, tanto en su forma sintética como analítica. Su posición en la oración es siempre posverbal.

Los adverbios superlativos registrados en las entrevistas expresan modo, cantidad, tiempo.

Adverbios superlativos sintéticos

Esta forma del superlativo registra sólo 10 usos en las entrevistas. Algunos ejemplos de adverbios sintéticos de cantidad usados por los hablantes son los siguientes:

a. "Esto, creo, se debe a que hay grandes consorcios que ganan mucha plata y no se preocupan de lo social, ni del medio ambiente y se preocupan muchísimo sólo de su familia". (Entrevista № 25).

b. "Eeh, yo tengo un amigo en un préstamo, eeh, no pudo pagarlo y repactó. Luego empezó a darse cuenta que cada vez que paga, en vez de disminuir, le aumenta muchísimo su deuda en el mismo valor que paga: $\$ 10.000$ por $\$$ 1.000.000, al mes siguiente paga $\$ 110.000$." (Entrevista $\left.\mathrm{N}^{\circ} 25\right)$.

También se registra el uso de adverbios superlativos sintéticos, que expresan el modo de la acción verbal. Algunos ejemplos son los siguientes:

a. "Ah, claro... sí, porque a la prima le fue pésimo... tiene problemas de lenguaje... sacó 430 y $450 \ldots$ no poh, pero ella tiene problemas de lenguaje". (Entrevista № 1). 
b. "Claro, o sea, la PSU es una prueba poco triangulada, o poco validada, si tú quieres, porque, claro, es obvio que a los colegios particulares les va mejor...". (Entrevista № 5 ).

Adverbios superlativos analíticos

Igual que en el caso de los adjetivos superlativos analíticos, los adverbios con esta estructura son también los más empleados por los entrevistados. Para la expresión del superlativo analítico se usan diversos cuantificadores, especialmente "muy".

A continuación, se transcriben algunos usos de adverbios superlativos analíticos con distintos cuantificadores, que expresan mayoritariamente el modo de la acción verbal.

Ejemplos con cuantificador "muy":

a. "No vamos a decir que ¡huy! que me pagaban muy bien, pero obviamente mucho mejor que como yo había empezado". (Entrevista № 8).

b. "Con mi papá yo soy súper regalona, siempre fui muy regalona, siempre me entendí muy bien con él". (Entrevista $\left.N^{\circ} 34\right)$.

Ejemplos con cuantificador "súper":

a. "Porque hubo una posibilidad de haberme quedado, que era hacer una práctica de la Universidad, pero, me pagaban súper poco, entonces...". (Entrevista №8). 
b. "En el caso de nosotros no, somos súper unidas, somos todas bien amigas, nos llevamos súper bien, así que es rico adentro, a mí me gusta, lo pasamos bien". (Entrevista № 34).

Ejemplos con cuantificador "demasiado":

a. "Él ha mejorado mucho su impulsividad, hartas cosas, y nosotros hemos tratado harto de ir manejando eso bien y lo que produjo por error de enmendarlo en el camino, aprovechando que era chico y que antes que fuera demasiado tarde, ...”. (Entrevista № 34).

b. 2. "Que era el mejor amigo de los dos..., con él me quedé, no..., como a los..., cuando el Marcelo tenía como aproximadamente dos años de vida y que yo duré demasiado poco con él...". (Entrevista № 11).

Ejemplos con cuantificador "bastante":

a. "'Es que era tan extraña que no me interesó verla de nuevo. No, hay gente que es muy fanática y entiende bastante bien de que se trata, pero no en mi caso". (Entrevista № 14).

b. "Bueno, yo hubiese hecho lo mismo que hicieron mis padres conmigo, porque a mí me castigaban bastante severo, mi madre me pegaba con el cordón de la plancha cuando... nunca un robo en todo caso.... Jamás un robo, pero tonteras como romper de un pelotazo el vidrio del vecino...". (Entrevista № 17). 
Con cuantificador "más":

a. "..., porque para mí el trabajo es trabajo, uno va a trabajar, uno tiene que hacer lo que tiene que hacer y mucho mejor si no hay distracción, porque hacía las cosas más rápido". (Entrevista № 8).

b. “...si yo tenía ya... sabía tomar una tijera, podía cortar con máquina, con navaja... no me iba a costar, quería que fuera más rápido". (Entrevista № 19).

Con cuantificador "harto"

"No, buena..., por primera vez sí que convivo con alguien así fuera del hogar poh, pero buena, porque en realidad, nos llevamos harto bien..., los problemas entre nosotros no han surgido así mucho en..." (Entrevista № 10).

Con cuantificador "tan":

“... y así yo le podría nombrar muchas personas ligadas al fútbol, con Jaime Zapaata, arquero, arquero de Wanderers, en un momento lo vi entrenando a Eeverton, que no le fue tan bien, pero con ellos hice el curso de iniciador y me fue bastante bien". (Entrevista № 23). 


\section{CONCLUSIONES}

El superlativo es un recurso que los hablantes emplean para dar mayor énfasis a la expresión. Para ello, hacen uso de diversos tipos de recursos, a saber: morfológicos (empleo de la sufijación y prefijación); sintácticos (estructura de frase adjetiva o adverbial construida con un elemento cuantificador); recursos léxicos (adjetivos, adverbios, sustantivos o locuciones adjetivas o adverbiales con carácter ponderativo o enfático); y recursos estilísticos( reiteraciones, hipérboles, metáforas y comparaciones), que, en el habla oral, adquieren una especial relevancia como expresiones enfáticas de la elocución de los hablantes)

Luego del estudio realizado para constatar el uso del superlativo en la elocución de los hablantes entrevistados, en conversaciones informales sostenidas con el entrevistador, sobre temas de diversa índole, podemos formular las siguientes conclusiones:

1. En primer lugar, se puede afirmar que las personas entrevistadas usaron distintas formas para manifestar el carácter enfático de la expresión. Entre éstas, están las siguientes: el adjetivo en grado superlativo, tanto sintético como analítico, el adverbio superlativo, léxico con valor superlativo y recursos estilísticos como reiteraciones, metáforas, hipérboles y comparaciones, usados para dar mayor énfasis a la expresión.

2. El adjetivo de grado extremo o elativo (sintético y analítico) es usado por los hablantes en la función propia de un adjetivo, es decir, la de calificar a un sustantivo, como un elemento adyacente a éste (antepuesto o pospuesto), y 
también en las funciones sintácticas de atributo predicativo (con los verbos ser y estar) y de complemento predicativo (con verbos no copulativos).

3. En el caso del adjetivo superlativo elativo, se ha constatado que éste, en función de atributo predicativo con los verbos ser y estar, tanto expresado en forma sintética como analítica, es el que tiene mayor uso en las personas entrevistadas. La totalidad de superlativos registrados es 1.164; de éstos, 417 corresponden a la función atributiva, equivalente a $36 \%$ del total.

4. La atribución con el verbo "ser" es la de mayor ocurrencia, ya que de los 417 casos de atributos predicativos, 348 corresponden a este uso (83.45\%), mientras que, con el verbo "estar", sólo se registran 69 casos (16.54\%).

5. El adjetivo en función de predicativo, tanto referido al sujeto como al objeto directo, es el que registra el menor uso entre los hablantes entrevistados (30 usos, correspondientes a $3 \%$ del total).

6. Para la expresión de la cualidad o característica de un sustantivo, los hablantes usaron tanto la forma sintética como analítica del adjetivo. Sin embargo, la estructura sintáctica, es decir, la frase adjetiva construida con un cuantificador es la de más usada. Su uso corresponde a $80 \%$ del total de formas adjetivas; en cambio, la forma sintética, con el sufijo -ísimo, sólo registra 9\% de uso.

7. La forma superlativa morfológica con el sufijo -ísimo, de acuerdo con los resultados obtenidos, es poco usada por los hablantes entrevistados.

8. En cuanto al adverbio superlativo, se puede afirmar que es menos usado por los entrevistados. En la forma analítica, registra 10\% de uso, mientras que en forma sintética, sólo $1 \%$. 
9. En la construcción de la frase superlativa, tanto adjetiva como adverbial, los hablantes entrevistados usaron distintos cuantificadores adverbiales. Entre éstos están los siguientes: muy, bastante, súper, tan, bien, más, totalmente, demasiado, mucho, mucho más, extremadamente, absolutamente, harto, sumamente, completamente, realmente, prácticamente, sencillamente, medio, totalmente.

10.De estos cuantificadores, el que tiene mayor uso entre los hablantes entrevistados es "muy". De los 687 casos registrados de uso de cuantificadores, 329 corresponden a "muy", lo que equivale a $48 \%$ del total.

11.Se registra el uso coloquial de "súper" como adverbio cuantificador para expresar la superlación. Este uso no está aceptado por la Real Academia Española.

12. La utilización de elemento prefijador para la expresión superlativa tiene escaso uso en los hablantes entrevistados. El único prefijo registrado es "re-", con sólo 7 ocurrencias.

13. En relación con el uso de léxico con valor superlativo, los hablantes entrevistados emplearon un total de 248 palabras. Entre éstas, se encuentran adjetivos, adverbios, sustantivos y locuciones adjetivas y adverbiales, que los hablantes emplean para dar mayor énfasis a su expresión.

14. Entre las voces usadas para la expresión superlativa, los entrevistados usan también anglicismos, como "heavy", que, en el habla coloquial juvenil de Chile, tiene este valor superlativo.

15. De este léxico con valor superlativo, la mayor ocurrencia corresponde a adjetivos, que registran 174 casos (correspondiente a 70\%); los adverbios con 
este valor se ubican en segundo lugar, con 52 casos (21\%); luego sigue el sustantivo, con 17 casos( 7\%); y, finalmente, las locuciones tanto adjetivas como adverbiales, con 2 y 3 casos de uso, respectivamente ( $1 \%$ cada una).

16. En la elocución de los entrevistados, se encuentra también la utilización de recursos estilísticos, como una forma de dar más énfasis a la expresión. Entre estos recursos se encuentran reiteraciones, hipérboles, metáforas y comparaciones.

17. El recurso que registra mayor número de uso es la reiteración, con 68 casos, correspondiente a 64.15\%; el uso de la hipérbole o exageración se ubica en segundo lugar de uso con 19 casos (17.92\%); luego, la metáfora, con 13 casos de uso (12.26\%); y, finalmente, la comparación registra 6 casos de uso, correspondiente a $5.66 \%$.

18. En relación con las variables sociolingüísticas consideradas para este estudio, sexo, edad y nivel educacional, se puede afirmar, en términos generales, que tienen incidencia en el uso de las distintas formas de expresión del superlativo.

19. En cuanto a la variable sexo, se pudo constatar que, en el uso de las distintas formas superlativas, el sexo femenino registra mayor uso de éstas, ya que de los 1.164 usos, 646 corresponden al sexo femenino (55.5\%); mientras que 518 corresponden al sexo masculino (44.5\%).

20. El uso del superlativo elativo adyacente del sustantivo es el único que no presenta diferencia en la variable sexo, ya que se registraron 134 usos de esta forma, tanto en el género masculino como en el femenino. 
21. El uso del adjetivo superlativo sintético, con el sufijo -ísimo, es el único que registra mayor uso en los hablantes de sexo masculino (11\%); en el sexo femenino, sólo registra $6 \%$.

22. En el uso de los adverbios superlativos, se produce una evidente diferencia de acuerdo con la variable sexo, ya que los entrevistados de sexo femenino registran $69 \%$ de uso de este superlativo, mientras que el sexo masculino sólo tiene $39 \%$ de uso.

23. En relación con los 6 cuantificadores adverbiales más usados por los entrevistados para la construcción del superlativo analítico, se pudo constatar que los hablantes de sexo femenino tienen mayor porcentaje de uso de "muy" (57\%), "súper" (79\%) y "bien" (54\%). Los entrevistados de sexo masculino tienen registro de mayor porcentaje de uso de "más" (56\%), "bastante" (65\%) y "tan" (52\%).

24. El uso de léxico con valor superlativo tiene mayor ocurrencia en los hablantes de sexo femenino, 145 usos (58\%); en cambio, en los hablantes de sexo masculino, el uso corresponde a $42 \%$ (103 usos).

25. Los hablantes entrevistados usaron recursos estilísticos con valor superlativo como metáforas, reiteraciones, hipérboles y comparaciones. También en este caso se evidencia una diferencia de uso de acuerdo con la variable sexo. El sexo femenino registra mayor uso en los siguientes recursos: metáfora (5 entrevistadas), hipérbole (6 entrevistadas), reiteración (14 entrevistadas). El recurso comparación registra uso sólo en las personas de sexo masculino (4 personas). 
26. La diferencia de uso de superlativos de acuerdo con la variable sexo, se evidencia también al considerar al entrevistado con mayor número de formas superlativas. Efectivamente, los resultados muestran que, en el sexo femenino, la entrevistada con mayor cantidad de superlativos registra 89 usos, mientras que, en el masculino, la mayor ocurrencia corresponde al entrevistado №33, con 48 usos.

27. En relación con la variable edad, los resultados obtenidos demuestran que el grupo etario de los más jóvenes (de 21 a 31 años de edad) es el que registra el mayor porcentaje de uso de las distintas formas de expresión del superlativo (38.6\%, correspondiente a 449 usos). El grupo de los de mayor edad es el que tiene menor uso, con 344 , correspondiente a $29.5 \%$.

28. Al considerar el uso de adjetivos superlativos elativos, tanto sintéticos como analíticos, los resultados demuestran que los entrevistados del primer grupo etario (los de menor edad) son los que registran el mayor porcentaje de uso, $40 \%$; mientras que el grupo etario con menor porcentaje de uso es el tercero (mayor edad), con $27 \%$.

29. El uso del adverbio en grado superlativo tiene un mayor porcentaje entre los hablantes del tercer grupo etario (35\%). El grupo que menos porcentaje de uso tiene es el segundo (31\%).

30. En relación con el uso de los adjetivos superlativos de grado extremo, expresados en forma sintética y analítica, se puede decir que, en los tres grupos etarios considerados para este estudio, la forma analítica es la más recurrente. 
31. En cuanto al adverbio superlativo sintético, de acuerdo a los resultados obtenidos, se puede decir que se registra solamente en la elocución de los entrevistados del segundo y tercer grupo etario.

32. El primer grupo etario registra un porcentaje muy alto de adjetivos superlativos analíticos ( $83 \%$ ), en cambio, el adjetivo superlativo sintético sólo tiene en este grupo $7 \%$ de uso. En el caso de los adverbios, los hablantes únicamente emplean la forma analítica (10\%).

33. El segundo grupo de hablantes empleó adjetivos y adverbios superlativos analíticos y sintéticos. Los adjetivos superlativos analíticos tienen en este grupo 82\% de uso; los adjetivos sintéticos, 7\%; los adverbios superlativos analíticos, 10\%; y el adverbio superlativo sintético sólo registra $1 \%$.

34. El tercer grupo etario registra uso de adverbios y adjetivos superlativos, tanto sintéticos como analíticos. El mayor porcentaje de uso corresponde al adjetivo superlativo analítico, con $74 \%$, y el menor porcentaje es el del adverbio superlativo sintético, con $3 \%$.

35. El grupo etario de los de mayor edad es el que registra el mayor porcentaje de adjetivos superlativos sintéticos (11\%).

36. En relación con el uso de los cuantificadores de mayor ocurrencia, se puede afirmar que, en el empleo del cuantificador "muy", los tres grupos etarios no presentan mayor diferencia en cuanto al porcentaje de uso (el primero tiene $34 \%$; el segundo, $31 \%$ y el tercero, $35 \%$ ).

37. El cuantificador "más" es usado mayoritariamente por el primer grupo etario (48\%), y el grupo que menos porcentaje registra es el segundo (24\%). 
38. De acuerdo con los resultados obtenidos, el uso del cuantificador "súper" evidencia claramente una diferencia en los grupos etarios extremos, ya que los entrevistados más jóvenes registran $67 \%$ de uso de este cuantificador y los de mayor edad, sólo 8\%. Lo mismo ocurre con los siguientes cuantificadores: "bien", que registra $46 \%$ en el primer grupo etario y $17 \%$ en el tercer grupo; "bastante", con $48 \%$ en el primer grupo y $16 \%$ en el tercero.

39. El cuantificador "tan" es mayoritariamente usado por los entrevistados del segundo grupo etario (55\%). El grupo que menos uso registra es el de los más jóvenes (16\%).

40. En el uso de léxico con valor superlativo, de acuerdo con las categorías gramaticales, se constatan algunas diferencias entre los grupos etarios.

41. El sustantivo con valor superlativo registra mayor porcentaje de uso en el grupo etario de mayor edad (13\%); mientras que en los dos grupos restantes sólo se registra un $3 \%$.

42. El único grupo etario que registra uso de la locución adverbial es el primero, con $2 \%$.

43. En relación con los recursos estilísticos con valor superlativo, los resultados demuestran que en el caso de la metáfora, el tercer grupo etario es el que registra mayor uso (4 de las 10 personas pertenecientes a este grupo).La hipérbole también es usada principalmente por los hablantes del tercer grupo (5 personas) y es menos usada por el grupo dos. La reiteración, que es el recurso más usado en las entrevistas, tiene mayor uso en el primer grupo, ya que 12 de 15 personas pertenecientes a este grupo la usaron, a lo menos, una vez. Por último, la comparación es usada sólo por los grupos 1 y 2; sin embargo, se 
puede afirmar, de acuerdo con los resultados, que su uso es escaso, ya que solamente 3 personas del primer grupo la usaron, y, en el segundo grupo, una sola persona la usó una vez.

44. De acuerdo con la variable sociolingüística nivel educacional, los resultados por niveles nos indican que las personas de nivel no universitario (medio y técnico) usaron un total de 528 superlativos en su elocución (45.4\%), mientras que las de nivel universitario registraron un total de 636 superlativos (54.6\%).

45. El uso del adjetivo superlativo como atributo tiene mayor uso en el nivel educacional técnico (44\%). El menor porcentaje corresponde al nivel medio, con $29 \%$.

46. El adjetivo adyacente al sustantivo (antepuesto o pospuesto) registra mayor porcentaje de uso en el nivel medio (30\%), y el menor porcentaje, en el nivel técnico (18\%).

47. Los adjetivos superlativos, tanto sintéticos como analíticos, registran mayor porcentaje de uso en el nivel universitario (54\%). En los niveles medio y técnico, se registra el mismo porcentaje (23\%).

48. En cuanto al uso del adverbio superlativo, el nivel universitario es el que registra el mayor porcentaje de uso, $62 \%$.

49. En el nivel medio, el mayor porcentaje de uso corresponde al adjetivo superlativo analítico (81\%), en tanto que el adverbio superlativo sintético registra el menor uso (1\%).

50. En el nivel técnico, el mayor porcentaje corresponde al adjetivo superlativo analítico (83\%). En este nivel, el adverbio superlativo sintético no registra uso. 
51. En el nivel universitario, el adjetivo superlativo analítico tiene $78 \%$ de uso. El menor uso corresponde al adverbio superlativo sintético con $2 \%$ de uso.

52. Los adjetivos usados con valor superlativo tienen en los niveles educacionales los siguientes resultados: en el nivel medio, $62 \%$ de uso; en el técnico, $69 \%$; y, en el universitario, $74 \%$.

53. Los sustantivos con valor superlativo registran mayor porcentaje de uso en el nivel universitario (9\%), y el menor porcentaje, en el nivel técnico (4\%).

54. Los adverbios con valor superlativo registran mayor porcentaje de uso en el nivel medio (33\%) y el menor porcentaje, en el nivel universitario (15\%).

55. La locución adjetiva con valor superlativo sólo registra uso en los niveles técnico y universitario con $2 \%$ y $1 \%$ respectivamente.

56. La locución adverbial con valor superlativo sólo es usada por los entrevistados de nivel universitario (1\%).

57. En cuanto a la ocurrencia de los recursos estilísticos con valor superlativo, se puede decir que, en el caso de la metáfora, $28 \%$ de los entrevistados de nivel medio la usó a lo menos una vez; en el nivel universitario, la usó 26 \% de los entrevistados; y, en el nivel técnico, sólo el 13\%. La hipérbole registra una ocurrencia de $57 \%$ en el nivel medio; $38 \%$ en el nivel técnico; $\mathrm{y}$, en el universitario, $26 \%$. La reiteración es el recurso que registra mayor ocurrencia en la elocución de los entrevistados. En el nivel medio, $86 \%$ de los entrevistados de este nivel la usó a lo menos una vez; en el universitario, 74\%; y, en el técnico, 63\%. El recurso comparación registra uso sólo en dos de los niveles: técnico (38\%) y universitario (5\%). 
58. Se ha constatado la incidencia de elementos pragmáticos como la posición de los superlativos en relación con el elemento gramatical al que modifica y el énfasis con que los hablantes expresan aquello que quieren manifestar con mayor fuerza.

59. En cuanto a la posición del adjetivo superlativo sintético adyacente del sustantivo, se puede concluir que es usado tanto antepuesto como pospuesto al nombre que califica, sin embargo, la anteposición es la de mayor ocurrencia en la elocución de los entrevistados.

60.En las entrevistas, se registran algunos adjetivos superlativos sintéticos correspondientes a adjetivos numerales ordinales, cuya posición es siempre antepuesta al sustantivo (Ej.: primerísima fila).

61. También se encuentra el uso de adjetivos superlativos sintéticos antepuestos, provenientes de adjetivos indefinidos, cuya posición natural en la lengua española es ésta (Ej.: muchísima pena).

62. Los superlativos clásicos de origen latino como mejor, peor, pésimo, máximo, etc., que la RAE considera superlativos léxicos, tienen, en las entrevistas, un mayor uso como elemento antepuesto a un sustantivo.

63. La anteposición del adjetivo superlativo analítico es menos frecuente en la elocución de los entrevistados.

64. La posición posnominal del adjetivo superlativo adyacente es la más recurrente en la elocución de los entrevistados, tanto en su forma sintética como analítica.

65. La posición posnominal del adjetivo superlativo analítico, en función de adyacente del sustantivo, es la que registra mayor cantidad de usos. Para la 
construcción de esta frase adjetiva superlativa, los entrevistados emplean, principalmente el cuantificador "muy".

66. El adjetivo superlativo en función de atributo de los verbos ser y estar es el que registra el mayor uso en la elocución de los entrevistados. La posición de este superlativo, tanto analítico como sintético, en español es naturalmente posverbal.

67. Los entrevistados usan mayoritariamente la función atributiva del adjetivo superlativo con el verbo "ser".

68. El uso menos recurrente del adjetivo superlativo entre las personas entrevistadas es en la función de complemento predicativo, tanto referido al sujeto como al objeto directo. Sólo se registra su uso en forma analítica, y construida principalmente con el cuantificador "muy". La posición lógicamente es posverbal.

69. El adverbio superlativo es, en general, poco usado por los entrevistados, tanto en su forma sintética como analítica. Su posición es, en los casos registrados, siempre posverbal.

70. Para la intensificación de lo expresado, el hablante entrevistado emplea recursos morfológicos como la utilización del sufijo - ísimo.

71. Algunas veces, la sola expresión del superlativo morfológico no basta para el énfasis que se quiere dar a la expresión y se recurre a otros elementos enfatizadores, junto con el superlativo flexivo, centrando principalmente en ellos la manifestación del énfasis de la expresión. Tal es el caso de la utilización de "pero", como elemento ponderativo, junto con la forma flexiva superlativa. Se puede afirmar que hay aquí una doble forma para expresar el énfasis. 
72. Para el énfasis de la expresión, los entrevistados usan diferentes categorías de palabras, muchas de ellas pertenecen al habla coloquial que le ha ido otorgando este carácter enfático. Entre éstas, encontramos adverbios, sustantivos, adjetivos, y algunas frases adjetivas y frases adverbiales.

73. La utilización de estos elementos gramaticales le sirve a los entrevistados para expresar distintos estados anímicos o de valoración subjetiva de la realidad, como lo agradable, lo grandioso o hermoso, la ausencia o carencia de algo, la cantidad excesiva de algo, lo desagradable, etc.

74. Algunos de los sustantivos usados con valor enfático no registran significado con este valor en los diccionarios, como la palabra "caracha", que, en el lenguaje coloquial de Chile, significa algo de muy poco valor.

75. El uso de recursos estilísticos como la reiteración, hipérbole, metáfora y comparación, en el habla oral, tiene una clara intención intensificadora de aquello que dicen los hablantes.

76. En el corpus de la investigación, se registran 106 recursos estilísticos. De éstos, el de mayor ocurrencia es la reiteración (63\%); luego, la hipérbole con $20 \%$ de los usos; la metáfora, con 11\%; y la comparación con 6\%.

77. La reiteración es el recurso más utilizado por los entrevistados para enfatizar la expresión. Se reiteran cuantificadores, palabras, frases y hasta oraciones, como una forma de los hablantes para hacer más intenso aquello que dicen.

78. Algunas comparaciones, que corresponden al registro vulgar de la lengua en Chile, tienen, en la elocución de los entrevistados, un uso coloquial (por ejemplo, la expresión "como el hoyo"). 
79. En el habla coloquial, la posición que tenga el adjetivo superlativo en el sintagma nominal o en la oración, está determinada por factores subjetivos y enfáticos, y depende de la intención comunicativa del hablante.

80. Finalmente, se puede afirmar que el superlativo es un recurso que los hablantes utilizan con frecuencia para enfatizar lo que expresan en sus conversaciones y que, para ponderar lo dicho, no sólo emplean los recursos que ofrece la morfología o la sintaxis de la lengua española (prefijos, sufijos y cuantificadores adverbiales), sino también recursos léxicos o estilísticos que son tanto o más ricos para expresar enfáticamente lo que se quiere decir. 


\section{BIBLIOGRAFÍA}

Acín Villa, Esperanza (1994). Sobre Pero enfático. XXIII Simposio de la Sociedad Española de Lingüística, Lérida, España.

Academia Chilena de la Lengua (2010). Diccionario del Uso del Español de Chile (DUECH). Santiago de Chile: Ed. MN Editorial LTDA.

ALBELDA, M. (2007). La intensificación como categoría pragmática. Frankfurt amm Main, Peter Lang.

Alcina Franch, Juan y Blecua, José Manuel (1975). Gramática Española. Barcelona: Ed. Ariel.

Alarcos Llorach, Emilio (1996). Gramática de la Lengua Española. Madrid: Espasa Calpe.

Alvar, Manuel (1976). Lengua y Sociedad. Barcelona.

Alvar, Manuel y VILLENA, J. (1994). Estudios sobre el corpus del Español. Universidad de Málaga.

Alvar, Manuel (1980).Introducción a la Lingüística Española”. Barcelona: Ed. Ariel S.A.

Alcaraz Varó, Enrique (1990). Tres Paradigmas de la Investigación Lingüística. España: Ed. Marfil, Alcoy.

Almeida, Manuel (2003). Sociolingüística. Universidad de la Laguna.

Asociación de Academias de la Lengua Española (2010). Diccionario de Americanismos. Lima: Santillana Editores. 
Beinhauer, W. (1978). El Español Coloquial. Madrid: Gredos.

Bello, Andrés (1928). Gramática de la Lengua Castellana. París.

Bosque, Ignacio y Demonte, Violeta (2000). Gramática Descriptiva de la Lengua Española. Tomo 3, Madrid: Ed. Espasa Calpe.

Briz, Antonio y Grupo VAL.ES.CO.(2000). ¿Cómo se comenta un texto coloquial? Barcelona, España: Ed. Ariel. Barcelona.

Briz et alt. (1995). La conversación coloquial, materiales para su estudio. Anexo XVI de Cuadernos de Filología. Valencia.

Briz et alt. (1998). El Español coloquial en la conversación. Esbozo de Pragmagramática. Barcelona: Ed. Ariel.

Caminos, Miguel Ángel (2003). La Gramática Actual. Buenos Aires: Ed. Magisterio del Río de la Plata.

Bruyne, Jacques de (1993). Acerca de sombreros novísimos y nuevísimos. Complemento al Esbozo de una nueva gramática de la lengua española. Iberoromania, 37, 106-LL5.

Bruyne, Jacques de (2006). Aspectos elativos de una lengua superlativa. Revista Mosaico, Consejería de Educación en Bélgica, Países Bajos y Luxemburgo.

Bruyne, Jacques de (1986). Onomástica y elativos en "-ísimo". Anuario de Lingüística Hispánica, 2, 9-20. 
Caminos, Miguel Ángel (2003). La Gramática Actual. Buenos Aires: Ed. Magisterio del Río de la Plata.

Canavos,G. (1988). Probabilidad y Estadística: Aplicaciones y Métodos. Madrid: McGrawHill.

Carratalá, Ernesto (1980). Morfosintaxis del Castellano Actual. Barcelona: Editorial Labor S. A.

Costa, Andrea y Ferreyra, Patricia (1997). Re-superlativo: prefijo cuantificador de las categorías verbo, nombre, adjetivo, adverbio y portador de la subjetividad en el lenguaje adolescente. Instituto de Formación Docente № 27, San Nicolás, Buenos Aires.

Di Tulio, Ángela (2010). Manual de gramática del español. Buenos Aires: Waldhuter Editores.

Ducrot, Oswald (1986): "El decir y lo dicho. Polifonía de la enunciación". Barcelona: Ed. Paidós.

Giammateo, M. \& Albano, H (2006). ¿Cómo se clasifican las palabras? Buenos Aires: Littera Ediciones.

Fernández Loya, Carmelo (2005). Estrategias de intensificación y de atenuación en el español y en el italiano coloquiales. AISPI. Actas XXIII. Centro Virtual Cervantes.

Fernández Ramírez, Salvador (1986). Gramática Española. Madrid: Arco/Libros.

Fishmann, Joshua (1971): “Sociolinguistique”. Bruxellas, París.

Fishman, Joshua (1982): "Sociología del Lenguaje". Madrid: ED. Cátedra, S.A. 
García-Page Sánchez, Mario (1997): “Formas de superlación en español: la repetición”. Verba, 24, 133-157.

García-Page Sánchez, Mario (1990). Frases Elativas, en Actas del XX Aniversario de la Sociedad Española de Lingüística I, Madrid: Gredos, pp. 485-496.

García Zapata, Carlos Arturo (2011) Intensificadores fraseológicos en el español coloquial de Medellín. Revista Virtual Universidad Católica del Norte, número 33, mayo-agosto 2011, pp.1-19.

Gili y Gaya, Samuel (1964). Curso Superior de Sintaxis Española. Barcelona: Ed. Vox.

Gómez Torrego, Leonardo (2002). Gramática Didáctica del Español. Madrid: Ed. SM, $8^{\circ}$ edición.

Gómez Torrego, Leonardo (2007). Hablar y escribir correctamente (Gramática Normativa del español actual), Madrid: Arcos.

González Calvo, José Manuel (1984). Sobre la expresión de lo "superlativo" en español, Anuario de Estudios Filológicos, VII.

Grijalbo (1987). Diccionario del español actual. Barcelona: Ed. Grijalbo. S.A.

Halliday, M. (1979). El lenguaje como semiótica social. México: Fondo de Cultura Económica.

Hernández Alonso, César (1996). Gramática Funcional del Español. Tercera edición corregida y aumentada. Madrid: Gredos.

Hernández Alonso, César (1995) Nueva Sintaxis de la Lengua Española. Salamanca: Ediciones Colegio de España. 
Hernández Campoy, Juan Manuel y Almeida, Manuel (2005). Metodología de la investigación sociolingüística. Málaga: Editorial Comares.

Hernández Sampieri, R., et alt. (1998). Metodología de la investigación. México: McGraw Hill Interamericana.

Herrero Moreno, G. (1991). Procedimientos de intensificación -ponderación en el español coloquial, Español Actual 56, pp. $39-51$.

Hidalgo, A. (1998). Expresividad y función pragmática en la conversación coloquial. Cuadernos de Filología. Estudios Lingüísticos II. Universidad de Valencia.

Hudson, R.A. (2000). Sociolingüística. Ed. Anagrama. 2ª Edición.

Jauralde Pou, Pablo (1982). Introducción al conocimiento de la Lengua Española. España: Ed. Everest.

Kerbrat-Orechioni, Catherine (1997). La Enunciación". Buenos Aires: Edicial S.A.

Kornfeld, Laura M (2010). La cuantificación del adjetivo en el español de Argentina. Buenos aires: El 8VO. Ediciones.

Labov, William (1983). Modelos Sociolingüísticos. Madrid: Gredos.

Labov, William. 2001. Principles of Linguistic Change. Vol. II: Social Factors. Oxford: Blackwell. [En español: "Principios del cambio lingüístico". Vol. II: Factores sociales. Pedro Martín Butragueño (Trad.). Madrid: Gredos, 2006].

Lago Alonso, Julio (1965-67). Consideraciones sobre la idea de superlativo en francés y en español, en Suárez Fernández, Luis (ed.), Homenaje al Profesor Alarcos García, II, Valladolid, Universidad de Valladolid, 49-61. 
Lamíquiz Ibáñez, Vidal (1998). Lengua Española: Método y estructuras lingüísticas. Barcelona: Ariel.

Lamíquiz lbáñez, Vidal (1991). La cuantificación lingüística y los cuantificadores. Madrid: Uned.

Lavandera, Beatriz: Variación y Significado. Buenos Aires. Argentina.

Lenz, Rodolfo (1935). La Oración y sus Partes. Madrid: Revista de Filología Española Leymann, Annalien (2010) La expresión del valor superlativo en francés y en español. Faculteit Letteren en Wijsbegeerte Taal- en Letterkunde: Frans-Spaans Universiteit Gent.

Lope Blanch, Juan (1984). Problemas Sociolingüísticos de Iberoamérica.

López Morales, Humberto (1993). Sociolingüística. Madrid: Ed. Gredos

López Morales, Humberto (1994). Métodos de Investigación Lingüística. Salamanca:

Ed. Colegio de España.

Marsá, F. (1984). Cuestiones de Sintaxis Española. Barcelona: Ariel S. A.

Marcos Marín, Francisco (1975). Lingüística y Lengua Española. Madrid: Ed. Cincel.

Marcos Marín, Francisco et alt. (1998). Gramática Española. Madrid: Ed. Síntesis.

Martín García, Josefa (1998): Los prefijos intensivos del español: caracterización morfo-sintáctica. Estudios de Lingüística de la Universidad de Alicante.

Martinell, Emma (1992): Estilística en la gradación del adjetivo. Actas del X Congreso de Asociación Internacional de Hispanistas, Universidad de Barcelona. España.

Matte Bon, Francisco (1995): Gramática Comunicativa del Español. Tomo II. De la idea a la Lengua, Centro de Investigación y Publicaciones del Español Lengua Extranjera, Madrid. 
Meyer-Hermann, Reinhard (1988). Atenuación e intensificación (análisis pragmático de sus formas y funciones en español hablado), Anuario de Estudios Filológicos XI, pp. 275-290.

Moliner, María (1989). Diccionario de uso del español, Madrid: Gredos.

Montecino, Lesmer Antonio (2004). Estrategias de intensificación y atenuación en la conversación coloquial de jóvenes chilenos. Onomazien 10. Pontificia Universidad Católica de Chile.

Morales Pettorino, Félix (2006). Nuevo Diccionario Ejemplificado de Chilenismos y de otros usos diferenciales del Español de Chile. Chile: Ed. Puntángeles, UPLACED.

Moreno Fernández, Francisco (1990). Metodología Sociolingüística. Madrid: Ed.Gredos.

Moreno Fernández, Francisco (1998). Principios de Sociolingüística y Sociología del Lenguaje. Barcelona: Ed. Ariel.

Navarro, Tomás (1974). Manual de Entonación Española. Madrid: Ed. Guadarrama.

Padilla García, Xosé (2003). El orden de las palabras en el español coloquial. Alicante: Biblioteca Virtual Miguel de Cervantes.

Palomo Olmos, Bienvenido (2002). El afijo "-ísimo" en el español actual con bases no adjetivales. Verba, 29, 139-152.

Palomo Olmos, Bienvenido (2001). El afijo "-ísimo" en el español actual. Verba, 28, 159-185 
Penas Ibáñez, Mª Azucena (1993-94). Los intensivos léxicos y morfológicos: su importancia lingüística y estilística. Cuadernos de Investigación Filológica, XIX-XX, 129-150.

Pérez Salazar, Carmela (2005). El superlativo en -ísimo y otros recursos de intensificación en el siglo XVIII, en R. García Bourrellier; J. Ma․ Usunáriz (eds.): Aportaciones a la historia social del lenguaje: España, siglos XIV-XVIII. Madrid / Frankfurt: Iberoamericana / Vervuert, 261-283.

Porto Dapena, José Álvaro (1985). La cuantificación del adjetivo en español actual desde el punto de vista de la expresión. Philologica Hispaniensia in Honorem Manuel Alvar. Ed. Gredos. Madrid.

Porto Dapena, José Álvaro (1973). A propósito de los grados del adjetivo: aportación al estudio del sistema de cuantificacion en el adjetivo español. Thesaurus XXVIII, № 2 .

Pottier, B. (1970): “Gramática del Español', Alcalá, Madrid.

Quilis, A (1980-1981). Funciones de la Entonación. Boletín de Filología de la Universidad de Chile, XXXI, 443-460.

Real Academia Española (1997). Esbozo de una Nueva Gramática de le Lengua Española. Madrid: Ed. Espasa Calpe.

Real Academia Española (2010). Nueva Gramática de la Lengua Española. Buenos Aires: Ed. Planeta.

Real Academia Española y Asociación de Academias de la Lengua Española (2005). "Diccionario Panhispánico de Dudas. Ed. Santillana. 
Renkema, Jan (2001). Intensificadores: Un marco de análisis. Universiteit Brabant, Tilburg.

Robles Ávila, Sara: ASELE. Actas VIII (1997). Análisis de errores: el caso de los comparativos y superlativos en español. Centro Virtual Cervantes.

Roca Pons, J. (1970). Introducción a la Gramática, Teide, Barcelona.

Seco, Manuel (1977). Gramática Esencial del Español. Madrid: Ed Aguilar.

Seco, Manuel (1986). Diccionario de dudas y dificultades de la lengua española. Madrid: Espasa- Calpe.

Serradilla Castaño, Ana $M^{a}$ (2004). Superlativos cultos y populares en la historia del español. Edad de Oro 23, 95-133.

Serradilla Castaño, Ana: CAUCE. Núm. 28 (2005). Evolución de la expresión del grado superlativo absoluto en el adjetivo: las perífrasis sustitutivas del superlativo sintético en español antiguo. Centro Virtual Cervantes.

Serradilla Castaño, Ana (2006). Bien + adjetivo como perífrasis de superlativo en español: particularidades semánticas y sintácticas. Verba, 33, 215-233.

Silva Corvalán, Carmen (1989). Sociolingüística.Teoría y análisis. Madrid: Editorial Alhambra.

Simons \& Schuster`S (1975). International Dictionary English/Spanish. 2 $2^{\underline{a}} \quad$ Edición.

Uribe Villegas, Oscar (1970). Sociolingüística. Una Introducción a su estudio. México.

Vigara Tauste, Ana María (2005). Morfosintaxis del español coloquial. Esbozo estilístico. Madrid: Gredos. 
Weinreich, Uriel (1953). Lenguas en Contacto. La Haya: Mouton \&Co.

Zuluaga, A. (1980). Introducción al estudio de las expresiones fijas, Studia románica et lingüística. 10 Frankfurt a M. Berna, Cirencester/U.K. Lang. 


\section{ANEXO 1 \\ LÉXICO CON VALOR SUPERLATIVO}

Absoluto - ta: adj.// 3 entero, total, completo. (DRAE, pág.15). Ej.: "Evidentemente estamos en un relativismo y en un conocimiento absoluto de lo que es el derecho a la vida". (Entrevista $\left.\mathrm{N}^{\circ} 4\right)$.

Amigote: adj. (del aum. de amigo).m. despectivo. Compañero habitual de francachelas y diversiones. (DRAE pág.137). Ej.: "No obviamente que tiene que haber confianza eso es..., es que son cosas totalmente diferentes..., el ser el amigote, a tener confianza de contarse las cosas...”. (Entrevista №17).

Asqueroso, sa: adj. Que causa asco (DRAE, pág. 134). Ej.: "los fotógrafos asquerosos". (Entrevista № 3).

Atroz: adj. // 3. Fam. Muy grande o desmesurado (DRAE, pág. 142). Ej.: “...al principio pensó que era un temblor común y corriente, y ese lugar tenía unas vigas de madera con, tenía candelabros y lámparas de fierro forjado colgando por todos lados, y ahora se empieza a mover así como todo y el Gerdy me dice : No, esto es terremoto. Me acuerdo que salimos corriendo y el Gerdy me grita :iPaula, mi hijo! ¡Qué atroz! Me imaginaba al Thomas acá (en la casa)”. (Entrevista № 34).

Bacán,- na: I. 2. adj. Cu. Ec. Pe. Ch. juv. Referido a persona o cosa muy buena, estupenda. (Diccionario de Americanismos, pág. 189) Ej.: "Somos muy cariñosos, mantenemos una comunicación bacán". (Entrevista № 31). 
Bastante:* adj. p.a. de bastar. Que basta (DRAE, pág.170). Ej.: "Tengo bastante paciencia". (Entrevista № 13).

* adv. // 3. No poco (DRAE, pág. 170). Ej. "Ahora se ha perdido bastante el respeto a los papás sobre todo y a los adultos mayores en general". (Entrevista № 17).

Bastión: m. baluarte, fortificación (Diccionario del Español Actual, pág. 115). Ej.:"Era un bastión pa' mi". (Entrevista №9).

Brillante: adj. // 2. adj.fig. Admirable o sobresaliente en su línea (DRAE, pág. 203). Ej.: "... una juventud que tiene poco claro su norte; los que lo tienen claro, ¡excelente!, ;brillante!”. (Entrevista № 29).

Brutal : //adj. fig.coloq. macanudo ('magnífico, maravilloso '). (Nuevo Diccionario Ejemplificado de Chilenismos, DECH, Tomo I, pág. 326). Ej.: "Que los niños no lean más libros en el colegio, que - tú una vez me dijiste algo que se me quedó grabado para siempre - que fue es mucho más fácil, lo que se necesita no es el que niño sepa hacer el cálculo, sino que sepa ocupar la calculadora, me acuerdo que me lo dijiste y fue brutal'. (Entrevista №28).

Bueno,-a: adj. // 4. Grande, que excede a lo común (DRAE, pág. 207). Ej.: "...entonces, no sé poh, yo me acuerdo que estaba comiendo y...comía puras papas y tomates... y todos los demás comiéndose su buen pedazo de carne,". (Entrevista № 20).

Cabezón,-ona: adj. aumentativo de cabeza. De cabeza muy grande. (DRAE, pág. 217). Ej.: "Sí, la Santa María, pero es que ahí van los...la gente cabezona cabezona, intelectual intelectual'. (Entrevista $\mathrm{N}^{\circ} 1$ ). 
Caleta: IV. 1. adv. Ch. juv. Mucho. // 2. Ch. juv. Cantidad grande. (Diccionario de Americanismos, pág. 1363). Ej. "Caminamos caleta por Francia". (Entrevista № 31).

Caótico,ca: adj. Perteneciente o relativo al caos(confusión, desorden) (DRAE, pág. 249). Ej.: "Una semana después, estando justamente con un paciente en su domicilio. Ahí tuvimos, o sea fue caótico también porque hubo tres temblores seguidos muy grandes y la gente histérica corriendo por las calles". (Entrevista № 31).

Caracha: f. 2. am. Sarna de las personas (DRAE, pág. 445). Ej.: “..., pero cuando tú vas a jubilar, no te toman el total haberes, sino que te toman el sueldo base, que es una caracha,...". (Entrevista $\left.\mathrm{N}^{\circ} 12\right)$.

Cataclismo: m. // 3. Gran trastorno en el orden social o político. // 4. coloq. Disgusto, contratiempo, suceso que altera la vida cotidiana (DRAE, pág. 477). Ej.: "Para mí, era como que casi el epicentro había sido acá en Valparaíso, y la sensación en el momento era de que era casi un cataclismo, porque no, fue muy largo el terremoto". (Entrevista 31).

Cero: m. fig. calificación mínima que merece alguien o algo por su actuación o funcionamiento deficiente. (Nuevo Diccionario de Ejemplificado de Chilenismos, DECH, pág. 501). Ej.: “...poner una escuela de arquitectura es cero plata". (Entrevista $\left.\mathrm{N}^{\circ} 5\right)$.

Complicado,-da: adj. Enmarañado, de difícil comprensión. (DRAE, pág. 605). Ej.: "Eeh..., económicamente el país ha tenido altos, altos y bajos... Pienso, pienso que es un momento complicado el, el que se está viviendo". (Entrevista № 23). 
Completamente: adv. m. Cumplidamente, sin que nada falte (DRAE, pág. 332). Ej.: "Eeh, lamentablemente, es algo que nooo, no debería haber ocurrido, o sea,... desconocía yo completamente que esta mina no debería estar funcionando". (Entrevista № 23).

Concho: III. a // a concho. loc. adv. Ch. Hasta el fondo o máximo de algo. pop. + cult $\rightarrow$ espon. (Diccionario de Americanismos, pág. 646). Ej.: Me gustaría también ir a Barcelona, Madrid, eeh, volver a Francia en algún momento, pero volver a Francia sería más que nada para disfrutar a concho lo que vi ya,..." (Entrevista № 31).

Cuantioso,sa : adj. Grande en cantidad o número (DRAE, pág. 386). Ej.: "El capital que ellos tienen, que manejan es pero ya pa"decir basta, cuantioso, o sea, millones y millones, ...”. (Entrevista № 5 ).

Cuático, a: adj. Exagerado o desmesurado en el modo de hablar o en los ademanes (Nuevo Diccionario Ejemplificado de Chilenismos, DECH, pág. 782).Ej.: "Yo no sé si los papás ahora, no sé, no creo estar dentro del caso, porque yo, la verdad, es que soy bien estricta, soy complicada. De hecho, de repente: “¡Mamá, que eres cuática”, me dicen en casa”. (Entrevista № 21).

Cuesco (un):loc.pron.m.sing.pond.coloq. Un rábano (absolutamente nada). (Nuevo Diccionario Ejemplificado de Chilenismos, DECH, pág.747.). Ej.: "Siempre, o sea, a mí me importaba un cuesco que la fiesta empezara a las tres, cuatro de la mañana". (Entrevista № 17).

Demasiado, -a: *adj. Que es en demasía o tiene demasía (DRAE, pág. 431). Ej.: “. . o sea que es bastante poco pa' producciones como Machuca o como el mismo La Buena Vida que son películas que Andrés Wood gasta demasiada plata, demasiada y que yo creo que recupera un tercio si no un doceavo de todo lo que invirtió”.(Entrevista № 27). 
* 3. adv.c. en demasía. Ej. “...habían un... un dibujante que ponía los monos y los mandaban por Internet y todo el cuento, pero el de ella era demasiado pesado, se tuvo que quedar con el mono ahí nomás, porque era muy pesado, pesaba demasiado, pesaba cuatro veces más de lo que exigía". (Entrevista №1)

Desastre: m. // 2. Cosa de mala calidad, mal resultado, mala organización, mal aspecto, etc. (DRAE, pág. 762). Ej.: "Argentina está bastante estancada, mal, nadie sabe nada, un desastre”. (Entrevista № 5).

Descueve (el): m. sing. fig. pond. coloq. El colmo, el sumo, el grado más alto al que se puede llegar una cosa, como para producir notable impresión. (Nuevo Diccionario Ejemplificado de Chilenismos, DECH, pág. 877). Ej. “..., pero este gallo era en realidad el descueve". (Entrevista N5).

Enorme: adj. Desmedido, excesivo (DRAE, pág. 536). Ej.: “..., porque la PSU es una enorme forma de generar plata" (Entrevista № 5).

Entero, ra: adj. Cabal, cumplido, completo, sin falta alguna. (DRAE, pág. 928). Ej. "Viniendo de una mamá que es pinochetista entera, que no se puede hablar de otra cosa, o sea, si se toca ese tema, es como, ¡No sé!, es como un pegarle si le tocan el tema del gobierno militar, pero para mí los militares nunca deben existir en el poder". (Entrevista №33).

Escoba: // la escoba. f. sing. fig. Desbarajuste, desastre, ruina o destrucción general. (Nuevo Diccionario Ejemplificado de Chilenismos, DECH, pág. 1055).Ej.: "Pero era sin pensar que las personas que habían antes en la empresa... estaba la escoba, el desorden, las deudas, entonces."(Entrevista $\left.\mathrm{N}^{\circ} 8\right)$. 
Espantoso, sa: adj. Que causa espanto (DRAE, pág. 568). Ej.: “... ella hace poco nomás que dejó las pastillas y está muy bien como está, porque antes ni siquiera podía dormir, era algo espantoso". (Entrevista $\mathrm{N}^{\circ} 1$ ).

Espectacular: adj. fig. coloq. Maravilloso, magnífico, sorprendente. (Nuevo Diccionario Ejemplificado de Chilenismos, DECH, pág. 1064). Ej.: "Pero, finalmente tú puedes decir, ya pero como museos son espectaculares, ¿cachai?, son espectaculares, no sé, yo nunca he ido, ¿cachai?”. (Entrevista № 28).

Estratosférico: adj. fig. pond. coloq. Astronómico, dicho especialmente de un precio o una cantidad, excesivamente elevado. (Nuevo Diccionario Ejemplificado de Chilenismos, DECH, pág. 1085). Ej.: “; ahí va a poder entrar a estudiar, efectivamente, solo el que pueda pagar esos aranceles estratosféricos,..." (Entrevista № 5).

Estresante: adj. (de estrés). Que causa estrés (Diccionario Panhispánico de Dudas, pág. 279). Ej.: “ ..., porque tenía que hacer mi trabajo, tenía que hacer el trabajo de la persona que se había ido y más, enseñarle a dos personas nuevas que habian llegado, así que fue ...estresante, fue horrible". (Entrevista № 8).

Estúpido,-a: adj. necio, falto de inteligencia (DRAE, pág. 590). Ej.: "y he dicho que la televisión es un instrumento muy valórico para educar, pero a su vez lo mal, lo mal han usado para vender todo este tipo de cosas, de programas estúpidos, como Pelotón, como Yingo,...". (Entrevista № 17).

Eterno, na: adj. // 3 coloq. Que se prolonga muchísimo o excesivamente. (DRAE, pág. 1009). Ej.: "Se me hicieron eternos, eterno ese trayecto hasta llegar abajo". (Entrevista № 18). 
Excelencia // de //: loc. adj.: *Muy bueno Ej.: ", los médicos son de excelencia, o sea de película,..." (Entrevista № 5).

Excelente: adj. Que sobresale en bondad, mérito o estimación entre las cosas que son buenas en su misma especie (DRAE, pág. 594). Ej.: "...así que tuve que esperar un año más y ahí recién lo fui a dar, lo di sola y me fue excelente". (Entrevista № 8).

Exorbitante: adj. Excesivo, exagerado. (DRAE, pág. 1019). Ej.: "Es que, por ejemplo, ¡No sé!, se habla mucho de las mineras grandes, pero las medianas, las, las empresas medianas en minería, eeh, tienen unos capitales exorbitantes también,". (Entrevista № 22).

Exquisito, ta: adj. De singular y extraordinaria calidad, primor o gusto en su especie (DRAE, pág. 599). Ej.: "Estuvo buenísima la fiesta, porque tuvimos el bautizo de la pequeña y hizo una ceremonia muy bonita, eeh, y ahí estuvo festejando con una comida exquisita, así que eso". (Entrevista № 31).

Extraordinario, ria: adj. Fuera del orden o regla natural o común (DRAE, pág. 1026). Ej.: "Es decir, tenemos sentados en el Congreso a un montón de gente que se lleva una millonada extraordinaria... para que se dediquen... que el Presidente pisó mal, que la señora del presidente se corrió pa'l lado,...". (Entrevista № 24).

Fantástico, -a: adj. // 4. coloq. Magnífico, excelente. (DRAE, pág. 1039). Ej. "Tengo tres nietos fantásticos". (Entrevista № 29).

Flojazo, sa: adj. "(aumentativo de flojo). Muy flojo o floja. Ej.: "Es que a ella no le gusta leer los libros, noticias, los diarios, es flojaza para leer...”. (Entrevista № 1). 
Fome: adv.m.coloq. de manera insubstancial, carente de gracia y originalidad como para provocar tedio, aburrimiento o desinterés. (Nuevo Diccionario Ejemplificado de Chilenismos, DECH, Tomo II, pág. 1174). Ej.: "Y después a los pocos días, fue la alerta del tsunami, poh, que allí el Tommy ya estaba en el colegio. Noo, fome igual. Yo espero que, si hay otro, que estemos todos juntos, poh. Por último con el papá o conmigo, no con otra persona". (Entrevista № 34).

Fundamental: adj. Que sirve de fundamento o es lo principal en una cosa (DRAE, pág. 642). Ej.: “...el estudiar turismo fue netamente, porque yo ya viví en otro país y sé lo que es el turismo y ya tengo idiomas, que es una parte fundamental en un país como que es Chile". (Entrevista № 6).

Gigante : adj. Gigantesco //. 2. Mucho mayor que lo considerado como normal. (DRAE, pág. 1135).Ej.: "Entonces no, no, no muestran, no hay un cartel como poderoso afuera como hace el cine Hoyts, que pone unos lienzos gigantes "hoy miércoles, vuelve un clásico del cine a mil quinientos", o sea, ahí está el punto". (Entrevista №27).

Gorilón, na: adj. *aumentativo derivado de gorila. De cuerpo muy grande. Ej.: "Entonces él decía, ya mira, el hombre mide 1 metro 70, no sé en el caso de mis compañeras escandinavas son dos metros 47-gorilonas gorilonas-y eem, él hacía techos muy bajos, perdón cielos muy bajos...”. (Entrevista № 28).

Gran(de):adj. que excede a lo común y regular (DRAE, pág. 675).Ej. “...me preparé yo, o sea, egresé del Colegio Rubén Castro y el Colegio Rubén Castro me dio la gran oportunidad de ver en qué consistía la parte administrativa,...". (Entrevista №23). 
Grandote, ta: adj. Aumentativo de grande (DRAE, pág. 675). Ej.: "Tenemos grandes universidades, tres, cuatro, cinco, seis universidades grandotas". (Entrevista № 22).

Harto, ta : *adj. // 2. Bastante o sobrado (DRAE, pág. 696). Ej. "Aparte de que se hizo harta parafernalia con ;Vamos, Chile!, creo que la gente se paró. Me refiero a que la gente se unió." (Entrevista № 22).

* adv. cant. pond. coloq. Mucho o muy; con abundancia, en gran cantidad (Nuevo Diccionario Ejemplificado de Chilenismos, DECH, pág. 1334).Ej.: "Me ayudaron harto unos amigos míos y... uno de ellos también me dijo: yo prefiero que sufrai ahora... y que no seai un amargado toda la vida”.(Entrevista № 9).

Heavy: *adj. 1. Pesado, de mucho peso // 7. Grave, serio; de peso, importante, considerable (International Dictionary English/Spanish, pág.935).

*Voz inglesa. I. 1. adj. Ch. juv. referido a cosa, muy buena, excelente. (Diccionario de Americanismos, pág. 1134). Ej.: "Ahora trato de no hacerlo tanto, disfrutar el día a día, peroooo, pero no sé, por el momento me veo obviamente con, con mi pololo, con el Enrique, juntos yyy, no sé, eeh, espero con una pega heavy, que sea estable, que no tenga que estar estresada,..." (Entrevista 31).

Histérico,-a. adj. perteneciente el histerismo. Estado pasajero de excitación nerviosa producido a consecuencia de una situación anómala (DRAE, pág. 713). Ej.: Una semana después, estando justamente con un paciente en su domicilio. 
Ahí tuvimos, o sea fue caótico también porque hubo tres temblores seguidos muy grandes y la gente histérica corriendo por las calles". (Entrevista № 31).

Horrible: adj. 2. coloq. Muy feo. / 3. coloq. Muy intenso o acentuado. /4. coloq. Muy malo, pésimo. (DRAE, pág. 1231). Ej.: "Fue una experiencia horrible, tuvimos que estar durmiendo como una semana en otra casa,..." (Entrevista № 6).

Increíble: adj. // 2. Muy difícil de creer. (DRAE, pág. 1264). Ej.: "Porque no le prestó atención, le tiró un jarro con agua a la autoridad. O sea, la falta de respeto increíble". (Entrevista № 21).

Infinito, ta: adj. // 2. Muy numeroso o enorme. (DRAE, pág. 1273). Ej.: "Tiene una paciencia infinita conmigo y eso es impagable". (Entrevista № 21).

Inmenso, -a: adj. //. 2. fig. Muy grande o muy difícil de medirse o contarse (DRAE, pág. 747). Ej.: "Muestra de esto es la inmensa cantidad recaudada por las grandes empresas que donan porque ello les permite descontar impuestos. No obstante, todo es producto del apoyo de una inmensa población compradora: caso conocidísimo como es la Teletón". (Entrevista №25).

Intelectual:adj. // 3. Dedicado preferentemente al cultivo de las ciencias y letras (DRAE, pág. 753). Ej.:....es que ahí van los... la gente cabezona cabezona, intelectual intelectual...". (Entrevista № 1).

Irrestricto,ta: adj. Méx. Ur. Ilimitado. (DRAE, pág.1303) Ej.:" Pero afortunadamente, mi madre tenía un respeto irrestricto a este derecho que es el de la vida" (Entrevista № 4). 
Largo, ga: adj. Que tiene largor excesivo (DRAE, pág. 787). Ej. "Es un tema laargo no es algo que se va a solucionar de un día para otro, porque cada vez se levanta una piedra y salen más niños delincuentes” (Entrevista № 21).

Lote (al): loc. adv. / adj. Ch. De manera improvisada, sin orden ni método. pop. cult. espon. (Diccionario de Americanismos, 1315). Ej.: "Después de eso, entré a la Universidad y ahí claro, tuve algunas relaciones, pero claro, las relaciones universitarias son como bien, bien al lote, sobre todo así involucrándose con alguien que estudia la misma carrera que tú,...". (Entrevista № 16).

Maravilla: f. Suceso o cosa extraordinarios que causan admiración (DRAE, pág.845). Ej.: "Creo que me comí esa noche como cuarenta costillitas ¡Feliz!, pero no he vuelto a comer, y el jamón serrano, por ejemplo. Eso ya es una maravilla, hay siete, ocho, nueve variedades en jamón exquisito, exquisito,...”. (Entrevista № 29).

Maravilloso,sa: adj. (De maravilla). Extraordinario, excelente, admirable. (DRAE, pág. 1450). Ej.: "Casada dos veces, tengo dos hijos maravillosos: uno de 19, estudia Pedagogía en Inglés, en la Viña del Mar, y otro de 13, está en $8^{a}$ Básico en el Colegio San Nicolás, que llenan mi vida, son mi orgullo completamente". (Entrevista №21)

Medio.- a: I. 1. adj. Ch. Muy grande. pop. cult. espon. / 2. Ch. Muy bueno. (Diccionario de Americanismos, pág. 1850).Ej.: "Fue jel medio viaje!" (Entrevista №31).

Millonada: f. coloq. Cantidad muy grande, en unidades, de un millón o más. (Nuevo Diccionario Ejemplificado de Chilenismos, DECH, pág. 1769). Ej.: “iMira!, Por ejemplo, a mí lo que más me chorea en este país, es la lacra de los políticos..., porque son personas que ganan una millonada... que tienen tantas cosas de beneficio...". (Entrevista №24). 
Mucho, cha: adj. Abundante, numeroso o que excede a lo ordinario, regular o preciso (DRAE, pág. 901). Ej.:"Entonces él dijo ya, de por sí toda la gente que llega, llega con problemas, enferma, entonces ya han gastado mucha plata en medicamentos,....". (Entrevista № 19).

Mugre: f. I. 2. Cosa de escaso valor o calidad. pop. cult. espon. despect. (Diccionario de Americanismos, pág. 1479).Ej.: "Si tú vieras el sueldo base que ganan nuestros compañeros de trabajo y son auxiliares de servicio, es una mugre". (Entrevista $\mathrm{N}^{\circ} 12$ ).

Multifacético,- a: adj. cult. polifacético, que tiene muchas facetas o aspectos (Nuevo Diccionario Ejemplificado de Chilenismos, DECH, pág. 1844). Ej.: “El personal técnico está muy especializado, eh...es multifacético o multifuncional como se le llama". (Entrevista № 12).

Multifuncional: adj. "Que cumple muchas funciones. Ej.: "El personal técnico está muy especializado, eh...es multifacético o multifuncional como se le llama". (Entrevista № 12).

Ostracismo: m. exclusión voluntaria o forzosa de los oficios públicos a la cual suelen dar ocasión los trastornos políticos (DRAE, pág. 1639). Ej.: “..., pero ella no decía lo que le pasaba, la llevamos al psicólogo del consultorio municipal, pero no sirvió mucho, porque no, no sirvió para nada, ella era un ostracismo, se cerraba y no quería hablar, y hasta que a los tres años de arrastrar la depresión gatilló y tuvimos que llevarla al neurólogo particular...". (Entrevista № 1).

Película: // de película // loc. adj. pond. coloq. Espectacular, impresionante. (Nuevo Diccionario Ejemplificado de Chilenismos, DECH, Tomo II, pág. 2113). Ej.: "...los médicos, ejemplo típico, son de excelencia, o sea de película" (Entrevista № 5). 
Perfecto, ta: adj. Que tiene el mayor grado posible de bondad o excelencia en su línea (DRAE, pág. 1007). Ej.: "Pero son hitos de la arquitectura, lo mismo pasó con la Belleza de Hollar, la Belleza de Hollar son perfectos museos, como museos funcionan perfecto, ¿cachai?, perfecto, pero como casas no funcionan".(Entrevista № 2).

Picante: adj.fig.despect.coloq. Grosero, vulgar. Ordinario o de baja ralea (Nuevo Diccionario Ejemplificado de Chilenismos, DECH, página 2181). Ej.: "Esas películas picantes". (Entrevista № 14).

Precioso, sa. adj. Excelente, exquisito, primoroso y digno de estimación y aprecio (DRAE, pág. 1057). Ej.: "También, cuando fuimos a Brasil, que escribió en el Cristo de Luz, también dejó un mensaje precioso ahí". (Entrevista № 34).

Principal: adj. // 4. Esencial o fundamental por oposición a accesorio (DRAE, pág. 1065). Ej.: "Ahora, un cabro de veinticinco años que ya es obeso, es muy difícil hacerlo bajar de peso, pero la familia es principal, toda la familia es principal'. (Entrevista №33).

Puro, -a: adj. // 9. Mero, solo, no acompañado de otra cosa (DRAE, pág, 1086). Ej.: "Ahí hay problemas poh, ja,ja,ja, porque él es muy serio, entonces mi familia de repente, como somos puras mujeres..., eh..., casi siempre hay puros encontrones...". (Entrevista № 10).

Raja: VIII. b // la raja, loc.adj./ adv. Ch. Muy bueno, excelente. vulg. pop. hiperb. (Diccionario de Americanismos, pág. 1813). Ej.: "Estar ahí relajados, con un clima distinto, eeh, guatita al sol todo el día, comiendo bacán, sí la raja, perooo, faltó el carrete no más, en las discoteques, pero era muy chica todavía así que no podía salir sola”. (Entrevista № 31). 
Rico, ca: adj. // 4. Gustoso, sabroso, agradable (DRAE, 1148). Ej.: "Entonces fue rico, porque fue rapidito ya. Cuando estaba arriba del avión, no lo podía creer". (Entrevista № 34).

Ridículo, la: 1. adj. // 3. Extraño, irregular y de poco aprecio y consideración (DRAE, pág. 1148). Ej.: "Esta cosa de la libre competencia en Chile, ¡Es ridícula! Tú vas a comprar un saco de cemento a cualquier negocio de estos grandes y todos valen lo mismo". (Entrevista № 24).

Seco,- a: IV. Adj. Ch, juv. Referido a persona hábil o capacitada para una cosa. (Diccionario de Americanismos, pág. 1933). Ej.: "El compadre estudia y resulta que es un excelente historiador, está estudiando, está estudiando historia y el compadre es seco y gran profesor de historia,...”. (Entrevista № 27).

Talentoso, sa: adj. Que tiene talento, ingenio, capacidad y entendimiento (DRAE, pág. 1239). Ej.: "Armamos un equipo pero pa"qué te digo que el descueve, gente talentosa..." (Entrevista № 5).

Tanto: adv.c. Hasta tal punto; tal cantidad (DRAE, pág. 1242). Ej.: “. . y el doctor estaba muy molesto esa vez y salió para afuera a llamar a la... a llamarle la atención a las secretaria que por qué había... nos había hecho esperar tanto”. (Entrevista № 18).

Terrible: //. adj. 3. Muy grande o desmesurado. (DRAE, pág. 1259). Ej.: "Terrible, terrible ha sido toda esta situación, porque estar lejos de la familia y haber conocido a alguien que falleció en ... con el tsunami, fue terrible". (Entrevista № 15).

Tira): // hac/er/ tira (s). loc. tr. coloq. Hacer trizas ('despedazar a algo, destruirlo, ‘disgregarlo`. (Nuevo Diccionario Ejemplificado de Chilenismos, DECH, Tomo III, pág. 2997). Ej.: “..., bueno un día nos topamos con mi hermano, 
estábamos haciendo ejercicios y estamos todos así hechos tira, porque hacíamos ejercicio a pleno sol y en pleno verano,...". (Entrevista $\left.\mathrm{N}^{\circ} 7\right)$.

Titánico, ca: adj. // 2. fig. Desmesurado, excesivo, como de titanes (DRAE, pág. 1271). Ej.: "...no sé, titánico es escoger con pinzas a los mejores de los mejores". (Entrevista № 5).

Total: adj. pond. coloq. Absoluto, extremo, categórico (Nuevo Diccionario Ejemplificado de Chilenismos, DECH, pág. 3042). Ej.: “..., cuando yo llegué, era un desorden total, así muy,, muy desordenado". (Entrevista № 8).

Totalmente: adv. m. Enteramente, del todo (DRAE, pág. 1281). Ej.: “...actualmente, bueno, tenemos todo el flagelo esto de las drogas, eeh, el alcohol y muchas otras cosas que están quee, por lo menos, en los tiempos que yo hablaba del inicio del colegio desconocía totalmente”. (Entrevista № 23).

Traumático,-a: adj. Perteneciente o relativo al traumatismo, y éste de trauma, definido en sentido psíquico, como choque o sentimiento emocional que deja uma impresión duradera en la subconsciencia (DRAE, pág. 1293). Ej.: "Disfruté mucho hasta que tuve un accidente, no pude seguir trabajando, porque quedé inválida. Eso fue como a los veintisiete. Ahora tengo casi 60 , eeh, fue traumático". (Entrevista №29).

Tremendo,-da. // 4. coloq. Muy grande y excesivo en su línea (DRAE, pág. 2223). Ej.: "Por una bendición, eeh, no suficientemente agradecida, ellos se autosustentan, no digo económicamente, pero síl en cuanto a que no están inhabilitados, son autovalentes. Y esa es una cuestión quee, ¡Uuuh!, es tremenda, o sea tremenda de valor, Ah!, uno no lo, no lo valora en tanto no viva lo contrario, 0 , o vea por lo menos a otro que vive lo contrario". (Entrevista № 30). 
Triple: adj. Dicho de un número. Que contiene a otros tres veces exactamente (DRAE, pág. 2231). Ej.: "Esto fue en enero... y en abril yo ya empezaba a trabajar en Valparaíso, porque me tuve que quedar, fue... fue enero, febrero, marzo, trabajando el triple, porque tenía que hacer mi trabajo, tenía que hacer el trabajo de la persona que se había ido y más, enseñarle a dos personas nuevas que habian llegado". (Entrevista № 8).

Trucho, - a: adj. Falso, fraudulento. espon. (Diccionario de Uso del Español de Chile (DUECH), pág. 899). Ej.: “..., pero tú sabí que es un país medio trucho, y se hicieron papeles medios truchos..." (Entrevista $\left.\mathrm{N}^{\circ} 6\right)$ 


\section{ANEXO 2}

\section{REGISTRO DE SUPERLATIVOS EN LAS 34 ENTREVISTAS}

\section{ENTREVISTA 1}

№ Total de Superlativos: 38

\begin{tabular}{|c|c|c|c|}
\hline ADJETIVO & $\begin{array}{l}\text { ATRIBUTO } \\
\text { (verbos ser y } \\
\text { estar) }\end{array}$ & $\begin{array}{l}\text { ATRIBUTO ( otros } \\
\text { verbos) }\end{array}$ & ADVERBIOS \\
\hline $\begin{array}{l}\text { Período } \\
\text { demasiado difícil }\end{array}$ & $\begin{array}{l}\text { Es muy } \\
\text { diferente }\end{array}$ & $\begin{array}{l}\text { Se va poniendo ya } \\
\text { más complicada }\end{array}$ & Le fue pésimo \\
\hline $\begin{array}{l}\text { Una cosa muy } \\
\text { negra }\end{array}$ & $\begin{array}{l}\text { Es tan } \\
\text { importante }\end{array}$ & $\begin{array}{l}\text { Nos vimos muy } \\
\text { afectados }\end{array}$ & $\begin{array}{l}\text { Las recibió muy } \\
\text { bien }\end{array}$ \\
\hline Muy oscura & Está muy sola & $\begin{array}{l}\text { Le quedó muy } \\
\text { bueno }\end{array}$ & $\begin{array}{l}\text { La veo mucho } \\
\text { mejor }\end{array}$ \\
\hline Muy triste & $\begin{array}{l}\text { Ella fue muy } \\
\text { valiente }\end{array}$ & $\begin{array}{l}\text { Lo dibujó bien } \\
\text { bonito }\end{array}$ & Le iba pésimo \\
\hline $\begin{array}{l}\text { Adolescencia muy } \\
\text { complicada }\end{array}$ & $\begin{array}{l}\text { Las pastillas } \\
\text { eran muy fuertes }\end{array}$ & & \\
\hline \multirow{8}{*}{$\begin{array}{l}\text { Muy buena } \\
\text { persona }\end{array}$} & Está muy bien & & \\
\hline & $\begin{array}{l}\text { Era demasiado } \\
\text { pesada }\end{array}$ & & \\
\hline & Era muy pesado & & \\
\hline & Es muy fácil & & \\
\hline & $\begin{array}{l}\text { Hay que ser bien } \\
\text { cuadradito }\end{array}$ & & \\
\hline & Son muy buenas & & \\
\hline & $\begin{array}{l}\text { Eran muy } \\
\text { pobres }\end{array}$ & & \\
\hline & $\begin{array}{l}\text { Son muy } \\
\text { católicos }\end{array}$ & & \\
\hline 6 & 13 & 4 & 4 \\
\hline
\end{tabular}

\begin{tabular}{|l|l|}
\hline SUPERLATIVOS LÉXICOS & RECURSOS ESTILISTICOS \\
\hline Son terribles & Unos poemas horribles, horribles \\
\hline Era algo espantoso & Ella era un ostracismo \\
\hline Le sirvió harto & La gente cabezona, cabezona \\
\hline Pesaba demasiado & Intelectual, intelectual \\
\hline Una etapa pero horrible & \\
\hline Oscura total & \\
\hline Es flojaza & \\
\hline 7 & 4 \\
\hline
\end{tabular}




\section{ENTREVISTA 2}

№ Total de superlativos: 15

\begin{tabular}{|c|c|c|c|}
\hline ADJETIVO & $\begin{array}{l}\text { ATRIBUTO } \\
\text { (verbos ser y } \\
\text { estar) }\end{array}$ & $\begin{array}{l}\text { ATRIBUTO ( } \\
\text { otros verbos) }\end{array}$ & ADVERBIOS \\
\hline $\begin{array}{l}\text { Una cesárea } \\
\text { verdaderamente } \\
\text { justificada }\end{array}$ & Es más eficiente & $\begin{array}{l}\text { Hace más } \\
\text { rentable la } \\
\text { cesárea }\end{array}$ & $\begin{array}{l}\text { Reciba mejor estas } \\
\text { células }\end{array}$ \\
\hline $\begin{array}{l}\text { Los datos más } \\
\text { importantes }\end{array}$ & $\begin{array}{l}\text { (es) o más } \\
\text { rentable }\end{array}$ & & \\
\hline $\begin{array}{l}\text { Equipo más } \\
\text { especializado }\end{array}$ & $\begin{array}{l}\text { Era el más } \\
\text { importante }\end{array}$ & & \\
\hline Más complejo & $\begin{array}{l}\text { Eran las más } \\
\text { importantes }\end{array}$ & & \\
\hline $\begin{array}{l}\text { Un parto } \\
\text { totalmente natural }\end{array}$ & Es lo más natural & & \\
\hline \multirow[t]{2}{*}{ El tema más actual } & $\begin{array}{l}\text { Va a ser muy } \\
\text { doloroso }\end{array}$ & & \\
\hline & $\begin{array}{l}\text { Está como } \\
\text { totalmente } \\
\text { corroborada }\end{array}$ & & \\
\hline 6 & 7 & 1 & 1 \\
\hline
\end{tabular}

\begin{tabular}{|l|l|}
\hline SUPERLATIVOS LÉXICOS & RECURSOS ESTILÍSTICOS \\
\hline 0 & 0 \\
\hline
\end{tabular}




\section{ENTREVISTA 3}

№ Total de superlativos: 17

\begin{tabular}{|c|c|c|c|}
\hline ADJETIVO & $\begin{array}{l}\text { ATRIBUTO } \\
\text { (verbos ser y } \\
\text { estar) }\end{array}$ & $\begin{array}{l}\text { ATRIBUTO ( } \\
\text { otros verbos) }\end{array}$ & ADVERBIOS \\
\hline & $\begin{array}{l}\text { Es bastante } \\
\text { interesante }\end{array}$ & & \\
\hline & $\begin{array}{l}\text { Están muy bien } \\
\text { seleccionados }\end{array}$ & & \\
\hline & $\begin{array}{l}\text { Es súper } \\
\text { interesante }\end{array}$ & & \\
\hline & Es más real & & \\
\hline & Es la más bonita & & \\
\hline & Son muy fomes & & \\
\hline & Es peor & & \\
\hline & Eran pésimos & & \\
\hline & $\begin{array}{l}\text { Estaba muy mal } \\
\text { hecho }\end{array}$ & & \\
\hline & Son pésimas & & \\
\hline & $\begin{array}{l}\text { ( es) lo más } \\
\text { corriente }\end{array}$ & & \\
\hline & $\begin{array}{l}\text { Es bastante } \\
\text { culpable }\end{array}$ & & \\
\hline & Es lo más usual & & \\
\hline 0 & 13 & 0 & 0 \\
\hline SUPERLATIVOS L & EXICOS & \multicolumn{2}{|c|}{ RECURSOS ESTILÍSTICOS } \\
\hline \multicolumn{2}{|c|}{ Eran asquerosos } & \multirow{2}{*}{\multicolumn{2}{|c|}{$\begin{array}{l}\text { Va a ser puro puro } \\
\text { Formato original original }\end{array}$}} \\
\hline & & & \\
\hline & & \multicolumn{2}{|c|}{ Personas bastante, bastante amplias } \\
\hline 1 & & 3 & \\
\hline
\end{tabular}




\section{ENTREVISTA 4}

№ Total de superlativos: 14

\begin{tabular}{|c|c|c|c|}
\hline ADJETIVO & $\begin{array}{l}\text { ATRIBUTO } \\
\text { (verbos ser y } \\
\text { estar) }\end{array}$ & $\begin{array}{l}\text { ATRIBUTO ( } \\
\text { otros verbos) }\end{array}$ & ADVERBIOS \\
\hline $\begin{array}{l}\text { (opiniones) muy } \\
\text { objetivas }\end{array}$ & $\begin{array}{l}\text { Estoy en absoluto } \\
\text { desacuerdo }\end{array}$ & & \\
\hline Mayor facilidad & $\begin{array}{l}\text { (es) el más } \\
\text { importante }\end{array}$ & & \\
\hline $\begin{array}{l}\text { Secuelas más } \\
\text { importantes }\end{array}$ & $\begin{array}{l}\text { El más importante } \\
\text { de los derechos }\end{array}$ & & \\
\hline $\begin{array}{l}\text { Su fuero más } \\
\text { interno }\end{array}$ & Era lo mejor & & \\
\hline $\begin{array}{l}\text { Opiniones muy } \\
\text { científicas }\end{array}$ & Es muy posible & & \\
\hline & $\begin{array}{l}\text { (es) lo más } \\
\text { importante }\end{array}$ & & \\
\hline 5 & 6 & 0 & 0 \\
\hline
\end{tabular}

\begin{tabular}{|l|l|}
\hline SUPERLATIVOS LÉXICOS & RECURSOS ESTILÍSTICOS \\
\hline caminar, difícil, terrible & \\
\hline Conocimiento absoluto & \\
\hline Respeto irrestricto & \\
\hline 3 & 0 \\
\hline
\end{tabular}




\section{ENTREVISTA 5}

№ Total de superlativos: $\mathbf{3 1}$

\begin{tabular}{|c|c|c|c|}
\hline ADJETIVO & $\begin{array}{l}\text { ATRIBUTO } \\
\text { (verbos ser y } \\
\text { estar) }\end{array}$ & $\begin{array}{l}\text { ATRIBUTO ( } \\
\text { otros verbos) }\end{array}$ & ADVERBIOS \\
\hline Carrera carísima & No ser tan cínicos & $\begin{array}{l}\text { Se hizo re } \\
\text { famoso }\end{array}$ & Sonar re feo \\
\hline $\begin{array}{l}\text { Los mejores de los } \\
\text { mejores }\end{array}$ & Eran lo mejor & & Les va mejor \\
\hline $\begin{array}{l}\text { Un estilo bien } \\
\text { particular }\end{array}$ & Es muy simple & & \\
\hline Puntajes más altos & Era menor & & \\
\hline $\begin{array}{l}\text { Aranceles } \\
\text { carísimos }\end{array}$ & $\begin{array}{l}\text { Es bastante } \\
\text { estancada }\end{array}$ & & \\
\hline 5 & 5 & 1 & 2 \\
\hline
\end{tabular}

\begin{tabular}{|l|l|}
\hline SUPERLATIVOS LÉXICOS & RECURSOS ESTILISTICOS \\
\hline Este gallo era el descueve & Millones y millones \\
\hline Equipo el descueve & Es cero plata \\
\hline Aranceles estratosféricos & Es grito y plata \\
\hline Es titánico & Era para llorar \\
\hline Son de película & Es pero ya pa decir basta \\
\hline Es un desastre & Harto, harto profe gringo \\
\hline cuantioso & Es escoger con pinzas \\
\hline es una enorme forma de generar plata & \\
\hline Son de excelencia & \\
\hline Gente talentosa & \\
\hline Pero talentosa & \\
\hline 11 & 7 \\
\hline
\end{tabular}




\section{ENTREVISTA 6}

№ Total de superlativos: 35

\begin{tabular}{|c|c|c|c|}
\hline ADJETIVO & $\begin{array}{l}\text { ATRIBUTO } \\
\text { (verbos ser y } \\
\text { estar) }\end{array}$ & $\begin{array}{l}\text { ATRIBUTO ( } \\
\text { otros verbos) }\end{array}$ & ADVERBIOS \\
\hline Entorno bien simpático & Es bien corta & & $\begin{array}{l}\text { Entiendo } \\
\text { bastante bien }\end{array}$ \\
\hline $\begin{array}{l}\text { Fueron los mejores años } \\
\text { de mi vida }\end{array}$ & Era muy diverso & & $\begin{array}{l}\text { No me explico } \\
\text { muy bien }\end{array}$ \\
\hline $\begin{array}{l}\text { La experiencia más } \\
\text { gratificante }\end{array}$ & $\begin{array}{l}\text { Fue un poco } \\
\text { traumante }\end{array}$ & & \\
\hline Es un país carísimo & $\begin{array}{l}\text { Son bien } \\
\text { simpáticos }\end{array}$ & & \\
\hline $\begin{array}{l}\text { Una necesidad más } \\
\text { personal }\end{array}$ & $\begin{array}{l}\text { Son bien } \\
\text { acogedores }\end{array}$ & & \\
\hline \multirow[t]{5}{*}{$\begin{array}{l}\text { Persona completamente } \\
\text { sociable }\end{array}$} & $\begin{array}{l}\text { Fueron súper } \\
\text { cariñosos }\end{array}$ & & \\
\hline & Eran más largos & & \\
\hline & Somos re amigos & & \\
\hline & Yo era bien pop & & \\
\hline & Era bien fanático & & \\
\hline 6 & 10 & & 2 \\
\hline
\end{tabular}

\begin{tabular}{|l|l|}
\hline SUPERLATIVOS LÉXICOS & RECURSOS ESTILISTICOS \\
\hline Fue terrible, & Yo era chico, chico \\
\hline (fue) horrible & Una cosa como de segundos \\
\hline Una experiencia horrible & Una profesora francesa francesa \\
\hline Es un país medio trucho & Es como más real \\
\hline Papeles medios truchos & Era como bien diverso \\
\hline Fue una experiencia bacán & Uno es más cerrado, más cerrado \\
\hline Es una parte fundamental & Pero está a punto \\
\hline Cambió harto & \\
\hline Tengo hartos amigos & \\
\hline Fue bastante tiempo & \\
\hline 10 & 7 \\
\hline
\end{tabular}




\section{ENTREVISTA 7.}

№ Total de superlativos: 19

\begin{tabular}{|l|l|l|l|}
\hline ADJETIVO & $\begin{array}{l}\text { ATRIBUTO (verbos } \\
\text { ser y estar) }\end{array}$ & $\begin{array}{l}\text { ATRIBUTO } \\
\text { (otros verbos) }\end{array}$ & ADVERBIOS \\
\hline Régimen muy estricto & $\begin{array}{l}\text { Soy medio } \\
\text { hiperquinético }\end{array}$ & & \\
\hline Bien estricta & Es muy inestable & & \\
\hline & Estaba muy cansado & & \\
\hline & $\begin{array}{l}\text { Era bien popular la } \\
\text { banda }\end{array}$ & & \\
\hline & $\begin{array}{l}\text { (eran)Como bien } \\
\text { metidos }\end{array}$ & $\begin{array}{l}\text { Son como muy } \\
\text { restringidos }\end{array}$ & \\
\hline & $\begin{array}{l}\text { Era muy directa la } \\
\text { letra }\end{array}$ & & \\
\hline & $\begin{array}{l}\text { (es) como lo más } \\
\text { penosos }\end{array}$ & & 0 \\
\hline 8 & 0 & \\
\hline 2 & 8 & & \\
\hline
\end{tabular}

\begin{tabular}{|l|l|}
\hline SUPERLATIVOS LÉXICOS & RECURSOS ESTILÍSTICOS \\
\hline Me interesaba harto & $\begin{array}{l}\text { Una experiencia que no se la doy a } \\
\text { nadie }\end{array}$ \\
\hline Todos así, hechos tira & Yo ya estaba ya agotado \\
\hline Hartos seguidores & Es muy... es muy... \\
\hline & Pero hasta con cinco candados. \\
\hline & bien así... car'e palo \\
\hline & Se sentía como orgullosa \\
\hline 3 & 6 \\
\hline
\end{tabular}




\section{ENTREVISTA 8}

№ Total de superlativos: 34

\begin{tabular}{|c|c|c|c|}
\hline ADJETIVO & $\begin{array}{l}\text { ATRIBUTO (verbos } \\
\text { ser y estar) }\end{array}$ & $\begin{array}{l}\text { ATRIBUTO } \\
\text { (otros verbos) }\end{array}$ & ADVERBIOS \\
\hline $\begin{array}{l}\text { Súper pocos } \\
\text { exámenes }\end{array}$ & $\begin{array}{l}\text { Estoy más que } \\
\text { segura }\end{array}$ & $\begin{array}{l}\text { Se siente } \\
\text { como más } \\
\text { acompañado }\end{array}$ & Fue súper bien \\
\hline $\begin{array}{l}\text { No fue muy buena } \\
\text { experiencia }\end{array}$ & Fue súper bueno & & (fue) súper bien \\
\hline $\begin{array}{l}\text { Expectativas } \\
\text { totalmente diferentes }\end{array}$ & Era lo máximo & & $\begin{array}{l}\text { Se te hace más } \\
\text { fácil }\end{array}$ \\
\hline \multirow[t]{9}{*}{$\begin{array}{l}\text { Mucho } \\
\text { mejores(sueldos) }\end{array}$} & Es mucho mejor & & $\begin{array}{l}\text { Me pagaban } \\
\text { muy bien }\end{array}$ \\
\hline & Es lo peor & & $\begin{array}{l}\text { Me pagaban } \\
\text { súper poco }\end{array}$ \\
\hline & Es como lo mejor & & $\begin{array}{l}\text { Hacía más } \\
\text { rápido las } \\
\text { cosas }\end{array}$ \\
\hline & Era todo muy... & & \\
\hline & $\begin{array}{l}\text { Era mi trabajo bien } \\
\text { específico }\end{array}$ & & \\
\hline & $\begin{array}{l}\text { Fue totalmente } \\
\text { diferente }\end{array}$ & & \\
\hline & $\begin{array}{l}\text { Ya es totalmente } \\
\text { diferente }\end{array}$ & & \\
\hline & $\begin{array}{l}\text { Es como totalmente } \\
\text { distinto }\end{array}$ & & \\
\hline & $\begin{array}{l}\text { (es) totalmente } \\
\text { distinto }\end{array}$ & & \\
\hline 4 & 12 & 1 & 6 \\
\hline
\end{tabular}

\begin{tabular}{|l|l|}
\hline SUPERLATIVOS LÉXICOS & RECURSOS ESTILISTICOS \\
\hline Fue horrible & Así muy, muy desordenado \\
\hline Me fue excelente & Me sacrificaba mucho, mucho,mucho. \\
\hline Era un desorden total & \\
\hline Estaba la escoba & \\
\hline Trabajaba el triple & \\
\hline Retribución cero & \\
\hline Fue estresante & \\
\hline Fue horrible & \\
\hline Todo es excelente & 2 \\
\hline 9 & \\
\hline
\end{tabular}




\section{ENTREVISTA 9}

№ Total de superlativos: 31

\begin{tabular}{|l|l|l|l|}
\hline ADJETIVO & $\begin{array}{l}\text { ATRIBUTO (verbos } \\
\text { ser y estar) }\end{array}$ & $\begin{array}{l}\text { ATRIBUTO } \\
\text { (otros verbos) }\end{array}$ & ADVERBIOS \\
\hline $\begin{array}{l}\text { Bien buen puntaje } \\
\text { profunda mucho más }\end{array}$ & $\begin{array}{l}\text { Eu bastante bueno } \\
\text { vilipendiados }\end{array}$ & $\begin{array}{l}\text { Me sentía más } \\
\text { distante }\end{array}$ & Era muy lejos \\
\hline $\begin{array}{l}\text { Era una realidad } \\
\text { como bien especial }\end{array}$ & Era bien agotador & $\begin{array}{l}\text { Hay muy } \\
\text { poquito }\end{array}$ \\
\hline $\begin{array}{l}\text { Clase económica } \\
\text { bastante media }\end{array}$ & $\begin{array}{l}\text { No puede ser tan } \\
\text { fácil }\end{array}$ & $\begin{array}{l}\text { Me fue muy } \\
\text { bien }\end{array}$ \\
\hline Lugar muy lejano & Estoy más maduro & $\begin{array}{l}\text { Aprenderlo muy } \\
\text { bien }\end{array}$ \\
\hline $\begin{array}{l}\text { Cometer un error muy } \\
\text { grande }\end{array}$ & Eras más joven & \\
\hline $\begin{array}{l}\text { Un tema más adulto } \\
\text { El animal más } \\
\text { maltratado }\end{array}$ & No es muy bueno & & \\
\hline $\begin{array}{l}\text { Tuve una historia muy } \\
\text { larga }\end{array}$ & & & \\
\hline $\begin{array}{l}\text { Cosas como más } \\
\text { lentas }\end{array}$ & 7 & & \\
\hline $\begin{array}{l}\text { (cosas) más } \\
\text { planificadas }\end{array}$ & & & \\
\hline 11 & & & \\
\hline
\end{tabular}

\begin{tabular}{|l|l|}
\hline SUPERLATIVOS LÉXICOS & RECURSOS ESTILISTICOS \\
\hline Se trató de trabajar harto & Era un bastión pa'mí \\
\hline Me ayudaron harto & Costó harto, costó harto \\
\hline Se recogió harto perro & Era como que había tocado fondo \\
\hline & Entonces hay harto, harto trabajo \\
\hline 3 & 4 \\
\hline
\end{tabular}




\section{ENTREVISTA 10}

№ Total de superlativos: 25

\begin{tabular}{|c|c|c|c|}
\hline ADJETIVO & $\begin{array}{l}\text { ATRIBUTO (verbos } \\
\text { ser y estar) }\end{array}$ & $\begin{array}{l}\text { ATRIBUTO } \\
\text { (otros verbos) }\end{array}$ & ADVERBIOS \\
\hline $\begin{array}{l}\text { La gente muy } \\
\text { simpática }\end{array}$ & Es muy serio & & $\begin{array}{l}\text { Empieza a } \\
\text { crecer muy } \\
\text { grande }\end{array}$ \\
\hline Carácter muy fuerte & Es muy franco & & $\begin{array}{l}\text { Nos llevamos } \\
\text { harto bien }\end{array}$ \\
\hline \multirow[t]{6}{*}{$\begin{array}{l}\text { Dan puras malas } \\
\text { noticias }\end{array}$} & $\begin{array}{l}\text { Son como bien } \\
\text { protectores }\end{array}$ & & $\begin{array}{l}\text { Demoré como } \\
\text { muy poco }\end{array}$ \\
\hline & $\begin{array}{l}\text { Son como medios } \\
\text { infantiles }\end{array}$ & & \\
\hline & $\begin{array}{l}\text { Es más complicado } \\
\text { vivir }\end{array}$ & & \\
\hline & Sea más apegado & & \\
\hline & $\begin{array}{l}\text { Estamos bien } \\
\text { contentos }\end{array}$ & & \\
\hline & Fue muy buena & & \\
\hline 3 & 8 & 0 & 3 \\
\hline
\end{tabular}

\begin{tabular}{|l|l|}
\hline SUPERLATIVOS LÉXICOS & RECURSOS ESTILISTICOS \\
\hline Somos hartas mujeres & Estaba muy, muy feliz \\
\hline Produzco harta insulina & \\
\hline Tení harta paciencia & \\
\hline A harta gente & \\
\hline Harto trabajo & \\
\hline Hay puros encontrones & \\
\hline Conversamos harto & \\
\hline Controlándose harto & \\
\hline Le enseñan harto & \\
\hline Como somos puras mujeres & 1 \\
\hline 10 & \\
\hline
\end{tabular}




\section{ENTREVISTA 11}

№ Total de superlativos: 30

\begin{tabular}{|l|l|l|l|}
\hline ADJETIVO & $\begin{array}{l}\text { ATRIBUTO (verbos } \\
\text { ser y estar) }\end{array}$ & $\begin{array}{l}\text { ATRIBUTO } \\
\text { (otros verbos) }\end{array}$ & ADVERBIOS \\
\hline Anécdota muy buena & Estoy muy alerta & $\begin{array}{l}\text { Lo encontraba } \\
\text { muy, muy } \\
\text { latero }\end{array}$ & $\begin{array}{l}\text { Duermo muy } \\
\text { poco }\end{array}$ \\
\hline $\begin{array}{l}\text { Muy buenos } \\
\text { promedios }\end{array}$ & Muy despierta & $\begin{array}{l}\text { Tú corres más } \\
\text { rápido }\end{array}$ \\
\hline $\begin{array}{l}\text { Era bastante buena } \\
\text { deportista }\end{array}$ & $\begin{array}{l}\text { Era lo más tranquilo } \\
\text { que había } \\
\text { Familia muy } \\
\text { numerosa }\end{array}$ & Era bastante buena & $\begin{array}{l}\text { Duré } \\
\text { demasiado } \\
\text { poco }\end{array}$ \\
\hline $\begin{array}{l}\text { Los mejores } \\
\text { deportistas }\end{array}$ & Fue muy bueno & & \\
\hline $\begin{array}{l}\text { Muy buenos puntajes } \\
\text { complicada }\end{array}$ & $\begin{array}{l}\text { Estaba } \\
\text { complicadísimo }\end{array}$ & $\begin{array}{l}\text { Es muy } \\
\text { irresponsable }\end{array}$ & Fue complicadísimo \\
\hline $\begin{array}{l}\text { Embarazo muy } \\
\text { complicado }\end{array}$ & 8 & & 3 \\
\hline $\begin{array}{l}\text { Era el mejor amigo } \\
\text { situación re }\end{array}$ & & & \\
\hline
\end{tabular}

\begin{tabular}{|l|l|}
\hline SUPERLATIVOS LÉXICOS & RECURSOS ESTILISTICOS \\
\hline Cansancio horrible & Era un canguro saltando \\
\hline Fue excelente alumna & Era una pulga todo el día \\
\hline & Yo corría y corría y corría \\
\hline & Como tres horas puro corriendo \\
\hline & Yo quedaba muerta, muerta \\
\hline & Mi hermana también un pan de Dios. \\
\hline 2 & 6 \\
\hline
\end{tabular}




\section{ENTREVISTA 12}

№ Total de superlativos: 25

\begin{tabular}{|c|c|c|c|}
\hline ADJETIVO & $\begin{array}{l}\text { ATRIBUTO (verbos } \\
\text { ser y estar) }\end{array}$ & $\begin{array}{l}\text { ATRIBUTO } \\
\text { (otros verbos) }\end{array}$ & ADVERBIOS \\
\hline $\begin{array}{l}\text { Gente muy } \\
\text { especializada }\end{array}$ & $\begin{array}{l}\text { Está muy } \\
\text { especializada }\end{array}$ & & $\begin{array}{l}\text { Trabajar muy } \\
\text { rápido }\end{array}$ \\
\hline Falencia muy grande & Está muy dejado & & $\begin{array}{l}\text { Ganan muy } \\
\text { poco }\end{array}$ \\
\hline \multirow{8}{*}{$\begin{array}{l}\text { Sobrecarga emocional } \\
\text { tan grande }\end{array}$} & Era muy joven & & Gana muy bien \\
\hline & Era como muy joven & & \\
\hline & $\begin{array}{l}\text { Están mal } \\
\text { distribuidos mucho }\end{array}$ & & \\
\hline & Muy mal distribuidos & & \\
\hline & Es más desprotegida & & \\
\hline & Sea más suave & & \\
\hline & $\begin{array}{l}\text { Fue un poco más } \\
\text { tranquila }\end{array}$ & & \\
\hline & $\begin{array}{l}\text { Estaba tan } \\
\text { angustiada }\end{array}$ & & \\
\hline 3 & 10 & 0 & 3 \\
\hline
\end{tabular}

\begin{tabular}{|l|l|}
\hline SUPERLATIVOS LÉXICOS & RECURSOS ESTILISTICOS \\
\hline multifacético & Se te achicó así ( el sueldo) \\
\hline multifuncional & $\begin{array}{l}\text { Está con su problema hasta más } \\
\text { arriba }\end{array}$ \\
\hline Es una mugre & \\
\hline Es una caracha & \\
\hline Uno ayuda harto & \\
\hline Ganan mucho & \\
\hline Es demasiado & 2 \\
\hline 7 & \\
\hline
\end{tabular}




\section{ENTREVISTA 13}

№ Total de superlativos: 27

\begin{tabular}{|c|c|c|c|}
\hline ADJETIVO & $\begin{array}{l}\text { ATRIBUTO (verbos ser y } \\
\text { estar) }\end{array}$ & $\begin{array}{l}\text { ATRIBUT } \\
\text { O (otros } \\
\text { verbos) }\end{array}$ & ADVERBIOS \\
\hline $\begin{array}{l}\text { Apoyo súper } \\
\text { importante }\end{array}$ & $\begin{array}{l}\text { Fue como súper } \\
\text { impactante }\end{array}$ & & Muy bien \\
\hline Presión tan fuerte & Fue más desgastador & & \\
\hline $\begin{array}{l}\text { Una preocupación tan } \\
\text { grande }\end{array}$ & $\begin{array}{l}\text { Hubiese sido mucho más } \\
\text { complicado }\end{array}$ & & \\
\hline Fundimiento máximo & Estaba muy convencido & & \\
\hline Algo muy bonito & Estaba muy agradecida & & \\
\hline Algo muy bonito & Es muy fundido & & \\
\hline (etapa) la más difícil & Es muy fundido & & \\
\hline $\begin{array}{l}\text { Una lucha súper } \\
\text { grande }\end{array}$ & Muy contenta(estoy) & & \\
\hline $\begin{array}{l}\text { Carga social súper } \\
\text { grande }\end{array}$ & Estoy muy contenta & & \\
\hline \multirow[t]{4}{*}{$\begin{array}{l}\text { Carga social súper } \\
\text { fuerte }\end{array}$} & $\begin{array}{l}\text { No estaba muy } \\
\text { convencida }\end{array}$ & & \\
\hline & Soy bien mal genio & & \\
\hline & Es bien significativo & & \\
\hline & Sea mínimo, mínimo & & \\
\hline 11 & 13 & 0 & 1 \\
\hline
\end{tabular}

\begin{tabular}{|l|l|}
\hline SUPERLATIVOS LÉXICOS & RECURSOS ESTILISTICOS \\
\hline Tengo bastante paciencia & $\begin{array}{l}\text { Estar muy agradecida, muy, muy } \\
\text { agradecida }\end{array}$ \\
\hline & Súper, súper fuerte \\
\hline 1 & 2 \\
\hline
\end{tabular}




\section{ENTREVISTA 14}

№ Total de superlativos: 39

\begin{tabular}{|c|c|c|c|}
\hline ADJETIVO & $\begin{array}{l}\text { ATRIBUTO (verbos } \\
\text { ser y estar) }\end{array}$ & $\begin{array}{l}\text { ATRIBUTO } \\
\text { (otros verbos) }\end{array}$ & ADVERBIOS \\
\hline Luz más nítida & $\begin{array}{l}\text { Son un poco más } \\
\text { costosas }\end{array}$ & & $\begin{array}{l}\text { Entiende } \\
\text { bastante bien }\end{array}$ \\
\hline Tema tan delicado & Son muy buenas & & $\begin{array}{l}\text { Hace ver muy } \\
\text { mal }\end{array}$ \\
\hline Manera muy especial & Es más fantástica & & \\
\hline $\begin{array}{l}\text { Historia muy } \\
\text { fantástica }\end{array}$ & $\begin{array}{l}\text { Está bien } \\
\text { fundamentada }\end{array}$ & & \\
\hline Materia muy indirecta & Es muy mala & & \\
\hline $\begin{array}{l}\text { Fotografía muy } \\
\text { saturada }\end{array}$ & Era muy buena & & \\
\hline Un pésimo director & $\begin{array}{l}\text { Estén bien } \\
\text { fundamentadas }\end{array}$ & & \\
\hline Los mejores aviones & Es muy sangriento & & \\
\hline Mejores tanques & Es muy bonita & & \\
\hline $\begin{array}{l}\text { Películas con muy } \\
\text { malos efectos }\end{array}$ & Es muy buena & & \\
\hline $\begin{array}{l}\text { Gente que es muy } \\
\text { fanática }\end{array}$ & Es muy mala & & \\
\hline $\begin{array}{l}\text { Tendencia política } \\
\text { muy marcada }\end{array}$ & Es pésima & & \\
\hline Guión bien estudiado & $\begin{array}{l}\text { Es muy mala (esa } \\
\text { película) }\end{array}$ & & \\
\hline $\begin{array}{l}\text { Un mundo de } \\
\text { bastante ficción }\end{array}$ & Son muy buenas & & \\
\hline \multirow[t]{3}{*}{$\begin{array}{l}\text { Tendencia mucho } \\
\text { más fantástica }\end{array}$} & Era tan extraña & & \\
\hline & $\begin{array}{l}\text { Es mucho más } \\
\text { amplio }\end{array}$ & & \\
\hline & Son súper buenas & & \\
\hline 15 & 17 & 0 & 2 \\
\hline
\end{tabular}

\begin{tabular}{|l|l|}
\hline SUPERLATIVOS LÉXICOS & RECURSOS ESTILISTICOS \\
\hline Esas películas picantes & \\
\hline Me gusta harto & \\
\hline Me gusta bastante & \\
\hline Ya se hizo demasiado & \\
\hline Se ha jugado demasiado & 0 \\
\hline 5 & \\
\hline
\end{tabular}




\section{ENTREVISTA 15}

№ Total de superlativos: 19

\begin{tabular}{|l|l|l|l|}
\hline ADJETIVO & $\begin{array}{l}\text { ATRIBUTO (verbos } \\
\text { ser y estar) }\end{array}$ & $\begin{array}{l}\text { ATRIBUTO } \\
\text { (otros verbos) }\end{array}$ & ADVERBIOS \\
\hline Él, súper inteligente & $\begin{array}{l}\text { Era como súper } \\
\text { estrecho }\end{array}$ & $\begin{array}{l}\text { Lo pasamos } \\
\text { súper bien }\end{array}$ \\
\hline Los más angustiados & $\begin{array}{l}\text { Era bien } \\
\text { emprendedor el niño }\end{array}$ & $\begin{array}{l}\text { Estábamos } \\
\text { súper bien }\end{array}$ \\
\hline $\begin{array}{l}\text { Un precipicio súper } \\
\text { grande }\end{array}$ & & $\begin{array}{l}\text { (a buscar) bien } \\
\text { lejos }\end{array}$ \\
\hline 3 & 2 & $\begin{array}{l}\text { Estamos súper } \\
\text { bien }\end{array}$ \\
\hline & 2 & 4 \\
\hline
\end{tabular}

\begin{tabular}{|l|l|}
\hline SUPERLATIVOS LÉXICOS & RECURSOS ESTILÍSTICOS \\
\hline Terrible, terrible ha sido & Es increíble, increíble \\
\hline Fue terrible & Quedó para la historia \\
\hline Todo es terrible & Estaba solita, estaba solita \\
\hline Fue terrible & Casi me morí \\
\hline Fue terrible, terrible & \\
\hline Nos han dado harta fuerza & \\
\hline 6 & 4 \\
\hline
\end{tabular}


ENTREVISTA 16

№ de superlativos: 43

\begin{tabular}{|c|c|c|c|}
\hline ADJETIVO & $\begin{array}{l}\text { ATRIBUTO (verbos } \\
\text { ser y estar) }\end{array}$ & $\begin{array}{l}\text { ATRIBUTO } \\
\text { (otros verbos) }\end{array}$ & ADVERBIOS \\
\hline $\begin{array}{l}\text { Una relación muy } \\
\text { seria }\end{array}$ & Era como muy obvia & & $\begin{array}{l}\text { Me fue súper } \\
\text { bien }\end{array}$ \\
\hline $\begin{array}{l}\text { Una historia media } \\
\text { larga }\end{array}$ & $\begin{array}{l}\text { Fue como bien } \\
\text { entretenido }\end{array}$ & & $\begin{array}{l}\text { Nos llevamos } \\
\text { un poco mejor }\end{array}$ \\
\hline $\begin{array}{l}\text { Fueron relaciones } \\
\text { muy serias }\end{array}$ & $\begin{array}{l}\text { Es como súper } \\
\text { importante }\end{array}$ & & $\begin{array}{l}\text { Se hace súper } \\
\text { difícil }\end{array}$ \\
\hline $\begin{array}{l}\text { Trabajos súper } \\
\text { distintos }\end{array}$ & Es como desastroso & & \\
\hline relación) súper buena & Es súper complicado & & \\
\hline $\begin{array}{l}\text { Trabajos muy } \\
\text { paralelos }\end{array}$ & $\begin{array}{l}\text { Como súper } \\
\text { sedentaria y } \\
\text { silenciosa }\end{array}$ & & \\
\hline $\begin{array}{l}\text { Una convivencia más } \\
\text { formal }\end{array}$ & $\begin{array}{l}\text { Fue como muy de } \\
\text { adaptación }\end{array}$ & & \\
\hline $\begin{array}{l}\text { Como hombres muy } \\
\text { serios }\end{array}$ & $\begin{array}{l}\text { Era como súper } \\
\text { invasivo }\end{array}$ & & \\
\hline Mayor estabilidad & Está como más firme & & \\
\hline $\begin{array}{l}\text { Como pareja súper } \\
\text { contemporánea }\end{array}$ & $\begin{array}{l}\text { Es como súper } \\
\text { preocupado }\end{array}$ & & \\
\hline $\begin{array}{l}\text { No hay como mayor } \\
\text { conflicto }\end{array}$ & Es muy grande & & \\
\hline \multirow[t]{10}{*}{$\begin{array}{l}\text { Relación súper bien } \\
\text { encaminada }\end{array}$} & $\begin{array}{l}\text { Es como mucho más } \\
\text { madura }\end{array}$ & & \\
\hline & Y mucho más sana & & \\
\hline & Es mejor & & \\
\hline & $\begin{array}{l}\text { Son más, más } \\
\text { ordenadas }\end{array}$ & & \\
\hline & $\begin{array}{l}\text { Bastante } \\
\text { fraudulentas }\end{array}$ & & \\
\hline & $\begin{array}{l}\text { Son como muy } \\
\text { infantiles }\end{array}$ & & \\
\hline & $\begin{array}{l}\text { Son como bien, bien } \\
\text { al lote }\end{array}$ & & \\
\hline & Es como más normal & & \\
\hline & Es más fácil & & \\
\hline & $\begin{array}{l}\text { Es mucho más } \\
\text { complicado }\end{array}$ & & \\
\hline 12 & 21 & 0 & 3 \\
\hline
\end{tabular}




\begin{tabular}{|l|l|}
\hline SUPERLATIVOS LÉXICOS & RECURSOS ESTILISTTICOS \\
\hline Harto tiempo & Hace muchos, muchos años \\
\hline Por hartos meses & \\
\hline Hartas ideas & \\
\hline Hartas veces & \\
\hline Un gran tema & \\
\hline Costó harto adaptar & \\
\hline Es como desastroso & 1 \\
\hline 6 & \\
\hline
\end{tabular}




\section{ENTREVISTA 17}

№ Total de superlativos: 33

\begin{tabular}{|c|c|c|c|}
\hline ADJETIVO & $\begin{array}{l}\text { ATRIBUTO (verbos } \\
\text { ser y estar) }\end{array}$ & $\begin{array}{l}\text { ATRIBUTO } \\
\text { (otros verbos) }\end{array}$ & ADVERBIOS \\
\hline $\begin{array}{l}\text { Son cosas totalmente } \\
\text { diferente }\end{array}$ & $\begin{array}{l}\text { Es muy negativo, } \\
\text { muy negativo }\end{array}$ & & $\begin{array}{l}\text { Castigaban } \\
\text { bastante } \\
\text { severo }\end{array}$ \\
\hline $\begin{array}{l}\text { Un joven bien } \\
\text { arregladito }\end{array}$ & Es muy importante & & $\begin{array}{l}\text { Se tome las } \\
\text { cosas más en } \\
\text { serio }\end{array}$ \\
\hline $\begin{array}{l}\text { Estrato económico } \\
\text { más bien bajo }\end{array}$ & Sea muy inteligente & & \\
\hline $\begin{array}{l}\text { Son muy raras } \\
\text { ocasiones }\end{array}$ & Es bien difícil & & \\
\hline Drogas más duras & $\begin{array}{l}\text { Es el castigo más } \\
\text { grande }\end{array}$ & & \\
\hline $\begin{array}{l}\text { Las drogas más } \\
\text { fuertes }\end{array}$ & Está muy arraigada & & \\
\hline La gente más pobre & Son súper bajos & & \\
\hline Con ropa más cara & $\begin{array}{l}\text { La televisión es muy } \\
\text { culpable }\end{array}$ & & \\
\hline $\begin{array}{l}\text { Instrumento muy } \\
\text { valioso }\end{array}$ & Fue bastante dura & & \\
\hline $\begin{array}{l}\text { Las pololas más } \\
\text { lindas }\end{array}$ & $\begin{array}{l}\text { Hubiese sido más } \\
\text { blanda }\end{array}$ & & \\
\hline $\begin{array}{l}\text { Influencia bastante } \\
\text { fuerte }\end{array}$ & & & \\
\hline $\begin{array}{l}\text { Un castigo más o } \\
\text { menos severo }\end{array}$ & & & \\
\hline 12 & 10 & 0 & 2 \\
\hline
\end{tabular}

\begin{tabular}{|l|l|}
\hline SUPERLATIVOS LÉXICOS & RECURSOS ESTILISTICOS \\
\hline Me importaba un cuesco & Es muy negativo, muy negativo \\
\hline El ser el amigote & Es muy raro, muy raro \\
\hline El desorden es total & \\
\hline Programas estúpidos & \\
\hline Ha perdido bastante el respeto & \\
\hline Se discrimina bastante & \\
\hline Se han perdido bastante los valores & \\
\hline 7 & 2 \\
\hline
\end{tabular}




\section{ENTREVISTA 18}

№ Total de superlativos: 36

\begin{tabular}{|l|l|l|l|}
\hline ADJETIVO & $\begin{array}{l}\text { ATRIBUTO (verbos } \\
\text { ser y estar) }\end{array}$ & $\begin{array}{l}\text { ATRIBUTO } \\
\text { (otros verbos) }\end{array}$ & ADVERBIOS \\
\hline Úvula muy grande & $\begin{array}{l}\text { Fue como la más } \\
\text { importante } \\
\text { asustada }\end{array}$ & $\begin{array}{l}\text { Me dejó } \\
\text { totalmente sin } \\
\text { movimiento }\end{array}$ \\
\hline $\begin{array}{l}\text { Músculos totalmente } \\
\text { duros }\end{array}$ & $\begin{array}{l}\text { Una de las más } \\
\text { importante }\end{array}$ & $\begin{array}{l}\text { Lo sentí muy } \\
\text { molesta }\end{array}$ & $\begin{array}{l}\text { Se van } \\
\text { haciendo más } \\
\text { grande }\end{array}$ \\
\hline $\begin{array}{l}\text { La preocupación más } \\
\text { grande }\end{array}$ & Como más riesgosa & $\begin{array}{l}\text { Estoy súper } \\
\text { bien }\end{array}$ \\
\hline No tuve muy buenos & Más temerosa & $\begin{array}{l}\text { Súper bien } \\
\text { (estoy) }\end{array}$ \\
\hline & Era tan importante & $\begin{array}{l}\text { No estuve muy } \\
\text { bien }\end{array}$ \\
\hline & Es súper importante & $\begin{array}{l}\text { Me dejó } \\
\text { totalmente sin } \\
\text { fuerza }\end{array}$ \\
\hline & $\begin{array}{l}\text { Estuve muy } \\
\text { temerosa }\end{array}$ & & \\
\hline & Yo soy muy creyente & & 6 \\
\hline Soy bien llorona & & \\
\hline & Estaba muy molesto & & \\
\hline & Estaba más repuesto & & \\
\hline & $\begin{array}{l}\text { Estaba más } \\
\text { comprometido }\end{array}$ & & \\
\hline Estuve muy asustada & & \\
\hline 13 & & \\
\hline & & & \\
\hline & & & \\
\hline & & & \\
\hline & & & \\
\hline & & & \\
\hline & & & \\
\hline & & & \\
\hline & & & \\
\hline & & & \\
\hline & & & \\
\hline
\end{tabular}

\begin{tabular}{|l|l|}
\hline SUPERLATIVOS LÉXICOS & RECURSOS ESTILÍSTICOS \\
\hline Se me hicieron eternos & Yo le agradezco mucho, mucho \\
\hline Eterno ese trayecto & $\begin{array}{l}\text { Me da un miedo terrible, terrible, } \\
\text { terrible, terrible }\end{array}$ \\
\hline Un miedo terrible & $\begin{array}{l}\text { Estaban muy buenos médicos, muy } \\
\text { buenos }\end{array}$ \\
\hline Me dio harta confianza & Fue muy, muy molesto \\
\hline Me preocupó bastante & \\
\hline Me extrañó bastante & \\
\hline Nos había hecho esperar tanto & 4 \\
\hline 7 & \\
\hline
\end{tabular}




\section{ENTREVISTA 19}

№ Total de superlativos: 24

\begin{tabular}{|c|c|c|c|}
\hline ADJETIVO & $\begin{array}{l}\text { ATRIBUTO (verbos } \\
\text { ser y estar) }\end{array}$ & $\begin{array}{l}\text { ATRIBUTO } \\
\text { (otros verbos) }\end{array}$ & ADVERBIOS \\
\hline El más entretenido & $\begin{array}{l}\text { Que fuera más } \\
\text { rápido }\end{array}$ & $\begin{array}{l}\text { Me tiene más } \\
\text { preocupada }\end{array}$ & $\begin{array}{l}\text { Se me fuera } \\
\text { más fácil }\end{array}$ \\
\hline Una vida más digna & $\begin{array}{l}\text { Estaba súper } \\
\text { agradecida }\end{array}$ & Más ansiosa & $\begin{array}{l}\text { Le cobro más } \\
\text { barato }\end{array}$ \\
\hline $\begin{array}{l}\text { Súper buenos } \\
\text { resultados }\end{array}$ & Fue mucho más fácil & & $\begin{array}{l}\text { Dura mucho } \\
\text { más }\end{array}$ \\
\hline Da mejores resultados & Que sea más fácil & & \\
\hline $\begin{array}{l}\text { Una mejor calidad de } \\
\text { vida }\end{array}$ & Es muy similar & & \\
\hline \multirow[t]{8}{*}{ Da mejores resultados } & $\begin{array}{l}\text { Es como el más } \\
\text { capacitado }\end{array}$ & & \\
\hline & Era súper barato & & \\
\hline & Está muy contenta & & \\
\hline & $\begin{array}{l}\text { Es como más } \\
\text { relajado }\end{array}$ & & \\
\hline & Es súper bueno & & \\
\hline & $\begin{array}{l}\text { Es como lo más } \\
\text { fuerte }\end{array}$ & & \\
\hline & $\begin{array}{l}\text { Es como muy } \\
\text { amargo }\end{array}$ & & \\
\hline & (es) muy fuerte & & \\
\hline 6 & 13 & 2 & 3 \\
\hline
\end{tabular}

\begin{tabular}{|l|l|}
\hline SUPERLATIVOS LÉXICOS & RECURSOS ESTILISTTICOS \\
\hline Ha gastado mucha plata & \\
\hline $\mathbf{1}$ & 0 \\
\hline
\end{tabular}




\section{ENTREVISTA 20}

№ Total de superlativos: 29

\begin{tabular}{|c|c|c|c|}
\hline ADJETIVO & $\begin{array}{l}\text { ATRIBUTO (verbos } \\
\text { ser y estar) }\end{array}$ & $\begin{array}{l}\text { ATRIBUTO } \\
\text { (otros verbos) }\end{array}$ & ADVERBIOS \\
\hline Un familiar muy querido & Es súper carnívora & $\begin{array}{l}\text { Me ponía muy } \\
\text { nerviosa }\end{array}$ & Está mejor \\
\hline & $\begin{array}{l}\text { Yo soy súper pro } \\
\text { animales }\end{array}$ & & $\begin{array}{l}\text { Murieron súper } \\
\text { luego }\end{array}$ \\
\hline & Era tan adorable & & $\begin{array}{l}\text { Se me murió } \\
\text { súper luego }\end{array}$ \\
\hline & $\begin{array}{l}\text { Soy mucho más } \\
\text { fanática }\end{array}$ & & \\
\hline & Muy bueno & & \\
\hline & Fue bastante triste & & \\
\hline & Está más viejito & & \\
\hline & Está súper viejito & & \\
\hline & $\begin{array}{l}\text { Estuvo súper } \\
\text { enfermo }\end{array}$ & & \\
\hline & $\begin{array}{l}\text { La verdad es que } \\
\text { súper grande }\end{array}$ & & \\
\hline & Era súper bravo & & \\
\hline & $\begin{array}{l}\text { Yo soy súper pro } \\
\text { animales }\end{array}$ & & \\
\hline & Fue muy difícil & & \\
\hline & Está más madura & & \\
\hline & Golpe súper duro & & \\
\hline 1 & 15 & 1 & 3 \\
\hline \multicolumn{2}{|c|}{ SUPERLATIVOS LÉXICOS } & \multicolumn{2}{|c|}{ RECURSOS ESTILÍSTICOS } \\
\hline \multicolumn{2}{|l|}{ Su buen pedazo de carne } & \multicolumn{2}{|c|}{ Yo sufrí mucho, mucho, mucho } \\
\hline \multicolumn{2}{|l|}{ Quiero harto } & \multicolumn{2}{|c|}{ Quedaba muerta de hambre } \\
\hline \multicolumn{2}{|c|}{ Él se asusta tanto } & \multicolumn{2}{|c|}{ Eran súper carnívoros, carnívoros } \\
\hline \multicolumn{2}{|c|}{ Han pasado harto (los temblores) } & \multicolumn{2}{|c|}{ Es lo más madura del mundo } \\
\hline \multirow{2}{*}{\multicolumn{2}{|c|}{$\begin{array}{l}\text { He tenido hartos perros } \\
5\end{array}$}} & & \\
\hline & & 4 & \\
\hline
\end{tabular}




\section{ENTREVISTA 21}

№ Total de superlativos: 50

\begin{tabular}{|l|l|l|l|}
\hline ADJETIVO & $\begin{array}{l}\text { ATRIBUTO (verbos } \\
\text { ser y estar) }\end{array}$ & $\begin{array}{l}\text { ATRIBUTO } \\
\text { (otros verbos) }\end{array}$ & ADVERBIOS \\
\hline Vida bien movida & Ha sido bien vivida & $\begin{array}{l}\text { Todo el } \\
\text { mundo se } \\
\text { sintió muy } \\
\text { libre }\end{array}$ & Estamos peor \\
\hline $\begin{array}{l}\text { Momentos bastante } \\
\text { difíciles }\end{array}$ & Muy activa & Cada vez peor \\
\hline $\begin{array}{l}\text { Horario bastante } \\
\text { extenso }\end{array}$ & Muy parecida & $\begin{array}{l}\text { Tengo muy } \\
\text { presente }\end{array}$ \\
\hline Apoyo importantísimo & Muy regaloneada & & \\
\hline $\begin{array}{l}\text { Siempre } \\
\text { incondicionales, pero } \\
\text { totalmente }\end{array}$ & Muy querida & & \\
\hline Día bastante tenso & Fue muy impactante & & \\
\hline Muchísima pena & Soy bien estricta & & \\
\hline Muchísimas cosas & Está muy cansado & & \\
\hline Primerísimo lugar & $\begin{array}{l}\text { Está complicadísima } \\
\text { la cosa }\end{array}$ & & \\
\hline La mejor disposición & $\begin{array}{l}\text { Es completamente } \\
\text { abierto }\end{array}$ & & 3 \\
\hline $\begin{array}{l}\text { Cosas muy } \\
\text { entretenidas }\end{array}$ & Está peor & & \\
\hline Muy poca paciencia & Demasiado relajado & & \\
\hline & Son muy buenos & & \\
\hline 12 & Son muy al lote & & 1 \\
\hline
\end{tabular}

\begin{tabular}{|l|l|}
\hline SUPERLATIVOS LÉXICOS & RECURSOS ESTILISTICOS \\
\hline Dos hijos maravillosos & Muchas alegrías, muchas alegrías \\
\hline Un esposo maravilloso & Lo tomé muy a pecho \\
\hline Paciencia infinita & Me lo tomé muy a pecho \\
\hline Un silencio absoluto & Se fuera a acabar el mundo \\
\hline Fue horrible & $\begin{array}{l}\text { Es una cosa increíble, es una cosa } \\
\text { increíble }\end{array}$ \\
\hline Falta de respeto increíble & $\begin{array}{l}\text { Que son muy buenos, que son muy } \\
\text { buenos }\end{array}$ \\
\hline Es un tema laargo & \\
\hline Es increíble & \\
\hline Pero es increíble & \\
\hline Es una cosa increíble & \\
\hline Guía demasiado & \\
\hline Me costaba harto & \\
\hline
\end{tabular}


Se han arrancado demasiado de las manos

13

6 


\section{ENTREVISTA 22}

№ Total de superlativos: 31

\begin{tabular}{|c|c|c|c|}
\hline ADJETIVO & $\begin{array}{l}\text { ATRIBUTO (verbos } \\
\text { ser y estar) }\end{array}$ & $\begin{array}{l}\text { ATRIBUTO } \\
\text { (otros verbos) }\end{array}$ & ADVERBIOS \\
\hline Sus cosas muy bonitas & $\begin{array}{l}\text { Estamos tan } \\
\text { tecnológicos }\end{array}$ & $\begin{array}{l}\text { Dejó al país } \\
\text { muy mal } \\
\text { parado }\end{array}$ & $\begin{array}{l}\text { Nos fue } \\
\text { bastante bien }\end{array}$ \\
\hline Terremoto tan extenso & $\begin{array}{l}\text { Estuve totalmente } \\
\text { desinformado }\end{array}$ & & \\
\hline Es muy buena carrera & Es muy buena & & \\
\hline $\begin{array}{l}\text { Casas totalmente } \\
\text { destruidas }\end{array}$ & Está bien colocada & & \\
\hline $\begin{array}{l}\text { Una cosa muy } \\
\text { tremenda }\end{array}$ & No estoy muy... & & \\
\hline \multirow[t]{6}{*}{ Esa cosa más finita } & Yo era más joven & & \\
\hline & Son muy importantes & & \\
\hline & $\begin{array}{l}\text { No estoy tan } \\
\text { informado }\end{array}$ & & \\
\hline & Mejor para el país & & \\
\hline & Podría ser mejor & & \\
\hline & Eso sería mejor & & \\
\hline 6 & 11 & 1 & 1 \\
\hline
\end{tabular}

\begin{tabular}{|l|l|}
\hline SUPERLATIVOS LÉXICOS & RECURSOS ESTILISTICOS \\
\hline Seis universidades grandotas & $\begin{array}{l}\text { Si uno no está muy, muy, como muy } \\
\text { claro }\end{array}$ \\
\hline Unos capitales exorbitantes & $\begin{array}{l}\text { Se cayó un edificio completo, } \\
\text { completo }\end{array}$ \\
\hline Las dos más grandotas & $\begin{array}{l}\text { Es una de las grandes, grandes } \\
\text { industrias }\end{array}$ \\
\hline Multifacético & \\
\hline Con bastantes destrozos & \\
\hline Se hizo harta parafernalia & \\
\hline Tenemos bastante acceso & \\
\hline Se puede explotar bastante & 3 \\
\hline Se mueve bastante & \\
\hline 9 &
\end{tabular}




\section{ENTREVISTA 23}

№ Total de superlativos: 37

\begin{tabular}{|c|c|c|c|}
\hline ADJETIVO & $\begin{array}{l}\text { ATRIBUTO (verbos } \\
\text { ser y estar) }\end{array}$ & $\begin{array}{l}\text { ATRIBUTO } \\
\text { (otros verbos) }\end{array}$ & ADVERBIOS \\
\hline $\begin{array}{l}\text { Con muy malos } \\
\text { antecedentes }\end{array}$ & Es mínimo & $\begin{array}{l}\text { Parece muy } \\
\text { extraña }\end{array}$ & $\begin{array}{l}\text { Me fue } \\
\text { bastante bien }\end{array}$ \\
\hline Gente muy valiosa & $\begin{array}{l}\text { Estaba como bien } \\
\text { compartido }\end{array}$ & & $\begin{array}{l}\text { No le fue tan } \\
\text { bien }\end{array}$ \\
\hline Plazo pero brevísimo & $\begin{array}{l}\text { Era totalmente } \\
\text { diferente }\end{array}$ & & $\begin{array}{l}\text { Entró muy } \\
\text { fuertemente }\end{array}$ \\
\hline $\begin{array}{l}\text { Una muy buena } \\
\text { relación }\end{array}$ & Soy bien enfático & & \\
\hline $\begin{array}{l}\text { Momentos totalmente } \\
\text { diferentes }\end{array}$ & $\begin{array}{l}\text { (la droga) está pero } \\
\text { realmente } \\
\text { complicada }\end{array}$ & & \\
\hline $\begin{array}{l}\text { Una pasada pero muy } \\
\text { breve }\end{array}$ & $\begin{array}{l}\text { Era totalmente } \\
\text { desconocida }\end{array}$ & & \\
\hline $\begin{array}{l}\text { Persona bastante } \\
\text { conocida }\end{array}$ & $\begin{array}{l}\text { Es lo más fácil de } \\
\text { llegar (la droga) }\end{array}$ & & \\
\hline $\begin{array}{l}\text { Esta persona muy } \\
\text { querida }\end{array}$ & $\begin{array}{l}\text { Era prácticamente } \\
\text { inhumano }\end{array}$ & & \\
\hline Muy conocida & $\begin{array}{l}\text { Estaban todos muy } \\
\text { unidos }\end{array}$ & & \\
\hline Esa mínima parte & Es muy difícil & & \\
\hline $\begin{array}{l}\text { Algo realmente } \\
\text { importante }\end{array}$ & & & \\
\hline $\begin{array}{l}\text { A los países más } \\
\text { chicos }\end{array}$ & & & \\
\hline Mayores beneficios & & & \\
\hline 13 & 10 & 1 & 3 \\
\hline
\end{tabular}

\begin{tabular}{|l|l|}
\hline SUPERLATIVOS LÉXICOS & RECURSOS ESTILÍSTICOS \\
\hline Es un momento complicado & $\begin{array}{l}\text { Es fundamental, es fundamental la } \\
\text { parte deportiva. }\end{array}$ \\
\hline Me dio la gran oportunidad & $\begin{array}{l}\text { Trabajando hasta las últimas } \\
\text { consecuencias }\end{array}$ \\
\hline Fue demasiado & $\begin{array}{l}\text { Lo lamento demasiado, lo lamento } \\
\text { demasiado }\end{array}$ \\
\hline Yo diría que bastante & \\
\hline Desconocía totalmente & \\
\hline Se metió demasiado & 3 \\
\hline Desconocía yo completamente & \\
\hline 7 &
\end{tabular}




\section{ENTREVISTA 24}

№ Total de superlativos: 29

\begin{tabular}{|c|c|c|c|}
\hline ADJETIVO & $\begin{array}{l}\text { ATRIBUTO (verbos } \\
\text { ser y estar) }\end{array}$ & $\begin{array}{l}\text { ATRIBUTO } \\
\text { (otros verbos) }\end{array}$ & ADVERBIOS \\
\hline Muy poca preparación & $\begin{array}{l}\text { Lo más difícil es la } \\
\text { gente }\end{array}$ & & $\begin{array}{l}\text { (significó) muy } \\
\text { poco }\end{array}$ \\
\hline $\begin{array}{l}\text { Contrato más } \\
\text { complicado }\end{array}$ & Que sea mejor & & $\begin{array}{l}\text { Avanza más } \\
\text { rápido }\end{array}$ \\
\hline Mejores terminaciones & Yo era más rápido & & Va más rápido \\
\hline Una mejor evaluación & Esto va a ser peor & & $\begin{array}{l}\text { Están viviendo } \\
\text { muy apurados }\end{array}$ \\
\hline $\begin{array}{l}\text { Sociedad más } \\
\text { complicada }\end{array}$ & (servicio) es lo mejor & & \\
\hline \multirow[t]{4}{*}{ Cosas tan simples } & Son los más capaces & & \\
\hline & $\begin{array}{l}\text { ¿Cómo pueden ser } \\
\text { tan tontos? }\end{array}$ & & \\
\hline & $\begin{array}{l}\text { Era totalmente } \\
\text { trastrocada }\end{array}$ & & \\
\hline & $\begin{array}{l}\text { Que sea más } \\
\text { vivaracho }\end{array}$ & & \\
\hline 6 & 9 & 0 & 4 \\
\hline
\end{tabular}

\begin{tabular}{|l|l|}
\hline SUPERLATIVOS LÉXICOS & RECURSOS ESTILISTICOS \\
\hline Gente complicada & Cumplir mil requisitos \\
\hline Es complicado el trato & Esos tremendos monstruos oruga \\
\hline Es complicado & Alguien era la vergüenza del colegio \\
\hline Es complicado & \\
\hline Es ridícula & \\
\hline Ganan una millonada & \\
\hline Se lleva una millonada extraordinaria & \\
\hline 7 & 3 \\
\hline
\end{tabular}




\section{ENTREVISTA 25}

№ Total de superlativos: 25

\begin{tabular}{|c|c|c|c|}
\hline ADJETIVO & $\begin{array}{l}\text { ATRIBUTO (verbos } \\
\text { ser y estar) }\end{array}$ & $\begin{array}{l}\text { ATRIBUTO } \\
\text { (otros verbos) }\end{array}$ & ADVERBIOS \\
\hline $\begin{array}{l}\text { Las cosas más } \\
\text { hermosas }\end{array}$ & Era muy complicado & & Es lejísimo \\
\hline Violencia tan grande & $\begin{array}{l}\text { Sus ganancias son } \\
\text { altísimas }\end{array}$ & & $\begin{array}{l}\text { Voy a ingresar } \\
\text { muy } \\
\text { suavemente }\end{array}$ \\
\hline $\begin{array}{l}\text { Una grandísima crisis } \\
\text { valórica }\end{array}$ & Ser más criteriosas & & $\begin{array}{l}\text { Se preocupan } \\
\text { muchísimo }\end{array}$ \\
\hline Caso conocidísimo & $\begin{array}{l}\text { Actualmente muy } \\
\text { crucial }\end{array}$ & & $\begin{array}{l}\text { Le aumenta } \\
\text { muchísimo }\end{array}$ \\
\hline Ejemplo muy aclarador & $\begin{array}{l}\text { Están } \\
\text { preocupadísimos }\end{array}$ & & \\
\hline Una copia muy calcada & Están lejísimos & & \\
\hline $\begin{array}{l}\text { Imperios económicos } \\
\text { muy grandes }\end{array}$ & & & \\
\hline Una cantidad muy alta & & & \\
\hline $\begin{array}{l}\text { Dispositivos de altísima } \\
\text { seguridad }\end{array}$ & & & \\
\hline He hecho cosas peores & & & \\
\hline $\begin{array}{l}\text { Valores muy } \\
\text { importantes }\end{array}$ & & & \\
\hline $\begin{array}{l}\text { Muchísima } \\
\text { responsabilidad }\end{array}$ & & & \\
\hline 6 & 6 & 0 & 4 \\
\hline
\end{tabular}

\begin{tabular}{|l|l|}
\hline SUPERLATIVOS LÉXICOS & RECURSOS ESTILÍSTICOS \\
\hline Es una inmensa población compradora & \\
\hline Se pasó demasiado & \\
\hline Inmensa cantidad recaudada & \\
\hline 3 & 0 \\
\hline
\end{tabular}




\section{ENTREVISTA 26}

№ Total de superlativos: 15

\begin{tabular}{|l|l|l|l|}
\hline ADJETIVO & $\begin{array}{l}\text { ATRIBUTO (verbos } \\
\text { ser y estar) }\end{array}$ & $\begin{array}{l}\text { ATRIBUTO } \\
\text { (otros verbos) }\end{array}$ & ADVERBIOS \\
\hline $\begin{array}{l}\text { Una experiencia } \\
\text { bastante enriquecedora }\end{array}$ & $\begin{array}{l}\text { Esto es totalmente } \\
\text { distinto }\end{array}$ & $\begin{array}{l}\text { Trabaja más } \\
\text { tranquila }\end{array}$ & $\begin{array}{l}\text { Trabajar más } \\
\text { seriamente }\end{array}$ \\
\hline Muy enriquecedora & Estoy más tranquilo & & \\
\hline & Están muy bajos & & \\
\hline & Están muy bajos & & 1 \\
\hline 2 & Es muy cochina & & 1 \\
\hline
\end{tabular}

\begin{tabular}{|l|l|}
\hline SUPERLATIVOS LÉXICOS & RECURSOS ESTILISTICOS \\
\hline Yo lo encuentro ridículo & \\
\hline Me ha servido bastante & \\
\hline Me sirvió bastante & \\
\hline Me sirvió bastante & \\
\hline Aprendí bastante & \\
\hline He aprendido bastante & 0 \\
\hline 6 & \\
\hline
\end{tabular}




\section{ENTREVISTA 27}

№ Total de superlativos: 35

\begin{tabular}{|c|c|c|c|}
\hline ADJETIVO & $\begin{array}{l}\text { ATRIBUTO (verbos } \\
\text { ser y estar) }\end{array}$ & $\begin{array}{l}\text { ATRIBUTO } \\
\text { (otros verbos) }\end{array}$ & ADVERBIOS \\
\hline $\begin{array}{l}\text { Comedia bastante } \\
\text { absurda }\end{array}$ & Es bastante simple & $\begin{array}{l}\text { Las encuentro } \\
\text { demasiado } \\
\text { banales }\end{array}$ & $\begin{array}{l}\text { Acompaña muy } \\
\text { bien }\end{array}$ \\
\hline Historias muy trilladas & Sea muy compleja & & $\begin{array}{l}\text { Toman muy en } \\
\text { cuenta }\end{array}$ \\
\hline $\begin{array}{l}\text { Plataforma bastante } \\
\text { interesante }\end{array}$ & Es bastante triste & & \\
\hline Actuaciones pésimas & $\begin{array}{l}\text { Está muy bien } \\
\text { equilibrado }\end{array}$ & & \\
\hline $\begin{array}{l}\text { Cuestión sencillamente } \\
\text { genial }\end{array}$ & $\begin{array}{l}\text { Están muy bien } \\
\text { contados }\end{array}$ & & \\
\hline Muy poca plata & Son súper esenciales & & \\
\hline $\begin{array}{l}\text { Medidas mucho } \\
\text { mayores }\end{array}$ & $\begin{array}{l}\text { Está muy bien } \\
\text { lograda }\end{array}$ & & \\
\hline Un mejor proyecto & Es bien raro & & \\
\hline Mejores grupos & $\begin{array}{l}\text { Va a ser muy } \\
\text { complicado }\end{array}$ & & \\
\hline Tipos re buenos & Es bastante poco & & \\
\hline Muy buen bajista & Es bastante fome & & \\
\hline Muy buen baterista & $\begin{array}{l}\text { Está muy mal } \\
\text { mantenido }\end{array}$ & & \\
\hline Cosas muy buenas & Son súper esenciales & & \\
\hline 13 & 13 & 1 & 2 \\
\hline
\end{tabular}

\begin{tabular}{|l|l|}
\hline SUPERLATIVOS LÉXICOS & RECURSOS ESTILÍSTICOS \\
\hline Unos lienzos gigantes & Los atienden como el hoyo \\
\hline Demasiada plata. & Es muy, muy parecido \\
\hline el compadre es seco & \\
\hline Ahí estuve excelente & \\
\hline Un excelente historiador & \\
\hline 5 & 2 \\
\hline
\end{tabular}




\section{ENTREVISTA 28}

№ Total de superlativos: 30

\begin{tabular}{|c|c|c|c|}
\hline ADJETIVO & $\begin{array}{l}\text { ATRIBUTO (verbos } \\
\text { ser y estar) }\end{array}$ & $\begin{array}{l}\text { ATRIBUTO } \\
\text { (otros verbos) }\end{array}$ & ADVERBIOS \\
\hline Forma muy de artista & $\begin{array}{l}\text { Que sea como } \\
\text { posiblemente eterno }\end{array}$ & & $\begin{array}{l}\text { Está más lejos } \\
\text { de su } \\
\text { pensamiento }\end{array}$ \\
\hline $\begin{array}{l}\text { Una cuestión súper } \\
\text { entretenida }\end{array}$ & Es súper religioso & & \\
\hline Súper contradictoria & Es súper conocido & & \\
\hline $\begin{array}{l}\text { Son súper malos } \\
\text { ejemplos }\end{array}$ & Es súper extraño & & \\
\hline Techos muy bajos & $\begin{array}{l}\text { No estoy tan } \\
\text { equivocado }\end{array}$ & & \\
\hline \multirow[t]{8}{*}{ Cuestión súper extraña } & $\begin{array}{l}\text { Puede ser muy } \\
\text { bonita }\end{array}$ & & \\
\hline & $\begin{array}{l}\text { (puede ser) muy } \\
\text { todo }\end{array}$ & & \\
\hline & $\begin{array}{l}\text { Están súper } \\
\text { prostituidos }\end{array}$ & & \\
\hline & $\begin{array}{l}\text { Somos muy poco } \\
\text { funcionales }\end{array}$ & & \\
\hline & $\begin{array}{l}\text { Esos es } \\
\text { complicadísimo }\end{array}$ & & \\
\hline & $\begin{array}{l}\text { Es bastante } \\
\text { necesario }\end{array}$ & & \\
\hline & $\begin{array}{l}\text { Estaba todo súper } \\
\text { consolidado }\end{array}$ & & \\
\hline & Es súper interesante & & \\
\hline 6 & 13 & 0 & 1 \\
\hline
\end{tabular}

\begin{tabular}{|l|l|}
\hline SUPERLATIVOS LÉXICOS & RECURSOS ESTILISTICOS \\
\hline Funcionan pero perfecto & Director favorito, favorito \\
\hline Iban hartos europeos & \\
\hline De una manera tremenda & \\
\hline Compañeras gorilonas. & \\
\hline Son perfectos museos & \\
\hline Como museos son espectaculares & \\
\hline Fue brutal & \\
\hline Me estoy mandando un carril gigante & \\
\hline Es como brutal & 1 \\
\hline 9 & \\
\hline
\end{tabular}




\section{ENTREVISTA 29}

№ Total de superlativos: 62

\begin{tabular}{|c|c|c|c|}
\hline ADJETIVO & $\begin{array}{l}\text { ATRIBUTO (verbos } \\
\text { ser y estar) }\end{array}$ & $\begin{array}{l}\text { ATRIBUTO } \\
\text { (otros verbos) }\end{array}$ & ADVERBIOS \\
\hline $\begin{array}{l}\text { Esas mujeres muy } \\
\text { jóvenes }\end{array}$ & Muy complicado & $\begin{array}{l}\text { Me siento muy } \\
\text { intrigada }\end{array}$ & $\begin{array}{l}\text { Trabajé desde } \\
\text { muy niña }\end{array}$ \\
\hline Vivencias muy intensas & Siendo muy niña & $\begin{array}{l}\text { Me siento muy } \\
\text { plena con él }\end{array}$ & $\begin{array}{l}\text { Haber sentido } \\
\text { desde muy niña }\end{array}$ \\
\hline $\begin{array}{l}\text { Son cementerios } \\
\text { hermosísimos }\end{array}$ & Es todo hermosísimo & & $\begin{array}{l}\text { Es realmente } \\
\text { bien }\end{array}$ \\
\hline España muy seco & Es muy hermosos & & $\begin{array}{l}\text { La profesional } \\
\text { chilena está } \\
\text { muy bien }\end{array}$ \\
\hline Lugares muy secos & Soy muy fácil & & \\
\hline $\begin{array}{l}\text { (lugares) muy } \\
\text { inhóspitos }\end{array}$ & $\begin{array}{l}\text { Películas que he } \\
\text { visto realmente son } \\
\text { terribles }\end{array}$ & & \\
\hline $\begin{array}{l}\text { Soy una mujer } \\
\text { totalmente auditiva }\end{array}$ & $\begin{array}{l}\text { Pero totalmente } \\
\text { regalona }\end{array}$ & & \\
\hline $\begin{array}{l}\text { Estoy en primerísima ( } \\
\text { fila) }\end{array}$ & Está muy chiquitito & & \\
\hline Comida bien preparada & $\begin{array}{l}\text { Ellos son tan } \\
\text { famosos }\end{array}$ & & \\
\hline (comida) muy exquisita & Estaban tan lúcidos & & \\
\hline (comida) muy delicada & (es ) muy inteligente & & \\
\hline Muy buenos vinos & Un muy buen hijo & & \\
\hline Una niñez muy bonita & $\begin{array}{l}\text { Va a ser un muy } \\
\text { buen compañero }\end{array}$ & & \\
\hline \multicolumn{4}{|l|}{ (niñez) muy libre } \\
\hline \multicolumn{4}{|l|}{ Mi hermana tan joven } \\
\hline \multicolumn{4}{|l|}{ Ellos muy humanos } \\
\hline \multicolumn{4}{|l|}{ Muy buen niño } \\
\hline \multicolumn{4}{|l|}{ Muy limitada } \\
\hline \multicolumn{4}{|l|}{ Muy...no sé , indefensa } \\
\hline \multicolumn{4}{|l|}{ Muy buenos ejemplos } \\
\hline \multicolumn{4}{|l|}{$\begin{array}{l}\text { Encuentro lo más } \\
\text { atractivo el idioma }\end{array}$} \\
\hline 21 & 13 & 2 & 4 \\
\hline
\end{tabular}




\begin{tabular}{|l|l|}
\hline SUPERLATIVOS LÉXICOS & RECURSOS ESTILÍSTICOS \\
\hline Fue traumático & Es una monada \\
\hline Todas esas cosas maravillosas & Son muy, muy violentos \\
\hline Fue complicado & $\begin{array}{l}\text { Mi vida es más, más plena, más } \\
\text { conforme }\end{array}$ \\
\hline Para mí era complicado & Todo bellísimo, bellísimo \\
\hline ¡Excelente! & Todo tan, tan natural \\
\hline ¡Brillante! & Pude comprar todo en un dos por tres \\
\hline Tres nietos fantásticos & Tiene harto, harto ganado \\
\hline Eso ya es una maravilla & Cien por ciento sibarita \\
\hline Encuentro fantástico el francés & Persona muy, muy, muy desvalida \\
\hline Un hijo que es fantástico & Fue muy, muy pesado \\
\hline Hace bastante tiempo & Muy, muy dados a entregar \\
\hline 11 & 11 \\
\hline
\end{tabular}




\section{ENTREVISTA 30}

№ Total de superlativos: 45

\begin{tabular}{|c|c|c|c|}
\hline ADJETIVO & $\begin{array}{l}\text { ATRIBUTO (verbos } \\
\text { ser y estar) }\end{array}$ & $\begin{array}{l}\text { ATRIBUTO } \\
\text { (otros verbos) }\end{array}$ & ADVERBIOS \\
\hline Ciudad muy hermosa & Así bien entretenido & $\begin{array}{l}\text { La hizo muy } \\
\text { propia }\end{array}$ & $\begin{array}{l}\text { Hablar bastante } \\
\text { mal }\end{array}$ \\
\hline $\begin{array}{l}\text { Bien educadita la } \\
\text { respuesta }\end{array}$ & $\begin{array}{l}\text { Yo súper metida en } \\
\text { la cuestión }\end{array}$ & $\begin{array}{l}\text { Se ve muy } \\
\text { lindo }\end{array}$ & $\begin{array}{l}\text { Partir súper } \\
\text { temprano }\end{array}$ \\
\hline $\begin{array}{l}\text { Un sistema bien } \\
\text { especial }\end{array}$ & Fue muy entretenido & $\begin{array}{l}\text { Lo tengo muy } \\
\text { claro }\end{array}$ & \\
\hline $\begin{array}{l}\text { Los más diversos } \\
\text { proyectos }\end{array}$ & $\begin{array}{l}\text { Es absolutamente de } \\
\text { plástico }\end{array}$ & & \\
\hline $\begin{array}{l}\text { Una persona muy } \\
\text { franca }\end{array}$ & Me es muy grato & & \\
\hline $\begin{array}{l}\text { (una persona) muy } \\
\text { directa }\end{array}$ & Era muy válida & & \\
\hline $\begin{array}{l}\text { Aceptado por muy } \\
\text { pocos }\end{array}$ & $\begin{array}{l}\text { No soy en absoluto } \\
\text { experta }\end{array}$ & & \\
\hline Tema muy interesante & Súper asistenciales! & & \\
\hline $\begin{array}{l}\text { Técnicos bien } \\
\text { preparados }\end{array}$ & $\begin{array}{l}\text { Es totalmente en el } \\
\text { aire }\end{array}$ & & \\
\hline \multirow[t]{3}{*}{$\begin{array}{l}\text { (futuro) muy } \\
\text { complicado }\end{array}$} & $\begin{array}{l}\text { Pasó a ser más } \\
\text { entretenido }\end{array}$ & & \\
\hline & $\begin{array}{l}\text { Eso es muy } \\
\text { incómodo }\end{array}$ & & \\
\hline & No sean las óptimas & & \\
\hline 10 & 12 & 3 & 2 \\
\hline
\end{tabular}

\begin{tabular}{|l|l|}
\hline SUPERLATIVOS LÉXICOS & RECURSOS ESTILISTICOS \\
\hline Recorrimos bastante de Génova & Salía muy, muy temprano \\
\hline Tipo extraordinario & Harto viaje, harto viaje \\
\hline iTremendo! & Harto, harto ruido \\
\hline Hartos lugares & Mucha, mucha suerte \\
\hline Tengo harto tiempo & Son técnicos, técnicos \\
\hline Reuniones familiares grandes & ¡Grito y plata! \\
\hline Es tremenda & Son muy, muy completos \\
\hline Es tremenda de valor & Muy motivado, muy, muy \\
\hline Ha viajado caleta & \\
\hline Una cosa extraordinaria & \\
\hline 10 & 8 \\
\hline
\end{tabular}




\section{ENTREVISTA 31}

№ Total de superlativos: 57

\begin{tabular}{|c|c|c|c|}
\hline ADJETIVO & $\begin{array}{l}\text { ATRIBUTO (verbos } \\
\text { ser y estar) }\end{array}$ & $\begin{array}{l}\text { ATRIBUTO } \\
\text { (otros verbos) }\end{array}$ & ADVERBIOS \\
\hline $\begin{array}{l}\text { (Trabajo) bastante } \\
\text { dinámico }\end{array}$ & $\begin{array}{l}\text { Es como bien } \\
\text { variado }\end{array}$ & $\begin{array}{l}\text { Lo encuentro } \\
\text { muy bueno }\end{array}$ & Súper bien \\
\hline (Trabajo) re- movido & $\begin{array}{l}\text { Fue muy largo el } \\
\text { terremoto }\end{array}$ & & \\
\hline $\begin{array}{l}\text { (formación) bastante } \\
\text { buena }\end{array}$ & Fue muy largo & & \\
\hline $\begin{array}{l}\text { Un nivel } \\
\text { socioeconómico muy } \\
\text { bajo }\end{array}$ & (Eso) fue súper & & \\
\hline $\begin{array}{l}\text { Un nivel mucho más } \\
\text { alto }\end{array}$ & Que era muy bonita & & \\
\hline $\begin{array}{l}\text { Bien estresante, la } \\
\text { verdad, la experiencia }\end{array}$ & Era muy pesada & & \\
\hline $\begin{array}{l}\text { Tres temblores } \\
\text { seguidos muy grandes }\end{array}$ & (Era) muy densa & & \\
\hline $\begin{array}{l}\text { Otro momento muy } \\
\text { estresante }\end{array}$ & $\begin{array}{l}\text { (Es) mucho más } \\
\text { refinado }\end{array}$ & & \\
\hline Una cosa tan rutinaria & No es tan rutinario & & \\
\hline $\begin{array}{l}\text { Callecitas bien } \\
\text { chiquititas }\end{array}$ & $\begin{array}{l}\text { El segundo mes fue } \\
\text { más entretenido }\end{array}$ & & \\
\hline (Viaje) Buenísimo & $\begin{array}{l}\text { Fue como más } \\
\text { estresante }\end{array}$ & & \\
\hline Ceremonia muy bonita & Era muy chica & & \\
\hline \multirow[t]{4}{*}{ Todo bien espectacular } & $\begin{array}{l}\text { Estamos bien } \\
\text { distanciadas }\end{array}$ & & \\
\hline & $\begin{array}{l}\text { Estuvo buenísima la } \\
\text { fiesta }\end{array}$ & & \\
\hline & $\begin{array}{l}\text { Somos muy } \\
\text { cariñosos }\end{array}$ & & \\
\hline & Era muy seco & & \\
\hline 13 & 16 & 1 & 1 \\
\hline
\end{tabular}




\begin{tabular}{|l|l|}
\hline SUPERLATIVOS LÉXICOS & RECURSOS ESTILISTICOS \\
\hline Era seco en su área & Una actividad muy, muy, muy fuerte \\
\hline Mucho más bacanes & Eso fue muy, muy interesante \\
\hline Una experiencia traumática & Son muy, muy loquillos \\
\hline Es casi un cataclismo & \\
\hline La intensidad fue gigante & \\
\hline O sea, fue caótica & \\
\hline La gente histérica & \\
\hline Cuesta harto & \\
\hline Una pega heavy & \\
\hline Fue el medio viaje & \\
\hline Nos pegamos un pique tremendo & \\
\hline Caminamos caleta & \\
\hline Era gigante (la Torre Eiffel) & \\
\hline De conocer harto Granada & \\
\hline Unos recovecos pero tremendos & \\
\hline Disfrutar a concho & \\
\hline Cenas) bacanes de ricas & \\
\hline Comiendo bacán & \\
\hline (comiendo) la raja & \\
\hline Comida exquisita & \\
\hline Comunicación bacán & 3 \\
\hline Unas cenas heavy & \\
\hline 23 & \\
\hline
\end{tabular}




\section{ENTREVISTA 32}

№ Total de superlativos: 46

\begin{tabular}{|c|c|c|c|}
\hline ADJETIVO & $\begin{array}{l}\text { ATRIBUTO (verbos } \\
\text { ser y estar) }\end{array}$ & $\begin{array}{l}\text { ATRIBUTO } \\
\text { (otros verbos) }\end{array}$ & ADVERBIOS \\
\hline $\begin{array}{l}\text { la parte más importante } \\
\text { de mi vida }\end{array}$ & $\begin{array}{l}\text { Soy como más } \\
\text { optimista }\end{array}$ & $\begin{array}{l}\text { Tengo súper } \\
\text { regulado el } \\
\text { tema }\end{array}$ & $\begin{array}{l}\text { Soy una } \\
\text { persona que } \\
\text { vivo súper } \\
\text { sencillo }\end{array}$ \\
\hline Una niñez muy humilde & $\begin{array}{l}\text { Soy como bien } \\
\text { simple }\end{array}$ & $\begin{array}{l}\text { Se va bien } \\
\text { arreglado }\end{array}$ & $\begin{array}{l}\text { Nos ha ido } \\
\text { bastante bien }\end{array}$ \\
\hline $\begin{array}{l}\text { Una persona muy } \\
\text { conflictiva }\end{array}$ & $\begin{array}{l}\text { Somos muy } \\
\text { envidiosos }\end{array}$ & & $\begin{array}{l}\text { Resistió muy } \\
\text { bien }\end{array}$ \\
\hline La vida muy relajada & $\begin{array}{l}\text { Somos muy } \\
\text { consumistas }\end{array}$ & & \\
\hline Un costo muy grande & $\begin{array}{l}\text { Un estadio estaba } \\
\text { muy bueno }\end{array}$ & & \\
\hline Mi hija menor & $\begin{array}{l}\text { Somos demasiado } \\
\text { triunfalistas }\end{array}$ & & \\
\hline $\begin{array}{l}\text { Un pueblo muy } \\
\text { triunfalista }\end{array}$ & $\begin{array}{l}\text { Somos muy } \\
\text { cortoplacistas }\end{array}$ & & \\
\hline $\begin{array}{l}\text { Tenemos tan pocos } \\
\text { triunfos }\end{array}$ & $\begin{array}{l}\text { Somos muy } \\
\text { consumistas }\end{array}$ & & \\
\hline $\begin{array}{l}\text { Una postura bien } \\
\text { especial }\end{array}$ & $\begin{array}{l}\text { No son tan } \\
\text { importantes }\end{array}$ & & \\
\hline $\begin{array}{l}\text { Idiosincrasia muy } \\
\text { triunfalista }\end{array}$ & Soy súper crítico & & \\
\hline $\begin{array}{l}\text { Distanciamiento muy } \\
\text { grande }\end{array}$ & $\begin{array}{l}\text { Soy como bien } \\
\text { (crítico) }\end{array}$ & & \\
\hline $\begin{array}{l}\text { Nivel socioeconómico } \\
\text { más bajo }\end{array}$ & $\begin{array}{l}\text { Uno tiene que ser } \\
\text { muy cauto }\end{array}$ & & \\
\hline Mis hijos mayores & (ser) muy precavido & & \\
\hline $\begin{array}{l}\text { (gente ) muy } \\
\text { responsable }\end{array}$ & $\begin{array}{l}\text { Son sumamente } \\
\text { estrictas }\end{array}$ & & \\
\hline Gente muy honesta & $\begin{array}{l}\text { Fue muy poco dinero } \\
\text { (el robo) }\end{array}$ & & \\
\hline 15 & 15 & 2 & 3 \\
\hline
\end{tabular}

\begin{tabular}{|l|l|}
\hline SUPERLATIVOS LÉXICOS & RECURSOS ESTILISTICOS \\
\hline Me complica bastante & $\begin{array}{l}\text { Somos muy irresponsables, ¿ya?, } \\
\text { muy irresponsables }\end{array}$ \\
\hline Una casa maravillosa & (una niñez) pero muy, muy feliz \\
\hline Es una parte fundamental del cambio & Una ciudad muy limpia, muy limpia \\
\hline & Estoy completamente de acuerdo, \\
\hline
\end{tabular}




\begin{tabular}{|l|l|}
\hline Yo creo que bastante & completamente de acuerdo \\
\hline El tema fundamental & Gente muy, muy buena \\
\hline & Son de por vida \\
\hline 5 & 6 \\
\hline
\end{tabular}




\section{ENTREVISTA 33}

№ Total de superlativos: 47

\begin{tabular}{|c|c|c|c|}
\hline ADJETIVO & $\begin{array}{l}\text { ATRIBUTO (verbos } \\
\text { ser y estar) }\end{array}$ & $\begin{array}{l}\text { ATRIBUTO } \\
\text { (otros verbos) }\end{array}$ & ADVERBIOS \\
\hline $\begin{array}{l}\text { Las comunicaciones } \\
\text { absolutamente } \\
\text { manejadas }\end{array}$ & No fui muy regular & $\begin{array}{l}\text { No se vean } \\
\text { tan oscuros }\end{array}$ & Está muy bien \\
\hline Un tema muy delicado & $\begin{array}{l}\text { He sido muy } \\
\text { estudioso }\end{array}$ & & $\begin{array}{l}\text { Estamos muy } \\
\text { bien }\end{array}$ \\
\hline $\begin{array}{l}\text { Sea un escándalo tan } \\
\text { grave }\end{array}$ & Chiloé es muy bonito & & $\begin{array}{l}\text { Han acoplado } \\
\text { muy bien }\end{array}$ \\
\hline \multirow[t]{16}{*}{ Países tan prósperos } & $\begin{array}{l}\text { La gente no es muy } \\
\text { buena }\end{array}$ & & $\begin{array}{l}\text { Comamos más } \\
\text { sano }\end{array}$ \\
\hline & $\begin{array}{l}\text { Gente que no es muy } \\
\text { buena }\end{array}$ & & \\
\hline & Está todo muy mal & & \\
\hline & $\begin{array}{l}\text { Todos (son) súper } \\
\text { tira p'arriba }\end{array}$ & & \\
\hline & $\begin{array}{l}\text { Es muy } \\
\text { apechugadora }\end{array}$ & & \\
\hline & $\begin{array}{l}\text { No es tan } \\
\text { apechugadora }\end{array}$ & & \\
\hline & Son muy marcados & & \\
\hline & Muy simpáticos & & \\
\hline & $\begin{array}{l}\text { Mi mamá es muy } \\
\text { religiosa }\end{array}$ & & \\
\hline & Un país muy rico & & \\
\hline & Es súper importante & & \\
\hline & $\begin{array}{l}\text { Es súper importante } \\
\text { un parlamento }\end{array}$ & & \\
\hline & $\begin{array}{l}\text { La alternancia en el } \\
\text { poder es lo más sano }\end{array}$ & & \\
\hline & Es muy difícil & & \\
\hline & Están tan alejados & & \\
\hline & Es muy importante & & \\
\hline
\end{tabular}




\begin{tabular}{|l|l|l|l|}
\hline & $\begin{array}{l}\text { Esa planta era muy } \\
\text { Antigua }\end{array}$ & & \\
\hline & $\begin{array}{l}\text { Es muy difícil( una } \\
\text { planta) }\end{array}$ & & \\
\hline & $\begin{array}{l}\text { Son extremadamente } \\
\text { caras }\end{array}$ & & \\
\hline & Es sumamente caro & & \\
\hline & $\begin{array}{l}\text { Es absolutamente } \\
\text { positivo }\end{array}$ & & \\
\hline & $\begin{array}{l}\text { Son criticadas } \\
\text { absolutamente }\end{array}$ & & \\
\hline & Es tan re barato & & \\
\hline & Es muy grande & & \\
\hline & Está muy centrado & & \\
\hline 4 & 28 & 1 & \\
\hline
\end{tabular}

\begin{tabular}{|l|l|}
\hline SUPERLATIVOS LÉXICOS & RECURSOS ESTILISTICOS \\
\hline Es harto espacio & \\
\hline Desastres gigantes & \\
\hline Van a pasar hartas generaciones & \\
\hline Es fundamental & \\
\hline Los papás son los fundamentales & \\
\hline Hay unas cosas increíbles & \\
\hline Me pasó hartas veces & \\
\hline Es pinochetista entera & \\
\hline La familia es principal & \\
\hline Toda la familia es principal & \\
\hline El deporte es importante y fundamental & \\
\hline Ahora, no, es importante y fundamental & \\
\hline 10 & 0 \\
\hline
\end{tabular}




\section{ENTREVISTA 34}

№ Total de superlativos: 89

\begin{tabular}{|c|c|c|c|}
\hline ADJETIVO & $\begin{array}{l}\text { ATRIBUTO (verbos } \\
\text { ser y estar) }\end{array}$ & $\begin{array}{l}\text { ATRIBUTO } \\
\text { (otros verbos) }\end{array}$ & ADVERBIOS \\
\hline (Relación) súper buena & Estar bien presentes & $\begin{array}{l}\text { Lo encuentro } \\
\text { súper cabro } \\
\text { chico }\end{array}$ & $\begin{array}{l}\text { Fuera } \\
\text { demasiado } \\
\text { tarde }\end{array}$ \\
\hline $\begin{array}{l}\text { Tenía como hartas más } \\
\text { obligaciones }\end{array}$ & Somos muy unidas & $\begin{array}{l}\text { Tenía muy } \\
\text { idealizado a mi } \\
\text { papá }\end{array}$ & $\begin{array}{l}\text { Salió como } \\
\text { muy de } \\
\text { improviso }\end{array}$ \\
\hline Desde bien corta edad & $\begin{array}{l}\text { (ambiente) es bien } \\
\text { competitivo }\end{array}$ & & $\begin{array}{l}\text { Nos llevamos } \\
\text { súper bien }\end{array}$ \\
\hline Recuerdos más fuertes & Somos súper unidas & & $\begin{array}{l}\text { Siempre me } \\
\text { entendí muy } \\
\text { bien con él }\end{array}$ \\
\hline $\begin{array}{l}\text { Una relación más } \\
\text { distante }\end{array}$ & $\begin{array}{l}\text { Somos todas bien } \\
\text { amigas }\end{array}$ & & $\begin{array}{l}\text { Había } \\
\text { temblado } \\
\text { como bien } \\
\text { seguido }\end{array}$ \\
\hline $\begin{array}{l}\text { Figura paterna como } \\
\text { tan potente }\end{array}$ & $\begin{array}{l}\text { Es una muy buena } \\
\text { persona }\end{array}$ & & $\begin{array}{l}\text { Lo habíamos } \\
\text { pasado súper } \\
\text { bien }\end{array}$ \\
\hline $\begin{array}{l}\text { Tenía muy buenos } \\
\text { sentimientos }\end{array}$ & $\begin{array}{l}\text { Los jueces son más } \\
\text { complicados }\end{array}$ & & $\begin{array}{l}\text { Trata de } \\
\text { hacerlo mejor }\end{array}$ \\
\hline $\begin{array}{l}\text { (es) amiga desde súper } \\
\text { chica }\end{array}$ & $\begin{array}{l}\text { Es una persona } \\
\text { bien cercana }\end{array}$ & & $\begin{array}{l}\text { Le hizo muy } \\
\text { bien viajar }\end{array}$ \\
\hline $\begin{array}{l}\text { Tenemos muy pocos } \\
\text { conflictos }\end{array}$ & $\begin{array}{l}\text { Fui como bien } \\
\text { protectora }\end{array}$ & & \\
\hline $\begin{array}{l}\text { La situación ya más } \\
\text { consolidada }\end{array}$ & $\begin{array}{l}\text { Yo soy súper } \\
\text { regalona }\end{array}$ & & \\
\hline $\begin{array}{l}\text { Una red de amigos } \\
\text { bien grande }\end{array}$ & Fui muy regalona & & \\
\hline \multirow[t]{7}{*}{ Al círculo más cercano } & $\begin{array}{l}\text { Ha sido más } \\
\text { cercana ahora }\end{array}$ & & \\
\hline & Fue más distante & & \\
\hline & $\begin{array}{l}\text { Era un hombre muy } \\
\text { inteligente }\end{array}$ & & \\
\hline & $\begin{array}{l}\text { Ese período fue } \\
\text { como súper duro }\end{array}$ & & \\
\hline & $\begin{array}{l}\text { Fue como súper } \\
\text { difícil }\end{array}$ & & \\
\hline & Ha sido súper lindo & & \\
\hline & $\begin{array}{l}\text { Ha sido muy } \\
\text { complicado }\end{array}$ & & \\
\hline
\end{tabular}




\begin{tabular}{|c|c|c|c|}
\hline & Qué es lo mejor & & \\
\hline & Él es súper inquieto & & \\
\hline & Ha sido mucho mejor & & \\
\hline & Fue súper difícil & & \\
\hline & $\begin{array}{l}\text { Fueron muy } \\
\text { apoyadores }\end{array}$ & & \\
\hline & Muy ayudadores & & \\
\hline & $\begin{array}{l}\text { Es un niño de muy } \\
\text { buen corazón }\end{array}$ & & \\
\hline & $\begin{array}{l}\text { Lugar que era súper } \\
\text { lindo }\end{array}$ & & \\
\hline & $\begin{array}{l}\text { Fue súper } \\
\text { emocionante }\end{array}$ & & \\
\hline & Fue súper rico & & \\
\hline & El viaje fue súper rico & & \\
\hline & $\begin{array}{l}\text { La gente era súper } \\
\text { cariñosa }\end{array}$ & & \\
\hline & $\begin{array}{l}\text { Era súper lindo el } \\
\text { lugar }\end{array}$ & & \\
\hline & $\begin{array}{l}\text { La gente era muy } \\
\text { amable }\end{array}$ & & \\
\hline & Fue súper rico & & \\
\hline & Fue súper lindo & & \\
\hline & $\begin{array}{l}\text { Si serán las } \\
\text { mejores(reformas) }\end{array}$ & & \\
\hline & $\begin{array}{l}\text { Los dos somos súper } \\
\text { amistosos }\end{array}$ & & \\
\hline & $\begin{array}{l}\text { (Somos) muy amigos } \\
\text { de los papás }\end{array}$ & & \\
\hline & $\begin{array}{l}\text { Esos son como los } \\
\text { más actuales }\end{array}$ & & \\
\hline & $\begin{array}{l}\text { Es más fácil } \\
\text { encontrarnos }\end{array}$ & & \\
\hline & $\begin{array}{l}\text { El auto era muy } \\
\text { moderno }\end{array}$ & & \\
\hline & $\begin{array}{l}\text { Fue como bien } \\
\text { angustiosos }\end{array}$ & & \\
\hline 12 & 41 & 2 & 8 \\
\hline
\end{tabular}




\begin{tabular}{|l|l|}
\hline SUPERLATIVOS LÉXICOS & RECURSOS ESTILISTICOS \\
\hline Tenemos harto contacto & Soy muy, muy cercana \\
\hline Es rico adentro & Una relación muy, muy cercana \\
\hline Mi mamá trabajaba harto & \\
\hline Era harto desorden & \\
\hline Harto cabro chico & \\
\hline Yo los quiero harto & \\
\hline Me iba a costar harto enamorarme & \\
\hline Lenguaje jurídico complicado & \\
\hline Es una tremenda relación & \\
\hline Un tremendo corazón & \\
\hline El embarazo complicado & \\
\hline Hartas cosas & \\
\hline $\begin{array}{l}\text { Hemos tratado harto de ir manejando } \\
\text { eso }\end{array}$ & \\
\hline El mensaje era precioso & \\
\hline ¡Pa mí fue bacán! & \\
\hline Entonces fue rico & \\
\hline Fue espectacular & \\
\hline Eso era como heavy & \\
\hline Va harto chileno & \\
\hline Lo encuentro como tremendo & \\
\hline ¡Qué atroz! & \\
\hline No, fome igual & \\
\hline Estaba la escoba y todo & \\
\hline Dejó un mensaje precioso & \\
\hline 24 & \\
\hline
\end{tabular}




\begin{abstract}
ANEXO 3 (en CD)
CORPUS TESIS DOCTORAL ESTUDIO SOCIOLINGÜÍSTICO SOBRE EL USO DEL SUPERLATIVO EN LA REGIÓN DE VALPARAÍSO, CHILE.
\end{abstract}

